\title{
TRANSURANIC WASTE CHARACTERIZATION QUALITY ASSURANCE PROGRAM PLAN Revision 0
}

\author{
DISCLAIMER
}

This report was prepared as an account of work sponsored by an agency of the United States Government. Neither the United States Government nor any agency thereof, nor any of their employees, makes any warranty, express or implied, or assumes any legal liability or responsibility for the accuracy, completeness, or usefulness of any information, apparatus, product, or process disclosed, or represents that its use would not infringe privately owned rights. Reference herein to any specific commercial product, process, or service by trade name, trademark, manufacturer, or otherwise does not necessarily constitute or imply its endorsement, recommendation, or favoring by the United States Government or any agency thereof. The views and opinions of authors expressed herein do not necessarily state or reflect those of the United States Government or any agency thereof.

Controlled Copy No. NA

U.S. Department of Energy - Carlsbad Area Office National TRU Program Office 


\section{DISCLAIMER}

Portions of this document may be illegible in electronic image products. Images are produced from the best available original document. 


\section{TRANSURANIC WASTE CHARACTERIZATION QUALITY ASSURANCE PROGRAM PLAN}

\section{Revision 0}

April 30, 1995

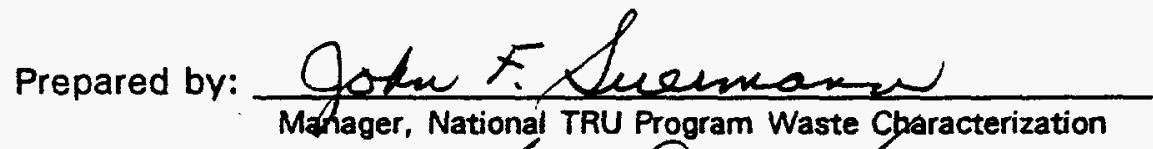

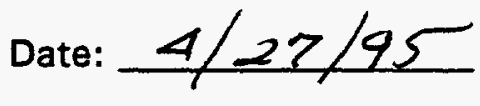

Approved by:

Date: $4 / 27 / 25$

Concurred by:
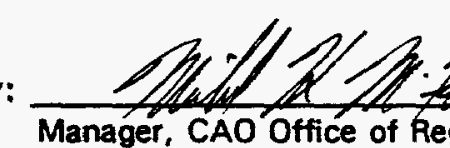

Regulatory Compliance

Date:

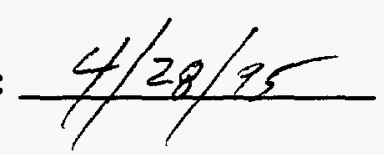

concurred by: $\frac{4 \text { in }}{\text { Team Leader, National Thu Program }} 4 / 27 / 55$

Concurred by: $\frac{x \bigotimes \text { emie } \$ \text { Mown }}{\text { Manager, CAO Quality Assurance }}$

Date: $4 / 28 / 95$ 
TABLE OF CONTENTS

Section

REVIEW/APPROVAL PAGE

LIST OF TABLES

LIST OF FIGURES

LIST OF ACRONYMS, ABBREVIATIONS, AND SYMBOLS

1.0

\section{PROGRAM MANAGEMENT}

1.1 Program Organization

1.1.1 Assistant Secretary, DOE Office of Environmental Restoration and Waste Management

1.1.2 Deputy Assistant Secretary, DOE Office of Waste Management

1.1.3 Manager, DOE Carlsbad Area Office

1.1.4 Manager, CAO Office of Regulatory Compliance

1.1.5 Manager, CAO Quality Assurance

1.1.6 Team Leader, National TRU Program Office

1.1.7 DOE Field Office

\subsubsection{Site Project Manager \\ 1.1.7.2 Site Project Quality Assurance Officer}

1.2 Program Documents

1.2.1 Quality Assurance Program Plan

1.2.2 Quality Assurance Project Plans

1.2.3 Document Review, Approval, and Control

1.3 Problem Definition and Background

1.4 Program Description

1.5 Data Quality Objectives for Measurement Data

1.6 Special Training Requirements and Certifications

1.7 Documentation and Records

1.7.1 Site Project Files

1.7.2 Flow of Records

$\begin{array}{ccc}\text { Page } & \text { Rev } & \text { Date } \\ \text { i } & 0 & 4 / 30 / 95 \\ \text { ix } & 0 & 4 / 30 / 95 \\ \text { xi } & 0 & 4 / 30 / 95 \\ \text { A-1 } & 0 & 4 / 30 / 95 \\ 1-1 & 0 & 4 / 30 / 95 \\ 1-2 & 0 & 4 / 30 / 95 \\ 1-2 & 0 & 4 / 30 / 95\end{array}$

$1-2$

0

$4 / 30 / 95$

$1-7 \quad 0 \quad 4 / 30 / 95$

$1-7$

0

$4 / 30 / 95$

$1-7$

0

$4 / 30 / 95$

$1-8$

0

4/30/95

1-8

0

4/30/95

1-8

0

4/30/95

1-8

0

4/30/95

$1-9$

1-9

1-11

1-11

1-14

1-18

1-30

1-33

1-34

1-34

1-36
4/30/95

4/30/95

4/30/95

4/30/95

4/30/95

4/30/95

4/30/95

4/30/95

4/30/95

4/30/95

$4 / 30 / 95$ 
TABLE OF CONTENTS

(Continued)
Section

1.8 Procurement

1.8.1 Procurement Document Control

1.8.2 Control of Purchased Items and Services

1.8.3 Control of Subcontractors

1.9 Work Processes

1.9.1 Control of Processes

1.9.2 Identification and Control of Items

1.9.3 Computer Hardware and Software

2.0 ASSESSMENT AND OVERSIGHT

2.1 Assessment and Response Actions

2.1.1 Audits

2.1.2 Nonconformances and Operational Variances

\subsubsection{Nonconformances \\ 2.1.2.2 Operational Variances}

2.1.3 Quality Improvement

2.1.4 Management Assessment

2.1.5 Independent Assessment

2.2 Reports to Management

2.3 Performance Demonstration Program

3.0 DATA VALIDATION, USABILITY, AND REPORTING

3.1 Data Review, Validation, and Verification Requirements

3.1.1 Data Generation Level

3.1.2 Project Level

3.1.3 CAO Level

3.2 Validation Methods

3.2.1 Precision

3.2.2 Accuracy

3.2.3 Method Detection Limit

$\begin{array}{ccc}\text { Page } & \text { Bev } & \text { Date } \\ 1-36 & 0 & 4 / 30 / 95 \\ 1-36 & 0 & 4 / 30 / 95 \\ 1-38 & 0 & 4 / 30 / 95 \\ 1-38 & 0 & 4 / 30 / 95 \\ 1-39 & 0 & 4 / 30 / 95 \\ 1-39 & 0 & 4 / 30 / 95 \\ 1-39 & 0 & 4 / 30 / 95 \\ 1-40 & 0 & 4 / 30 / 95 \\ 2-1 & 0 & 4 / 30 / 95 \\ 2-1 & 0 & 4 / 30 / 95 \\ 2-1 & 0 & 4 / 30 / 95 \\ 2-3 & 0 & 4 / 30 / 95 \\ & & \\ 2-3 & 0 & 4 / 30 / 95 \\ 2-4 & 0 & 4 / 30 / 95 \\ 2-5 & 0 & 4 / 30 / 95 \\ 2-5 & 0 & 4 / 30 / 95 \\ 2-5 & 0 & 4 / 30 / 95 \\ 2-6 & 0 & 4 / 30 / 95 \\ 2-6 & 0 & 4 / 30 / 95 \\ 3-1 & 0 & 4 / 30 / 95 \\ 3-1 & 0 & 4 / 30 / 95\end{array}$

3-2 $0 \quad 4 / 30 / 95$

3-4 $0 \quad 4 / 30 / 95$

3-5 $\quad 0 \quad 4 / 30 / 95$

3-6 $0 \quad 4 / 30 / 95$

3-7 $0 \quad 4 / 30 / 95$

3-8 $\quad 0 \quad 4 / 30 / 95$

3-8 $\quad 0 \quad 4 / 30 / 95$ 
TABLE OF CONTENTS (Continued)
Section

\subsubsection{Completeness}

\subsubsection{Comparability}

3.3 Reconciliation with Data Quality Objectives

\subsubsection{Reconciliation at the Project Level}

3.3.2 Reconciliation at the CAO Level

3.4 Data Reporting Requirements

3.4.1 Data Generation Level

3.4.2 Project Level

4.0 MEASUREMENT AND DATA ACQUISITION

4.1 Quality Assurance Objective

4.2 Methods Requirements

4.3 Quality Control Requirements

4.4 Equipment Testing, Inspection, and Maintenance Requirements

4.5 Equipment Calibration and Frequency

4.6 Data Management

5.0 SAMPLING PROCESS DESIGN

5.1 Description of Acceptable Matrix Parameter Categories

5.2 Parameters, Rationale, and Test Methods

5.2.1 Homogenous Solids and Soil/Gravel

5.2.2 Debris Wastes and Special Waste

5.3 Sampling Plan

5.3.1 RCRA Characterization of Retrievably Stored Homogenous Solids and Soil/Gravel

5.3.2 Visual Examination of Retrievably Stored Homogenous Solids, Soil/Gravel, Debris Wastes, and Special Waste

5.3.3 Characterization of Newly Generated Homogenous Solids, Soil/Gravel, Debris Wastes, and Special Waste

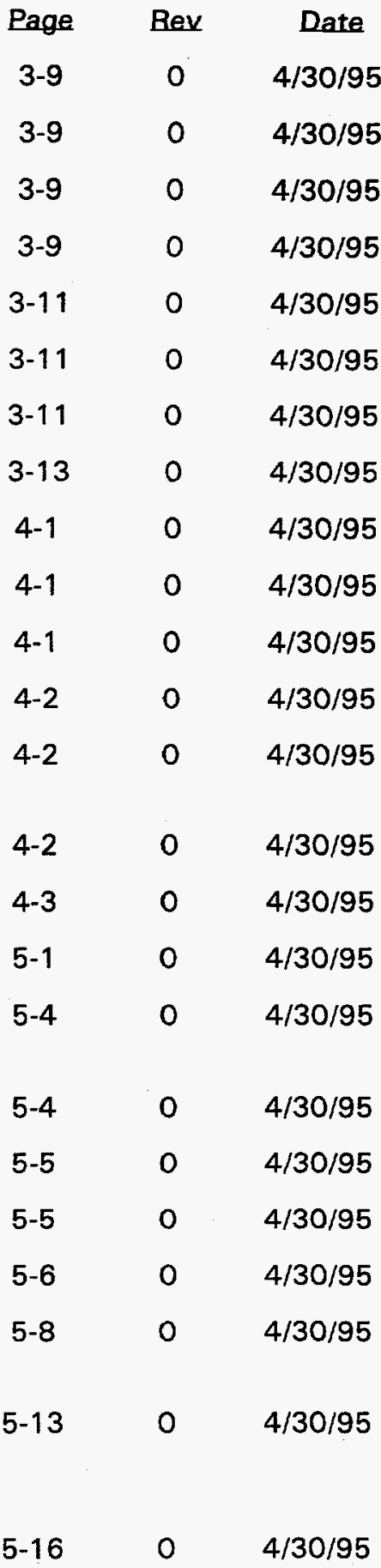




\section{TABLE OF CONTENTS}

(Continued)

Section

6.0

SAMPLE HANDLING AND CUSTODY REOUIREMENTS

6.1 Field Documentation

6.2 Labeling

6.2.1 Waste Container Labeling

6.2.2 Innermost Layer of Confinement

6.2.3 Headspace Gas Sample Containers

6.2.4 Homogenous Solids and Soil/Gravel Sample Containers

6.3 Chain-of-Custody

6.3.1 Waste Container

6.3.2 Sample Containers

6.4 Handling

6.4.1 Waste Container

6.4.2 Gas Sample Container

6.4.3 Homogenous Solids and Soil/Gravel Sample Container

7.0

HEADSPACE GAS SAMPLING

7.1 Quality Assurance Objectives

7.2 Method Requirements

7.2.1 Manifold

7.2.2 Direct Canister

7.2.3 Sampling Heads

7.3 Quality Control

7.4 Equipment Testing, Inspection, and Maintenance Requirements

7.5 Equipment Calibration and Frequency

7.6 Data Management

8.0 SAMPLING OF HOMOGENOUS SOLIDS AND SOIL/GRAVEL

8.1 Quality Assurance Objectives

8.2 Method Requirements
8.2.1 Core Collection

Page Rev Date

6-1 $\quad 0 \quad 4 / 30 / 95$

6-1 $\quad 0 \quad 4 / 30 / 95$

6-2 $\quad 0 \quad 4 / 30 / 95$

6-2 $\quad 0 \quad 4 / 30 / 95$

6-3 $\quad 0 \quad 4 / 30 / 95$

6-3 $\quad 0 \quad 4 / 30 / 95$

6-5 $\quad 0 \quad 4 / 30 / 95$

6-6 $\quad 0 \quad 4 / 30 / 95$

6-8 $\quad 0 \quad 4 / 30 / 95$

6-8 $\quad 0 \quad 4 / 30 / 95$

6-11 $0 \quad 4 / 30 / 95$

6-11 $0 \quad 4 / 30 / 95$

6-11 $0 \quad 4 / 30 / 95$

6-11 $0 \quad 4 / 30 / 95$

$\begin{array}{lll}7-1 & 0 & 4 / 30 / 95\end{array}$

$\begin{array}{lll}7-3 & 0 & 4 / 30 / 95\end{array}$

$\begin{array}{lll}7-6 & 0 & 4 / 30 / 95\end{array}$

$\begin{array}{lll}7-6 & 0 & 4 / 30 / 95\end{array}$

$\begin{array}{lll}7-11 & 0 & 4 / 30 / 95\end{array}$

$\begin{array}{lll}7-13 & 0 & 4 / 30 / 95\end{array}$

7-16 $0 \quad 4 / 30 / 95$

7-19 $0 \quad 4 / 30 / 95$

$\begin{array}{lll}7-21 & 0 & 4 / 30 / 95\end{array}$

7-21 $0 \quad 4 / 30 / 95$

8-1 $0 \quad 4 / 30 / 95$

8-1 $0 \quad 4 / 30 / 95$

8-3 $0 \quad 4 / 30 / 95$

8-3 $0 \quad 4 / 30 / 95$ 
TABLE OF CONTENTS (Continued)
Section

\subsubsection{Sample Collection}

8.3 Quality Control

8.4 Equipment Testing, Inspection, and Maintenance Requirements

8.5 Equipment Calibration and Frequency

8.6 Data Management

9.0 NONDESTRUCTIVE ASSAY

9.1 Quality Assurance Objectives

9.2 Methods Requirements

9.3 Quality Control

\subsubsection{Measurement System Checks}

9.3.2 Intercomparison Programs

\subsubsection{NDA Operator Training}

9.4 Instrument Testing, Inspection, and Maintenance Requirements

9.5 Calibration Procedures and Frequencies

9.6 Data Management

10.0 RADIOGRAPHY

10.1 Quality Assurance Objectives

10.2 Methods Requirements

10.3 Quality Control

10.4 Instrument Testing, Inspection, and Maintenance Requirements

10.5 Instrument Calibration and Frequency

10.6 Data Management

11.0 HYDROGEN AND METHANE ANALYSIS

11.1 Quality Assurance Objectives

11.2 Methods Requirements

11.3 Quality Control

11.4 Instrument Testing, Inspection, and Maintenance Requirements
Page Rev Date

$\begin{array}{ccc}8-7 & 0 & 4 / 30 / 95 \\ 8-8 & 0 & 4 / 30 / 95 \\ 8-10 & 0 & 4 / 30 / 95\end{array}$

8-11 $\quad 0 \quad 4 / 30 / 95$

8-11 $0 \quad 4 / 30 / 95$

9-1 $\quad 0 \quad 4 / 30 / 95$

9-2 $\quad 0 \quad 4 / 30 / 95$

$9-6 \quad 0 \quad 4 / 30 / 95$

$\begin{array}{lll}9-9 & 0 & 4 / 30 / 95\end{array}$

$9-9 \quad 0 \quad 4 / 30 / 95$

9-11 $\quad 0 \quad 4 / 30 / 95$

$\begin{array}{lll}9-11 & 0 & 4 / 30 / 95\end{array}$

$\begin{array}{lll}9-11 & 0 & 4 / 30 / 95\end{array}$

$9-11 \quad 0 \quad 4 / 30 / 95$

9-14 $0 \quad 4 / 30 / 95$

10-1 $0 \quad 4 / 30 / 95$

10-1 $0 \quad 4 / 30 / 95$

10-3 $0 \quad 4 / 30 / 95$

10-4 $0 \quad 4 / 30 / 95$

10-7 $0 \quad 4 / 30 / 95$

10-7 $0 \quad 4 / 30 / 95$

10-7 $0 \quad 4 / 30 / 95$

11-1 $0 \quad 4 / 30 / 95$

11-1 $0 \quad 4 / 30 / 95$

11-3 $0 \quad 4 / 30 / 95$

$11-4 \quad 0 \quad 4 / 30 / 95$

11-6 $0 \quad 4 / 30 / 95$ 


\section{TABLE OF CONTENTS}

(Continued)

Section

11.5 Instrument Calibration and Frequency

11.6 Data Management

12.0 GAS VOLATILE ORGANIC COMPOUND ANALYSIS

12.1 Quality Assurance Objectives

12.2 Methods Requirements

12.3 Quality Control

12.4 Instrument Testing, Inspection, and Maintenance Requirements

12.5 Instrument Calibration and Frequency

12.6 Data Management

13.0 TOTAL VOLATILE ORGANIC COMPOUND ANALYSIS

13.1 Quality Assurance Objectives

13.2 Methods Requirements

13.3 Quality Control

13.4 Instrument Testing, Inspection, and Maintenance Requirements

13.5 Instrument Calibration and Frequency

13.6 Data Management

14.0 TOTAL SEMI-VOLATILE ORGANIC COMPOUND ANALYSIS

14.1 Quality Assurance Objectives

14.2 Methods Requirements

14.3 Quality Control

14.4 Instrument Testing, Inspection, and Maintenance Requirements

14.5 Instrument Calibration and Frequency

14.6 Data Management

15.0 TOTAL METAL ANALYSIS

15.1 Quality Assurance Objectives

15.2 Methods Requirements

15.3 Quality Control

\begin{tabular}{|c|c|c|}
\hline Page & Rev & Date \\
\hline $11-7$ & 0 & $4 / 30 / 95$ \\
\hline $11-9$ & 0 & $4 / 30 / 95$ \\
\hline $12-1$ & 0 & $4 / 30 / 95$ \\
\hline $12-1$ & 0 & $4 / 30 / 95$ \\
\hline $12-3$ & 0 & $4 / 30 / 95$ \\
\hline $12-6$ & 0 & $4 / 30 / 95$ \\
\hline $12-8$ & 0 & $4 / 30 / 95$ \\
\hline $12-9$ & 0 & $4 / 30 / 95$ \\
\hline $12-11$ & 0 & $4 / 30 / 95$ \\
\hline $13-1$ & 0 & $4 / 30 / 95$ \\
\hline 13-1 & 0 & $4 / 30 / 95$ \\
\hline $13-3$ & 0 & $4 / 30 / 95$ \\
\hline $13-5$ & 0 & $4 / 30 / 95$ \\
\hline $13-7$ & 0 & $4 / 30 / 95$ \\
\hline $13-8$ & 0 & $4 / 30 / 95$ \\
\hline $13-10$ & 0 & $4 / 30 / 95$ \\
\hline $14-1$ & 0 & $4 / 30 / 95$ \\
\hline $14-1$ & 0 & $4 / 30 / 95$ \\
\hline $14-3$ & 0 & $4 / 30 / 95$ \\
\hline $14-5$ & 0 & $4 / 30 / 95$ \\
\hline $14-7$ & 0 & $4 / 30 / 95$ \\
\hline $14-8$ & 0 & $4 / 30 / 95$ \\
\hline $14-10$ & 0 & $4 / 30 / 95$ \\
\hline $15-1$ & 0 & $4 / 30 / 95$ \\
\hline $15-1$ & 0 & $4 / 30 / 95$ \\
\hline $15-3$ & 0 & $4 / 30 / 95$ \\
\hline $15-7$ & 0 & $4 / 30 / 95$ \\
\hline
\end{tabular}




\section{TABLE OF CONTENTS}

(Continued)

Section

15.4 Instrument Testing, Inspection, and Maintenance Requirements

15.5 Instrument Calibration and Frequency

15.6 Data Management

\section{DEFINITIONS}

REFERENCES

APPENDIX A

DETERMINING THE NUMBER OF CONTAINERS TO
Page

$15-9$

Rev

0

$4 / 30 / 95$

15-9

0

4/30/95

15-9

0

$4 / 30 / 95$

D-1

0

$4 / 30 / 95$

R-1

0

$4 / 30 / 95$ VISUALLY EXAMINE USING THE HYPERGEOMETRIC DISTRIBUTION 


\section{LIST OF TABLES}

Table

1-1 Cross Reference of Quality Assurance Requirements

1-2 Requirements for Review, Approval, Implementation, and Control of the QAPP and QAPjPs

1-3 Summary of Waste Characterization Requirements

1-4 Minimum Training and Qualifications Requirements

3-1 TC Levels Expressed as RTL Values in the Waste

3-2 Requirements for Electronic Transmittal of Data Packages

5-1 Number of Waste Containers Requiring Visual Examination

6-1 Gas Sample Containers and Holding Times

6-2 Sample Handling Requirements for Homogenous Solids and Soil/Gravel

7-1 Analyses Required for Each Type of Headspace Sample Collected

7-2 Summary of Drum Field QC Headspace Sample Frequencies

7-3 Summary of Sampling Quality Control Sample Acceptance Criteria

9-1 Quality Assurance Objectives for Nondestructive Assay

9-2 NDA Methods for Potential Use for TRU Waste Assay

10-1 Waste Material Parameters and Descriptions

11-1 Hydrogen and Methane Analysis Quality Assurance Objectives

11-2 Summary of Laboratory Quality Control Samples and Frequencies for Hydrogen and Methane Analysis

11-3 Summary of MS and GC Calibration Requirements for Hydrogen and Methane Analysis

12-1 Gas Volatile Organic Compounds Target Analyte List and Quality Assurance Objectives

12-2 Flammable and Nonflammable Volatile Organic Compounds

$12-4$

13-1

Frequencies for Gas Volatile Organic Compounds Analysis

Summary of GC/MS and GC Calibration Requirements for Gas Volatile Organic Compounds Analysis
Page

Bev.

Date

$1-3$

1-12

0

4/30/95

$1-12$

0

4/30/95

1-25

0

4/30/95

1-35

0

$4 / 30 / 95$

3-12

0

4/30/95

3-15

0

4/30/95

5-14

0

4/30/95

6-12

0

4/30/95

6-14

0

4/30/95

7-5

0

4/30/95

7-17

0

$4 / 30 / 95$

7-18

0

$4 / 30 / 95$

9-3

0

4/30/95

9-8

0

4/30/95

10-2

0

4/30/95

11-2

0

4/30/95

11-5

0

$4 / 30 / 95$

$11-8$

0

$4 / 30 / 95$

$12-2$

0

$4 / 30 / 95$

$12-4$

0

$4 / 30 / 95$

12-7

0

$4 / 30 / 95$

$12-10 \quad 0 \quad 4 / 30 / 95$

13-2

0

$4 / 30 / 95$ Quality Assurance Objectives 


\section{LIST OF TABLES}

(Continued)

Table

13-2 Summary of Laboratory Quality Control Samples and Frequencies for Total Volatile Organic Compound Analysis

13-3 Summary of Calibration Requirements for Total Volatile Organic Compounds Analysis

14-1 Semi-Volatile Organic Compound Target Analyte List and Quality Assurance Objectives

14-2 Summary of Laboratory Quality Control Samples and Frequencies for Total Semi-Volatile Organic Compounds Analysis

14-3 Summary of Calibration Requirements for Semi-Volatile Organic Compounds Analysis

15-1 Total Metals Target Analyte List and Quality Assurance Objectives

15-2 Total Metal Analytical Methods

15-3 Summary of Laboratory Quality Control Samples and Frequencies for Total Metals Analyses

15-4 Summary of Calibration Requirements and Analysis OC for Total Metals Analysis

$\begin{array}{ccr}\text { Page } & \text { Rev. } & \begin{array}{r}\text { Date } \\ 13-6\end{array} \\ 0 & 4 / 30 / 95 \\ 13-9 & 0 & 4 / 30 / 95 \\ 14-2 & 0 & 4 / 30 / 95 \\ 14-6 & 0 & 4 / 30 / 95 \\ 14-9 & 0 & 4 / 30 / 95 \\ 15-2 & 0 & 4 / 30 / 95 \\ 15-5 & 0 & 4 / 30 / 95 \\ 15-8 & 0 & 4 / 30 / 95\end{array}$

$15-10 \quad 0 \quad 4 / 30 / 95$ 


\section{LIST OF FIGURES}

Figure

$1-3 a$

$1-3 b$

$1-3 c$

$1-3 d$

$1-4$

1-5

5-1

5-2

5-3

6-1

6-2

6-3

6-4

6-5

6-6

6-7

7-1

7-2

$7-3$

7-4

$7-5$
Program Functional Organizational Chart

Program QA Document Hierarchy

Relationship between Compliance Programs and Data

Requirements for the Performance Assessment

Relationship between Compliance Programs and Data Requirements for the RCRA Land Disposal Restrictions

Relationship between Compliance Programs and Data

Requirements for the RCRA General Waste Analysis

Relationship between Compliance Programs and Data

Requirements for the TRUPACT-II Certificate of

Compliance

Idealized Sequence of Events for Waste Characterization Program

Flow of Records for the Program

Data Collection Design for Characterization of Retrievably Stored Waste

Data Collection Design for Characterization of Newly Generated Waste

Statistical Approach to Sampling and Analysis of Waste Streams of Retrievably Stored Homogenous Solids and Soil/Gravel

\section{Gas Sample Canister Tag}

Homogenous Solids and Soil/Gravel Sample Container Label

Waste Container Chain-of-Custody Form

Sample Chain-of-Custody Form

Sample Custody Seal

Waste Container Tracking Log Sheet

Sample Tracking Log

Schematic Diagram of Waste Drum with Minimum Layers of Confinement and Sampling Locations

Overall Headspace Gas Sampling Scheme Illustrating Manifold Sampling

Headspace Sampling Manifold

SUMMA ${ }^{\circledR}$ Canister Components Configuration

Schematic Diagram of Direct Canister with the Poly Bag Sampling Head

\begin{tabular}{|c|c|c|}
\hline Page & Bev. & Date \\
\hline $1-6$ & 0 & $4 / 30 / 95$ \\
\hline $1-10$ & 0 & $4 / 30 / 95$ \\
\hline $1-19$ & 0 & $4 / 30 / 95$ \\
\hline $1-20$ & 0 & $4 / 30 / 95$ \\
\hline $1-21$ & 0 & $4 / 30 / 95$ \\
\hline $1-22$ & 0 & $4 / 30 / 95$ \\
\hline $1-28$ & 0 & $4 / 30 / 95$ \\
\hline $1-37$ & 0 & $4 / 30 / 95$ \\
\hline $5-2$ & 0 & $4 / 30 / 95$ \\
\hline $5-3$ & 0 & $4 / 30 / 95$ \\
\hline & 0 & $4 / 30 / 95$ \\
\hline
\end{tabular}

6-4 $0 \quad 4 / 30 / 95$

6-7 $\quad 0 \quad 4 / 30 / 95$

6-9 $0 \quad 4 / 30 / 95$

6-10 $0 \quad 4 / 30 / 95$

6-13 $0 \quad 4 / 30 / 95$

6-16 $0 \quad 4 / 30 / 95$

6-17 $0 \quad 4 / 30 / 95$

7-2 $0 \quad 4 / 30 / 95$

$\begin{array}{lll}7-4 & 0 & 4 / 30 / 95\end{array}$

$\begin{array}{lll}7-8 & 0 & 4 / 30 / 95\end{array}$

7-9 $0 \quad 4 / 30 / 95$

7-12 $0 \quad 4 / 30 / 95$ 
Revision: 0

Date: 4/30/95

Page xii of xii

\section{LIST OF FIGURES}

(Continued)

\section{Figure}

8-1

Rotational Coring Tool

Page Rev.

Date

8-2

Non-Rotational Coring Tool

8-5

8-6

0

4/30/95

10-1

Overall Programmatic Approach to Visual Examination

$10-6$

4/30/95

$4 / 30 / 95$ 


\title{
LIST OF ACRONYMS, ABBREVIATIONS, AND SYMBOLS
}

\author{
ALARA \\ ANSI \\ ASME \\ ASOC \\ ASTM \\ BFB \\ BIR \\ ${ }^{\circ} \mathrm{C}$ \\ $\% \mathrm{C}$ \\ CAO \\ CCC \\ CFR \\ $\mathrm{CH}_{4}$ \\ $\mathrm{CH}$ TRU \\ $\mathrm{COC}$ \\ $\mathrm{Cr}-\mathrm{NiO}$ \\ CV \\ CVAA \\ $\% D$ \\ DFTPP \\ DOE \\ DQO \\ EICP \\ EM \\ EM-1 \\ EM-30 \\ EPA \\ FFCA \\ FLAA \\ FR \\ ft lbs \\ g \\ Gas PDP Plan \\ GC \\ GC/ECD \\ GC/FID \\ As Low As Reasonably Achievable \\ American National Standards Institute \\ American Society of Mechanical Engineers \\ American Society for Quality Control \\ American Society for Testing and Materials \\ Bromofluorobenzene \\ Waste Isolation Pilot Plant Transuranic Waste Baseline Inventory Report (DOE \\ 1995f) \\ Degrees Centigrade \\ Percent complete \\ Carlsbad Area Office \\ Calibration check compounds \\ Code of Federal Regulations \\ Methane \\ Contact Handled Transuranic \\ Chain-of-Custody \\ Chromium-Nickel Oxide \\ Coefficient of variation \\ Cold Vapor Atomic Absorption Spectroscopy \\ Percent difference \\ Decafluorotriphenylphosphine \\ Department of Energy \\ Data Quality Objective \\ Extracted Ion Current Profile \\ Environmental Management \\ DOE Office and Environmental Restoration and Waste Management \\ DOE Office of Waste Management \\ Environmental Protection Agency \\ Federal Facility Compliance Act of 1992 \\ Flame Atomic Absorption Spectroscopy \\ Federal Register \\ foot pounds \\ gram \\ Performance Demonstration Program Plan for the Analysis of Simulated \\ Headspace Gases for the TRU Waste Characterization Program (DOE 1995c) \\ Gas Chromatography \\ Gas Chromatography/Electron Capture Detection \\ Gas Chromatography/Flame Ionization Detector




\section{LIST OF ACRONYMS, ABBREVIATIONS, AND SYMBOLS} (Continued)

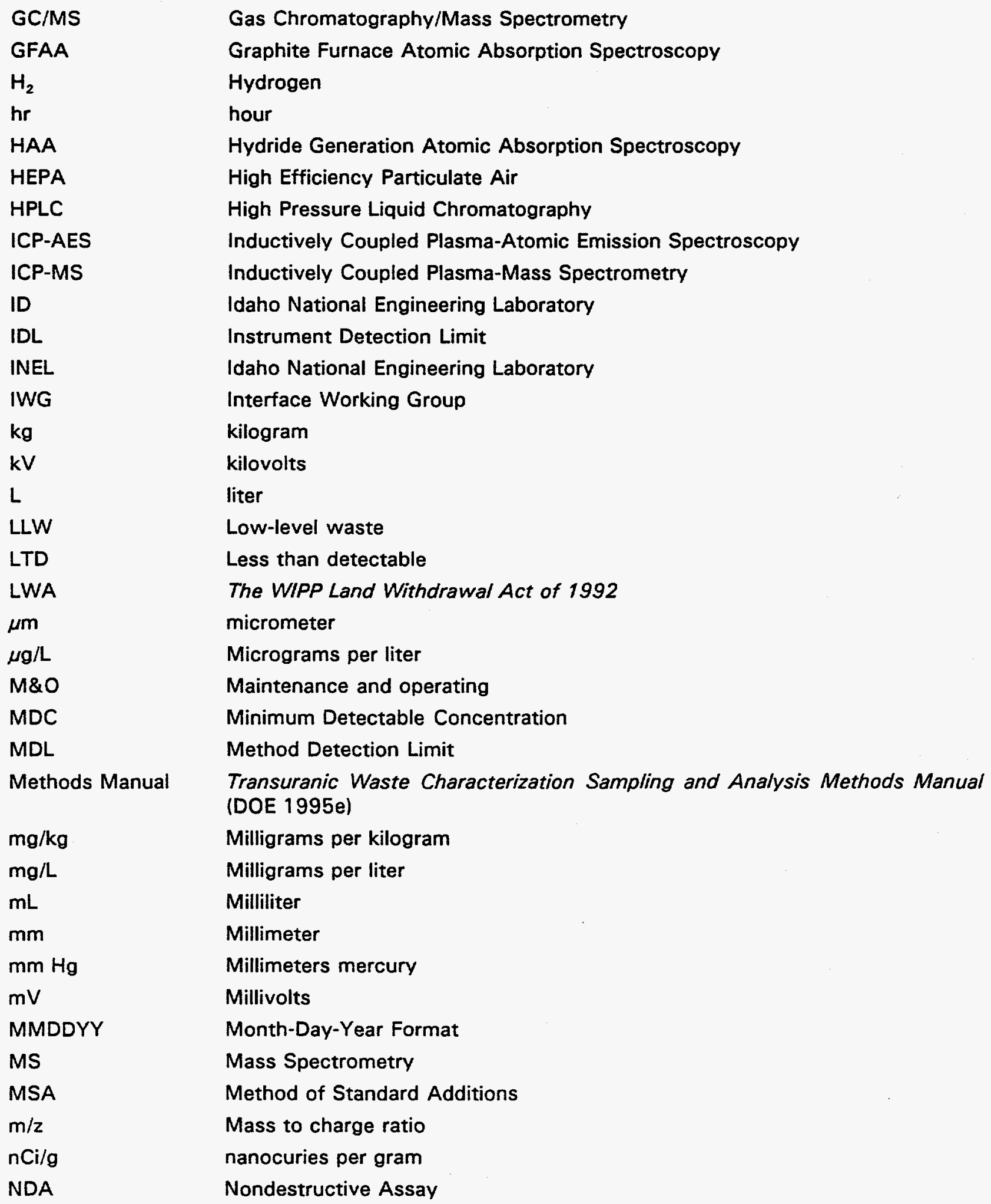




\section{LIST OF ACRONYMS, ABBREVIATIONS, AND SYMBOLS} (Continued)

NDA PDP Plan

NEIC

ng

NIST

NMED

NQA-1

NRC

NTP

OVA

$P$

PA

PAN

PCBS

PDP

PRDL

PFTBA

ppm

ppmv

Program

PROL

psig

pt

Pu

QA

QAO

QA/OC

QAPD

QAPjP

QAPP

$Q C$

\%R

RA

RCRA

RFP

RPD

rpm

RRT

RT

Performance Demonstration Program Plan for Nondestructive Assay for the TRU Waste Characterization Program (DOE 1994a)

National Enforcement Investigation Center

nanogram

National Institute of Standards and Technology

New Mexico Environment Department

Quality Assurance Requirements for Nuclear Facility Applications (ASME 1994)

Nuclear Regulatory Commission

National TRU Program

Organic vapor analyzer

Pressure

Performance Assessment

Passive/Active Neutron Counting

Polychlorinated biphenyls

Performance Demonstration Program

Program Required Detection Limit

Perfluorotributylamine

Parts per million

Parts per million by volume

WIPP TRU Waste Characterization Program

Program Required Quantitation Limit

Pounds per square inch gauge

point

Plutonium

Quality assurance

Quality Assurance Objective

Quality assurance/quality control

Quality Assurance Program Description (DOE 1994b)

Quality Assurance Project Plan

Quality Assurance Program Plan

Quality control

Percent recovery

Radioassay

Resource Conservation and Recovery Act

Rocky Flats Plant

Relative percent difference

Revolutions per minute

Relative retention time

Retention time 


\section{LIST OF ACRONYMS, ABBREVIATIONS, AND SYMBOLS} (Continued)

RTL

$\% R S D$

SARP

SGS

sites

SNL

Solid PDP Plan

SOP

SPCC

SVOC

SW-846

$T$

TC

TCLP

TIC

TRAMPAC

TRU

TRUCON

TRUPACT-II

$U \mathrm{UL}_{90}$

VOA

VOC

vol\%

VTSR

$w \%$

Westinghouse/WID

WG Pu

WIPP

WIPP-WAC
Regulatory Threshold Limit

Percent relative standard deviation

Safety Analysis Report for the TRUPACT-/l Shipping Package (Nuclear Packaging Inc. 1992)

Segmented Gamma Scan Counting

DOE generator/storage sites

Sandia National Laboratories

Performance Demonstration Program Plan for the Analysis of Solidified Wastes for the TRU Waste Characterization Program (DOE 1995d)

Standard Operating Procedure

System performance check compound

Semi-volatile organic compound

Test Methods for Evaluating Solid Waste, Physical/Chemical Methods, Third Edition, Final Update I, and Final Update II (EPA 1995)

Temperature

Toxicity Characteristic

Toxicity Characteristic Leaching Procedure

Tentatively Identified Compounds

TRUPACT-I/ Authorized Methods for Payload Control (Nuclear Packaging Inc. 1992, Appendix 1.3.7)

Transuranic

TRUPACT-// Content Codes (DOE 1992)

Transuranic Package Iransporter-1I

Upper 90-percent confidence limit

Void of air

Volatile organic compound

Volume percent

Validated time of sample receipt

Weight percent

Westinghouse Electric Corporation/Waste Isolation Division

Weapons grade plutonium

Waste Isolation Pilot Plant

Waste Acceptance Criteria for the Waste Isolation Pilot Plant (DOE 1991) 


\subsection{PROGRAM MANAGEMENT}

This Quality Assurance Program Plan (QAPP) identifies the quality of data necessary, and techniques designed to attain and ensure the required quality, to meet the specific Data Quality Objectives (DOOs) associated with the Department of Energy (DOE) Waste Isolation Pilot Plant (WIPP) Transuranic (TRU) Waste Characterization Program (the Program). Waste characterization data will be collected to support regulatory compliance programs associated with the WIPP facility. These regulatory compliance programs include an assessment and certification of the WIPP repository performance, the preparation of permit applications and a variance petition, and an evaluation of existing TRU waste transportation restrictions. Although this QAPP specifies waste testing, sampling, and analytical methods, it also allows for the introduction, consideration, and development of innovative techniques for TRU waste characterization. Prior to implementation of new waste characterization techniques for use in Program activities, the proposed techniques must be submitted to the Carlsbad Area Office (CAO) for review and approval. This QAPP will be reviewed annually, and revised as necessary, to incorporate lessons learned during waste characterization activities.

The CAO Quality Assurance Program Description (QAPD) (DOE 1994b) is the quality management document which identifies federal, state, and industry quality requirements applicable to the CAO quality assurance (QA) program. The QAPD establishes the minimum requirements for the development of QA programs by WIPP program and National TRU Program participants. Requirements contained in the QAPD are based on the QA requirements and criteria contained in 10 CFR Part 830 , "Nuclear Safety Management," and other programmatic requirements. The QAPD also is consistent with applicable Environmental Protection Agency (EPA) QA requirements. This QAPP addresses the applicable requirements outlined in the QAPD, as appropriate.

This QAPP follows the guidelines recommended by EPA in QA/R-5, EPA Requirements for Quality Assurance Project Plans for Environmental Data Operations (EPA 1994a). This QAPP satisfies all applicable requirements of 10 CFR $\S 830.120$, which governs the conduct of the DOE management and operating (M\&O) contractors and other persons at DOE nuclear facilities. Because DOE facilities are managing nuclear materials contained in TRU waste, all applicable quality elements in the American Society of Mechanical Engineers (ASME), Quality Assurance Program Requirements for Nuclear Facility Applications (ASME NOA-1) (ASME 1994) are addressed.

This QAPP addresses all of the basic requirements, and their supplements, of ASME NQA-1. However, nothing in this document relieves any Program participant from the responsibility of complying with any existing requirement. All exceptions to the basic requirements of NOA-1 such as applicable federal, 
state, and local regulation; DOE Orders; permits and interagency agreements; or any site-specific controls on operations, shall be documented in quality assurance project plans (QAPjPs)(Section 1.2.2) which must be prepared by each participating DOE generator/storage site (site). The CAO manager shall be notified immediately of any conflicts between this QAPP and any existing requirements.

Because the American National Standards Institute/American Society for Quality Control (ANSI/ASOC) E4-1993, Quality Systems Requirements for Environmental Programs (ANSI/ASOC 1993), incorporates the QA requirements of applicable EPA, DOE, and ASME documents, the requirements stated in the ANSI/ASOC E4-1993 document were considered in developing this QAPP. A cross reference of the content of this QAPP; the EPA QA/R-5 elements; the analogous CAO QAPD and 10 CFR \$830.120 criteria; and ASME NOA-1 basic requirements is provided in Table 1-1.

\subsection{Program Organization}

Responsibility for Program quality is shared between DOE Headquarters, CAO, and participating sites. The DOE Office of Environmental Restoration and Waste Management (EM-1) provides policy guidance and centralized management for DOE waste operations. The CAO manager ensures that program plans and operations are coordinated, integrated, and consistent with Headquarters programs, policies, and guidance. CAO has responsibility to oversee the specific activities being performed at participating sites and ensure that Program requirements are met with regard to TRU waste testing, sampling, sample handling and custody, and associated data management. Figure 1-1 shows the functional organization chart for the Program.

\subsubsection{Assistant Secretary, DOE Office of Environmental Restoration and Waste Management}

The assistant secretary, EM-1, has responsibility and authority for ensuring that DOE QA policy is implemented in association with waste management operations. The assistant secretary provides guidance and direction to field organizations consistent with the requirements related to $Q A$. The assistant secretary also ensures that proper planning for resources and budget are provided in DOE waste management programs for effective $\mathrm{QA}$ activities that are responsive to Program objectives.

\subsubsection{Deputy Assistant Secretary, DOE Office of Waste Management}

The deputy assistant secretary, DOE Office of Waste Management (EM-30), is responsible for providing key policy guidelines for the Program and reviewing proposed guidance and planning documents developed by CAO, including this QAPP, to assure consistency with planning efforts for other DOE waste management programs (i.e., low-level waste (LLW) and high-level waste programs). In coordination with the CAO manager, the deputy assistant secretary will prioritize Program activities to ensure compliance with federal mandates and regulations associated with TRU waste management. 
TABLE 1-1

\section{Section 1.0 Program Management}

Program Organization

Program Documents

Problem Definition and Background

Program Description

Data Quality Objectives for

Measurement Data

Special Training Requirements and Certifications

Documentation and Records

\section{Procurement}

Work Processe日 for Measurement Data
Problem Definition/Background Project Narrative

Project/Task Description Project Narrative

Quality Objectives and Criteria

Special Training Requirements/ Certification

Documentation and Records

Inspection/Acceptance Requirements for Supplies and Consumables

Quality Control Requirements Equipment Testing, Inspection, and Maintenance Requirements

Equipment Calibration and Frequency

\section{Quality Assurance Program and} Organization

(Program)

Documents

(Documents and Records)

Planning Scientific Investigations

Quality Assurance Program and Organization

\section{(Program)}

Design Control

Planning Scientific Investigations (Design)

Personnel Qualification and Training (Personnel Training and Qualification)

Records

Data Documentation, Control, and

Qualification

(Documents and Records)

Procurement

(Procurement)

Work Processes

Software QA Requirements

(Work Processes)
Organization

Document Control

Quality Assurance Program

Design Control

Quality Assurance Program

Quality Assurance Records

Procurement Document Control Control of Purchased Items and Services

Control of Processes

Identification and Control of Items 
TABLE 1-1

Cross Reference of Quality Assurance Requirements

(Continued)

\begin{tabular}{|c|c|c|c|c|}
\hline QAPP Section & EPA QA/R-5 Elements & $\begin{array}{l}\text { DOE/CAO QAPD Requirements } \\
\text { (10 CFR } 5830.120 \text { (c) Quality } \\
\text { Assurance Criteria) }\end{array}$ & $\begin{array}{l}\text { ASME NOA-1 } \\
\text { Basic Requirements }\end{array}$ & \\
\hline \multicolumn{5}{|l|}{ Section 2.0 Assessment and Oversight } \\
\hline Assessment and Response Actions & $\begin{array}{l}\text { Assessments and Response Actions } \\
\text { Project Nerrative }\end{array}$ & $\begin{array}{l}\text { Quality Improvement } \\
\text { Management Assessment } \\
\text { Independent Assessment } \\
\text { (Quality Improvement, Management } \\
\text { Assessment, Independent } \\
\text { Assessment) }\end{array}$ & $\begin{array}{l}\text { Control of Nonconforming Items } \\
\text { Corrective Action } \\
\text { Audits }\end{array}$ & \\
\hline Reports to Management & Reports to Management & $\begin{array}{l}\text { Quality Improvement } \\
\text { Independent Assessment } \\
\text { (Quality Improvement) }\end{array}$ & $\begin{array}{l}\text { Quality Assurance Program } \\
\text { Corrective Action }\end{array}$ & \\
\hline Performance Demonstration Program & $\begin{array}{l}\text { Assessments and Response Actions } \\
\text { Project Narrative }\end{array}$ & $\begin{array}{l}\text { Inspection and Testing } \\
\text { (Inspection and Acceptance) }\end{array}$ & Inspection & \\
\hline \multicolumn{5}{|l|}{$\begin{array}{c}\text { Section 3.0 Data Validation and } \\
\text { Usability }\end{array}$} \\
\hline $\begin{array}{l}\text { Data Review, Validation, and } \\
\text { Verification Requirements }\end{array}$ & $\begin{array}{l}\text { Data Review, Validation, and } \\
\text { Verification Requirements }\end{array}$ & $\begin{array}{l}\text { Data Documentation, Control, and } \\
\text { Qualification } \\
\text { Work Processes } \\
\text { Design Control } \\
\text { (Work Processes, Design) }\end{array}$ & Control of Nonconforming Items & \\
\hline Validation Methods & Validation and Verification Methods & $\begin{array}{l}\text { Design Control } \\
\text { (Design) }\end{array}$ & Test Control & \\
\hline $\begin{array}{l}\text { Reconciliation with Data Quality } \\
\text { Objectives }\end{array}$ & $\begin{array}{l}\text { Reconciliation with User Requirements } \\
\text { Project Narrative }\end{array}$ & $\begin{array}{l}\text { Design Control } \\
\text { Data Documentation, Control, and } \\
\text { Qualification } \\
\text { (Design) }\end{array}$ & Design Control & \\
\hline Data Reporting Requirements & Data Management & $\begin{array}{l}\text { Records } \\
\text { Data Documentation, Control, and } \\
\text { Qualification } \\
\text { (Documents and Records) }\end{array}$ & Quality Assurance Records & $\begin{array}{l}0 \\
0 \\
0 \\
0 \\
0\end{array}$ \\
\hline $\begin{array}{c}\text { Section 4.0 Measurement and Date } \\
\text { Acquisition }\end{array}$ & $\begin{array}{l}\text { Measurement/Data } \\
\text { Acquisition } \\
\text { Project Narrative }\end{array}$ & $\begin{array}{l}\text { Work Processes } \\
\text { Design Control } \\
\text { (Work Processes, Design) }\end{array}$ & Design Control & 志 \\
\hline
\end{tabular}


TABLE 1-1

\begin{tabular}{|c|c|c|c|}
\hline QAPP Section & EPA QA/R-5 Elements & $\begin{array}{l}\text { DOE/CAO QAPD Requirements } \\
\text { (10 CFR \$ 830.120(c) Quality } \\
\text { Assurance Criteria) }\end{array}$ & $\begin{array}{l}\text { ASME NQA-1 } \\
\text { Basic Requirements }\end{array}$ \\
\hline Section 6.0 Sampling Process Design & $\begin{array}{l}\text { Sampling Process Design } \\
\text { Project Narrative }\end{array}$ & $\begin{array}{l}\text { Design Control } \\
\text { (Design) }\end{array}$ & $\begin{array}{l}\text { Design Control } \\
\text { Instructions, Procedures, and Drawings }\end{array}$ \\
\hline $\begin{array}{l}\text { Section 6.0 Sample Handling and } \\
\text { Custody Requirements }\end{array}$ & $\begin{array}{l}\text { Sample Handling and Custody } \\
\text { Requirements } \\
\text { Project Narrative }\end{array}$ & $\begin{array}{l}\text { Sample Control } \\
\text { Sample Identification } \\
\text { Handling, Storing, and Shipping } \\
\text { Samples } \\
\text { Disposition of Nonconforming } \\
\text { Samples } \\
\text { Work Processes } \\
\text { (Work Processes) }\end{array}$ & $\begin{array}{l}\text { Identification and Control of Items } \\
\text { Handling, Storage, and Shipping }\end{array}$ \\
\hline Section 7.0 through 15.0 Techniques & Project Narrative & & \\
\hline Quality Assurance Objectives & $\begin{array}{l}\text { Quality Objectives and Criteria } \\
\text { for Measurement Data }\end{array}$ & $\begin{array}{l}\text { Design Control } \\
\text { (Design) }\end{array}$ & Design Control \\
\hline Methods Requirements & $\begin{array}{l}\text { Sampling Methods Requirements } \\
\text { Analytical Methods Requirements }\end{array}$ & $\begin{array}{l}\text { Performing Scientific Investigation } \\
\text { Work Processes } \\
\text { (Work Processes) }\end{array}$ & $\begin{array}{l}\text { Instructions, Procedures, and Drawings } \\
\text { Control of Processes }\end{array}$ \\
\hline Quality Control Requirements & Quality Control Requirements & $\begin{array}{l}\text { Work Processes } \\
\text { (Work Processes) }\end{array}$ & $\begin{array}{l}\text { Control of Processes } \\
\text { Test Control }\end{array}$ \\
\hline $\begin{array}{l}\text { Instrument/Equipment Testing, } \\
\text { Inspection, and Maintenance } \\
\text { Requirements }\end{array}$ & $\begin{array}{l}\text { Instrument/Equipment Testing, } \\
\text { Inspection, and Maintenance } \\
\text { Requirements }\end{array}$ & $\begin{array}{l}\text { Work Processes } \\
\text { Inspection and Testing } \\
\text { (Work Process, Inspection and } \\
\text { Acceptance) }\end{array}$ & $\begin{array}{l}\text { Inspection } \\
\text { Inspection, Test, and Operating Status }\end{array}$ \\
\hline $\begin{array}{l}\text { Instrument Calibration and } \\
\text { Frequency }\end{array}$ & Instrument Calibration and Frequency & $\begin{array}{l}\text { Work Processes } \\
\text { Inspection and Testing } \\
\text { (Work Processes, Inspection, and } \\
\text { Acceptance) }\end{array}$ & $\begin{array}{l}\text { Control of Measuring and Test } \\
\text { Equipment }\end{array}$ \\
\hline Data Management & Data Management & $\begin{array}{l}\text { Records } \\
\text { Data Documentation, Control,. and } \\
\text { Qualification } \\
\text { (Documents and Records) }\end{array}$ & Quality Assurance Records \\
\hline
\end{tabular}




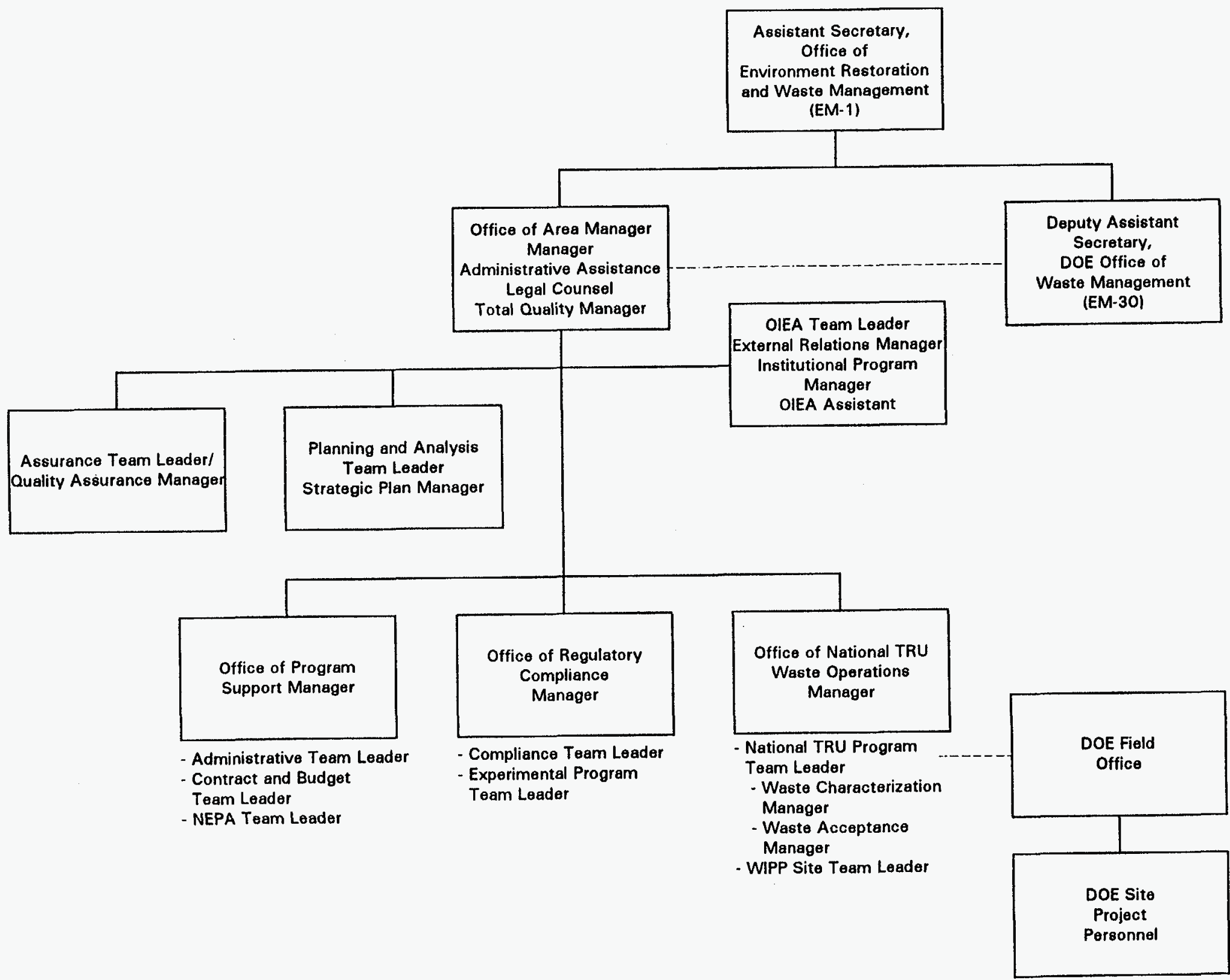

\section{FIGURE 1-1}

Program Functional Organizational Chart 
The deputy assistant secretary will also provide guidance on budget development and acquisition of resources to accomplish Program activities consistent with the priorities of the overall DOE Environmental Management (EM) program. Finally, EM-30 will integrate Program activities with other DOE waste management programs and Headquarters organizations.

\subsubsection{Manager, DOE Carlsbad Area Office}

The CAO manager is responsible for overall implementation of DOE Headquarter programs, policies, and guidance for the National TRU Program (NTP). The CAO manager is responsible for providing policy direction and oversight for waste characterization activities at participating sites. Authority for execution of the NTP team leader function, which ensures Program requirements are met with regard to TRU waste testing, sampling, analysis, sample handling and custody, and associated data management, is delegated to the NTP team leader. Overall responsibility for the development and implementation of the CAO QA program belongs to the CAO manager. As part of this responsibility, the CAO manager shall review and approve this QAPP. Authority for execution of the OA function, which ensures effective implementation, is delegated to the CAO OA manager. The CAO OA manager reports directly to the CAO manager.

\subsubsection{Manager, CAO Office of Regulatory Compliance}

The CAO Office of Regulatory Compliance manager is responsible for the preparation of compliance documentation and the implementation of programs to meet the requirements specified in final operating permits for the WIPP facility. The CAO Office of Regulatory Compliance manager is responsible for the verification of data completeness before waste acceptance at the WIPP facility. As part of this responsibility, the CAO Office of Regulatory Compliance manager shall review and concur with this QAPP.

\subsubsection{Manager, CAO Quality Assurance}

The CAO QA manager is responsible for QA oversight and planning, which includes implementing the requirements of the QAPD. The CAO QA manager is responsible for review and concurrence with this QAPP and site QAPjPs. This individual is also responsible for verifying Program compliance at participating sites through audits. The CAO QA manager is responsible for approving the participation of all audit team members and observers. He/she also has responsibility for ensuring that through periodic audits at sites, waste characterization activities comply with applicable QAPJPs and implementing standard operating procedures (SOPs), as described in Section 2.1 of this QAPP. 


\subsubsection{Team Leader, National TRU Program}

The NTP team leader is responsible for identifying issues that need to be addressed to properly manage TRU waste. The NTP team leader will develop options and recommendations, and propose priorities and guidelines for Program activities at participating sites. The NTP team leader is responsible for identifying data collection needs, establishing a TRU Waste Characterization Program Plan, and technical oversight. The NTP team leader is responsible for development and management of the planning process for the National TRU Program and waste characterization. In association with these activities, the NTP team leader has responsibility for review and concurrence with this QAPP.

\subsubsection{DOE Field Office}

As a part of the Program, each DOE field office shall review and approve the site QAPjPs for the facility under that office's responsibility. The DOE field offices are responsible for ensuring that the requirements of the QAPjPs are in compliance with all DOE orders and that the resources and funding are available to accomplish Program activities. All revisions to the QAPjPs that affect compliance with the quality assurance/quality control $(\mathrm{QA} / \mathrm{QC})$ requirements specified in this $\mathrm{QAPP}$ must be approved by the DOE field offices before implementing the change and notification provided to the NTP team leader. The DOE field offices are responsible for providing a liaison between the $M \& O$ contractors at the various DOE facilities and the NTP team leader to resolve any problems that could affect the quality of the Program.

\subsubsection{Site Project Manager. Each participating site's M\&O contractor must designate a site project} manager who shall be responsible for overseeing Program activities at the site. The site QAPjPs must include a description of the role and define the responsibility and authority of the site project manager in relation to the other organizational functions at the site. The site project manager shall review and approve the site QAPjP before its implementation. Specific Program responsibilities assigned to the site project manager include the following:

- Waste selection and tracking

- Operational variance approval

- Analytical data validation/verification

- Analytical data reconciliation with DOOs

- Assignment of EPA Hazardous Waste Numbers

- QA/OC reports to DOE field office

- Analytical data transmission to CAO

1.1.7.2 Site Proiect Quality Assurance Officer. Each participating site's M\&O contractor shall designate a site project $\mathrm{QA}$ officer for the Program and include a detailed description of the responsibility and authority of this person in the site QAPjP. The site project QA officer shall review 
and approve the site QAPjP. The site project $Q A$ officer is responsible for verifying the implementation of the $Q A$ requirements for the Program and providing the necessary day-to-day guidance to the project staff on quality-related matters. This individual will have the authority to stop Program activities at a participating site if quality is not assured or controlled. Specific Program responsibilities assigned to the site project $Q A$ officer include the following:

- Operational variance approval

- Laboratory/testing facility assessment

- Nonconformance tracking

- Corrective action verification

- Analytical data validation/verification

- Analytical data QA documentation verification

- Evaluating trends in compliance with Program objectives

- $Q A / O C$ reports to site project manager

\subsection{Program Documents}

The Program includes a hierarchy of documents that will guide QA activities. Figure 1-2 shows the hierarchy and relationship of Program $Q A$ documents. Program requirements that are mandatory for Program participants are specified in these documents by the use of the terms "shall" or "must." Information that is provided as guidance that constitutes an acceptable means of accomplishing a task is designated by the terms "should" or "may." An explanation of how Program QA documents will be reviewed, approved, controlled, and procedures for change to these documents, is presented in Section 1.2.3.

\subsubsection{Quality Assurance Program Plan}

This QAPP describes the activities to be undertaken at participating sites to characterize TRU waste. It currently addresses only contact-handled TRU (CH TRU) waste characterization activities. Future revisions will include requirements for both $\mathrm{CH}$ TRU and remote-handled TRU waste. This QAPP includes both management and technical aspects of Program implementation and the data quality requirements that each DOE facility must meet in characterizing TRU wastes intended for disposal at the WIPP facility. This QAPP also includes the performance-based QA/OC requirements that each facility participating in the Program must comply with and the performance criteria for site QAPjP preparation, review, and approval.

The QAPP refers to the Transuranic Waste Characterization Sampling and Analysis Methods Manual (Methods Manual)(DOE 1995e) to provide a detailed description of acceptable testing, sampling, and analytical methods. Furthermore, this QAPP describes how the Performance Demonstration Program (PDP) (Section 2.3) will be used to ensure testing, sampling, and analytical facilities are capable of meeting Program $Q A$ requirements. 
Revision: 0

Date: $4 / 30 / 95$

Page 10 of 40

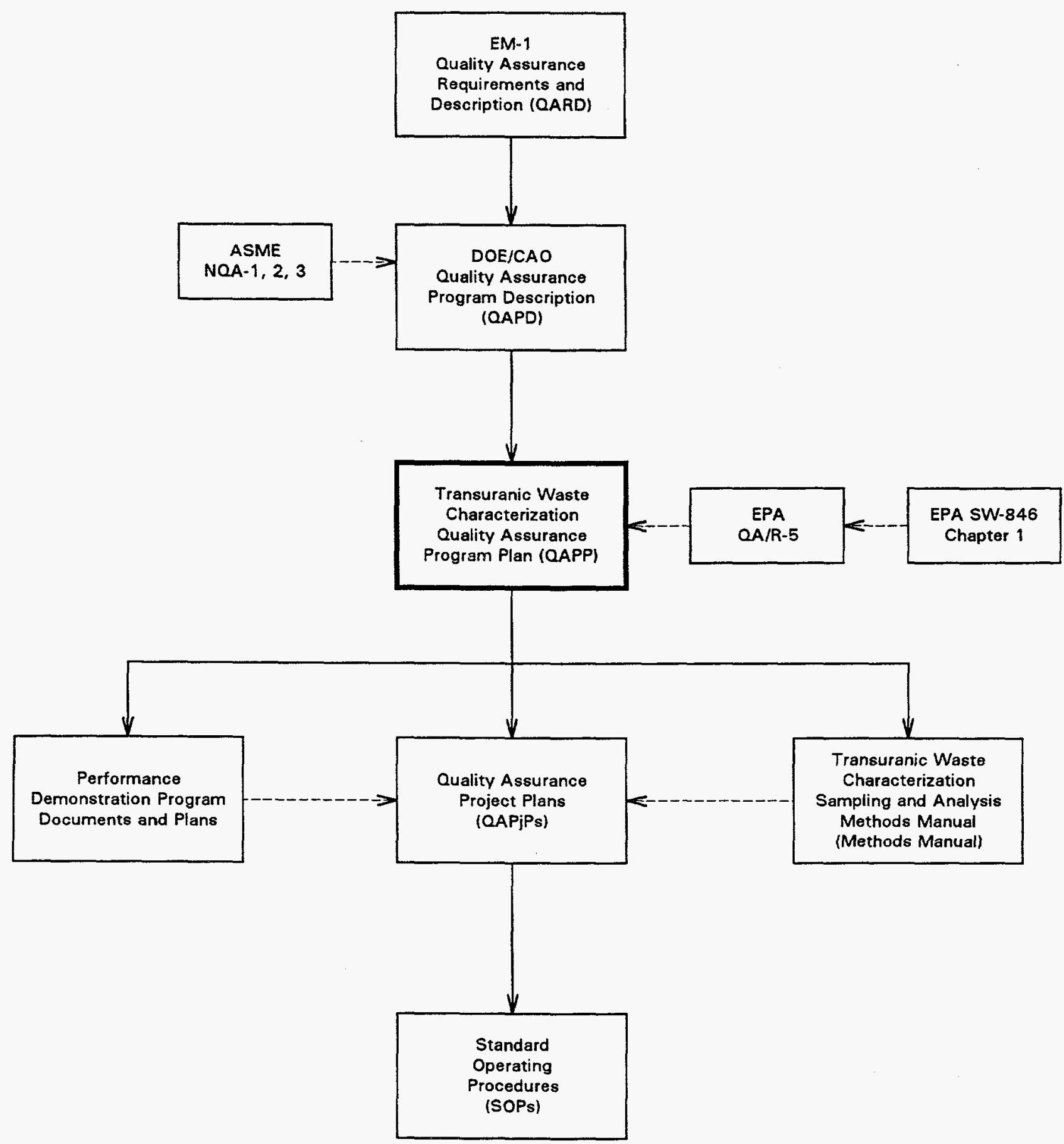

FIGURE 1-2

Program QA Document Hierarchy 


\subsubsection{Quality Assurance Project Plans}

Each participating site shall develop and implement a QAPjP that addresses all the requirements specified in this QAPP. These QAPjPs shall include or reference the appropriate management and technical criteria of the Program, as well as qualitative or quantitative criteria for determining that Program activities are being satisfactorily performed. QAPjPs shall identify the organization(s) and position(s) responsible for their implementation. The QAPjPs shall also reference site-specific documentation that details how each of the required elements of the Program will be performed.

Prior to the implementation of Program activities at participating sites, SOPs will be developed for all activities affecting Program quality that require written instructions or procedures. For the purposes of the Program, the term SOP refers to any site-specific implementing document. Compliance with SOPS will ensure that tasks are performed in a consistent manner that results in achieving the quality required for the Program. The organization, format, content, and designation of SOPs must be described in the QAPjPs.

\subsubsection{Document Review, Approval, and Control}

The preparation, issue, and change to documents that specify quality requirements or prescribe activities affecting quality for the Program shall be controlled to assure that correct and current documents are used and referenced. The QAPjPs shall include the document control format used in this QAPP consisting of a unique document identification number in the upper left-hand corner of each page and the section number, current revision number, date, and page number placed in the upper right-hand corner of each page. All quality documents for the Program shall be reviewed prior to approval and issuance by qualified and independent individuals. This review shall consider, as appropriate, the technical adequacy, completeness, and correctness of the documents and the inclusion of appropriate quality requirements. Approval shall be indicated by a signature and date page included in the front of each document. Table 1-2 shows the parties responsible for document review, review/approval, implementation, change approval, and change control. Whenever the $Q A$ documents are revised, review and approval of the revision shall be conducted by the same level of approval authority and in accordance with the requirements of review as the original documents.

At a minimum, revisions to $Q A$ documents shall be denoted by including the current revision number on the document title page, the revised signature page, and each page that has been revised. Only revised pages need to be reissued. A vertical bar, indicating the change to the text, shall be included along the left-hand margin of the page. Revised document submittals shall also identify the changes, the reason for the changes, and the justification for concluding that the revised contents continue to satisfy the requirements of the Program. 
TABLE 1-2

Requirements for Review, Approval, Implementation, and Control of the QAPP and QAPjPs

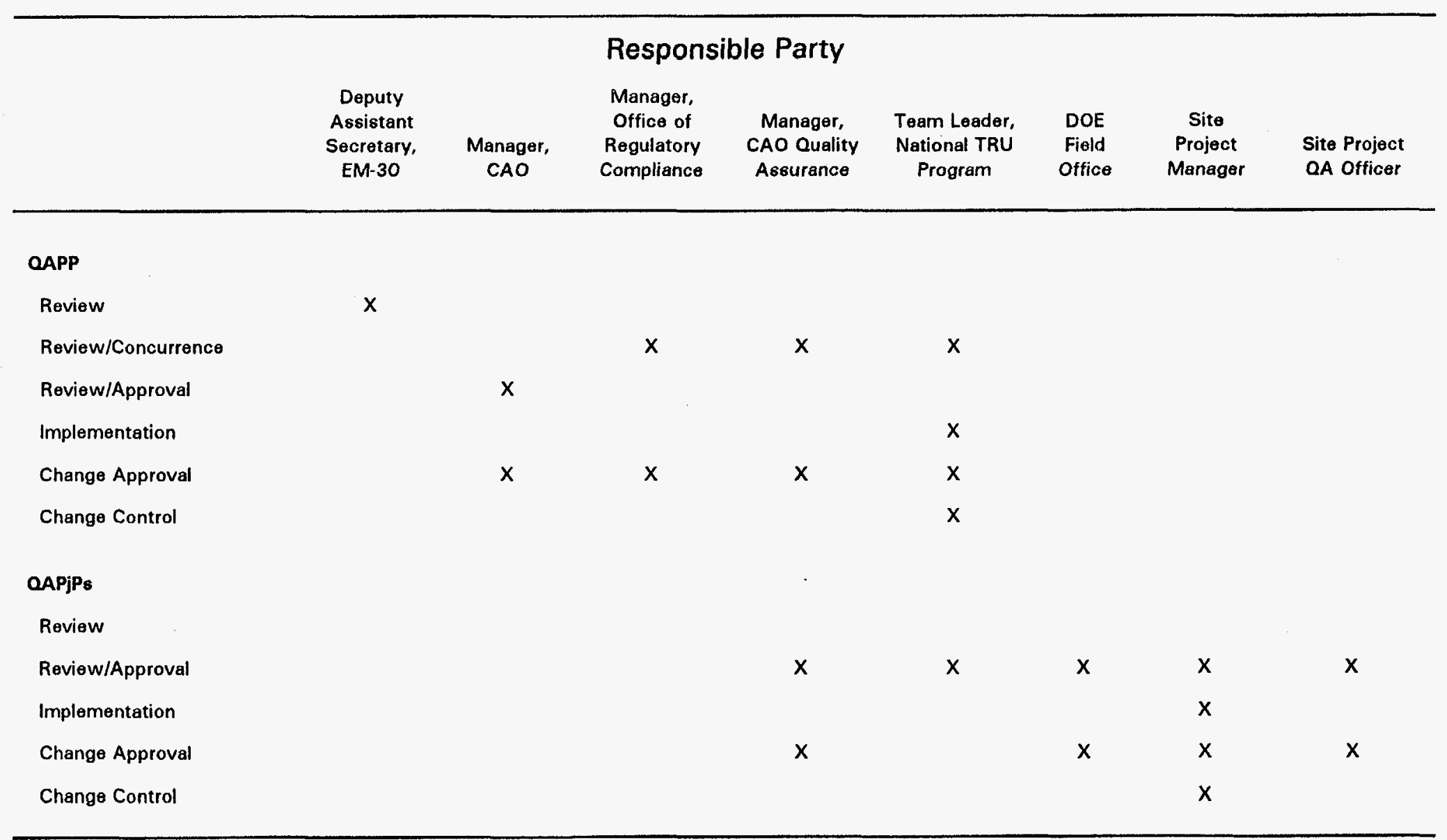


This QAPP shall be controlled by the NTP team leader and distributed by this position to the applicable DOE field offices. A distribution list for the QAPP shall be used to control the issuance of revisions and shall be maintained by the NTP team leader.

This QAPP shall be initially reviewed, approved, and concurred with by those positions indicated in Table 1-2, and thereafter reviewed by the NTP team leader at least annually to ensure it addresses the current needs of the Program. If changes to the QAPP are required, the NTP team leader shall be responsible for scheduling and coordinating the review and approval of the revised document. Changes shall be reported by the NTP team leader to the DOE field office managers for notification to the sites. The site project manager shall be responsible for revision of the QAPjP and SOPs in accordance with the approved changes to the QAPP.

Each site must have a document control system to control the review and approval of controlled documents. The NTP team leader, the applicable DOE field office, the site project manager, and the site project $Q A$ officer, are responsible for the initial review and approval of the QAPjPs. Thereafter the QAPjPs shall be reviewed at least annually by the site project manager. If changes to the QAPjP are required, the site project manager shall be responsible for scheduling and coordinating the review and approval of the revised document. The QAPjPs shall include a description of the organization(s) or person(s) responsible for distributing revisions to those plans.

The QAPjPs shall include a detailed description of the reporting and approval requirements for changes to approved $Q A$ documents and SOPs, including procedures for implementing changes to these documents. All members of the site project staff are responsible for reporting any obsolete or superseded information to the site project manager. All site-specific changes shall be evaluated and approved by the site project manager and the site project $Q A$ officer before implementation. The site project manager shall notify the appropriate personnel, and the affected documents shall be revised as necessary. The site project manager shall also be responsible for notifying the DOE field office of the changes. No changes that affect performance criteria or data quality; such as sample handling and custody requirements, sampling, and analytical procedures, quality assurance objectives, calibration requirements, or $Q C$ sample acceptance criteria; shall be made without prior approval of the DOE field office and the NTP team leader. However, minor changes to QAPjPs and SOPs that do not affect Program performance criteria or data quality may be made without prior notification of the DOE field office and the NTP team leader. 


\subsection{Problem Definition and Background}

The WIPP facility was authorized by Public Law 96-164, The Department of Energy National Security and Military Applications of Nuclear Energy Authorization Act of 1980, and funded by Congress to provide a research and development facility to demonstrate the safe disposal of radioactive wastes produced by national defense activities. The DOE plans to dispose of approximately 175,600 cubic meters (6.2 million cubic feet) of TRU waste in the WIPP facility over the 25-year disposal phase. The DOE defense program TRU wastes result primarily from plutonium reprocessing and fabrication, research and development activities, environmental restoration, and decontamination and decommissioning programs at various sites.

Although TRU waste has been retrievably stored at sites since 1970, approximately two-thirds of the TRU waste destined for the WIPP facility has not yet been generated. The existing and future wastes include a variety of forms ranging from laboratory tools, glassware, and equipment to solidified wastewater treatment sludges, contaminated soil/gravel, and decommissioning debris wastes. A portion of the TRU waste also contains hazardous waste that is regulated under the Resource Conservation and Recovery Act (RCRA). The Hazardous and Solid Waste Amendments to RCRA greatly expanded the scope of the existing regulations, and included in part, stringent new requirements pertaining to the land disposal of hazardous waste. Any discussion in this QAPP that refers to RCRA regulations found in 40 CFR Parts 260 through 270 also refers to the corresponding New Mexico Environment Department (NMED) regulations found in Title 20 of the New Mexico Administrative Code, Chapter 4, Part 1.

Mixed waste refers to waste regulated by both the Atomic Energy Act and RCRA. In this QAPP, the term TRU waste includes TRU and TRU mixed waste. To ensure consistency throughout the DOE complex regarding TRU waste inventory information, TRU waste characterization information will be correlated to the matrix parameter categories established by DOE as acceptable to the WIPP facility in the Waste Isolation Pilot Plant Transuranic Waste Baseline Inventory Report (BIR)(DOE 1995f).

The Federal Facility Compliance Act of 1992 (FFCA) was established by Congress to address the management of mixed waste. The FFCA requires DOE to inventory all existing and future generated mixed wastes and develop plans for the treatment of mixed waste subject to the RCRA regulations as promulgated under 40 CFR Part 268, "Land Disposal Restrictions." As provided under 40 CFR $\S 268.6$, DOE plans to seek a no-migration variance from the Land Disposal Restrictions for TRU wastes to be sent to the WIPP facility. 
Public Law 102-579, The WIPP Land Withdrawal Act of 1992 (LWA) transferred jurisdiction of the land used for the WIPP facility from the U.S. Bureau of Land Management to DOE and provided additional authorization to continue the activities initiated by Public Law 96-164. One section of the LWA focused on the criteria for certification of compliance with the long-term disposal regulation developed by EPA ( 40 CFR Part 191). The LWA reinstated certain portions of 40 CFR Part 191 that had been remanded by the courts. On December 20, 1993, EPA promulgated amendments to 40 CFR Part 191 pertaining to individual and groundwater protection requirements. The LWA also requires that EPA finalize criteria for the certification and determination of WIPP's compliance with environmental standards as stated in 40 CFR Part 191. These criteria will be codified as 40 CFR Part 194.

TRU waste characterization, which involves obtaining chemical, radiological, and physical data, is a primary component of compliance activities to support the WIPP program. The waste that may be disposed of at the WIPP facility will be limited to that for which adequate waste characterization data is available. This QAPP establishes waste testing, sampling, and analytical techniques to support regulatory compliance programs associated with the WIPP facility.

Implementation of the requirements specified in this QAPP will result in data necessary to meet a number of objectives. From a programmatic viewpoint, the Program encompasses the characterization of wastes at sites, and the verification of this data by CAO. From a regulatory compliance viewpoint, the Program addresses several data needs associated with the following regulatory compliance programs:

- Performance Assessment (PA), conducted to evaluate long-term radionuclide containment as required by the "Environmental Radiation Protection Standards for Management and Disposal of Spent Nuclear Fuel, High-level, and Transuranic Radioactive Wastes" (40 CFR Part 191). The criteria for the certification of compliance with the requirements specified in 40 CFR Part 191 will be promulgated under 40 CFR Part 194, a separate rule announced in the Notice of Proposed Rulemaking on February 11, 1993 (58 FR 8029).

- Land Disposal Restrictions, specified under 40 CFR § 268.6 with regard to the containment of hazardous constituents, including efforts by DOE to petition EPA for a disposal phase no-migration variance for the WIPP facility.

- General Waste Analysis, specified in 40 CFR $\S \S 270.14(b)(2)$ and $270.23(\mathrm{c})$, with regard to verification of waste characterization data provided by sites that plan to ship wastes to the WIPP facility, including efforts by DOE to obtain a RCRA permit for the WIPP facility from NMED.

- Transportation of Radioactive Waste, specified under 10 CFR Part 71, including amendment of the Safety Analysis Report for the TRUPACT-I/ Shipping Package (SARP) (Nuclear Packaging Inc. 1992). 
The key decision makers for the compliance activities, as well as the key users of Program-generated data, include EPA, the Nuclear Regulatory Commission (NRC), and NMED. The EPA Office of Radiation and Indoor Air is responsible for reviewing the 40 CFR Part 191. Certification Application and issuance and enforcement of the Certificate of Compliance with 40 CFR Part 191. The EPA Office of Solid Waste, in conjunction with EPA Region VI, is responsible for reviewing the WIPP No-Migration Variance Petition, and making a determination of no-migration under 40 CFR $\S$ 268.6. The NMED is responsible for reviewing the WIPP RCRA permit application and issuing the WIPP disposal phase permit. NMED and EPA Region VI are responsible for enforcing RCRA regulations and permit provisions at the WIPP facility. Finally, certain Program data will be used in an effort to amend the SARP. NRC is responsible for reviewing and approving the SARP, and issuing and enforcing the Certificate of Compliance for the Iransuranic Package Iransporter-II (TRUPACT-II). Each of the regulatory compliance programs and the background information related to compliance is provided in more detail below.

\section{Performance Assessment}

To certify compliance under 40 CFR Part 191, Subparts B and C, a waste inventory must describe and include the radiological characteristics of the waste proposed for disposal at the WIPP facility. Waste characterization information regarding the types and quantities of radionuclides to be disposed of in the WIPP facility is necessary for calculations associated with the 40 CFR Part 191 Certification Application. DOE is developing a waste inventory that will include the activity of each TRU radionuclide that composes the total WIPP TRU waste inventory. The inventory will include an estimate of future-generated quantities of TRU waste and will be scaled to the maximum storage capacity of the repository. The estimate of future-generated TRU waste will be based on activities expected to take place at DOE sites that have the potential to generate TRU waste, such as environmental restoration and decontamination and decommissioning of facilities. To ensure compliance, DOE wili need to determine and report the activity of each radionuclide on a container-bycontainer basis before shipment to the WIPP facility in order to confirm the radionuclide inventory on which the 40 CFR Part 191 Certification Application is based.

To conduct PA, the waste inventory will be based on knowledge of the materials and processes that result in currently stored and future-generated wastes (i.e., acceptable knowledge). The PA will be evaluated using the expected waste inventory within a repository panel. The PA waste inventory information will be compiled from each participating site and summarized as outlined in the BIR.

\section{Land Disposal Restrictions}

A portion of the TRU waste inventory contains hazardous constituents in concentrations in excess of the Land Disposal Restrictions treatment standards (40 CFR Part 268). To land-dispose of these mixed 
wastes without prior treatment, DOE must submit a petition to EPA for a variance from the Land Disposal Restrictions.

Under 40 CFR $\$ 268.6$, petitioners must include waste characterization information for each waste covered by the variance. The three required aspects of this information are: 1) the applicable EPA Hazardous Waste Numbers as defined under 40 CFR Part 261, Subparts $C$ and D, 2) the quantities of hazardous constituents as defined under 40 CFR Part 261, Appendix VIII, and 3) the quantities of potentially flammable gases. In the past, DOE relied primarily on knowledge of the waste to obtain this information. EPA indicated in its preamble to the "Conditional No-Migration Determination for the Department of Energy Waste Isolation Pilot Plant (WIPP)" (55 FR 47700) that sampling and analytical data will be necessary if the DOE chooses to submit a petition for the disposal phase.

To evaluate potential migration of hazardous constituents before final closure and sealing of the repository shafts, data is required regarding the concentrations of hazardous constituents present in the headspace of containers to be sent to the WIPP facility. This includes the headspace directly under the lid of waste containers and the headspace of innermost layers of confinement. In 55 FR 47700 , the EPA requested additional information regarding the representativeness of concentrations of volatile organic compounds (VOCs) in the headspace of containers.

To evaluate the potential for migration of hazardous constituents after final closure and sealing of the repository shafts, a no-migration variance petition also must describe the total hazardous constituents associated with the waste that is proposed for land disposal. To meet these requirements, the types and average quantities of hazardous constituents contained in waste streams classified as homogenous solids and soil/gravel must be determined.

Because the potential flammability of TRU wastes was a concern of the EPA during its review of information provided in the WIPP No-Migration Variance Petition (DOE 1990). EPA imposed a 500 ppm concentration limit for flammable VOCs in the headspace of containers to be sent to the WIPP facility during the test phase (55 FR 47700). In its preamble to the conditional no-migration determination, the EPA stated that additional data would be required before the submittal of a petition for the WIPP disposal phase.

\section{RCRA General Waste Analysis}

The WIPP facility is defined as a miscellaneous unit subject to regulation under 40 CFR Part 264 , Subpart $X$. Permit applications for miscellaneous units must describe the wastes to be managed and assess the potential environmental impacts associated with the proposed waste management activities. 
This information must include a description of the physical form of the waste as well as the appropriate EPA Hazardous Waste Numbers. Process tolerance limits, such as chemical compatibility, must also be addressed to ensure safe handling and to meet the criteria for final waste disposal.

\section{Transportation of Radioactive Waste}

In 1989, DOE obtained the first Certificate of Compliance from NRC to ship CH TRU waste in the TRUPACT-II. TRU waste containers may contain hydrogen, methane, and potentially flammable VOCs due to the physical and chemical composition of the waste and radiological degradation of the waste. Currently, a $500 \mathrm{ppm}$ limit for flammable VOCs in the headspace of waste containers is imposed for transportation of TRU waste containers in the TRUPACT-II. In addition, NRC established thermal power limits by waste type for shipment in the TRUPACT-II. These limits are conservative and may limit the types and quantities of the TRU waste inventory allowed for shipment in the TRUPACT-II.

\subsection{Program Description}

The Program consists of testing, sampling, and analytical techniques that will be used to characterize retrievably stored and newiy generated TRU waste at sites that are planning to send their wastes to the WIPP facility. For the Program, retrievably stored waste is defined as that which has been generated before development and implementation of the QA/OC requirements specified in this QAPP. Newly generated waste is that which is generated after the development and implementation of the QA/OC requirements specified in this OAPP. TRU waste characterization will be initiated for retrievably stored waste currently in accessible retrievable storage (e.g., air-support buildings) and continue over the course of waste retrieval from earthen-covered storage units. Newly generated TRU waste will be characterized as it is generated. The Program is designed for the characterization of TRU waste on a waste stream basis. A waste stream is defined as waste material generated from a single process or activity that is similar in material, physical form, isotopic make-up, and hazardous constituents. Figures 1-3a through 1-3d provide a summary of the regulatory compliance programs, associated questions to be answered, data requirements, and associated waste characterization techniques.

The Program has adopted the waste description nomenclature outlined in the DOE Waste Treatability Group Guidance (DOE 1995a). The Program considers four broad matrix parameter categories of waste; homogenous solids (summary category \$3000), soil/gravel (summary category \$4000), debris wastes (S5000), and special waste (X7000). The matrix parameter categories are used to provide a description of the physical form of the waste and to determine characterization requirements for the Program. The BIR uses an earlier version of the waste description nomenclature known as waste matrix codes. DOE (1995a) provides a summary of the revisions made to this waste description 


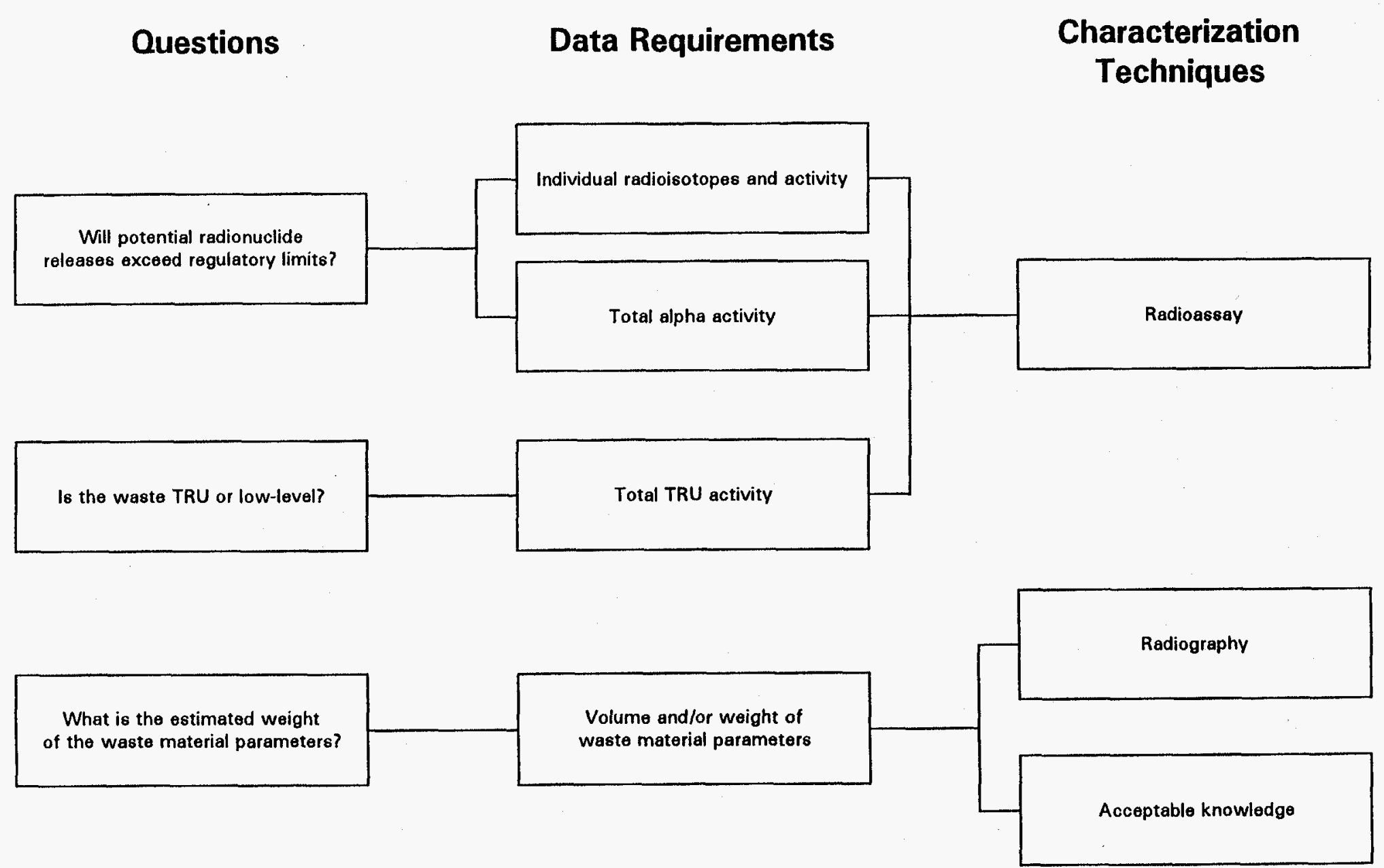

FIGURE 1-3a

Relationship between Compliance Programs and Data Requirements

for the Performance Assessment (40 CFR Part 191) 


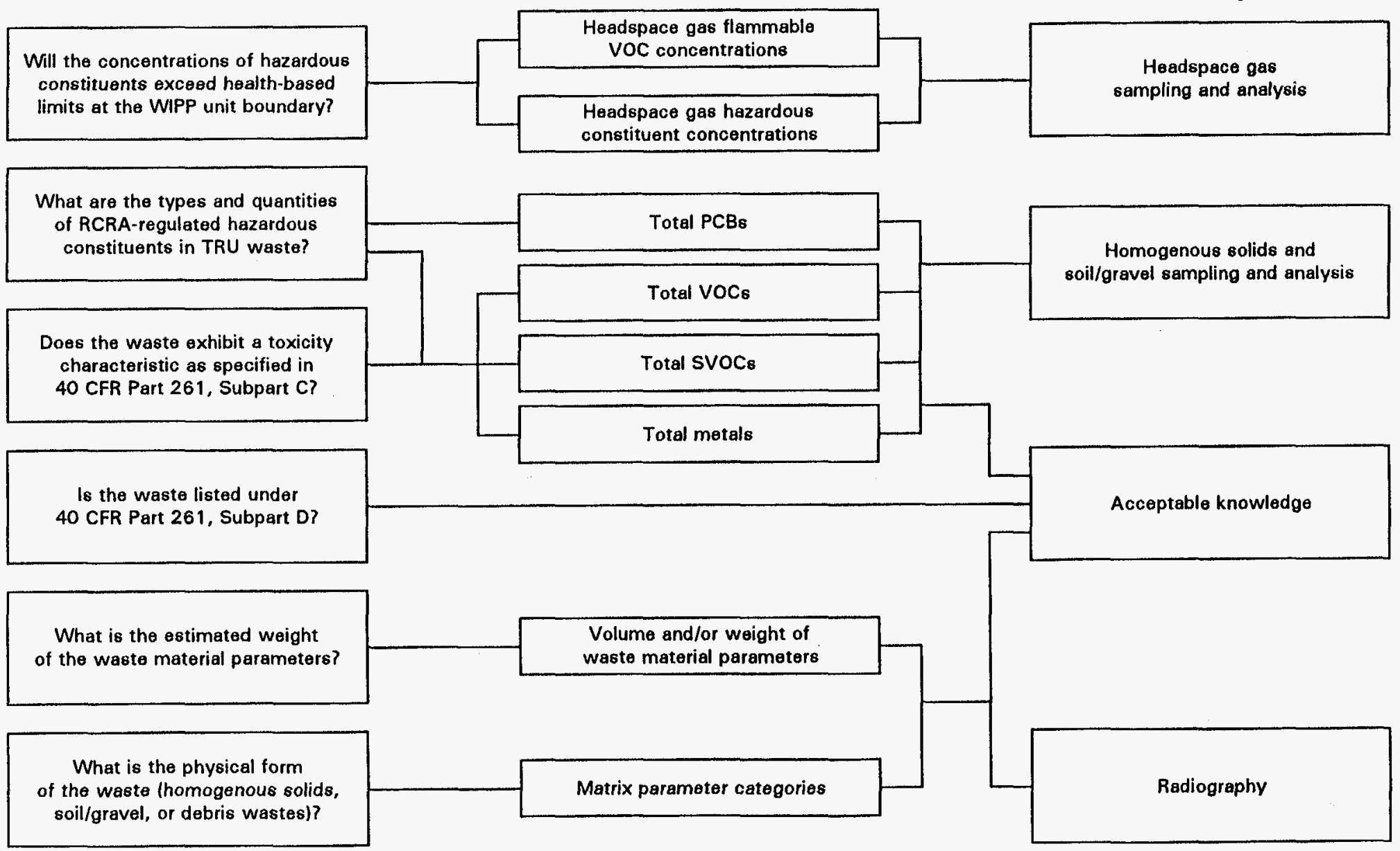

FIGURE 1-3b

Relationship between Compliance Programs and Data Requirements for the RCRA Land Disposal Restrictions (40 CFR Part 268) 


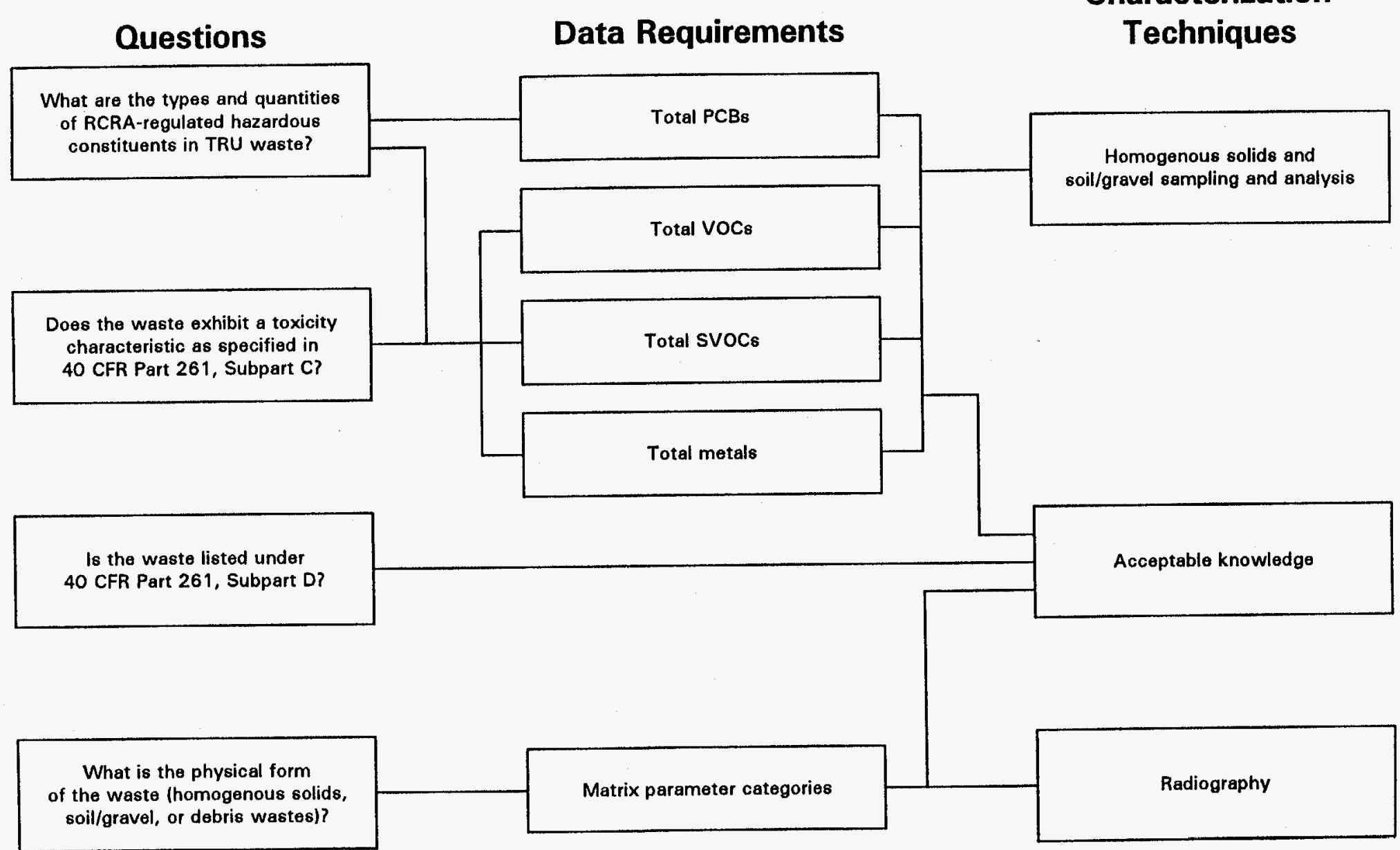

FIGURE 1-3c

Relationship between Compliance Programs and Data Requirements for the RCRA General Waste Analysis (40 CFR Part 270) 


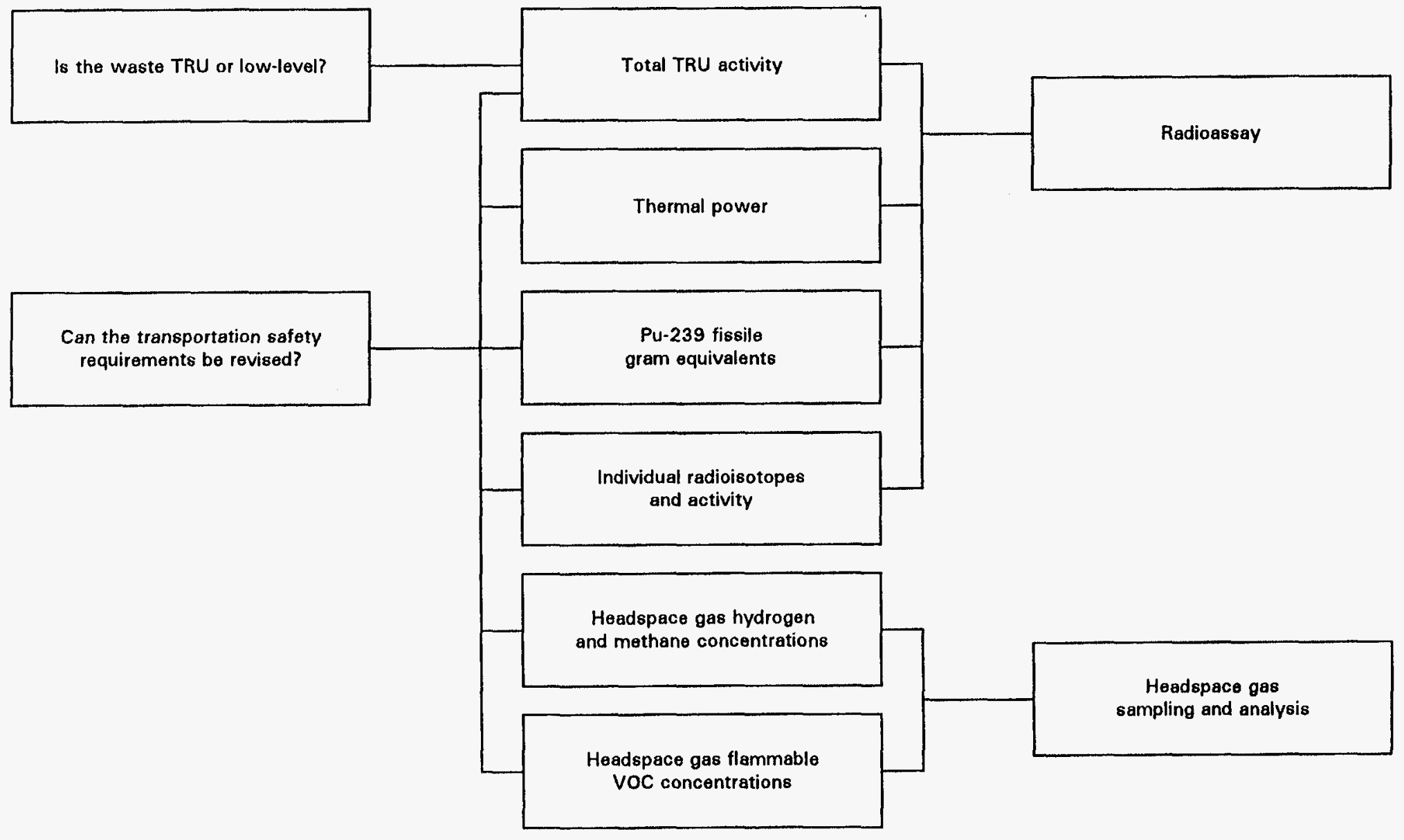

FIGURE 1-3d

Relationship between Compliance Programs and Data Requirements for the TRUPACT-Jl Certificate of Compliance (10 CFR Part 71) 
nomenclature and a correlation between the waste matrix codes used in the BIR and the matrix parameter categories used in this QAPP.

The frequency of testing, sampling, and analysis required for retrievably stored and newly generated TRU waste is specified in Section 5.0, Sampling Process Design. In the instances where only certain retrievably stored waste containers will undergo a specific characterization technique (e.g., total metal analysis), data representativeness will be ensured through the random sampling of waste streams. Data comparability between all participating sites will be achieved by compliance with the testing, sampling, and analytical requirements specified in Sections 7.0 through 15.0 of this QAPP. Acceptable methods are presented in detail in the Methods Manual and Test Methods for Evaluating Solid Waste, Physical/Chemical Methods Third Edition, Final Update I, and Final Update II (SW-846) (EPA 1995). Alternate methods that meet all of the requirements specified in Sections 7.0 through 15.0 may be submitted to CAO for approval.

The Program uses acceptable knowledge to accomplish several requirements for waste characterization. Acceptable knowledge refers to applying knowledge of the hazardous characteristic of the waste in light of the materials or processes used to generate the waste. This may include accompanying records; administrative, procurement, and quality controls associated with the processes generating the waste; past sampling and analytical data; material inputs to the waste generating process; and the time period during which the waste was generated. Information required for characterizing waste. using acceptable knowledge includes the physical form of the waste and documented changes to the process and/or material inputs. This use of acceptable knowledge is outlined in Waste Analysis at Facilities that Generate, Treat, Store, and Dispose of Hazardous Waste; A Guidance Manual (EPA 1994c). In this document, EPA has specifically referred to the characterization of radioactive mixed waste as a situation where the use of acceptable knowledge is appropriate.

Acceptable knowledge is used in Program activities in three ways; 11 to delineate waste streams, 2) to make all hazardous waste determinations for debris waste and special waste, and 3) to determine if homogenous solids and soil/gravel are RCRA-listed wastes. Used for these purposes, acceptable knowledge balances the requirements for providing definitive chemical and physical characterization of waste streams with those circumstances where sampling and analysis is not feasible or necessary. Acceptable knowledge, therefore, can be used for RCRA characterization of waste streams for which it is difficult to obtain a representative sample because of physical form and/or heterogenous composition (e.g., metal, glass, combustibles). In these instances, acceptable knowledge will be 
verified by radiography. Radiography will verify the physical form of debris wastes and special waste and by association, the RCRA constituents.

DOE will use its knowledge of the materials in debris wastes and special waste, and information regarding the processes that generated TRU waste (i.e., acceptable knowledge), in conjunction with radiography and headspace gas analysis to characterize these wastes. Acceptable knowledge will be applied to identify the composition of base materials (e.g., lead in shielding). Results of headspace gas analyses will be used as a fingerprint or screening technique le.g., to verify that flammable concentrations of VOCs are not present in the drum headspace).

Table 1-3 provides additional detail of the logic presented in Figures 1-3a through 1-3d, lists all parameters to be determined as part of the Program, and lists the analytical techniques and regulatory compliance programs associated with each parameter. Figure 1-4 presents an idealized sequence of events for the Program.

To comply with the TRUPACT-II Certificate of Compliance, waste must be classified as TRU. DOE has developed performance-based objectives for RA to distinguish TRU wastes from LLW and to confirm the radionuclide inventory used in the WIPP 40 CFR Part 191 Certification Application. The DOE policy is that TRU-contaminated wastes will be handled as TRU waste unless it can be demonstrated with a 95-percent probability that the TRU concentration is less than 100 nanocuries per gram (nCi/g) of waste. Information regarding the individual radionuclide activities will be used in conjunction with information regarding hydrogen concentrations in the headspace of containers to evaluate current thermal power limits for shipment of TRU waste. Data regarding potentially flammable VOCs also must be obtained to assess compliance with current TRUPACT-II payload restrictions.

The headspace gas of all waste containers will be sampled and analyzed for hydrogen, methane, and VOCs. A statistically selected portion of retrievably stored waste containers will undergo headspace sampling and analysis of inner layer of confinement. The selection of Program target analytes for headspace gas anaiysis is based on the requirements included in 55 FR 47700 .

The average quantity of volatile organic hazardous constituents in the headspace of TRU waste containers will be determined for assessment of the potential migration through the air pathway beyond the WIPP unit boundary above EPA-determined health-based limits. Headspace gas from under waste container lids will be collected for all TRU waste, and inner layers of confinement headspace will be collected for those wastes undergoing visual examination. Types and quantities of hazardous constituents that will comprise the source term for the air pathway will be developed based on the 
TABLE 1-3

\section{Radionuclide}

Pu-239 Fissile Gram Equivalents Total Alpha Activity

TRU Activity

Individual Radioisotopes

Thermal Power

\section{Physical Waste Form}

\section{Matrix Parameter Categories}

Summary

Category Names

$\begin{array}{ll}\text { S3000 } & \text { Homogenous Solids } \\ \text { S4000 } & \text { Soil/Gravel } \\ \text { S5000 } & \text { Debris Wastes } \\ \text { X7000 } & \text { Special Waste }\end{array}$

\section{Waste Material Parameters}

Iron-Based Metals/Alloys Aluminum-Based Metals/Alloys

Other Metals

Other Inorganic Materials

Cellulosics

Rubber

Plastics (waste material)

Organic Matrix

Inorganic Matrix

Soil

Steel (packaging material)

Plastics (packaging material)

\section{Radioassay}

Nondestructive Assay

(OAPP Section 9.0)

\section{Waste Inspection Procedures}

Radiography

Visual Examination

(QAPP Section 10.0)

\section{Regulatory Requirement}

Performance Assessment

(40 CFR Part 191)

Transportation of Radioactive Waste (10 CFR Part 71)

Regulatory Requirement

Performance Assessment (40 CFR Part 191)

Land Disposal Restrictions (40 CFR Part 268)

General Waste Analysis (40 CFR Part 270) 
TABLE 1-3

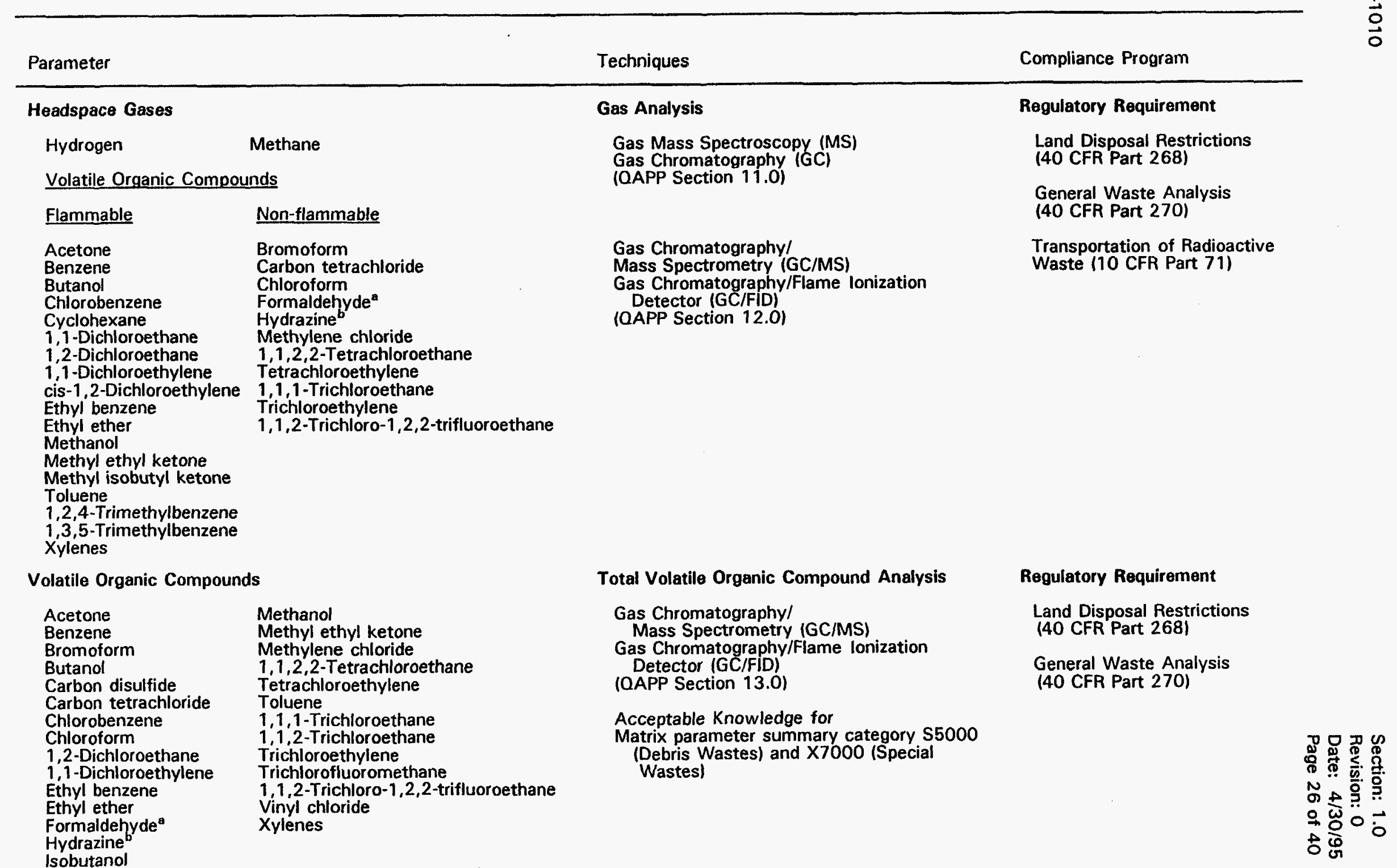




\section{TABLE 1-3}

Semi-Volatile Organic Compounds

$\begin{array}{ll}\text { Cresols } & \text { Hexachloroethane } \\ \text { 1,4-Dichlorobenzene } & \text { Nitrobenzene } \\ \text { ortho-Dichlorobenzene } & \text { Polychlorinated biphenyls (PCBs) } \\ \text { 2,4-Dinitrophenol } & \text { Pentachlorophenol } \\ \text { 2,4-Dinitrotoluene } & \text { Pyridine }\end{array}$

2,4-Dinitrotoluene Hexachlorobenzene

\section{Metals}

$\begin{array}{ll}\text { Antimony } & \text { Mercury } \\ \text { Arsenic } & \text { Nickel } \\ \text { Barium } & \text { Selenium } \\ \text { Beryllium } & \text { Silver } \\ \text { Cadmium } & \text { Thallium } \\ \text { Chromium } & \text { Vanadium } \\ \text { Lead } & \text { Zinc }\end{array}$

Total Semi-Volatile Organic Compound Analysis

Gas Chromatography/

Mass Spectrometry (GC/MS)

Gas Chromatography/Electron

Capture Detection (GC/ECD) for PCBs

Capture Detection
(OAPP Section 14.0)

Acceptable Knowledge for

Matrix parameter summary category $\$ 5000$

(Debris Wastes) and X7000 (Special

Wastes)

Total Metals Analysis

Atomic Mass Spectrometry

Atomic Emission Spectroscopy

Atomic Absorption Spectroscopy

(QAPP Section 15.0)

Acceptable Knowledge for

Matrix parameter summary category $\$ 5000$

(Debris Wastes) and X7000 (Special

Wastes)
Regulatory Requirement

Land Disposal Restrictions (40 CFR Part 268)

General Waste Analysis (40 CFR Part 270)

\section{Regulatory Requirement}

Land Disposal Restrictions (40 CFR Part 268)

General Waste Analysis (40 CFR Part 270)

${ }^{a}$ Required only for homogenous solids and soil/gravel from Los Alamos National Laboratory

${ }^{b}$ Required only for homogenous solids and soil/gravel from Oak Ridge National Laboratory and Savannah River Site 
Revision: 0

Date: $4 / 30 / 95$

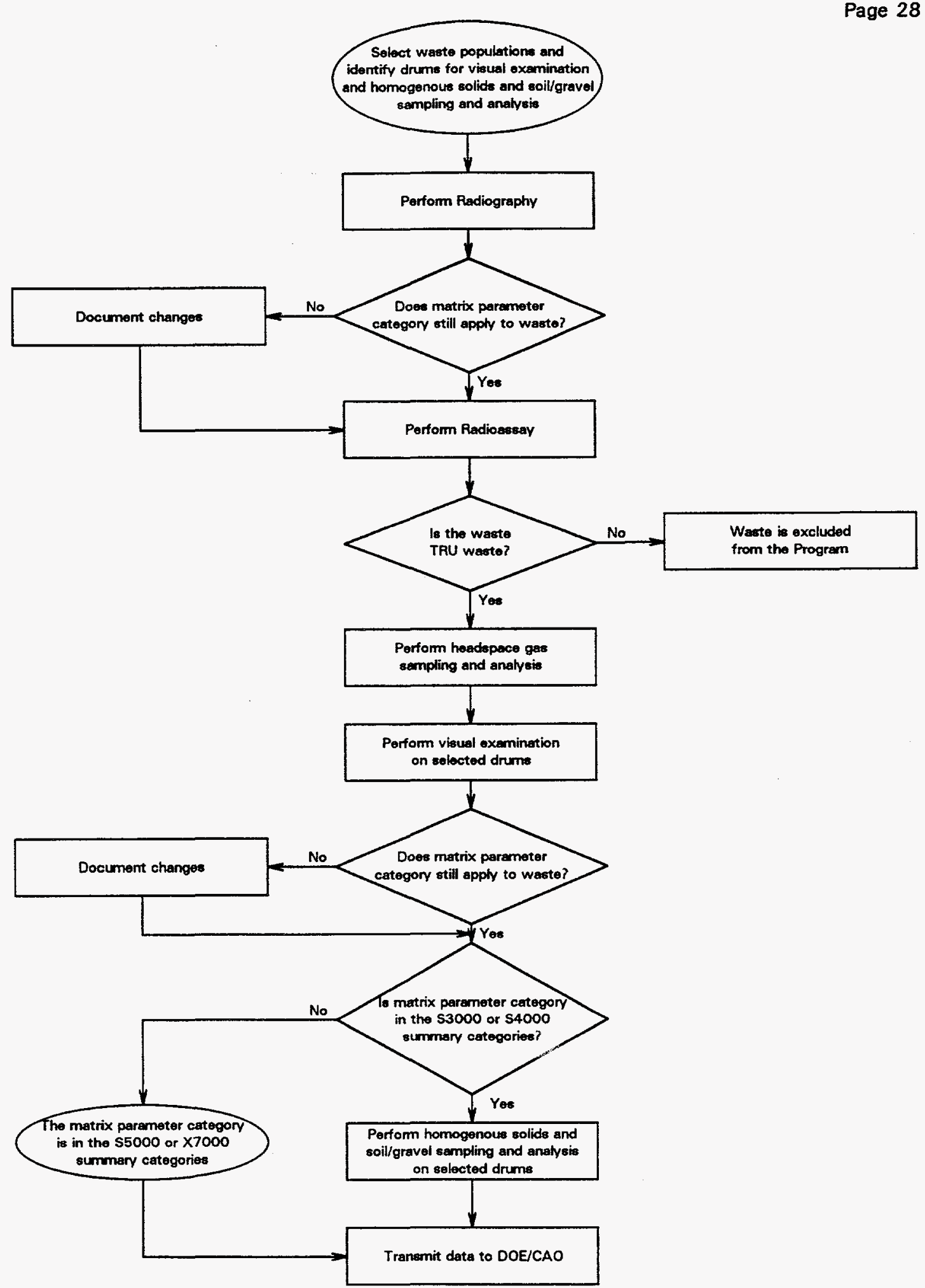

FIGURE $1-4$

Idealized Sequence of Events for Waste Characterization Program 
percentage of each waste form, the average void volume of waste containers, and the average concentration of volatile hazardous constituents present in the headspace.

A statistically selected portion of waste containers from waste streams of homogenous solids and soil/gravel will be sampled and analyzed for total VOCs, semi-volatile organic compounds (SVOCs), and metals. The selection of Program target analytes for characterization of homogenous solids and soil/gravel is based on the following selection strategy:

- Toxicity characteristic contaminants as listed in 40 CFR $\S 261.24$, Table 1 lexcept pesticides)

- F-listed solvents (F001, F002, F003, F004, FO05) found in 40 CFR § 261.31 and reported in the BIR

- Hazardous constituents included in 40 CFR Part 261, Appendix VIII, and reported in the BIR

- Non-flammable constituents included in 55 FR 47700

The mean concentration of hazardous constituents (40 CFR Part 261, Appendix VIII) present in the waste inventory must be estimated. Data from total analyses will be used to characterize the hazardous constituents in TRU waste as part of a WIPP disposal phase no-migration variance petition. The average concentrations of hazardous constituents in wastes classified as homogenous solids and soil/gravel will be determined using sampling and analysis. TRU waste classified as homogenous solids and soil/gravel must be statistically sampled and analyzed for the constituents listed in Table 1-3 as VOCs, SVOCs, and metals. The mean concentration of hazardous constituents 440 CFR Part 261 , Appendix VIII) must also be calculated by waste stream and then reported to CAO with an upper 90 percent confidence limit (UCL $\mathrm{CL}_{90}$ ) as described in Section 3.3 of this QAPP. TRU waste classified as debris wastes or special waste will be characterized based on acceptable knowledge.

DOE will obtain data to describe each TRU waste stream with regard to the EPA Hazardous Waste Numbers (40 CFR Part 261, Subparts $C$ and D). Acceptable knowledge is necessary to determine if a waste is listed as a hazardous waste under 40 CFR Part 261, Subpart D. For waste classified as debris wastes and special waste, hazardous waste characteristics (40 CFR Part 261, Subpart C) will be determined using acceptable knowledge. For waste classified as homogenous solids and soil/gravel, data from total analyses rather than the Toxicity Characteristic Leaching Procedure (TCLP) will be used. Because the WIPP facility is a bedded salt repository, total concentrations are more meaningful for a compliance demonstration. In addition, hazardous waste determinations based on data from total analyses will be conservative. For waste classified as homogenous solids and soil/gravel, the $U \mathrm{CL}_{90}$ values for the mean measured contaminant concentrations in a waste stream will be compared to the 
specified regulatory levels found in 40 CFR Part 261, Subpart C, expressed as total values, to determine if the waste stream exhibits a toxicity characteristic (TC) (Section 3.3).

If a participating site chooses to perform a TCLP extraction on its waste, a hazardous waste determination can be made using the analytical results from the extract. For example, a site may wish to perform a TCLP extraction followed by analysis for purposes of determining if a waste is hazardous to comply with on-site storage requirements. However, a total determination for Program-required VOCs, SVOCs, and metals must also be performed and the results reported as specified in this QAPP.

The data collected during the Program will be used in conjunction with data from other WIPP-related programs to obtain answers to regulatory compliance questions. Other WIPP-related programs, which are not addressed under this QAPP but are necessary for compliance demonstration, include site certification programs for compliance with the Waste Acceptance Criteria for the Waste Isolation Pilot Plant (WIPP-WAC) (DOE 1991) and the TRUPACT-II Authorized Methods for Payload Control (TRAMPAC) (Nuclear Packaging Inc. 1992, Appendix 1.3.7). These certification programs will provide additional required information, such as container weights, that will address many regulatory compliance requirements. Because these DOE programs already have established $Q A / O C$ criteria, the requirements and compliance protocols are not addressed in this QAPP.

\subsection{Data Quality Objectives for Measurement Data}

The design input of the Program is presented in this section as DOOs. DOOs are qualitative and quantitative statements that clarify Program technical and quality objectives, define the appropriate type of data, and specify tolerable levels of potential decision errors that will be used as the basis for establishing the quality and quantity of data needed to support decisions. The data obtained through the Program will be used in efforts to ensure that the WIPP project meets regulatory requirements with regard to: 1) the WIPP PA (40 CFR Parts 191 and 194); 2) the petition for a variance from the Land Disposal Restrictions (40 CFR § 268.6); 3) Part B of the RCRA permit application (40 CFR Part 270); and 4) transportation of radioactive waste (10 CFR Part 71). The DQOs established for the Program support these efforts and address the specific waste characterization parameters that will be evaluated. The waste characterization data obtained from the Program will be used by CAO in regulatory compliance programs. During the WIPP disposal phase, the data also will be evaluated by regulatory agencies to assess DOE's compliance with applicable regulations at the WIPP facility.

DQOs are derived from the DQO Process, a strategic planning tool based on the Scientific Method that is used to prepare for data collection activities. The DQO Process provides a systematic procedure for 
defining the criteria that a data collection design should satisfy. The DQO Process assures that the type, quantity, and quality of data used in decision making is appropriate.

The QAPP will be reviewed, and revised as necessary, on an annual basis. The DQOs and associated information needs will be revised as needed during the course of the Program in response to data users. This conforms to the assertion found in Guidance for the Data Quality Objectives Process (EPA QA/G-4)(EPA 1994b) that the DQO Process is iterative in nature and can be used repeatedly throughout the life cycle of a project. During the annual review of the QAPP, the DQO Process will be employed to ensure the QAPP remains current with respect to the needs of the end users of data generated from Program activities.

Section 1.4, Program Description, provides information concerning the scope of the Program, including the conclusions and decisions for which the data generated will be used. The DOOs for the Program activities, based on the regulatory compliance programs discussed in Section 1.3, are as follows:

\section{Performance Assessment (40 CFR Part 191)}

\section{Radioassay}

- To classify waste by activity as low level versus TRU by demonstrating with a 95-percent probability that the total TRU activity is less than $100 \mathrm{nCi} / \mathrm{g}$ of waste. The quality assurance objective (OAO) for the minimum detectable concentration for TRU measurements was selected to help ensure that measurements in the 60 to $80 \mathrm{nCi} / \mathrm{g}$ region can be made with sufficient precision to avoid designating excessive quantities of alpha contaminated TRU waste as LLW.

- To confirm the radionuclide inventory on which the 40 CFR Part 191 Certification Application is based and assess compliance with the individual protection requirements, ground water protection standards, and containment requirements (40 CFR Part 191).

Radiography

- To classify/verify the TRU waste inventory by matrix parameter category and waste material parameter, as described in the BIR, on which the 40 CFR Part 191 Certification Application is based.

\section{RCRA Land Disposal Restrictions (40 CFR Part 268)}

Radiography

- To verify the TRU waste streams by matrix parameter category, as described in the BIR, for purposes of physical waste form identification and determination of sampling and analytical requirements (Section 5.0 ). 
Gas Sampling and Analysis

- To quantify the concentrations of hydrogen, methane, and flammable VOCs by waste container and determine the potential flammability of TRU waste headspace gases.

- To quantify the concentrations of volatile organic hazardous constituents in the total waste inventory to support a demonstration that volatile organic hazardous constituents will not migrate through the air beyond the WIPP unit boundary in concentrations greater than EPAdetermined health-based limits during the WIPP disposal phase.

Homogenous Solids and Soil/Gravel Sampling and Analysis

- To compare the $\mathrm{UCL}_{90}$ values for the mean measured contaminant concentrations in a waste stream to the specified regulatory levels (40 CFR Part 261, Subpart C). That is, to determine if a waste stream exhibits a TC.

- To report the average concentrations, standard deviation, $U \mathrm{UL}_{90}$, and number of samples collected for hazardous constituents in a waste stream, as specified in 40 CFR Part 261, Appendix VIII.

\section{RCRA General Waste Analysis (40 CFR Part 270)}

\section{Radiography}

- To verify the TRU waste streams by matrix parameter category, as described in the BIR, for purposes of physical waste form identification and determination of sampling and analytical requirements (Section 5.0 ).

Gas Sampling and Analysis

- To quantify the concentrations of hydrogen, methane, and flammable VOCs in waste containers and determine the potential flammability of TRU waste headspace gases.

Homogenous Solids and Soil/Gravel Sampling and Analysis

- To compare the $\mathrm{UCL}_{90}$ values for the mean measured contaminant concentrations in a waste stream to the specified regulatory levels (40 CFR Part 261, Subpart C). That is, to determine if a waste stream exhibits a TC.

\section{Transportation of Radioactive Waste (10 CFR Part 70)}

Radioassay

- To classify waste by activity as low level versus TRU by demonstrating with a 95-percent probability that the TRU activity is less than $100 \mathrm{nCi} / \mathrm{g}$ of waste.

- To obtain the total activity in TRU waste to support revision of the thermal power restrictions for shipment of waste in the TRUPACT-II. 
Gas Sampling and Analysis

- To quantify the concentrations of hydrogen, methane, and flammable VOCs in waste containers and determine the potential flammability of TRU waste headspace gases during transport in the TRUPACT- 11 .

- To quantify hydrogen and methane headspace concentrations in waste containers to support revision of the thermal power restrictions for shipment of TRU waste in the TRUPACT-II.

Table 1-3 lists the parameters to be determined by the various characterization activities, the techniques to be used, and the regulatory compliance programs to be undertaken by data users. All the compounds to be determined by sampling and analysis of wastes are also included in Table 1-3.

The action levels to support compliance decisions, including the detection limits and reporting units (if applicable) for each testing, sampling, and analytical technique are presented in Sections 7.0 through 15.0 of this QAPP. These sections also state the requirements for precision, accuracy, bias, method detection limit, program required detection limit, minimum detectable concentration, program required quantitation limit, total uncertainty, completeness, comparability, and representativeness (if applicable) in the form of Quality Assurance Objectives (QAOs). Descriptions and calculation methods for these QAOs are presented in Section 3.2, Validation Methods, or in the specific section describing the technique for which they apply.

\subsection{Special Training Requirements and Certifications}

Before performing activities that affect Program quality, all personnel are required to receive indoctrination into the scope, purpose, and objectives of the Program and the specific QAOs of the assigned task. Personnel assigned to perform activities for the Program shall have the education, experience, and training applicable to the functions associated with the work. Evidence of personnel proficiency and demonstration of competence in the task(s) assigned must be demonstrated and documented. All personnel designated to work on specific aspects of the Program shall maintain qualification (i.e., training and certification) throughout the duration of the work as specified in this QAPP and applicable QAPjPs. Job performance shall be evaluated and documented at periodic intervals, as specified in the QAPjPs.

Personnel involved in Program activities shall receive continuing training to ensure that job proficiency is maintained. Training includes both education in principles and enhancement of skills. Each participating site shall include in its QAPjP a description of the procedures for implementing personnel qualification and training in accordance with the QAPD and 10 CFR $\S 830.120$. All training records 
that specify the scope of the training, the date of completion, and documentation of job proficiency shall be maintained in the site project file.

Analytical laboratory line management must ensure that analytical personnel are qualified to perform the analytical method(s) for which they are responsible. The minimum qualifications for certain specified positions for the Program are summarized in Table 1-4. QAPjPs, or their implementing SOPs, shall specify the site-specific titles and minimum training and qualification requirements for personnel performing Program activities. QAPjPs shall also contain the requirements for maintaining records of the qualification, training, and demonstrations of proficiency by these personnel.

An evaluation of personnel qualifications shall include comparing and evaluating the requirements specified in the job/position description and the skills, training, and experience included in the current resume of the person. This evaluation also must be performed for personnel who change positions because of a transfer or promotion as well as personnel assigned to short-term or temporary work assignments that may affect the quality of the Program. QAPjPs shall identify the responsible person(s) for ensuring that all personnel maintain proficiency in the work performed and identify any additional training that may be required.

\subsection{Documentation and Records}

Records inventory, retention, and disposition shall meet the requirements of the QAPD, DOE Order 1324.5B, Records Management Program, and ASME NQA-1, Supplement 17S-1, "Supplemental Requirements for Quality Assurance Records." A data/records management system shall be defined, implemented, and enforced by each participating site, in accordance with written procedures, to maintain evidence of the conduct and quality of the work. The data/records management system shall provide adequate control and retention for all the Program-related information. Record control shall include receipt from external sources, transmittal, transfer to storage, and storage.

\subsubsection{Site Proiect Files}

Data and related information, as described in Section 3.4, shall be sent to CAO, where it shall be maintained in a central file by CAO or its M\&O contractor. All summarized data reported to the CAO Office of Regulatory Compliance manager must be traceable to the original, raw data records. Records must be legible, clearly identified, retrievable, and secured in a controlled-access facility. Electronically transmitted data must be compatible with and formatted in accordance with the WIPP computer system requirements. 
TABLE 1-4

\section{Minimum Training and Qualifications Requirements}

Personnel

Radiography Operators ${ }^{\circ}$

Gas Chromatography Technical Supervisors ${ }^{b}$

Gas Chromatography Operators ${ }^{\circ}$

Gas Chromatography/Mass Spectrometry Operators ${ }^{c}$ Mass Spectrometry Operators ${ }^{c}$

Gas Chromatography/Mass Spectrometry

Technical Supervisors ${ }^{b}$

Mass Spectrometry Technical Supervisors ${ }^{b}$

Atomic Absorption Spectroscopy Technical Supervisors ${ }^{b}$

Atomic Absorption Spectroscopy Operators ${ }^{\circ}$

Atomic Mass Spectrometry Operators ${ }^{\mathrm{C}}$

Atomic Emission Spectroscopy Operators ${ }^{\circ}$

Atomic Mass Spectrometry Technical Supervisors ${ }^{b}$

Atomic Emission Spectroscopy Technical Supervisors ${ }^{b}$
Requirements ${ }^{a}$

Site-specific training based on matrix parameter categories and waste material parameters; requalification every 2 years

B.S. or equivalent experience and 6 months previous applicable experience

B.S. or equivalent experience and 1 year independent spectral interpretation or demonstrated expertise

B.S. or equivalent experience and 1 year applicable experience

B.S. and specialized training in Atomic Mass Spectrometry and 2 years applicable experience

B.S. and specialized training in Atomic Emission Spectroscopy and 2 years applicable experience.

'Based on requirements contained in USEPA Contract Laboratory Program Statement of Work for Organics Analysis (Document Number OLM 01.0) and Statement of Work for Inorganics Analysis (Document Number ILM 03.0).

${ }^{b}$ Technical Supervisors are those persons responsible for the overall technical operation and development of a specific laboratory technique. OAPjPs shall include the site-specific title for this position.

'Operators are those persons responsible for the actual operation of analytical equipment. QAPjPs shall include the site-specific title for this position. 
Each participating site shall designate a person responsible for records administration. This individual shall be the point of contact regarding records and shall notify field and laboratory managers and $Q A$ personnel of the resulting status changes in Program documents, such as reporting formats or procedures.

\subsubsection{Flow of Records}

Figure 1-5 illustrates the flow of data, beginning with data generation and ending with final transmittal of data to CAO. All waste characterization documentation (e.g., chain-of-custody (COC) forms) generated or updated must be forwarded to the site project $\mathrm{QA}$ officer for validation and verification. The site project $Q A$ officer must then prepare a Site Project $O A$ Officer Summary which must be forwarded with all the waste characterization documentation and a signature release to the site project manager (or designee) (Section 3.1.2). The site project manager (or designee) must then prepare a Data Validation Summary and transmit data via hard copy, with a site project manager and site project $Q A$ officer signature release to CAO (Section 3.4.2). Finally, CAO must notify the site project manager in writing that the data package is acceptable.

\subsection{Procurement}

Participating sites must implement procedures to ensure that procured items and services meet established requirements and perform as specified. These procedures must address control of purchased items, services, subcontractors, and suppliers. Procurement controls specified by this QAPP are applicable to equipment and services that directly affect the quality of testing, sampling, and analytical data.

\subsubsection{Procurement Document Control}

The design bases and other requirements necessary to assure adequate quality shall be included or referenced in procurement documents for any equipment and services directly affecting the quality of Program data. Participating sites must include or reference in procurement documents the items and support services for the applicable requirements to maintain the quality of the Program. All procurement documents shall be reviewed for completeness and accuracy before release to the suppliers.

To the extent necessary, procurement documents shall specify the quality elements for which the supplier is responsible, and require suppliers of equipment or analytical services to have a QA program that meets or exceeds the applicable criteria of this QAPP. If suppliers do not have a QA program that addresses the requirements included herein, they must agree to comply with the applicable sections(s) of site QAPjPs. The site project manager is responsible for verifying supplier compliance with the applicable $\mathrm{OA} / \mathrm{OC}$ requirements. 
Section: 1.0

Revision: 0

Date: $4 / 30 / 95$

Page 37 of 40

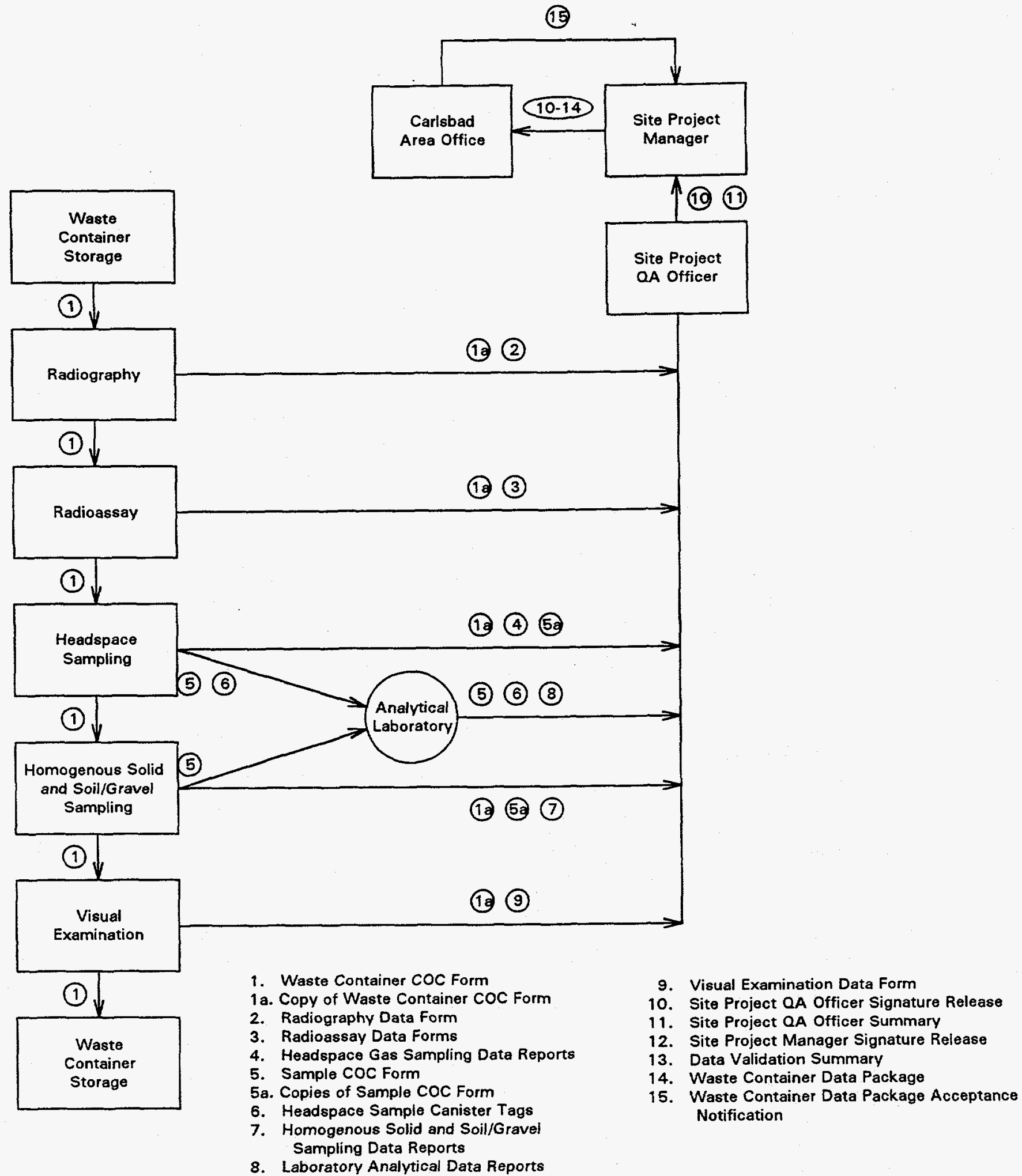

FIGURE 1-5

Flow of Records for the Program 


\subsubsection{Control of Purchased Items and Services}

The procurement of items and services that directly affect the quality of testing, sampling, and analytical data shall be controlled by DOE or its M\&O contractors to assure conformance with specified requirements. Such control must include, as appropriate, the evaluation of selected service or equipment, review and evaluation of the QA/OC provided by the supplier, and inspection, audit, and examination of items or services upon delivery or completion.

The purchase or use of all equipment and replacement parts, or design modifications to existing equipment used for the Program, shall be documented and controlled. The methods for accepting material or equipment from a supplier may include source verification, receiving inspection, supplier certificate of conformance, post-installation test, or a combination thereof. Documents traceable to these items must be maintained in the site project files. Services such as analytical services, engineering and consulting, installation, repair, overhaul, or maintenance work shall include oversight by technical verification of the data produced, surveillance, inspection, audit of the activity, or review of certifications for conformance to procurement documents.

\subsubsection{Control of Subcontractors}

Performance requirements and compliance with this QAPP must be communicated to subcontractors that directly affect the quality of waste characterization data and shall be part of subcontractor agreements associated with the Program. DOE M\&O contractors shall perform and document the results of $O C$ inspections of their subcontractor activities to verify compliance with the performance requirements included in this QAPP. Each subcontractor shall complete the necessary training required for implementing the QAPP requirements. Prequalification audits may be performed by DOE OA personnel to determine subcontractor acceptability. Subcontractors shall complete and submit copies of all project-related records to the site project manager.

To verify subcontractor conformance to the Program OA/OC requirements, the DOE M\&O contractor shall, as necessary, review documentation prepared by subcontractors, and perform assessments of subcontractor activities. Subcontractors shall provide access to their work areas and records for inspection and auditing. Inspections or audits shall be performed, and the results and tracking of any corrective actions to final resolution shall be documented as discussed in Section 2.0 of this QAPP.

Subcontractors providing analytical services in support of the Program must participate in the PDP as described in Section 2.3 of this QAPP. Each subcontractor for analytical services shall demonstrate their ability to meet the QA objectives for the Program by successfully completing the requirements of the PDP before waste testing, sampling, or analysis. The NTP team leader personnel located at 
CAO, shall review and approve the results of the PDP before the initiation of work by the subcontractor for analytical services. The NTP team leader, as the administrator of the PDP, shall notify each analytical laboratory, in writing, concerning the adequacy of its analytical performance and approval to participate in the Program.

\subsection{Work Processes}

All TRU waste characterization in support of the Program shall be performed using approved instructions or procedures. Personnel conducting work shall be trained to implement these procedures in accordance with the requirements specified in Section 1.6.

Site project managers shall be responsible for Program planning, including waste selection (Section 5.0), tracking (Section 6.0), and data validation (Section 3.0). The establishment of OAOs for measurement data provides definition, control, and verification of waste characterization activities. The OAOs for each waste characterization technique used in support of the Program are provided in Sections 7.0 through 15.0 of this QAPP. The site project QA officer must track compliance with the QAOs and evaluate trends in compliance with the Program objectives, including sample holding times and completeness of data.

\subsubsection{Control of Processes}

Processes affecting the quality of waste characterization data and information shall be controlled. Waste container and sample custody shall be maintained as specified in Section 6.0 of this QAPP. All testing, sampling, and analytical processes shall be conducted in accordance with controlled procedures. Sections 7.0 through 15.0 include the required sample preparation, equipment decontamination, and performance requirements for each specified technique. Other processes affecting quality of the Program that shall be controlled through the implementation of QAPjPs and SOPs include QC; equipment testing, inspection and maintenance; equipment calibration; and data management.

\subsubsection{Identification and Control of Items}

Participating sites shall establish methods for identifying and controlling materials or equipment in accordance with written detailed procedures. Identification of accepted items shall be maintained on the items or documents traceable to the items (i.e., tags, labels), or in a manner that assures that identification is established and maintained. Items having limited shelf life or operating life shall be identified and controlled to preclude use of items whose shelf life or operating life has expired. The methods for identification and traceability of items may include item identification from initial receipt up to and including installation and use, physical identification, clear and legible marking, or a 
combination thereof. The identification and control of samples and waste containers shall meet the requirements in Section 6.0 of this QAPP.

\subsubsection{Computer Hardware and Software}

Computer software and hardware/software configurations used in direct data collection, analysis of samples, data reduction, data processing, and data evaluation shall be tested prior to use in accordance with ASME NOA-1, Subpart 2.7, "Quality Assurance Requirements of Computer Software for Nuclear Facility Applications," (ASME 1994), and the QAPD. The resuits of such testing shall be documented and maintained traceable to the specific equipment configuration in the site project files. Computer hardware/software configurations that are regularly calibrated for a specific purpose (e.g., automated analytical equipment) do not require further testing unless the scope of the usage changes or there are modifications to the hardware/software configuration.

Computer software and hardware/software configurations specifically developed as part of the Program shall be verified, validated, tested, and documented with user's manuals prior to use in accordance with the requirements of ASME NQA-1, Subpart 2.7 and the QAPD. Commercially available software does not require testing prior to use. Site QAPjPs will define the specific procedures to be implemented for computer software development. 


\subsection{ASSESSMENT AND OVERSIGHT}

Specific assessment actions will be taken during the Program to ensure all parties are adhering to the requirements of this QAPP. These actions include periodic audits, management and independent assessments, and participation in the PDP (Section 2.3). Corrective action shall be taken when conditions adverse to quality are identified. The results of these actions will be summarized in semiannual reports, nonconformance reports, and audit reports. Through this system of assessment and response, overall quality improvement of the Program will be realized.

\subsection{Assessment and Response Actions}

Audits shall include all management and technical aspects of the Program outlined in this QAPP and in site QAPjPs. In addition to audits, management and independent assessments shall be performed regularly. The goal of these assessments is to improve overall Program quality by focusing on management systems and work processes.

Corrective action shall be taken if any condition, or significant condition, adverse to quality is detected during an audit or assessment. The cause of any adverse condition, identified by any means, that affects compliance with the QA/OC requirements specified in this QAPP shall be promptly determined and action taken to preclude its recurrence. The identification, cause, and corrective action(s) for conditions not complying with the quality requirements for the Program must be documented and reported to appropriate levels of management as indicated throughout this section.

\subsubsection{Audits}

Formal audits of Program activities at each site shall be performed before shipment of any TRU waste from that site and at least annually thereafter. The CAO QA manager shall oversee performance of planned and documented system audits of Program activities described in QAPjPs. Audit records shall include audit plans, audit reports, written replies, and the record of completion of corrective actions, and shall be maintained in CAO project files.

The CAO QA manager shall develop and document an audit plan that includes written procedures and checklists, and identifies the scope, requirements, personnel, activities to be audited, organizations to be notified, applicable documents, and schedule. Formal audits must include evaluations of the sitespecific field and laboratory activities and analytical laboratory protocols specified in the QAPjPs. These evaluations should include observations of activities and interviews of selected personnel. Audits shall be performed in accordance with written procedures and checklists. 
The NTP Waste Acceptance manager has overall responsibility for scheduling site audits, notifying sites of audit results, tracking and ensuring appropriate corrective action in response to audit findings, and coordinating the performance of the audits with the CAO OA manager. The CAO QA manager will select the audit team leader and audit team members. When corrective actions are required, the site management shall provide a schedule that details all corrective action activities to the audit team leader. The audit team leader is responsible for the resolution of findings. The NTPO Performance Assessment and Certification manager will ensure that corrective action activities are being performed according to the schedule provided by site management.

The CAO QA manager is responsible for selecting an audit team that includes persons with the necessary analytical expertise and knowledge of DOE operations to address all the requirements established by this QAPP. All auditors shall be independent of any direct responsibility for the activities they will audit. The lead auditor shall be trained, qualified, and certified in accordance with requirements specified in ASME NOA-1, Supplement 2S-3 (ASME 1994), and the OAPD. Auditors shall have sufficient authority, access to site programs and managers, and organizational freedom to identify and document problems that affect quality.

Results of the audit shall be documented by audit team members and reported by the audit team leader to the CAO QA manager. The audit report shall be signed by the audit team leader and shall include the following information:

- An executive summary

- A description of the audit scope

- Identification of the auditors

- Identification of persons contacted during audit activities

- A summary of the documents reviewed, persons interviewed, and the specific results of the reviews and interviews

- A summary of audit results, including a statement on the effectiveness of the OA program elements that were audited

- A description of each reported condition adverse to quality in sufficient detail to determine the cause of the adverse finding and to enable corrective action to be taken by the audited organization

Copies of all audit reports shall be sent to the appropriate DOE field office and CAO office managers. It is the responsibility of the site management to ensure that all conditions adverse to quality are resolved and the appropriate corrective actions are implemented in a timely manner. When corrective 
actions are required, the site management shall also provide a schedule that details all follow-up activities and the final resolution to the appropriate DOE field office. OAPjPs shall include a description of the organization(s) and person(s) responsible at each site for tracking corrective actions.

Before the initial waste shipment from each participating site, a final report of the status or resolution of all conditions adverse to quality resulting from the formal audit must be provided by the audit team leader to the CAO QA manager and the NTP Waste Acceptance manager.

\subsubsection{Nonconformances and Operational Variances}

The status of work and the Program activities at participating sites shall be monitored and controlled by the site project manager and site project $Q A$ officer. This monitoring and control shall include (1) nonconformance identification, documentation, and reporting and (2) operational variance identification, documentation, and reporting.

2.1.2.1 Nonconformances. Nonconformances are uncontrolled and unapproved deviations from an approved plan, procedure, or expected result. Nonconforming items and activities are those that do not meet the Program requirements, procurement document criteria, or approved work procedures. Nonconforming items shall be identified by marking, tagging, or segregation, and the affected organization(s) notified. Participating sites shall disposition nonconforming items as appropriate in accordance with the QAPD. Disposition of nonconforming items shall be identified and documented. The QAPjPs shall identify the person(s) responsible for evaluating and dispositioning nonconforming items and shall include referenced procedures for handling them.

Management at all levels shall foster a "no-fault" attitude to encourage the identification of nonconforming items and processes. Nonconformances may be detected and identified by anyone performing Program activities, including

- Project staff - during field operations, supervision of subcontractors, data validation and verification, and self-assessment

- Laboratory staff - during the preparation for and performance of laboratory testing; calibration of equipment; $O C$ activities; laboratory data review, validation, and verification; and self-assessment

- QA personnel - during oversight activities or audits

A nonconformance report shall be prepared for each nonconformance identified. Each nonconformance report shall be initiated by the individual(s) identifying the nonconformance. The nonconformance report shall then be processed by knowledgeable and appropriate personnel. For this purpose, a 
nonconformance report including, or referencing as appropriate, results of laboratory analysis, QC tests, audit reports, internal memoranda, or letters shall be prepared. The nonconformance report must provide the following information:

- Identification of the individual(s) identifying or originating the nonconformance

- Description of the nonconformance

- Method(s) or suggestions for correcting the nonconformance (corrective action) or description of the variance granted

- Schedule for completing the corrective action

- An indication of the potential ramifications and overall useability the data, if applicable

- Any approval signatures specified in the QAPjPs

The site project $Q A$ officer shall oversee the nonconformance report process and be responsible for developing a plan to identify and track all nonconformances and report this information to the DOE field office. Documentation of nonconformances shall be made available to the site project manager, who in turn is responsible for notifying project personnel of the nonconformance. Completion of the corrective action for nonconformances must be verified by the site project $Q A$ officer.

2.1.2.2 Operational Variances. Variances are approved and controlled changes to Program-related plans or procedures. The need for a variance is caused by the identification of improvement opportunities or unusual or nonroutine occurrences that affect operations but not the ability to achieve the performance standards or quality requirements specified in this QAPP or site QAPjPs. Each person performing Program activities is responsible for the quality of their work and adherence to the applicable requirements contained in this QAPP and site QAPjPs. When a need to deviate from established procedures is identified, it is the responsibility of the person performing the work to initiate a variance.

When a variance is required, the person identifying the need for the variation shall complete a Record of Variance and have a direct supervisor approve it. A Record of Variance must be completed and approved before initiation of the activity to document the variation from normal, approved procedures. The site project $Q A$ officer shall assess the significance of the variance and determine if changes to the plans or procedures and further notifications are required. 
A Record of Variance must contain at least the following information:

- Title or heading, "Record of Variance"

- Waste container or sample identification number

- Reason for the deviation from the requirements contained in the QAPjP or SOP

- A description of the variation from the accepted sampling, testing, or analytical procedure

- A description of special equipment or personnel required

- Initiator's signature and date

- Supervisor's signature and date

- Site project manager's signature and date

- Site project OA officer's signature and date

\subsubsection{Quality Improvement}

The NTPO team leader shall be responsible for implementing, assessing, and improving this QAPP. The objective is to ensure quality through appropriate training, planning, controlling of work operations, verifying, and reviewing results, and to achieve a rising standard of quality through continuous improvement. The focus of quality improvement should be to reduce the variability of each process that influences the quality of the data. Each participating site shall include in its QAPJP a description of the processes for detecting and preventing quality problems and ensuring quality improvement. This description shall include the specific quality-related information that will be analyzed to identify trends that adversely impact quality.

\subsubsection{Management Assessment}

Management at all levels of an organization participating in a CAO program shall periodically assess the performance of their organization, in conformance with the QAPD. Management assessment results shall be documented and used as input to the organization's continuous improvement process.

\subsubsection{Independent Assessment}

In addition to the audits performed by $\mathrm{CAO}$, site personnel shall perform at least one independent assessment annually in accordance with OAPD criteria. These assessments shall focus on the performance of work with regard to requirements contained in this QAPP, site QAPJPs, SOPS, and other site-specific documentation, as applicable. QAPjPs shall include a description of the personnel, roles, and responsibilities for these assessments. Personnel performing these assessments shall be technically knowledgeable of the processes they are assessing, but must not have any direct responsibilities for those processes. The results of these independent assessments shall be reported to the site project manager. Problems noted during the assessments shall be tracked and resolved by the line management having direct responsibility for that area. 
Analytical laboratories and testing facilities will be assessed by representatives of site project manager's office and site project $Q A$ personnel. At a minimum, the site project manager and site project $Q A$ officer shall ensure that a repeat of raw data review, validation, and verification is performed periodically as described in Section 3.1.2 of this QAPP.

\subsection{Reports to Management}

Conditions adverse to quality shall be identified, documented, and reported to management, and all follow-up action shall be tracked to final resolution in a timely manner. The NTP Waste Acceptance manager shall report all audit findings to the DOE field office. The NTP Waste Characterization manager at CAO shall provide the results of the PDP and an assessment of the analytical laboratory's adequacy in meeting Program requirements to the responsible DOE field office. The site project $Q A$ officer shall also report all nonconformances as described in Section 2.1.2.1 to the applicable DOE field office.

QAPjPs shall identify the responsible organization(s) and position(s) and describe procedure(s) for providing $O A$ reports to management to assess the adequacy of the Program and ensure its effective implementation. Pertinent $Q A / O C$ information shall be reported to the site project manager and the site project $Q A$ officer to allow assessment of the overall effectiveness of the Program.

The site project $Q A$ officer shall, at a minimum, summarize all relevant information on the $Q A / Q C$ activities during the period in a semiannual report. This semiannual report shall be distributed to the DOE field office and the site project manager at the same time. The site project manager shall review the report, comment if appropriate, and then forward a copy of the report with comments to the DOE field office. This semiannual report shall include the following applicable information:

- Changes in the QAPjP

- Significant $\mathrm{QA} / \mathrm{OC}$ problems, recommended solutions, and corrective actions taken

- Assessment of $\mathrm{QC}$ data gathered over the period, the frequency of analyses repeated because of unacceptable $\mathrm{OA}$ performance, the reason for unacceptable performance (if known), and corrective actions taken

- Discussion of whether the QA objectives have been met, and any resulting impact on decision making

- Limitations on the use of the measurement data

- Status of PDP sample results

- Results of audits, assessments, and surveillances 


\subsection{Performance Demonstration Program}

Each testing and analytical facility performing Program activities shall participate in the PDP and demonstrate conformance to the QA objectives for the Program. The NTP Waste Characterization manager at CAO shall administer the PDP. Each facility, through participation in the PDP, will demonstrate and document its performance characteristics. Overall system performance shall be evaluated by each testing and analytical facility's participation in the PDP. The PDP is described in the following series of documents or plans:

- Performance Demonstration Program Plan for Nondestructive Assay for the TRU Waste Characterization Program (NDA PDP Plan)(DOE 1994a)

- Performance Demonstration Program Plan for the Analysis of Simulated Headspace Gases for the TRU Waste Characterization Program (Gas PDP Plan)(DOE 1995c)

- Performance Demonstration Program Plan for the Analysis of Solidified Wastes for the TRU Waste Characterization Program (Solid PDP Plan)(DOE 1995d)

Single blind audit samples shall be prepared and distributed to each of the RA facilities and analytical laboratories participating in the Program by an independent organization. RA facilities and analytical laboratories shall be evaluated semiannually. The NTP Waste Characterization manager shall provide written notification of the adequacy of a RA facility and analytical laboratory and approval of its participation in the Program to the appropriate DOE field office management. 


\subsection{DATA VALIDATION, USABILITY, AND REPORTING}

Certain steps are necessary to ensure Program data meet the level of quality needed for the compliance activities outlined in Section 1.3. These steps will be taken at three levels; 1 ) the data generation level; 2) the project level; and 3) the CAO level. This system of data review, validation, and verification will ensure that proper data generation and management procedures are followed by all parties participating in the Program. QAPjPs and SOPs shall implement the requirements contained in this section.

As part of the Program, waste containers will be tested in testing batches. A testing batch is a suite of waste containers undergoing radioassay (Section 9.0) or radiography (Section 10.0) using the same testing equipment. A testing batch can be up to 20 waste containers without regard to waste matrix. Samples will be collected in sampling batches. A sampling batch is a suite of samples of similar matrix (i.e., gas or solid) collected consecutively using the same sampling equipment within a specific time period. A sampling batch can be up to 20 samples (excluding field $Q C$ samples), all of which must be collected within 14 days of the first sample in the batch. Samples will be analyzed in analytical batches. An analytical batch is a suite of samples of similar matrix (i.e., gas or solid) processed as a unit, using the same analytical method, within a specific time period. An analytical batch can be up to 20 samples (excluding laboratory $Q C$ samples), all of which must be received by the laboratory within 14 days of the validated time of sample receipt (VTSR) of the first sample in the batch.

Data from testing, sampling, and analytical operations will be generated, and reported to the site project office, as testing, sampling, or analytical batch data reports. The requirements for testing, sampling, and analytical batch data reports are included in Sections 9.0 through 15.0 .

\subsection{Data Review, Validation, and Verification Requirements}

Data review, validation, and verification requirements include procedures for the review, validation, and verification of data at the data generation level; the validation and verification of data at the project level; and the verification of data at the CAO level. Data review determines if raw data have been properly collected and ensures raw data are properly reduced. Requirements for data reduction are provided in Sections 9.0 through 15.0, as appropriate, and in the Methods Manual. Data validation confirms that the data reported satisfy the requirements defined by the user and is accompanied by signature release. Data verification authenticates that data are in fact that which is claimed. The procedures presented in this section ensure that Program records furnish documentary evidence of quality. 


\subsubsection{Data Generation Level}

The following are minimum requirements for raw data collection and management:

- All raw data shall be signed and dated in black ink by the person generating it.

- All data must be recordec clearly, legibly, and accurately in field and laboratory records (bench sheets and/or logbooks), and include applicable sample identification numbers.

- All changes to original data must be lined out, initialed, and dated by the individual making the change. A justification for changing the original data must also be included. Original data must not be obliterated or otherwise disfigured so as not to be readable.

- All data must be transferred and reduced from field and laboratory records completely and accurately.

- All field and laboratory records must be maintained in permanent files according to NEIC guidelines (Section 1.7).

- Data must be organized into a standard format for reporting purposes (testing, sampling, or analytical batch data report), as outlined in specific sampling and analytical techniques (Sections 7.0 through 15.0 ).

- All electronic and video data must be stored appropriately to ensure that waste container, sample, and associated $Q C$ data are readily retrievable (Section 1.7 ).

Data review, validation, and verification at this level involves scrutiny and signature release from qualified independent technical reviewer(s), technical supervisors(s), and a OA officer, as specified below. Any nonconformance identified during this process shall be documented on a nonconformance report (Section 2.1.2.1). Facilities may combine the positions of technical supervisor and QA officer. Individuals conducting this data review, validation, and verification must use checklists that address all of the items included in this section. Checklists must contain tables showing the results of sampling or analytical batch OC samples, if applicable. Completed checklists must be forwarded with testing, sampling, and analytical batch data reports to the project level.

- One hundred percent of the data must receive an independent technical review. This review shall be performed by an individual other than the data generator who is qualified to have performed the initial work. The reviewer(s) must release the data as evidenced by signature, and as a consequence ensure the following:

- Data generation and reduction were conducted in a technically correct manner in accordance with the methods used. Data were reported in the proper units and correct number of significant figures.

- Calculations have been verified by a valid calculation program, a spot check of verified calculation programs, and/or 100-percent check of all hand calculations.

- All variances from an accepted method and the rationale for the variations have been documented and approved (Section 2.1.2.2). 
- The data have been reviewed for transcription errors.

- The testing, sampling, or analytical data OA documentation (testing batch, sampling batch, or analytical batch) is complete and includes raw data, calculation records, COC forms, calibration records, QC sample results, and gas canister sample tags lif applicable).

- QC sample results are within established control limits, and if not, the data have been appropriately qualified (Sections 7.0 through 15.0).

- Reporting flags were assigned correctly as specified in Sections 11.0 through 15.0.

- Sample holding time and preservation requirements were met, or exceptions documented.

- Radiography tapes have been reviewed, at a minimum for every tenth waste container, against the data reported on the radiography form to ensure that the data are correct and complete.

- Field sampling records are complete and include the documentation specified in Section 6.1 of this QAPP.

- One hundred percent of the data must receive technical supervisory signature release for each testing batch, sampling batch, and analytical batch. This release must ensure the following:

- The data are technically reasonable based on the technique used.

- All data have received independent technical review with the exception of radiography tapes, which shall receive periodic technical review as specified above.

- The testing, sampling, or analytical data $Q A$ documentation (testing batch, sampling batch, or analytical batch) is complete and includes raw data, calculation records, COC forms, calibration records, $Q C$ sample results, and gas sample canister tags (if applicable).

- Sample holding time requirements were met, or exceptions documented.

- Field sampling records are complete and include the documentation specified in Section 6.1 of this QAPP.

- One hundred percent of the data must receive $Q A$ officer signature release. This release must ensure the following:

- Independent technical and technical supervisory reviews have been performed as evidenced by the appropriate signature releases.

- The testing, sampling, or analytical data OA documentation (testing batch, sampling batch, or analytical batch) is complete as appropriate for the point of data generation (i.e., radiography, RA, sampling, and analysis). 
- Sampling and analytical $Q C$ checks have been properly performed. $Q C$ criteria that were not met are documented.

- QAOs have been met according to the methods outlined in Section 3.2.

\subsubsection{Project Level}

Data validation and verification at this level involves scrutiny and signature release from the site project manager and the site project $Q A$ officer. This must be accomplished by meeting the following minimum requirements for each waste container. Any nonconformance identified by the site project manager during this process shall be documented on a nonconformance report (Section 2.1.2.1).

- One hundred percent of the testing, sampling, and analytical data must have site project manager signature release. This signature release must ensure the following:

- Data generation level independent technical, technical supervisory, and QA officer review, validation, and verification have been performed as evidenced by the appropriate signature releases.

- Testing, sampling, and analytical batch data review checklists are complete.

- Testing, sampling, and analytical batch data reports are complete and data are properly reported (e.g., data are reported in the correct units, with the correct number of significant figures, and with qualifying flags).

- Reconciliation with the DOOs was performed (Section 3.3).

- One hundred percent of the testing, sampling, and analytical data must receive site project QA officer signature release. This signature release must ensure the following:

- Sampling batch $O C$ checks (e.g., equipment blanks, field duplicates, field reference standards) were properly performed, and meet the established QAOs (Sections 7.0 and 8.0).

- Testing batch QC checks (e.g., replicate scans, measurement system checks, replicate counts) were properly performed (Sections 9.0 and 10.0).

- Analytical batch OC checks le.g., laboratory duplicates, laboratory blanks, matrix spikes, matrix spike duplicates, laboratory control samples) were properly performed and meet the established QAOs (Sections 11.0 through 15.0).

- Proper procedures were followed to ensure representative samples of headspace gas and homogenous solids and soil/gravel were taken.

- Radiography data are complete and acceptable based on the videotape review of one waste container per testing batch, at a minimum.

- RA data are complete and acceptable. 
- The site project manager and site project $Q A$ officer shall ensure that a repeat of the data generation level review, validation, and verification is performed on the data for a minimum of one randomly chosen waste container quarterly (every three months). This exercise will document that the data generation level review, validation, and verification is being performed according to implementing procedures.

In association with the project-level validation and verification described above, the site project QA officer must prepare a Site Project $Q A$ Officer Summary and the site project manager (or designee) must prepare a Data Validation Summary. The Site Project OA Officer Summary includes, on a per waste container basis, a validation checklist for each testing, sampling, and analytical batch. Checklists for the Site Project $Q A$ Officer Summary must be sufficiently detailed to validate all aspects of a testing, sampling, or analytical batch that affect data quality. The Data Validation Summary provides confirmation that, on a per waste container basis, all data have been validated in accordance with the site QAPjP. The Data Validation Summary must list each testing, sampling, or analytical batch, describe how the validation was performed and whether or not problems were detected, and include a statement indicating that all data are acceptable.

Once the data have received project-level validation and verification, the site project manager must ensure that the laboratory is notified. Samples must be retained by the laboratory until this notification is received. Gas sample canisters may then be released from storage for cleaning, recertification, and subsequent reuse. Sample tags must be removed and forwarded to the site project QA officer before recycling the canisters. If the site project manager requests that samples or canisters be retained for future use (e.g., an experimental holding time study), the same sample identification and COC forms shall be used and cross-referenced to a document which specifies the purpose for sample or canister retention.

\subsubsection{CAO Level}

The third and final level of data verification occurs at CAO and must, at a minimum, consist of an inventory check of the data packages to verify completeness. The CAO Office of Regulatory Compliance manager is responsible for the verification that data packages include the following:

- Project-level signature releases

- Listing of all waste containers being reported in the package

- Listing of all testing, sampling, and analytical batch numbers associated with each waste container being reported in the package

- Data package case narrative

- Site Project QA Officer Summary 


\section{- Data Validation Summary}

- Complete summarized qualitative and quantitative data for all waste containers

The CAO Office of Regulatory Compliance manager must verify that each data package is complete and notify the originating site in writing of the acceptance status of the data within two weeks of data package receipt. CAO will maintain the data as appropriate for use in the regulatory compliance programs described in Section 1.3.

\subsection{Validation Methods}

Validation of all data (qualitative as well as quantitative) shall be performed so that data used for WIPP compliance programs will be of known and acceptable quality. Validation includes a quantitative determination of precision, accuracy, completeness, comparability, and method detection limit (as appropriate) for analytical data (headspace hydrogen, methane, and VOC data and total VOC, SVOC, and metals data). Quantitative data validations shall be performed by the data generation level QA officer according to the conventional procedures outlined below (equations 3-1 to 3-8). These quantitative determinations will be compared to the QAOs specified in Sections 11.0 through 15.0. A qualitative determination of representativeness will also be performed. Validation methods for the QAOs for RA are presented in Section 9.0 of this QAPP.

The qualitative data or descriptive information generated by radiography is not amenable to statistical analysis. However, radiography and visual examination are complementary techniques yielding similar data for determining the matrix parameter category and waste material parameter weights of waste present in a waste container. Therefore, visual examination results shall be used to verify the matrix parameter category and waste material parameter weights determined by radiography as described in Section 10.0 .

Representativeness of waste containers from waste streams subjected to visual examination and homogenous solids and soil/gravel sampling and analysis will be validated through documentation that a true random sample was collected. Since representativeness is a quality characteristic that expresses the degree to which a sample or group of samples represents the population being studied, the random selection of waste containers ensures representativeness on a Program level. The site project manager shall document that the selected waste containers from within a waste stream were randomly selected. Sampling personnel shall verify that proper procedures are followed to ensure that samples are representative of the waste contained in a particular waste container (Sections 7.0 ) or a waste stream (Section 8.0). 


\subsubsection{Precision}

Precision is a measure of the mutual agreement among multiple measurements of a single analyte, either by the same method or by different methods. Precision is either expressed as the relative percent difference (RPD) for duplicate measurements or as the percent relative standard deviation (\%RSD) for three or more replicate measurements. For duplicate measurements, the precision expressed as the RPD is calculated as follows:

$$
R P D=\frac{C_{1}-C_{2}}{\frac{\left(C_{1}+C_{2}\right)}{2}} * 100
$$

where $C_{1}$ and $C_{2}$ are the two values obtained by analyzing the duplicate samples. $C_{1}$ is the larger of the two observed values.

For three or more replicate measurements, the precision expressed as the \%RSD is calculated as follows:

$$
\% R S D=\frac{s}{\bar{y}} * 100
$$

where $s$ is the standard deviation and $\bar{y}$ is the mean of the replicate sample analyses.

The standard deviation, $s$, is calculated as follows:

$$
s=\sqrt{\sum_{i=1}^{n} \frac{\left(y_{i}-\bar{y}\right)^{2}}{n-1}}
$$

where $y_{i}$ is the measured value of the $i^{\text {th }}$ replicate sample analysis measurement, and $n$ equals the number of replicate analyses.

Another aspect of precision is associated with analytical equipment calibration. In these instances, the percent difference (\%D) between multiple measurements of an equipment calibration standard shall be calculated as follows:

$$
\% D=\left|\frac{C_{1}-C_{2}}{C_{1}}\right| * 100
$$

where $C_{1}$ is the initial measurement and $C_{2}$ is the second or other additional measurement. 


\subsubsection{Accuracy}

Accuracy is the degree of agreement between a measured analyte concentration lor the average of replicate measurements of a single analyte concentration) and the true or known concentration. Accuracy is determined as the percent recovery $(\% R)$.

For situations where a standard reference material is used, the \% $\mathrm{R}$ is calculated as follows:

$$
\% R=\frac{C_{m}}{C_{s m m}} * 100
$$

where $C_{m}$ is the measured concentration value obtained by analyzing the sample and $C_{s m}$ is the "true" or certified concentration of the analyte in the sample.

For measurements where matrix spikes are used, the \%R is calculated as follows:

$$
\% R=\frac{S-U}{C_{s a}} * 100
$$

where $S$ is the measured concentration in the spiked aliquot, $U$ is the measured concentration in the unspiked aliquot, and $C_{s e}$ is the actual concentration of the spike added.

\subsubsection{Method Detection Limit}

The method detection limit (MDL) is the minimum concentration of an analyte that can be measured and reported with 99 percent confidence that the analyte concentration is greater than zero. The MDL for all quantitative measurements is defined as follows:

$$
M D L=t_{(n-1,1-\alpha=.99)} * s
$$

where $\left.t_{(\{n-1,1-a}=.99\right)$ is the $t$-distribution value appropriate to a 99-percent confidence level and a standard deviation estimate with $n-1$ degrees of freedom, $n$ is the number of observations, and $s$ is the standard deviation of replicate measurements. 


\subsubsection{Completeness}

Completeness is a measure of the amount of valid data (i.e., data that meets all QA/OC requirements) obtained from the overall measurement system compared to the amount of data collected and submitted for analysis. Completeness must be expressed as the number of samples analyzed with valid results as a percent of the total number of samples submitted for analysis. Completeness, expressed as the percent complete $(\% \mathrm{C})$, is calculated as follows:

$$
\% C=\frac{V}{n} * 100
$$

where $V$ is the number of valid analytical results obtained and $n$ is the number of samples submitted for analysis.

\subsubsection{Comparability}

Comparability is the degree to which one data set can be compared to another. Comparability of data generated at different sites will be assured through the use of standardized, approved testing, sampling and analytical techniques and by meeting the QAOs specified in Sections 7.0 through 15.0. The techniques presented in Sections 7.0 through 15.0 of this QAPP, and provided in greater detail in the Methods Manual, are acceptable and will meet Program requirements.

\subsection{Reconciliation with Data Quality Objectives}

Reconciling the results of waste testing and analysis with the DQOs provides a way to ensure that data will be of adequate quality to support the regulatory compliance programs described in Section 1.3 of this OAPP. Reconciliation with the DOOs will take place at both the project level and the CAO level. At the project level, reconciliation will be performed by the site project manager; at CAO, reconciliation will be performed by the CAO Office of Regulatory Compliance manager.

\subsubsection{Reconciliation at the Project Level}

In association with the data validation and verification described in Section 3.1.2, the site project manager will ensure that all data generated meet the DQOs provided in Section 1.5 of this QAPP. To do so, the site project manager must assess whether data of sufficient type, quality, and quantity have been collected. The site project manager must determine if the variability of the data set is small enough to provide the required confidence in the results. The site project manager must also determine if, based on the desired error rates and confidence levels, a sufficient number of valid data points have been determined. In addition, the site project manager must document that random sampling of containers was performed for the purposes of waste stream characterization. 
For each waste stream characterized, the site project manager must determine if sufficient data have been collected to determine the following Program-required waste parameters:

- Matrix parameter category

- Waste material parameter weights

- Average mass and activity of each radionuclide of concern

- If each waste container of waste is TRU radioactive waste

- Average concentration of hydrogen, methane, and each VOC in the headspace gas of waste containers in the waste stream

- Total masses of VOCs, hydrogen, and methane in the headspace gas of the waste stream

- The potential flammability of TRU waste headspace gases

- Mean concentrations, $\mathrm{UCL}_{90}$ for the mean concentrations, standard deviations, and number of samples collected for VOCs, SVOCs, and metals in the waste stream

- Total masses of VOCs, SVOCs, and metals in the waste stream

- Whether the waste stream exhibits a TC under 40 CFR Part 261, Subpart C

- Whether the waste stream can be classified as hazardous or nonhazardous at the 90-percent confidence level

- Whether a sufficient number of waste containers have been visually examined to determine with a reasonable level of certainty that the $U \mathrm{CL}_{90}$ for the miscertification rate is less than 14 percent

If the site project manager determines that insufficient data have been collected to make the determinations listed above, additional data collection efforts must be undertaken.

The statistical procedure presented in Section 5.0 shall be used by participating site project managers to evaluate and report waste characterization data from the analysis of homogenous solids and soil/gravel. The procedure, which calculates $U \mathrm{UL}_{90}$ values, shall be used to assess compliance with the DQOs in Section 1.5 as well as with PCRA regulations. The procedure must be applied to all laboratory analytical data for total VOCs, total SVOCs, and total metals. For RCRA regulatory compliance (40 CFR § 261.24), data from the analysis of the appropriate metals and organic compounds shall be compared to the TC levels expressed as total values. These total values will be considered the regulatory threshold limit (RTL) values for the Program. RTL values are obtained by calculating the weight/weight concentration (in the solid) of a TC analyte that would give the 
regulatory weight/volume concentration (in the TCLP extract) assuming 100-percent analyte dissolution. Table 3-1 lists the Program RTL values for the TC contaminants (VOCs, SVOCs, metals).

\subsubsection{Reconciliation at the CAO Level}

In association with the data verification described in Section 3.1.3, CAO must also ensure that data of sufficient type, quality, and quantity have been collected to meet Program DOOs. The CAO Office of Regulatory Compliance manager is responsible for determining if sufficient data have been collected to determine the following:

- The concentration of headspace gas VOCs in the total waste inventory to support a demonstration that VOCs will not migrate through the air beyond the WIPP unit boundary in concentrations greater than EPA-determined health-based limits during WIPP operations;

- The concentration of VOCs, SVOCs, and metals in the total waste inventory to support a demonstration that hazardous constituents will not migrate beyond the WIPP unit boundary in concentrations greater than EPA-determined health-based limits;

- The total curie, hydrogen, and methane concentrations in TRU waste to support revision of the thermal power restrictions for shipment of waste in the TRUPACT-II;

- An inventory of radioactive materials and physical waste forms to support an assessment of repository performance;

- Whether waste streams proposed for disposal in WIPP have been adequately characterized; and

- Whether data supports the preparation of the WIPP facility no-migration variance petition, the WIPP RCRA permit application, the WIPP facility 40 CFR Part 191 Certification Application, and a revised safety analysis report for the TRUPACT-II.

\subsection{Data Reporting Requirements}

Data reporting requirements define the type of information and the method of transmittal for data transfer from the data generation level to the project level and from the project level to CAO. The requirements for each level are discussed below and illustrated by Figure 1-5.

\subsubsection{Data Generation Level}

Data shall be transmitted by hard copy from the data generation level to the project level. Transmitted data shall include all testing, sampling, and analytical batch data reports, and data review checklists. The report forms and checklists used must contain all of the information required by the testing, sampling, and analytical techniques described in Sections 7.0 through 15.0 of this QAPP, as well as the signature releases to document the review, validation, and verification as described in Section 3.1. All testing, sampling, and analytical batch data reports and checklists shall be on approved forms, as provided in site-specific documentation. 
TABLE 3-1

TC Levels Expressed as RTL Values in the Waste

RTL Value

(mg/kg)

Metals and Semi-VOCs
Arsenic
Barium
Cadmium
Chromium
Cresols
1,4-Dichlorobenzene
2,4-Dinitrotoluene
Hexachlorobenzene
Hexachloroethane
Lead
Mercury
Nitrobenzene
Pentachlorophenol
Pyridine
Selenium
Silver

vocs
Benzene
Carbon tetrachloride
Chlorobenzene
Chloroform
1,2-Dichloroethane
1,1-Dichloroethylene
Methyl ethyl ketone
Pyridine
Tetrachloroethylene
Trichloroethylene
Vinyl chloride

100

2000

20

100

4000

150

2.6

2.6

60

100

4

40

2000

100

20

100

10

10

2000

120

10

14

4000

100

14

10

4

The caiculations assume 1) the maximum amount of material suggested by the TCLP is used, 2) wastes are 100-percent solid (no liquid fraction), 3) the maximum amount of extraction fluid is used, and 4) all analytes are 100 -percent soluble in the extraction fluid.

bFor metals e i semi-VOCs,

RTL value $(\mathrm{m} / \mathrm{kg})=(T C$ level, $\mathrm{mg} / \mathrm{L}$ ) (volume of extraction fluid, $2 \mathrm{~L}) /($ weight of sample, $0.100 \mathrm{~kg}$ )

'For VOCs,

$\mathrm{RTL}$ value $(\mathrm{mg} / \mathrm{kg})=(\mathrm{TC}$ level, $\mathrm{mg} / \mathrm{L}$ ) (volume of extraction fluid, $0.5 \mathrm{~L}) /($ weight of sample, $0.025 \mathrm{~kg}$ ) 
Testing, sampling, and analytical batch data reports shall be forwarded to the site project office. Site QAPjPs shall specify the individual at the site project office who will receive these reports. Testing batch data reports shall be forwarded to the site project office within 28 days of the testing of the last waste container in a testing batch. Sampling batch data reports shall be forwarded to the site project office within 28 days of sample collection of the last sample in a sampling batch. Analytical batch data reports shall be forwarded to the site project office within 28 days of the VTSR of the last sample in an analytical batch. After review by the site project $Q A$ officer, all batch data reports will be forwarded to the site project manager as indicated in Figure 1-5. Batch data report requirements are identified in Sections 7.0 and 8.0 for sampling techniques, and Sections 9.0 through 15.0 for testing and analytical techniques. All testing, sampling, and analytical batch data reports shall be assigned serial numbers, and each page shall be numbered at the bottom. The serial number used for data reports can be the same as the testing, sampling, or analytical batch number.

QA documentation shall be maintained in either testing, sampling, and analytical facility files, or site project files for those facilities located on sites. Contract waste operation facilities shall forward testing, sampling, and analytical $Q A$ documentation along with testing, sampling, and analytical batch data reports to the site project office for inclusion in site central files.

\subsubsection{Project Level}

There are two aspects to project level reporting. First, summarized testing, sampling, and analytical data must be reported on a per-waste container basis. Second, summarized characterization information must be reported on a waste stream basis.

Summarized testing, sampling, and analytical data shall be transmitted by hard copy from the site project manager to CAO when requested. Participating sites shall combine data from individual waste containers into data packages for reporting. Hard copy data packages shall consist of the following:

- Cover page with the site name, program identification, waste container numbers for containers included in the data package, and release signatures of the site project manager and site project QA officer

- Table of contents

- A concise narrative that summarizes the results of the project-level review and briefly describes any problems or other noteworthy items of interest associated with the data (i.e., nonconformance reports, operational variances). The narrative shall include separate sections which address results of duplicates/replicates and nonconformance reports associated with the waste containers being reported in the package. 
For each waste container being reported in the data package, the following information shall be included:

- Cover page with the site name, program identification, waste container number, and approval/release signatures of the site project manager and site project QA officer

- A table that relates sample numbers (testing, sampling, and analytical) to waste container number

- Table of contents

- Site Project OA Officer Summary

- Data Validation Summary

- Radiography results

- RA results

- Waste container headspace gas hydrogen, methane, and VOC analytical results

- Innermost layer of confinement headspace gas hydrogen, methane, and VOC analytical results for waste containers with inner layers of confinement (if applicable)

- Total VOC, SVOC, and metal analytical results for homogenous solids and soil/gravel lif applicable)

At present, sites are required to submit only hard copy data packages. Once the WIPP Waste Information System is finalized, sites will be required to submit electronic data packages. Electronic data packages shall include the same data that is transmitted by hard copy and must be accompanied by the release signature of the site project manager and site project $Q A$ officer. The electronic data package must be capable of conversion to and from ASCII format without loss of information. The required report elements, data fields, and field types are presented in Table 3-2.

In addition to the reporting requirements for individual waste containers, once a waste stream is fully characterized, the site project manager must submit to CAO a summary of the waste stream. This summary shall include all of the waste stream information and the reconciliation with DQOs as outlined in Section 3.3.1 of this QAPP. 
TABLE 3-2

\section{Requirements for Electronic Transmittal of Data Packages}

\begin{tabular}{|c|c|c|c|}
\hline Report Element & $\begin{array}{l}\text { Number of } \\
\text { Required } \\
\text { Fields }\end{array}$ & Description of Required Fields & Field Type ${ }^{a}$ \\
\hline Cover Page & 2 & $\begin{array}{l}\text { Site name } \\
\text { Program identification }\end{array}$ & $\begin{array}{l}\text { Memo } \\
\text { Memo }\end{array}$ \\
\hline Table of Contents & 1 & $\begin{array}{l}\text { Listing of the types of data included in the } \\
\text { data package }\end{array}$ & Memo \\
\hline Case Narrative & 1 & $\begin{array}{l}\text { Concise narrative which summarizes results of } \\
\text { project-level review and any problems } \\
\text { associated with the date }\end{array}$ & Memo \\
\hline Waste Container List & 2 & $\begin{array}{l}\text { Waste container number } \\
\text { Waste container package date }\end{array}$ & $\begin{array}{l}\text { Alpha-numeric } \\
\text { Alpha-numeric }\end{array}$ \\
\hline Radiography Data & 13 & $\begin{array}{l}\text { Waste container number } \\
\text { Item Description Code } \\
\text { TRUCON code } \\
\text { Matrix parameter category } \\
\text { Waste container examination date } \\
\text { Item Description Code changed (yes/no) } \\
\text { Visual examination performed (yes/no) } \\
\text { Matrix parameter category confirmed (yes/no) } \\
\text { Waste material parameters } \\
\text { Weight of waste material parameters } \\
\text { Weight of waste material parameters } \\
\text { confirmed (yes/no) } \\
\text { Layers of packaging present } \\
\text { Comment section }\end{array}$ & $\begin{array}{l}\text { Alpha-numeric } \\
\text { Alpha-numeric } \\
\text { Alpha-numeric } \\
\text { Numeric } \\
\text { Date } \\
\text { Logical } \\
\text { Logical } \\
\text { Logical } \\
\text { Memo } \\
\text { Numeric } \\
\text { Logical } \\
\text { Numeric } \\
\text { Memo }\end{array}$ \\
\hline
\end{tabular}

${ }^{a}$ Field types have the following minimum space requirements: Alpha 1 - 50 spaces; Alpha 2 - 2 spaces; Alphanumeric - 20 spaces; Date (MMDDYY) - 8 spaces; Logical - 1 space; Memo - N/A.

These items are not addressed by this program but are reported to consolidate information from the WIPP-WAC and TRAMPAC.

'Site project QA officer. 
TABLE 3-2

\section{Requirements for Electronic Transmittal of Data Packages}

(Continued)

\begin{tabular}{|c|c|c|c|}
\hline Report Element & $\begin{array}{c}\text { Number of } \\
\text { Required } \\
\text { Fields }\end{array}$ & Description of Required Fields & Field Type \\
\hline RA Data & 16 & $\begin{array}{l}\text { Waste container number } \\
\text { Item Description Code } \\
\text { TRUCON code } \\
\text { Matrix parameter category } \\
\text { NDA examination date } \\
\text { NDA Method } \\
\text { Total Pu-239 (fissile gram equivalents,g) } \\
\text { Pu-239 uncertainty (fissile gram } \\
\text { equivalents,g) } \\
\text { Total alpha activity (Ci) } \\
\text { Alpha activity uncertainty (Ci) } \\
\text { Thermal power (W) } \\
\text { Thermal power uncertainty (W) } \\
\text { Total TRU (nCi/g) } \\
\text { TRU uncertainty (nCi/g) } \\
\text { Individual radioisotopes (Ci) } \\
\text { Individual radioisotopes uncertainty (Ci) }\end{array}$ & $\begin{array}{l}\text { Alpha-numeric } \\
\text { Alpha-numeric } \\
\text { Alpha-numeric } \\
\text { Alpha-numeric } \\
\text { Date } \\
\text { Memo } \\
\text { Numeric } \\
\text { Numeric } \\
\text { Numeric } \\
\text { Numeric } \\
\text { Numeric } \\
\text { Numeric } \\
\text { Numeric } \\
\text { Numeric } \\
\text { Numeric } \\
\text { Numeric }\end{array}$ \\
\hline $\begin{array}{l}\text { Waste Container } \\
\text { Headspace Gas Data }\end{array}$ & 12 & $\begin{array}{l}\text { Waste container number } \\
\text { Item Description Code } \\
\text { TRUCON code } \\
\text { Matrix parameter category } \\
\text { Date sampled } \\
\text { Date analyzed } \\
\text { Analyte name } \\
\text { Concentration (vol\% for } \mathrm{H}_{2} \text { and } \mathrm{CH}_{4} \text { ) } \\
\text { Concentration (ppmv for } \mathrm{VOCs} \text { ) } \\
\text { Total flammables (vol\% or ppmv) } \\
\text { Total VOCs (ppmv) } \\
\text { Reporting flag }\end{array}$ & $\begin{array}{l}\text { Alpha-numeric } \\
\text { Alpha-numeric } \\
\text { Alpha-numeric } \\
\text { Alpha-numeric } \\
\text { Date } \\
\text { Date } \\
\text { Alpha } 1 \\
\text { Numeric } \\
\text { Numeric } \\
\text { Numeric } \\
\text { Numeric } \\
\text { Alpha } 2\end{array}$ \\
\hline
\end{tabular}

aField types have the following minimum space requirements: Alpha 1 - 50 spaces; Alpha 2 - 2 spaces; Alphanumeric - 20 spaces; Date (MMDDYY) - 8 spaces; Logical - 1 space; Memo - N/A.

bThese items are not addressed by this program but are reported to consolidate information from the WIPP-WAC and TRAMPAC.

'Site project QA officer. 
TABLE 3-2

Requirements for Electronic Transmittal of Data Packages

(Continued)

\begin{tabular}{|c|c|c|c|}
\hline Report Element & $\begin{array}{l}\text { Number of } \\
\text { Required } \\
\text { Fields }\end{array}$ & Description of Required Fields & Field Type ${ }^{a}$ \\
\hline $\begin{array}{l}\text { Innermost Layer of } \\
\text { Confinement } \\
\text { Headspace Gas Data }\end{array}$ & 11 & $\begin{array}{l}\text { Waste container number } \\
\text { ltem Description Code } \\
\text { TRUCON code } \\
\text { Matrix parameter category } \\
\text { Innermost layer identification } \\
\text { Date sampled (per layer) } \\
\text { Date analyzed (per layer) } \\
\text { Analyte name } \\
\text { Concentration (vol\% for } \mathrm{H}_{2} \text { and } \mathrm{CH}_{4} \text { ) } \\
\text { Concentration (ppmv for VOCs) } \\
\text { Reporting flag }\end{array}$ & $\begin{array}{l}\text { Alpha-numeric } \\
\text { Alpha-numeric } \\
\text { Alpha-numeric } \\
\text { Alpha-numeric } \\
\text { Alpha-numeric } \\
\text { Date } \\
\text { Date } \\
\text { Alpha } 1 \\
\text { Numeric } \\
\text { Numeric } \\
\text { Alpha } 2\end{array}$ \\
\hline $\begin{array}{l}\text { Solid Waste } \\
\text { Total VOC Data }\end{array}$ & 9 & $\begin{array}{l}\text { Waste container number } \\
\text { Item Description Code } \\
\text { TRUCON code } \\
\text { Matrix parameter category } \\
\text { Date sampled } \\
\text { Date analyzed } \\
\text { Analyte name } \\
\text { Concentration }(\mathrm{mg} / \mathrm{kg}) \\
\text { Reporting flag }\end{array}$ & $\begin{array}{l}\text { Alpha-numeric } \\
\text { Alpha-numeric } \\
\text { Alpha-numeric } \\
\text { Alpha-numeric } \\
\text { Date } \\
\text { Date } \\
\text { Alpha } 1 \\
\text { Numeric } \\
\text { Alpha } 2\end{array}$ \\
\hline $\begin{array}{l}\text { Solid Waste } \\
\text { Total SVOC Data }\end{array}$ & 9 & $\begin{array}{l}\text { Waste container number } \\
\text { Item Description Code } \\
\text { TRUCON code } \\
\text { Matrix parameter category } \\
\text { Date sampled } \\
\text { Date analyzed } \\
\text { Analyte name } \\
\text { Concentration }(\mathrm{mg} / \mathrm{kg}) \\
\text { Reporting flag }\end{array}$ & $\begin{array}{l}\text { Alpha-numeric } \\
\text { Alpha-numeric } \\
\text { Alpha-numeric } \\
\text { Alpha-numeric } \\
\text { Date } \\
\text { Date } \\
\text { Alpha } 1 \\
\text { Numeric } \\
\text { Alpha } 2\end{array}$ \\
\hline
\end{tabular}

aField types have the following minimum space requirements: Alpha 1 - 50 spaces; Alpha 2 - 2 spaces; Alphanumeric - 20 spaces; Date (MMDDYY) - 8 spaces; Logical - 1 space; Memo - N/A.

'These items are not addressed by this program but are reported to consolidate information from the WIPP-WAC and TRAMPAC.

'Site project $Q A$ officer. 
TABLE 3-2

\section{Requirements for Electronic Transmittal of Data Packages} (Continued)

\begin{tabular}{|c|c|c|c|}
\hline Report Element & $\begin{array}{l}\text { Number of } \\
\text { Required } \\
\text { Fields }\end{array}$ & Description of Required Fields & Field Type ${ }^{a}$ \\
\hline $\begin{array}{l}\text { Solid Waste } \\
\text { Total Metals Data }\end{array}$ & 9 & $\begin{array}{l}\text { Waste container number } \\
\text { Item Description Code } \\
\text { TRUCON code } \\
\text { Matrix parameter category } \\
\text { Date sampled } \\
\text { Date analyzed } \\
\text { Analyte name } \\
\text { Concentration }(\mathrm{mg} / \mathrm{kg} \text { ) } \\
\text { Reporting flag }\end{array}$ & $\begin{array}{l}\text { Alpha-numeric } \\
\text { Alpha-numeric } \\
\text { Alpha-numeric } \\
\text { Alpha-numeric } \\
\text { Date } \\
\text { Date } \\
\text { Alpha } 1 \\
\text { Numeric } \\
\text { Alpha } 2\end{array}$ \\
\hline Data Summaries & 2 & $\begin{array}{l}\text { SPQAO }{ }^{\complement} \text { summary completed? (yes/no) } \\
\text { Data Validation Summary completed? (yes/no) }\end{array}$ & $\begin{array}{l}\text { Logical } \\
\text { Logical }\end{array}$ \\
\hline WIPP Certification & 2 & $\begin{array}{l}\text { WIPP-WAC certifiable }\left(y e s / \mathrm{no}^{\mathrm{b}}\right. \\
\text { TRAMPAC certifiable }\left(y e s / \mathrm{no}^{\mathrm{b}}\right.\end{array}$ & $\begin{array}{l}\text { Logical } \\
\text { Logical }\end{array}$ \\
\hline
\end{tabular}

aField types have the following minimum space requirements: Alpha 1 - 50 spaces; Alpha 2 - 2 spaces; Alphanumeric - 20 spaces; Date (MMDDYY) - 8 spaces; Logical - 1 space; Memo - N/A.

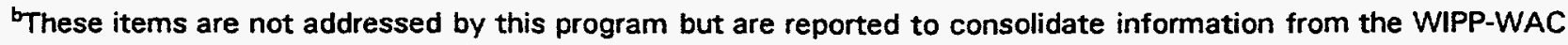
and TRAMPAC.

'Site project QA officer. 


\subsection{MEASUREMENT AND DATA ACQUISITION}

Participating sites shall develop QAPjPs and SOPs for implementing the Program as specified in this QAPP. The site project manager shall be responsible for developing site-specific sampling plans based on existing TRU waste inventory information and statistical sampling protocols as described in Section 5.0. Waste and sample custody shall be maintained throughout the Program activities as described in Section 6.0. All techniques shall be performed by qualified personnel using SOPs that address the requirements specified in Sections 7.0 through 15.0 .

The requirements described in Sections 4.1 to 4.6 are common to all testing, sampling, and analytical techniques and are in addition to the specific requirements described in Sections 7.0 through 15.0 of this QAPP. Sections 4.1 to 4.6 follow the format of Sections 7.0 through 15.0 and provide a general discussion of the information provided for each testing, sampling, and analytical technique. All of the requirements included in Sections 4.2 through 4.5 must be implemented at the sampling, testing, and analytical facilities with site-specific SOPs.

\subsection{Quality Assurance Objectives}

The objectives for data quality are presented in this subsection for each testing, sampling, and analytical technique in terms of precision, accuracy, MDL, PRQL, completeness, comparability, and representativeness, as applicable. By meeting the QAOs, data will support the DOOs presented in Section 1.5 of this QAPP and, in turn, support the regulatory compliance programs presented in Section 1.3 of this QAPP.

\subsection{Methods Requirements}

All participating sites must follow acceptable and approved testing, sampling, and analytical techniques so that processes affecting Program quality are controlled. If sites develop methods other than those specified in Sections 7.0 through 15.0, approval must be received from CAO prior to their use in Program activities. Included for each technique is a description of the required equipment, implementation or extraction requirements, decontamination procedures, and specific performance requirements.

Supplies and consumables support the testing, sampling, and analytical techniques and may include sampling containers, reagents, gases, deionized water, decontamination materials, hoses, and other ancillary equipment. If supplies or consumables of a certain material type, dimension, or purity are critical to the quality of the data, these criteria will be specified for the technique. 


\subsection{Quality Control Requirements}

The $\mathrm{OC}$ requirements for each testing, sampling, and analytical technique include the performance of replicate scans, visual examination, the collection and analysis of equipment blanks, field or laboratory blanks, field or laboratory duplicates, field reference standards, and laboratory control samples. Testing, sampling, and analytical laboratory personnel shall be responsible for the performance of specific $Q C$ activities and for collecting and analyzing the appropriate type and quantity of $O C$ samples. The laboratory $Q A$ officer must validate data before submittal to the site project office. The site project manager and site project $Q A$ officer will evaluate data and ensure that Program objectives have been met.

\subsection{Equipment Testing, Inspection, and Maintenance Requirements}

Equipment must be routinely tested and inspected to assure that it is being operated properly and is providing quality data. The status of inspection and test activities shall be documented to prevent the inadvertent use of malfunctioning equipment in Program activities. If a particular piece of equipment is found to be malfunctioning, it shall be tagged to prevent its use in Program activities until it is repaired.

Preventive maintenance must have two aspects: 1) a schedule of preventive maintenance activities to ensure the accuracy of measurement systems and to minimize downtime and 2) a collection of critical spare parts and backup systems and equipment. Maintenance of field and laboratory equipment and instrumentation shall be in accordance with manufacturers' specifications or applicable test specifications, and shall be documented.

\subsection{Equipment Calibration and Frequency}

Routine calibration of equipment ensures it is functioning properly and provides documentation of the measurements. Calibration shall be conducted using certified equipment or standards, as appropriate, with known valid relationships to nationally recognized performance standards (e.g., National Institute of Standards and Technology (NISTI). If no nationally recognized standards exist, such as in the case of radiography, the basis for the calibration must be documented.

Calibrated equipment must be uniquely identified by the manufacturer's serial number, a calibration system identification number, or some other means. This identification, along with a label/record indicating the date, time and individual performing the last calibration, and when the next calibration is due, must be attached and traceable to the equipment. Personnel must check and document the calibration status of equipment before using it. 
Reference standards (physical and chemical) must be used for calibration. Physical standards must be stored separately from working measurement and test equipment, where possible. Equipment that cannot be calibrated must be removed from service and isolated to prevent inadvertent use, or it must be tagged to indicate that it is out of calibration. Such equipment must be repaired and recalibrated to Program requirements before it can be used again.

Instrument instruction manuals must be kept on file for reference purposes. Records must be prepared and maintained for each piece of calibrated equipment to indicate that established calibration procedures have been followed. These records must be kept in the site project files and must include

- Equipment identification/serial number

- Name of device

- Calibration and/or maintenance schedule

- Procedure(s) and revision number for calibration and/or maintenance

- Date and results of last calibration with signature of person performing calibration

- Date for next scheduled calibration

- Facility or organization performing calibration

- Nonconforming conditions related to the equipment (if applicable)

- Corrective actions taken to eliminate nonconforming conditions (if applicable)

- Standards used for calibration with certification papers

Any piece of equipment that fails to meet continuing calibration requirements must be recalibrated and must be certified to be in calibration prior to reuse. All affected measurements, assays, or examinations made since the last calibration of that piece of equipment must be rerun.

\subsection{Data Management}

Raw data obtained by testing, sampling, and analyzing TRU waste in support of the Program shall be identifiable, legible, and provide documentary evidence of quality. The reporting requirements at the data generation level are provided for each technique in Sections 7.0 through 15.0 of this QAPP. All participating testing, sampling, and analytical facilities must use approved forms, provided in site-specific documentation, for reporting Program data. 


\subsection{SAMPLING PROCESS DESIGN}

The data collection design for the Program is presented in Figure 5-1 for retrievably stored waste and in Figure 5-2 for newly generated waste. All TRU waste must be characterized to meet the DOOs as specified in Section 1.5 of this QAPP. Characterization of newly generated waste can be largely accomplished prior to or during packaging operations, while characterization of retrievably stored waste requires testing, sampling, and analysis of waste in containers. Sites should pursue opportunities to determine matrix parameter category, waste material parameter weights, perform RA, and perform sampling of homogenous solids and soil/gravel prior to packaging newly generated waste. QAPjPs must describe the processes to be used for the efficient characterization of newly generated waste.

Sites will utilize acceptable knowledge to sort waste containers into waste streams. Elements of acceptable knowledge that should be utilized include; the process that generated the waste, the material inputs to the process that generated the waste, the time period during which the waste was generated, the material input changes to the process during the waste generation time period, and the physical form of the waste. Utilization of acceptable knowledge in sorting waste containers into waste streams should enable sites to minimize the variability of hazardous constituent concentrations among waste containers. In accordance with the statistical procedures described in this section, a reduction in variability of hazardous constituent concentrations in a waste stream will result in a reduction in the number of samples that must be collected and analyzed to characterize the waste stream, thus reducing the cost of characterization. Reduced waste stream variability also helps ensure that the waste stream will be properly characterized. Therefore, a waste stream should be comprised of relatively homogenous wastes and waste streams should not be combined.

For the Program, a waste stream is defined as waste material generated from a single process or activity. Waste may be generated as either process or process batch waste streams. A process is defined as a system or series of continuous or regularly occurring actions taking place in a predetermined manner over extended periods of time resulting in a product that is substantially uniform. A process batch is defined as an amount of material subjected to a particular unit chemical process, unit physical mixing process, or other short-term operation, resulting in a final product that is substantially uniform.

Each waste stream must be characterized in accordance with the requirements of Section 5.2. Retrievably stored waste containers from waste streams in the homogenous solids and soil/gravel matrix parameter categories (S3000 and $\$ 4000$ summary categories) must be selected for RCRA characterization following the statistical approach specified in Section 5.3.1. Retrievably stored waste 


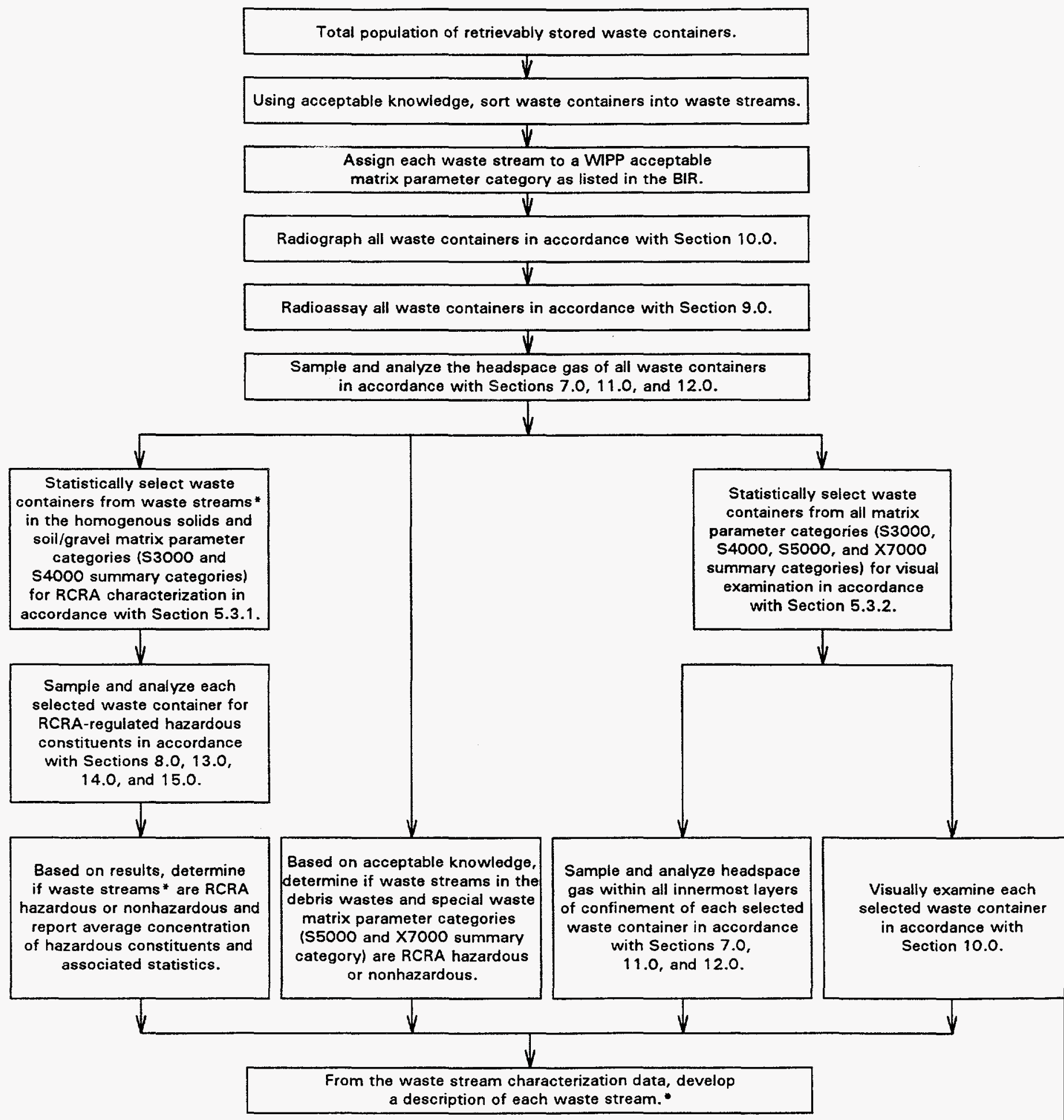

* or waste stream lot as described in Section 5.3.

FIGURE 5-1

Data Collection Design for Characterization of Retrievably Stored Waste 
Total population of newiy generated waste containers.

V

Verify that processes generating waste have operated within established and documented administrative controls.

\section{1}

Using acceptable knowledge, sort waste containers into waste streams.

I

Assign each waste stream to a WIPP acceptable

matrix parameter category as listed in the BIR.

1

Document and verify the matrix parameter category and waste material parameter weights during waste container packaging operations in accordance with Section 5.3.3.

$\downarrow$

Radioassay all waste containers in accordance with Section 9.0.

$\psi$

Sample and anaiyze the headspace gas of all waste containers in accordance with Sections 7.0, 11.0, and 12.0.

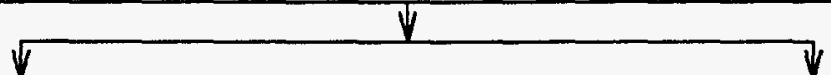

Randomly select one waste container per year or one per process batch from waste streams in the homogenous solids and soil/gravel matrix parameter categories ( $\$ 3000$ and $\$ 4000$ summary categories) for RCRA characterization in accordance with Section 5.3.3.

$$
\sqrt{1}
$$

Sample and analyze each selected waste container for RCRA-regulated hazardous constituents in accordance with Sections 8.0, 13.0, 14.0 , and 15.0 .

$$
\downarrow
$$

Based on results, determine if waste streams are RCRA hazardous or nonhazardous and report average concentration of hazardous constituents.

Based on acceptable knowledge, determine if waste streams in the debris wastes and special waste matrix parameter categories ( $\$ 5000$ and $X 7000$ summary categories) are RCRA hazardous or nonhazardous.

FIGURE 5-2

Data Collection Design for Characterization of Newly Generated Waste 
containers from waste streams in all matrix parameter categories (S3000, S4000, S5000, and X7000 summary categories) must be selected for visual examination to confirm the results of radiography following the statistical approach specified in Section 5.3.2. Newly generated waste containers from all waste streams (S3000, $\$ 4000,55000$, and $\times 7000)$ must be characterized in accordance with Section 5.3.3.

For the purposes of waste characterization, all waste generated at DOE facilities before the development and implementation of a TRU waste characterization program that meets the requirements of this QAPP shall be considered retrievably stored waste. Waste generated after development and implementation of a TRU waste characterization program that meets the requirements of this QAPP shall be considered newly generated.

\subsection{Description of Acceptable Matrix Parameter Categories}

The DOE Waste Treatability Group Guidance (DOE 1995a) provides a system for grouping wastes with similar physical and chemical properties. This system uses matrix parameter categories to identify wastes and then to group wastes by similar properties. These codes are divided into four broad groups: homogenous solids (S3000 summary category), soil/gravel (S4000 summary category), debris wastes (S5000 summary category), and special waste (X7000 summary category). Sampling and analytical requirements described in Section 5.2 are based on the summary category by which the waste stream is identified (i.e., homogenous solids, soil/gravel, debris wastes, or special waste). The appropriate matrix parameter category must be inscribed on all data forms associated with characterization of each waste stream.

\subsection{Parameters, Rationale, and Test Methods}

Once a waste stream has been identified, characterization information must be developed as specified in this section. All retrievably stored and newly generated waste containers must be characterized by RA and headspace gas sampling and analysis. RA must be performed in accordance with the requirements of Section 9.0 and headspace gas sampling and analysis must be performed in accordance with the requirements of Sections 7.0, 11.0, and 12.0. All retrievably stored waste containers must undergo radiography in accordance with the requirements of Section 10.0. In addition, retrievably stored homogenous solids and soil/gravel must be sampled and analyzed as described in Section 5.2.1. Newly generated waste streams of homogenous solids and soil/gravel must be sampled and analyzed as described in Section 5.2.1 once per year or once per process batch. All retrievably stored and newly generated debris wastes and special waste must be characterized as described in Section 5.2.2. All retrievably stored waste that is repackaged should be considered newly generated waste. 


\subsubsection{Homogenous Solids and Soil/Gravel}

Homogenous solids (summary category S3000) are defined in DOE (1995a) as solid waste materials, excluding soil/gravel that do not meet the EPA criteria for classification as debris. Homogenous solids may include water or other residual or absorbed liquids. Examples of homogenous solids are sludges and particulate-type materials. This summary category includes waste that is at least 50 percent by volume homogenous solids. The balance of the matrix may be other solid physical/chemical forms. DOE (1995a) defines soil/gravel (summary category $\$ 4000$ ) as waste estimated to be 50 percent by volume soil, including sand and silt, or rock and gravel that does not meet the EPA criteria for classification as debris.

The analytical parameters, techniques, and compliance programs for characterization of waste streams of homogenous solids and soil/gravel are listed in Table 1-3. RCRA-regulated VOCs and SVOCs may be present in waste streams in the homogenous solids and soil/gravel matrix parameter categories. With the exception of salt waste (matrix parameter category S3140), each of the waste streams must be sampled and analyzed for total RCRA-regulated VOCs and SVOCs (Tables 13-1 and 14-1), in accordance with the requirements of Sections 8.0, 13.0, and 14.0. Knowledge of the electrorefining processes that generate salt waste indicates high-temperature molten salt extraction is involved. This knowledge is adequate to demonstrate that organic constituents are not present in salt waste. Transformer oils containing polychlorinated biphenyls (PCBs) have been identified in a limited number of waste streams included in organic sludges (matrix parameter category S3220). Therefore, waste streams included in the organic sludges matrix parameter category must be analyzed for PCBs.

Waste streams of homogenous solids and soil/gravel may also contain RCRA-regulated metals. Therefore, these waste streams must be sampled and analyzed for total RCRA-regulated metals (Table 15-1), in accordance with the requirements of Sections 8.0 and 15.0, prior to transport to the WIPP facility. The rationale for using total analysis is discussed in Section 1.4.

\subsubsection{Debris Wastes and Special Waste}

DOE (1995a) defines debris wastes (summary category $\$ 5000$ ) as waste that is at least 50 percent by volume materials that meet the EPA criteria for classification as debris. These criteria are as follows:

Debris means solid material exceeding a $60 \mathrm{~mm}$ particle size that is intended for disposal and that is: 1) a manufactured object, or 2 ) plant or animal matter, or 3) natural geologic material. However, the following material are not debris: 1) any material for which a specific treatment standard is provided in [40 CFR] Part 268, 2) process residuals such as smelter slag and residues from the treatment of waste, wastewater, sludges, or air emission residues; and 3 ) intact containers of hazardous waste that are not ruptured and that retain at least 
75 percent of their original volume. A mixture of debris that has not been treated to the standards provided by [40 CFR] $\S 268.45$ and other material is subject to regulation as debris if the mixture is comprised primarily of debris, by volume, based on visual inspection.

This summary category includes waste that is at least 50 percent by volume materials that meet the above criteria. The balance of the matrix may be other physical or chemical waste forms.

DOE (1995a) defines special waste (summary category $\times 7000$ ) as waste that is inherently hazardous (i.e., the bulk material itself is RCRA hazardous), often with specific LDR treatment technology requirements; or presents unique treatment concerns. This summary category may contain elemental hazardous metals or batteries.

The analytical parameters, techniques, and compliance programs for characterization of waste streams of debris wastes and special waste are provided in Table 1-3. Knowledge of the original organics used and the operations that generate these waste streams is sufficient to determine if the waste is hazardous or contains PCBs and other hazardous constituents. RCRA-regulated metals present in debris wastes are associated with specific waste materials (e.g., lead in leaded rubber, leaded glass, or lead shielding). Knowledge of the materials and operations that generated these waste streams is sufficient to determine if they contain RCRA-regulated metals. Therefore, RCRA waste characterization of debris wastes and special waste shall be accomplished using acceptable knowledge instead of the sampling and analytical methods described in Sections 8.0, 13.0, 14.0, and 15.0.

\subsection{Sampling Plan}

Each site must develop a site-specific sampling plan which outlines the strategy to be used in the sampling of TRU waste to meet the requirements specified in this QAPP. At a minimum, this sampling plan must include the following:

- Identification and description of waste streams

- Identification of applicable matrix parameter categories consistent with the BIR and DOE (1995a)

- Identification of applicable waste material parameters

- Description of acceptable $\mathrm{kr}$ adge to be used in waste characterization activities

- Statistical sampling strategies orocedures

- Newly generated waste characterizcicion strategies 
Each site must document the random selection of waste containers in its site-specific sampling plan. The site-specific sampling plan must contain sufficient information to demonstrate that a random sample of the waste stream was obtained. Individual site-specific sampling plans must address issues, operational constraints, and As Low As Reasonably Achievable (ALARA) concerns related to container selection and retrieval. The site project manager shall be responsible for review and approval of the site-specific sampling plan.

Representativeness of containers of retrievably stored waste subjected to visual examination and retrievably stored and newly generated waste subjected to homogenous solids and soil/gravel sampling and analysis will be validated through documentation that a true random sample was collected. Since representativeness is a quality characteristic that expresses the degree to which a sample or group of samples represent the population being studied, the random sampling of waste streams ensures representativeness on a Program level. The site project manager shall verify that the samples collected from within a waste stream were selected randomly. True random sampling involves the proper use of random numbers for identifying samples to be collected; haphazard selection or selection based on convenience do not constitute random sampling. The random sampling process used to characterize a waste stream must ensure that all waste containers in that waste stream have an equal probability of being selected for characterization activities.

it is understood that it may not be logistically feasible to characterize some waste streams in their entirety with a single sampling episode because of staging and transportation requirements. In these cases, it is allowable to characterize an available portion, or lot, of a waste stream. The characterization then applies to the waste stream lot only. This is acceptable because the primary objective is to characterize a group of relatively homogenous wastes. The statistical method described in Section 5.3.1 applies directly to such a strategy. Therefore, in Section 5.3.1, waste stream may be considered synonymous with waste stream lot.

Statistical approaches must be followed to select retrievably stored waste containers from waste streams for characterization. Two statistical approaches are discussed. The first is applicable to retrievably stored homogenous solids and soil/gravel. Its goal is to classify specific waste streams as hazardous or nonhazardous by determining the average concentration of RCRA-regulated constituents in selected waste containers (Section 5.3.1). The second statistical procedure is applicable to retrievably stored homogenous solids, soil/gravel, debris wastes, and special waste. Its goal is to select representative waste containers for visual examination to confirm the matrix parameter category and waste material parameter weight estimates as determined by radiography (Section 5.3.2). Waste containers selected for visual examination must also undergo headspace gas sampling and analysis of R-4913 
all innermost layers of confinement within the waste container. This second statistical approach is based on a sampling program implemented at the Idaho National Engineering Laboratory (INEL) Stored Waste Examination Pilot Plant (EG\&G 1993b).

\subsubsection{RCRA Characterization of Retrievably Stored Homogenous Solids and Soil/Gravel}

This statistical approach relies on acceptable knowledge to segregate waste containers of homogenous solids and soil/gravel into relatively homogenous waste streams so it is reasonable to classify as hazardous or nonhazardous the entire waste stream rather than individual waste containers. Individual waste containers serve as convenient units for characterizing the combined mass of waste from the waste stream of interest. Once segregated by waste stream, random selection and sampling of the waste containers followed by analysis of the waste samples must be performed to ensure that the resulting mean contaminant concentration provides an unbiased representation of the true mean contaminant concentration for each waste stream. The site project manager shall verify that the samples collected from within a waste stream were selected randomly.

The sampling and analysis strategy is illustrated in Figure 5-3. Preliminary estimates of the mean concentration and variance of each RCRA-regulated contaminant in the waste will be used to determine the number of waste containers to select for sampling and analysis. The preliminary estimates will be made by obtaining a preliminary sample from the waste stream or from previous sampling from the waste stream. The applicability of the preliminary estimates to the waste stream to be sampled must be justified and documented. The estimates will be determined in accordance with the following equations:

$$
\begin{gathered}
\bar{x}=\frac{1}{n} \sum_{i=1}^{n} x_{i} \\
s^{2}=\frac{1}{n-1} \sum_{i=1}^{n}\left(x_{i}-\bar{x}\right)^{2}
\end{gathered}
$$

where $\bar{x}$ is the calculated mean concentration, $s^{2}$ is the calculated concentration variance, $n$ is the number of samples analyzed, $x_{i}$ is the concentration determined in the ith sample, and $i$ is an index from 1 to $n$.

The ratio of the standard deviation, $s$, to the mean is called the coefficient of variation $(\mathrm{CV})$; preliminary estimates for $\mathrm{CV}$ must be calculated for all contaminants of interest. The highest $\mathrm{CV}$ will be used in determining the number of samples to collect and analyze. Analysis results will then be 
Revision: 0

Date: $4 / 30 / 95$

Page 9 of 16

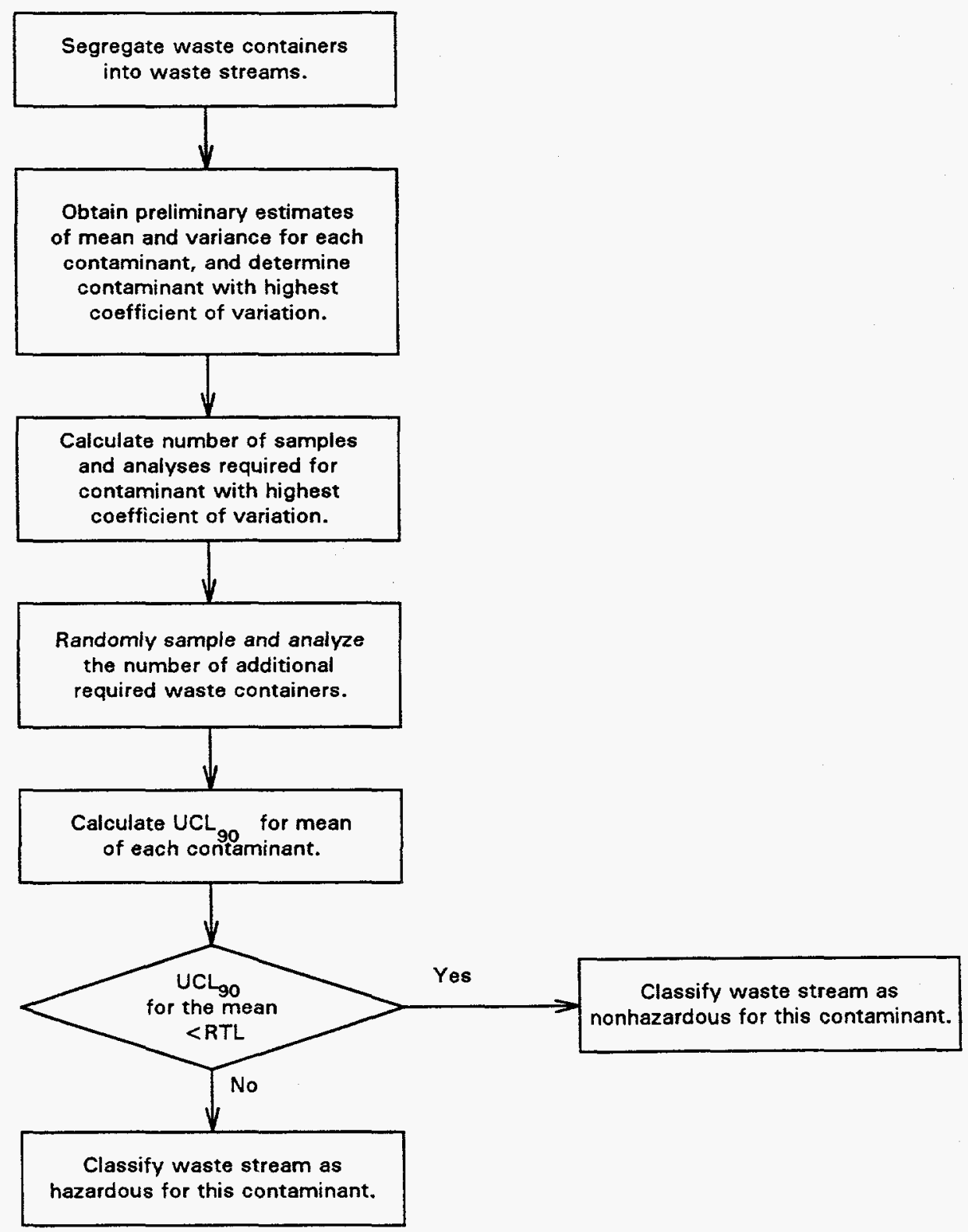

RTL = Regulatory Threshold Limit

$\mathrm{UCL}_{90}=$ Upper 90-percent one-sided confidence limit

FIGURE 5-3

Statistical Approach to Sampling and Analysis of Waste Streams of Retrievably Stored Homogenous Solids and Soil/Gravel 
summarized on a contaminant-specific basis. The calculations for the number of samples to collect and calculations for analysis summaries are described in subsequent paragraphs.

The preliminary estimated concentration means and associated variances nust then be used to calculate the number of samples required, $n$, in accordance with the procedure described in Cochran (1977). As a first approximation, take

$$
n_{0}=\frac{s^{2}}{\overline{x^{2} c}}
$$

where $s^{2}$ and $\bar{x}$ are the preliminary estimates for the variance and the mean and

$$
c=\frac{r^{2}}{t^{2}{ }_{\alpha, n_{0}-1}}
$$

where $t_{a, n_{0}-\text { is }}$ is the 90th percentile for a $t$ distribution with $n_{0}-1$ degrees of freedom. The parameter $r$ is taken as 1.0, which represents a relative error of 100 percent. This choice of $r$ is made in order to obtain the Type 1 and Type $I$ error rates discussed in a subsequent paragraph. This reduces Equation 5-3 to

$$
n_{0}=\frac{t_{\alpha, n_{0}-1}^{2} s^{2}}{\overrightarrow{x^{2}}}
$$

Because $t_{a, n_{0^{-}}}$is dependent on $n_{0}$, the calculation procedure is iterative. If the ratio of $n_{O}$ to the number of containers in the waste stream, $N$, is appreciable, the number of samples required may be reduced to

$$
n=\frac{n_{0}}{1+\left(\frac{n_{0}}{N}\right)}
$$

The effect of the ratio $n_{0} / N$ on $n$ in Equation 5-6 depends on $n_{0}$. Equation 5-6 should be used for cases where it results in a different number of samples from $n_{0}$. All calculations should round up to the nearest integer. A minimum of five containers must be sampled and analyzed in each waste stream. 
The calculated number of required waste containers will then be randomly sampled and analyzed. If waste container samples for the preliminary mean and variance estimates were randomly collected from the same waste stream lot being examined and were collected and analyzed in the manner required for characterization samples, then these samples may be counted toward meeting the required number. The number of waste containers that must be sampled is dependent on defined levels of acceptable error for the hazardous versus nonhazardous determination, as described below.

Upon completion of the required sampling, final mean and variance estimates, and the $\mathrm{UCL}_{90}$ for the mean concentration for each contaminant must be determined. The $\mathrm{UCL}_{90}$ for the mean concentration of each contaminant will be calculated in accordance with the following equation:

$$
U C L_{90}=\bar{x}+\frac{t_{\alpha, n-1} s}{\sqrt{n}}
$$

where $s$ is the sample standard deviation and $\bar{x}$ is the sample mean.

The observed sample CV must be checked against the preliminary estimate for $\mathrm{CV}$ used in determining the number of samples to be collected before proceeding. If the observed sample $\mathrm{CV}$ is greater than the preliminary estimate for $\mathrm{CV}$, the required number of samples must be recomputed using the observed CV. If the observed sample $\mathrm{CV}$ estimate results in greater than 20 percent more required samples, then additional sampling and analysis must occur. Once sufficient sampling and analysis has occurred, the determination of whether the waste stream is RCRA-hazardous or nonhazardous will proceed. The determination will be made with 90-percent confidence. If the $\mathrm{UCL}_{90}$ for the mean concentration is less than the RTL, the waste stream will be classified as nonhazardous for this contaminant. If the $\mathrm{UCL}_{90}$ is greater than or equal to the $R T L$, the waste stream will be classified as hazardous for this contaminant.

Another way of looking at this comparison is as a test of the null hypothesis for each contaminant that the mean contaminant concentration in the waste stream is greater than or equal to the RTL. The alternative hypothesis is that the mean contaminant concentration is less than the RTL. The hypothesis test must be performed with a nominal Type 1 error rate of 10 percent. This means that the contaminant must be considered present at hazardous levels unless it can be shown with 90-percent confidence that the mean is less than the RTL. The nominal Type II error rate must be set at 10 percent for the case in which the true mean value is one-half the RTL for the sample number 
calculation. Thus, the probability of falsely concluding the contaminant is present at hazardous levels when in fact the mean concentration is one-half the RTL will be 10 percent.

The statistical tests described above are based on the assumption that the measured concentrations of each contaminant are normally distributed. This assumption must be verified. Because the number of samples available are small, this will be best achieved by comparing the fit of the untransformed data to the fit after certain transformations. Appropriate transformation families are $\ln (x+c)$, and $-\exp (-a x)$, where $x$ is the raw data, and $c$ and $a$ are positive constants chosen to maximize fit.

The Shapiro-Wilk statistical test (Madansky 1988) should be used to assess goodness of the fit. For the family $\ln (x+c)$, for example, different values of $c$ can be tried, calculating the Shapiro-Wilk test statistic for the data after each transformation. (Note, values of $c$ must be large enough to ensure that $x+c$ is always greater than 0.1 The final value for $c$ that has the largest Shapiro-Wilk statistic, say $c_{m}$ must be chosen. Similarly, the value $a_{m}$ that maximizes the Shapiro-Wilk test statistic for -exp(-ax) must be found. Next, the Shapiro-Wilk statistic calculated for the untransformed data must be compared to that for $\ln \left(x+c_{m}\right)$ and $-\exp \left(-a_{m} x\right)$. If the value for the untransformed data is the largest, no transformation is required. Otherwise the transformation $\ln \left(x+c_{m}\right)$ or $-\exp \left(-a_{m} x\right)$ will be used, depending upon which has the largest Shapiro-Wilk test statistic.

If a transformation is required, the transformed RTL will also be calculated, that is either $/ n\left(R T L+c_{m}\right.$ ' or $-\exp \left(-a_{m} R T L\right)$, depending on which was chosen. Then the tests will be performed the same as before, with the transformed data and RTL being substituted into equations.

Every attempt should be made to obtain actual numeric values for each measurement, whether or not they are below the MDL. If chemical concentrations are reported as simply less than detectable (LTDI, a suitable substitution should be made for the data and calculations altered appropriately. The simplest suitable method is to substitute one-half the MDL for the measurement and then carry out the remaining calculations as indicated, except $t_{a_{s} n_{-1}}$ must be used in Equation (5-7) where $n^{*}$ is the number of non-LTD measurements in the data set. More precise (but more difficult to calculate) results may be obtained using the methods described in Gilliom and Helsel (1986) and EG\&G (1991).

All error levels and confidence levels given are nominal values; actual values will be somewhat different because the distributions are only approximately normal, estimates will be used to determine sample size, many compounds will be evaluated to determine whether or not a waste stream is hazardous, and data transformations and substitutions are approximate. The impact of these items is that either a 
lower or higher error rate could result, that is, the error rate may not be exactly 10 percent. Such potential impacts are not atypical of similar studies.

\subsubsection{Visual Examination of Retrievably Stored Homogenous Solids, Soil/Gravel, Debris Wastes, and Special Waste}

A different statistical procedure must be used to select retrievably stored waste containers for visual examination. As a $\mathrm{QC}$ check on radiography, a statistically selected portion of the certified waste containers must be opened and visually examined. The data from visual examination must be used to check the matrix parameter category and waste material parameter weights as determined by radiography (Section 10.0).

The data obtained from the visual examination must also be used to determine, with acceptable confidence, the percentage of miscertified waste containers. Miscertified containers are those that radiography indicates meet the WIPP-WAC and TRAMPAC criteria, but visual examination indicates do not meet these criteria. Note that the radiography requirements of Section 10.0 are separate from the radiography requirements of WIPP-WAC and TRAMPAC certification.

Experience at INEL indicates two-percent of the radiography-certified waste containers have been miscertified when compared to the results of visual examination (EG\&G 1994a). Participating sites must use this historical miscertification rate and incorporate future miscertification rates to calculate the number of waste containers that must be visually examined during the first year of Program activities. Once a site-specific miscertification rate can be determined, that miscertification rate must be used to determine the number of waste containers that must be visually examined. This miscertification rate must be determined each year based on results of certification activities over a minimum of 12 months. Table 5-1 provides the number of waste containers that must be visually examined for several miscertification rates and waste container population sizes.

Table 5-1 has been developed with the use of an EG\&G Idaho, Inc. engineering design file (EG\&G 1994a). The number of waste containers requiring visual examination will ensure the Program is 80-percent confident that if the true miscertification rate is the same as the percent in the column heading of Table 5-1 and if the indicated number of waste containers is examined, the $U_{C L_{g o}}$ of the miscertification percentage will be less than 14 percent (i.e., there is only a 10-percent chance that the miscertification rate is greater than 14 percent). If the number of containers listed in Table 5-1 are visually examined, it is simply guaranteed that the $\mathrm{UCL}_{90}$ of the miscertification percentage will be less than 14 percent; 14 percent is a worst case. In actuality, when $U \mathrm{UCL}_{90}$ s have been calculated from sample data, most of them will be much smaller than 14 percent. 
TABLE 5-1

Number of Waste Containers Requiring Visual Examination

\begin{tabular}{ccccccc}
\hline $\begin{array}{c}\text { Annual Number of Waste } \\
\text { Containers Undergoing } \\
\text { Characterization }\end{array}$ & $\begin{array}{c}\text { Number of Waste Containers Requiring Visual Examination } \\
\text { Based on Percent of Waste Containers Miscertified to } \\
\text { WIPP-WAC by Radiography in Previous Year(s) }\end{array}$ \\
\hline 50 & $1 \%$ & $2 \%$ & $3 \%$ & $4 \%$ & $5 \%$ & $6 \%$ \\
\hline 100 & $22^{a}$ & 22 & $22^{\text {a }}$ & 22 & $29^{a}$ & 29 \\
200 & 15 & 24 & 24 & 33 & 33 & 41 \\
300 & 15 & 26 & 26 & 35 & 44 & 52 \\
400 & 15 & 26 & 26 & 35 & 44 & 53 \\
500 & 15 & 26 & 26 & 36 & 45 & 62 \\
\hline
\end{tabular}

a Number of containers for the higher even-number percent of miscertified containers is used because an odd percent implies a noninteger number of containers are likely to be miscertified. 
To determine the number of waste containers requiring visual examination, the following assumptions are necessary:

- Waste containers were randomiy selected, placed in storage, retrieved, and examined. This random process ensures that a representative sample of waste containers is obtained.

- Only waste containers certified for compliance with WIPP-WAC and TRAMPAC will be selected.

- There is a definable finite population of waste containers for which the proportion miscertified is to be estimated (e.g., 200 drums).

- The percent of the waste containers that will be properly certified is based on site experience with the certification program or 98 percent if no site experience is available (first year only).

- The certification process is uniform for all waste containers and is therefore unbiased regardless of waste stream.

- The radiography system is functioning properly and is operated by qualified personnel.

The two-percent rate is used in the first year to ensure a required minimum of containers are opened and visually examined the first year. The project manager must evaluate whether or not the assumed miscertification rate (two percent in the first year) is consistent with the miscertification rate observed during visual examination. If the assumed rate is inconsistent with the observed rate, Table 5-1 will be consulted to determine whether additional containers must be visually examined. The requirement will hold for each yearly selection of containers for visual examination.

As stated in the assumptions above, the sampling effort is to estimate a proportion in a finite population. The number of containers to be selected for visual examination in Table 5-1 is based on the hypergeometric probability distribution (Johnson and Kotz 1969; Kupper and Hafner 1989; Department of Defense 1989). The acceptable level of uncertainty in the estimate of the proportion (along with the information on the previous percentage miscertified) determines the number of waste containers that must be examined. A detailed description of the method for determining the number of containers to be examined is given in Appendix $A$.

The hypergeometric probability distribution is a result of sampling to estimate a proportion from a finite population. Because it is easier to use, the normal distribution is sometimes used as an approximation to the hypergeometric probability distribution to estimate confidence limits and sample sizes in applications such as this. However, in this case, because the expected proportions are so small, the normal approximation should not be used as it will produce erroneous results. For a large $N$, say 500 
or more, the binomial distribution may be used with little error added. The binomial distribution is still more difficult to work with than the normal distribution, but may be easier than the hypergeometric probability distribution.

\subsubsection{Characterization of Newly Generated Homogenous Solids, Soil/Gravel, Debris Wastes, and Special Waste}

Newly generated waste streams of homogenous solids and soil/gravel must be randomly sampled once per year or once per process batch. Sampling frequency of once per year is only allowed if a process has operated within established and documented administrative controls. Otherwise the waste must be considered as process batches. Site QAPjPs and SOPs must document the newly generated waste stream sampling methods, which must be consistent with those required by this QAPP and methods described in SW-846. Analysis of newly generated waste samples must be performed in accordance with the requirements of this QAPP. RCRA waste characterization of newly generated debris wastes and special waste shall be accomplished using acceptable knowledge.

In order to avoid the requirement of performing radiography on newly generated waste, sites must document and verify the matrix parameter category and waste material parameter weights prior to or during waste packaging operations. Verification is accomplished by a second, qualified and independent operator reviewing the contents of the waste container to ensure they are reported correctly. The second operator shall document this verification by signing the reporting form. 


\subsection{SAMPLE HANDLING AND CUSTODY REQUIREMENTS}

In order to ensure that the Program-generated data meet accepted standards for legal admissability and defensibility, field logs, sample labels, and chain-of-custody $(\mathrm{COC})$ forms must be maintained and samples properly handled throughout the waste characterization process. These practices shall be documented in QAPjPs, implemented by SOPs, and must be in accordance with EPA guidelines as prescribed in NEIC policies and procedures (EPA 1991a).

\subsection{Field Documentation}

Field personnel must record information pertinent to the collection of samples and document modifications to planned sampling activities. The field documentation procedures must comply with the requirements specified in this section.

All information pertinent to field sampling shall be recorded. Records shall be dated and signed by the individual who made the entry. Entries must be legible and contain only facts and observations. Language should be objective, factual, and free of speculation.

At a minimum, the following information must be recorded:

- Name of sampling facility

- Waste container identification number

- Sample identification number of each sample referenced to the waste container from which it was collected

- Type of sample (e.g., gas, solid)

- Type of sampling equipment used (e.g., manifold, direct canister, syringe)

- Time and date of sample collection

- Quantity of sample collected

- Type of sample container used (e.g., $40 \mathrm{~mL}$ VOA vial) and the equipment cleaning batch or manufacturer's lot number assigned to that container

- Sample preservatives used (e.g., $\left.\mathrm{HCl}, 4^{\circ} \mathrm{C}\right)$

- Analysis requested

- QC designation, if applicable (e.g., equipment blank, field reference standard)

- COC record number 
- Analytical laboratory requested to perform the analysis

- Shipping information (e.g., date, time, shipper, mode of shipment)

- Sampler's name

- SOP document number and revision

- Real-time instrument readings, if applicable (e.g., OVA's ppmv indication)

- Comments pertinent to sampling activities

Additional information, specific to headspace gas sampling, that must be recorded includes:

- Ambient temperature and pressure measurements at the time of sample collection

- Sample identification number correlated to the innermost layer of confinement, if applicable

- Canister pressures before and after sampie collection

Additional information, specific to sampling homogenous solids and soil/gravel, that must be recorded includes:

- Coring tool identification

- Randomly selecting coring location

- Depth of waste and core recovery

- Visual observations of waste and recovered core

- Randomly selected sample location

This information shall be maintained in accordance with the requirements specified in Section 1.7.

\subsection{Labeling}

Site QAPjPs must describe the conventions for assigning unique identification numbers to all waste containers and samples included in the Program. The site numbering conventions must comply with the requirements included in this section.

\subsubsection{Waste Container Labeling}

For waste containers with pre-existing labels, the pre-existing identification numbers shall be used. A label containing an eight-digit identification number shall be affixed to each waste container (i.e., 208-liter (55-gallon) drum, standard waste box, metal storage boxes). The first two digits in the identification number shall be alpha characters identifying the site. The alpha characters shall be followed by six numeric characters unique to each waste container. For example, ID000001 corresponds to a waste container originating from the Idaho National Engineering Laboratory. 


\subsubsection{Innermost Layer of Confinement}

Innermost layers of confinement must be consecutively numbered, and labeled starting with 1, as they are sampled and removed from the waste container. The sample collected from each innermost layer of confinement must be referenced to that particular innermost layer of confinement and to the waste container.

\subsubsection{Headspace Gas Sample Containers}

Each SUMMA' canister used to collect samples of headspace gas must be inscribed with a five-digit canister identification number that is unique to the Program and labeled with a canister tag as described below. It is recommended that the canister identification number begin with two alpha characters that can be used to identify the laboratory that purchased the canister. These alpha characters should be followed by three numeric characters which may increase sequentially with each canister purchased.

\section{Canister Tags}

Canister tags shall be used to document the physical existence of a sample and certification after cleaning for the project file. A removable canister tag must be securely attached to each field and field OC sample canister prior to shipment to the field. All information recorded on the tag must be made in permanent ink. The completed canister tag will be removed by the analytical laboratory and placed in the site project file. An example of a canister tag is provided in Figure 6-1.

Site QAPjPs shall include a copy of the canister tags used in the Program. These completed tags, or documents traceable to the canister, must include the following:

- Sample identification number (13 digits, as described later in this section)

- Sampler's initials

- Ambient temperature and pressure $\left({ }^{\circ} \mathrm{C}\right.$ and $\mathrm{mm} \mathrm{Hg}$, respectively)

- Sampling organization

- Sample description

- Comment section

- Requested analyses

- Date and time of sample collection

- Designation of whether the sample is a blank 


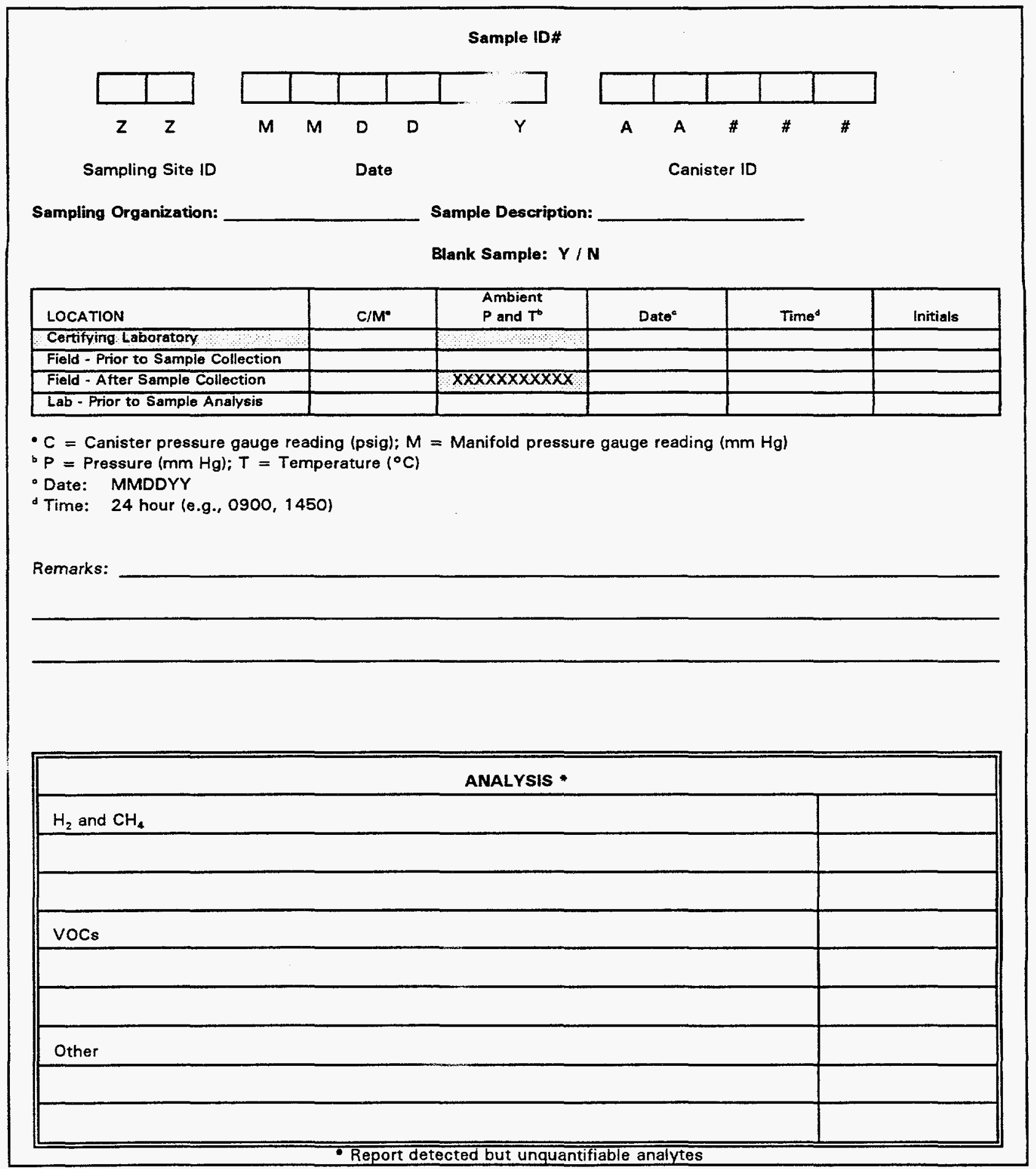

FIGURE 6-1

Gas Sample Canister Tag

EXAMPLE ONLY 
The QAPjP must describe a system for documenting sampling and canister conditions as follows:

- After cleaning, canister pressure must be recorded by the certifying laboratory. The final pressures must be recorded for the manifold gauge and the canister gauge.

- Canister gauge and sampling manifold pressures must be recorded in the field immediately prior to and after sample collection.

- In the analytical laboratory, canisters must be thermally equilibrated to laboratory ambient temperature for a minimum of 24 hours prior to measurement of their pressure, and canister pressure must be measured and recorded on the canister tag, or documents traceable to the canister, immediately prior to sample preparation or analysis.

- In the analytical laboratory, ambient temperature must be measured and recorded on the canister tag, or documents traceable to the canister, immediately prior to sample preparation or analysis.

- Date, time, and initials of the responsible individual must be documented for each of the above-mentioned measurements.

These documentation requirements may be met through the use of the example tag provided (Figure 6-1), or through other documentation as described in a site QAPjP.

\section{Sample Identification Number}

Each sample must be assigned a unique identification number. Thirteen-digit canister sample identification numbers shall be assigned in the following format:
$\mathrm{ZZ}$
MMDDYY
AA\#\#\#
sampling site identification
date
canister identification

where $Z Z$ is a two-digit alpha character that designates the sampling site le.g., IE for Idaho National Engineering Laboratory or RF for Rocky Flats Plant), MMDDYY are numeric characters corresponding to the sampling date (in month-day-year format), and AA\#\#\# is the alpha-numeric canister identification number inscribed on, or permanently attached to, the sample canister. For example, IE 031595 AW005 would uniquely specify a headspace sample collected at the Idaho National Engineering Laboratory on March 15, 1995, in SUMMA ${ }^{\oplus}$ canister number AWO05.

\subsubsection{Homogenous Solids and Soil/Gravel Sample Containers}

A twelve-digit sample identification number must be assigned to each sample of homogenous solids and soil/gravel collected. The sample identification number must have the following format: 12 alpha-numeric characters; two alpha characters must designate the sampling site (ZZ), and the remaining ten numeric characters must indicate the chronological sequence of homogenous solids and 
soil/gravel sample collection (\#\#\#\#\#\#\#\#). Sampling facilities shall determine two alpha characters (ZZ) to identify their facility, verify that these characters are unique in the DOE complex, and submit this identification to CAO for approval.

A sample label (Figure 6-2) must be affixed to each individual sample of homogenous solids and soil/gravel collected. The following information must be recorded in permanent ink on each sample label:

- Applicable waste container identification number

- Sample identification number

- Time and date of sample collection

- Type and number of sample containers

- Sample preservatives

- Analysis requested

- Sampler's initials

- Remarks

\subsection{Chain-of-Custody}

A waste container or sample will be considered under effective custody control if it is sealed (i.e., unopened) with the custody seal intact, and one or more of the following are true:

- It is in the possession of an authorized individual

- It is in the view of an authorized individual, after being in the possession of that individual

- It was in the possession of an authorized individual, and access to the sample(s) was controlled by locking or placement of signed custody seals that prevent undetected access

- It is in a designated secure area, such as a controlled access location with complete documentation of personnel access or a radiolos l containment area (hot cell or glove box)

Whenever a transfer of custody takes place, both parties must sign and date a COC form, with the relinquishing party retaining a copy of the form. The party that accepts custody must inspect the custody form and all accompanying documentation (e.g., custody seals, sample tags, shipping forms) to ensure that the information is complete and accurate. The custodian must also inspect all waste containers and samples for signs of damage or tampering. Any discrepancies in information, signs of damage, or tampering must be documented on a noncor mance report and on the COC form by the receiving custodian. The original $C O C$ forms shall be maintained in the site project files. 
SAMPLE ID:

ANALYSIS REQUESTED:

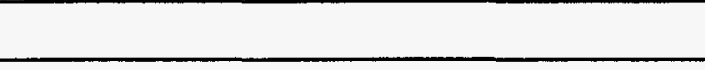

EQUIPMENT CLEANING BATCH NUMBER OR MANUFACTURER'S LOT NUMBER

REMARKS:
LABORATORY ID:

(for lab use only)

DATE SAMPLED:

TIME SAMPLED:

PRESERVATIVE:

SAMPLER'S INITIALS:

FIGURE 6-2

Homogenous Solids and Soil/Gravel Sample Container Label EXAMPLE ONLY 


\subsubsection{Waste Container}

$\mathrm{COC}$ on individual waste containers shall be initiated at the time the waste containers are removed from stored inventories or at the time of generation and closure for newly generated waste. Waste container custody must be maintained until the waste container is properly emplaced at the WIPP facility. An example waste container $\mathrm{COC}$ form is provided in Figure 6-3. Site QAPjPs must include copies of forms used to document waste container $\mathrm{COC}$; these forms shall inciude provisions for each of the following:

- Signature of the individual initiating custody control, along with the date and time

- The waste container number for the waste container under custody

- Signatures of custodians relinquishing and receiving custody, along with the date and time of the transfer

- Description of final waste container disposition, along with signature of individual removing waste container from custody

- Comment section

- COC number

\subsubsection{Sample Containers}

COC on field samples (including field $Q C$ samples) shall be initiated immediately after sample collection or preparation. Sample custody must be maintained until the associated analyses are completed and the data have been validated at the project level (Section 3.1.2). Sample custody shall be maintained until the sample is expended or until the sample is removed from the Program. An example COC form for samples is provided in Figure 6-4. Site QAPjPs must include a copy of the sample COC form; this form shall include provisions for each of the following:

- Signature of individual initiating custody co:trol, along with the date and time

- Documentation of sample numbers for each sample under custody

- Signatures of custodians relinquishing and receiving custody, along with date and time of the transfer

- Description of final waste container disposition, along with signature of individual removing waste container $f$ custody

- Comment section 


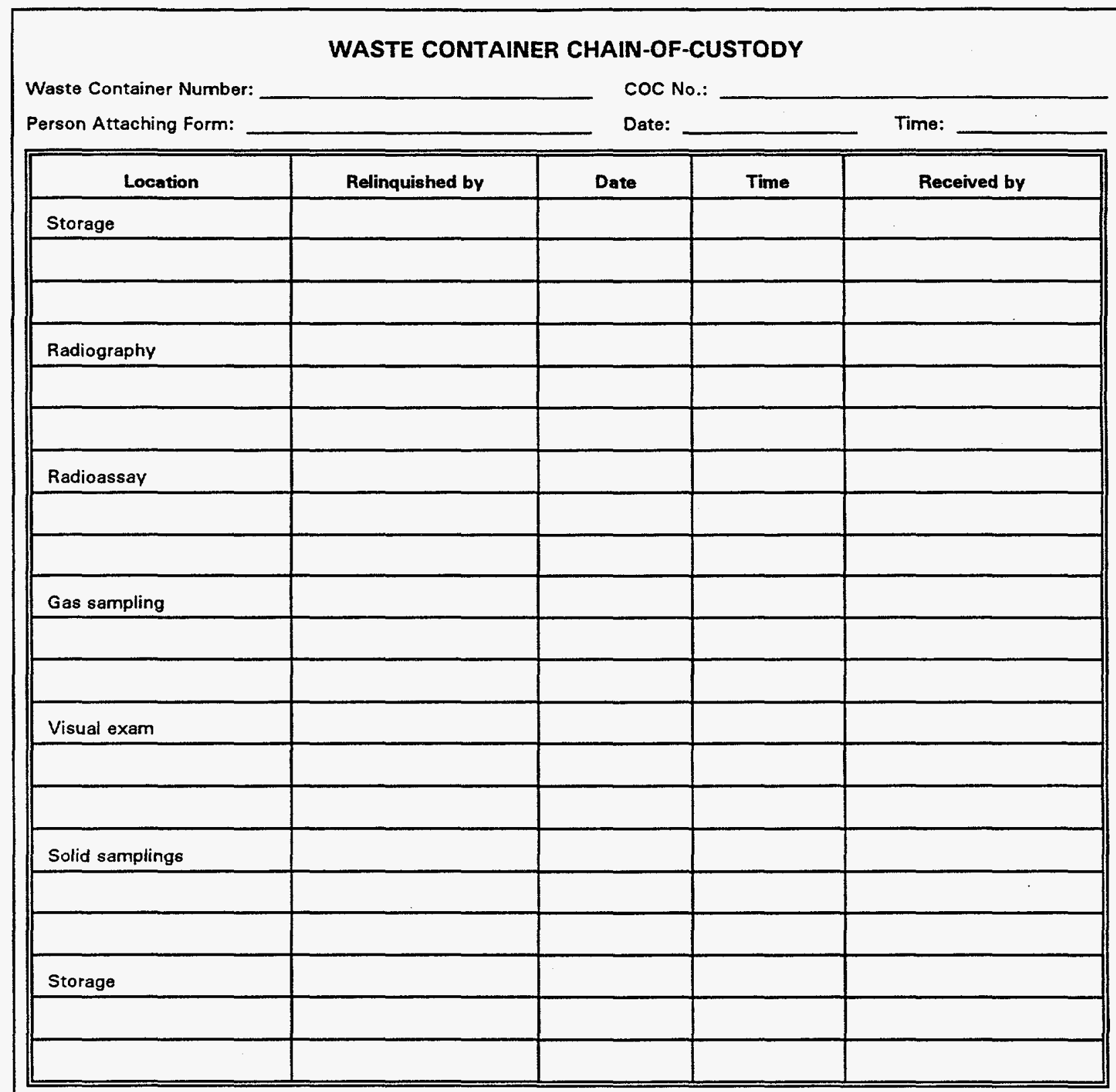

Comments (note any discrepancies):

Disposition: 
Sampling Site:

Waste Container No.:

Date:

Disposition:

Comments (note any discrepancies):

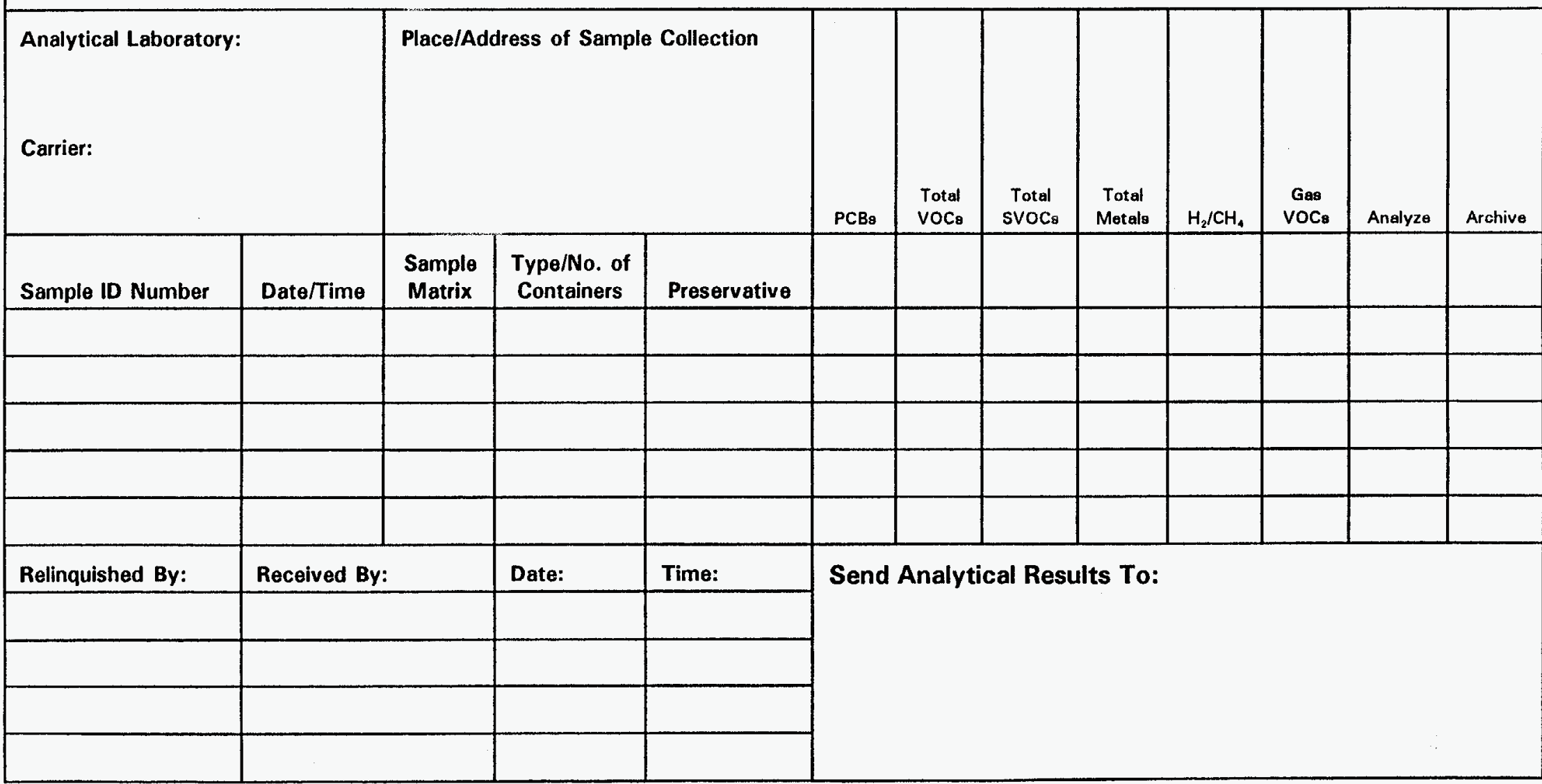

FIGURE 6-4

Sample Chain-of-Custody Form

EXAMPLE ONLY

Project Contact:
爵营要

$\overrightarrow{0}+\stackrel{9}{?}$

응

$\vec{\forall}$ 


\subsection{Handing}

Waste containers and samples must be handled in accordance with the requirements described below as implemented by site SOPs. These requirements include minimum sample quantity required, type of sample containers to be used, sample preservation requirements, and maximum allowable holding times. Procedures for handling waste containers and samples prior to shipment to the analytical laboratory and for tracking them throughout the sampling program are also described.

\subsubsection{Waste Container}

Waste containers and their contents must be allowed to equilibrate to the temperature of the sampling area. The equilibrium period must be, at a minimum, 72 hours prior to sampling. To assure waste characterization data are collected that will represent waste characteristics in the WIPP repository, waste containers must be characterized at temperatures in the range of $18^{\circ} \mathrm{C}$ to $29^{\circ} \mathrm{C}$.

\subsubsection{Gas Sample Container}

Gas samples must be collected in SUMMA' passivated sample canisters and promptly transferred to the responsible laboratory. Sample holding times and storage conditions must conform to the requirements specified in Table 6-1. An overall holding time of 34 days (four days field holding time plus two days transfer shipping allowance plus 28 days laboratory holding time) is required to expedite the sampling and analytical process. Headspace samples must not be retained at the sampling site longer than four days.

Based on data obtained on ambient air samples and mixed gas standards, it is anticipated that headspace samples will be stable longer than the specified holding times. The programmatic 28-day holding time and storage temperature for $\mathrm{VOC}$ analysis is also required for hydrogen and methane to ensure uniform sample treatment and to simplify program operations. Headspace samples must be kept between $0^{\circ} \mathrm{C}$ and $40^{\circ} \mathrm{C}$; and must be shipped from the sampling site to the laboratories using the fastest means available. All headspace samples must be handled in accordance with the COC requirements outlined in Section 6.3. A signed and dated custody seal must be affixed to each shipment container and installed across the container lid and body to provide visual evidence of tampering. An example custody seal is provided in Figure 6-5.

\subsubsection{Homogenous Solids and Soil/Gravel Sample Container}

Handling requirements for samples of homogenous solids and soil/gravel must conform to the requirements for sample quantity, container, preservation, and holding time specified in Table 6-2. The sample quantities provided are the minimum amount that must be collected for each parameter per 
TABLE 6-1

\section{Gas Sample Containers and Holding Times}

\begin{tabular}{|c|c|c|c|c|c|c|}
\hline Parameter & Container & $\begin{array}{c}\text { Minimum } \\
\text { Drum } \\
\text { Headspace } \\
\text { Sample } \\
\text { Volume }^{\mathbf{a}}\end{array}$ & $\begin{array}{c}\text { Holding } \\
\text { Temperatures }\end{array}$ & $\begin{array}{c}\text { Field } \\
\text { Holding } \\
\text { Time }^{b}\end{array}$ & $\begin{array}{l}\text { Shipping } \\
\text { Allowance }\end{array}$ & $\begin{array}{c}\text { Laboratory } \\
\text { Holding } \\
\text { Time }^{c}\end{array}$ \\
\hline $\mathrm{H}_{2}, \mathrm{CH}_{4}$ & $\begin{array}{l}\text { SUMMA } \\
\text { Canister }\end{array}$ & $\begin{array}{c}100 \\
\text { milliliters }\end{array}$ & $0-40^{\circ} \mathrm{C}$ & 4 days & 2 days & 28 days \\
\hline VOCs & $\begin{array}{l}\text { SUMMA' } \\
\text { Canister }\end{array}$ & $\begin{array}{c}250 \\
\text { milliititers }\end{array}$ & $0-40^{\circ} \mathrm{C}$ & 4 days & 2 days & 28 days \\
\hline
\end{tabular}

aAlternatively, if available headspace is limited, a single $100 \mathrm{~mL}$ sample may be collected for determination of VOCs, $\mathrm{H}_{2}$, and $\mathrm{CH}_{4}$.

bFrom time of headspace sample collection to shipment.

'Programmatic-based maximum holding time. Holding time begins at VTSR. 
DATE:

FIGURE 6-5

Sample Custody Seal

EXAMPLE ONLY 
TABLE 6-2

Sample Handling Requirements for Homogenous Solids and Soil/Gravel

\begin{tabular}{|c|c|c|c|c|}
\hline Parameter & $\begin{array}{l}\text { Minimum Quantity } \\
\text { Required }\end{array}$ & Preservative & Container & $\begin{array}{l}\text { Holding } \\
\text { Time }^{a}\end{array}$ \\
\hline VOCs & 15 Grams & Cool to $4^{\circ} \mathrm{C}$ & Glass Vial ${ }^{b}$ & $\begin{array}{c}14 \text { Days Prep/ } \\
40 \text { Days Analyze }\end{array}$ \\
\hline SVOCs & 50 Grams & Cool to $4^{\circ} \mathrm{C}$ & Glass Jar ${ }^{d}$ & $\begin{array}{l}14 \text { Days Prep/ } \\
40 \text { Days Analyze }\end{array}$ \\
\hline $\begin{array}{l}\text { Polychlorinated Biphenyls } \\
\text { (PCBs) }^{e}\end{array}$ & 50 Grams & Cool to $4^{\circ} \mathrm{C}$ & Glass Jar ${ }^{d}$ & $\begin{array}{l}14 \text { Days Prep/ } \\
40 \text { Days Analyze }\end{array}$ \\
\hline Metals & 10 Grams & Cool to $4^{\circ} \mathrm{C}$ & Plastic Jarf & 180 Days $^{\theta}$ \\
\hline
\end{tabular}

a Holding time begins at sample collection (holding times are consistent with SW-846 requirements).

${ }^{b} 40 \mathrm{~mL}$ VOA vial, must have septum cap.

‘40-day holding time allowable only for methanol extract -- 14-day holding time for non-extracted VOCs.

${ }^{d} 250 \mathrm{~mL}$ amber jar, must have Teflon ${ }^{\oplus}$ lined cap.

${ }^{\circ}$ Analysis for PCBs is required only for waste streams in matrix parameter category 53220 (organic sludges).

t $250 \mathrm{~mL}$ polyethylene or polypropylene.

gholding time for mercury analysis is 28 days. 
sample. Additional sample quantities should be collected for $O C$ samples. Samples to be shipped to the laboratory for analysis must be kept at a temperature of $4^{\circ} \mathrm{C}\left( \pm 2^{\circ} \mathrm{C}\right)$ from the time of collection through the transport of samples to the laboratory.

Prior to shipment of samples to the laboratory, sample jars should be wrapped in plastic such as bubble wrap to prevent breakage, and placed in a cooler or other appropriate container for shipment. The sample COC forms must be placed in a waterproof plastic bag and taped to the underside of the shipment container lid. If more than one shipment container is being used, documentation should be placed in the same container as the samples listed on that documentation. A trip blank must be included in each shipment container containing samples for VOC analysis. The trip blank must travel with the VOC sample containers from the point of sample container preparation, through shipment to the sampling facility, and through shipment of the samples to the analytical laboratory. A signed and dated custody seal must be affixed to each shipment container and installed across the container lid and body to provide visual evidence of tampering. An example custody seal is provided in Figure 6-5. Implementation of waste container and sample tracking requirements must begin in the planning stage of the sampling program. The tracking system to monitor the location and status of waste containers and samples on a routine basis is the responsibility of each site project manager. Figure 6-6 is an example of a waste container tracking log sheet that may be used for this purpose. Sample tracking procedures shall also be implemented by the site project manager and documented in the site QAPjP. The procedure must outline the flow of information between parties responsible for sample acquisition, sample analysis, data validation, data storage, data evaluation, and data use. An example sample tracking log sheet is provided in Figure 6-7.

Participating laboratories must have a documented sample custody program that includes procedures for sample receiving and log-in, sample storage and numbering, sample tracking in the laboratory, and storage of laboratory data. At a minimum, this program must include written procedures for the following:

- Chronological sample number sequencing

- Sample log-in (including determination of proper sample preservation)

- Identification of sample custodian

- Internal sample numbering and tracking systems

- Transfers of custody within the laboratory

- Example custody forms with instructions for use

- Sample storage

- Sample disposal

- Analytical data maintenance and custody 


\section{WASTE CONTAINER TRACKING LOG SHEET}

Waste Container Number:

\begin{tabular}{|l|l|l|l||}
\hline \multicolumn{1}{|c|}{ Operation } & \multicolumn{1}{|c|}{ Date } & \multicolumn{1}{c|}{ Time } & Initials \\
\hline Removed from storage & & & \\
\hline Transported to radiography & & & \\
\hline Radiography performed & & & \\
\hline Transpc ted to radioassay & & & \\
\hline Radioassay performed & & & \\
\hline Transported to gas sampling & & & \\
\hline Gas sampling performed & & & \\
\hline Transported to visual & & & \\
\hline Visual examination performed & & & \\
\hline Transported to solid sampling & & & \\
\hline Solid sampling performed & & & \\
\hline
\end{tabular}

Comments (note any discrepancies):

FIGURE 6-6

Waste Container Tracking $\mathcal{L}$, Sheet

EXAMPLE ONLY 
SAMPLE TRACKING LOG SHEET

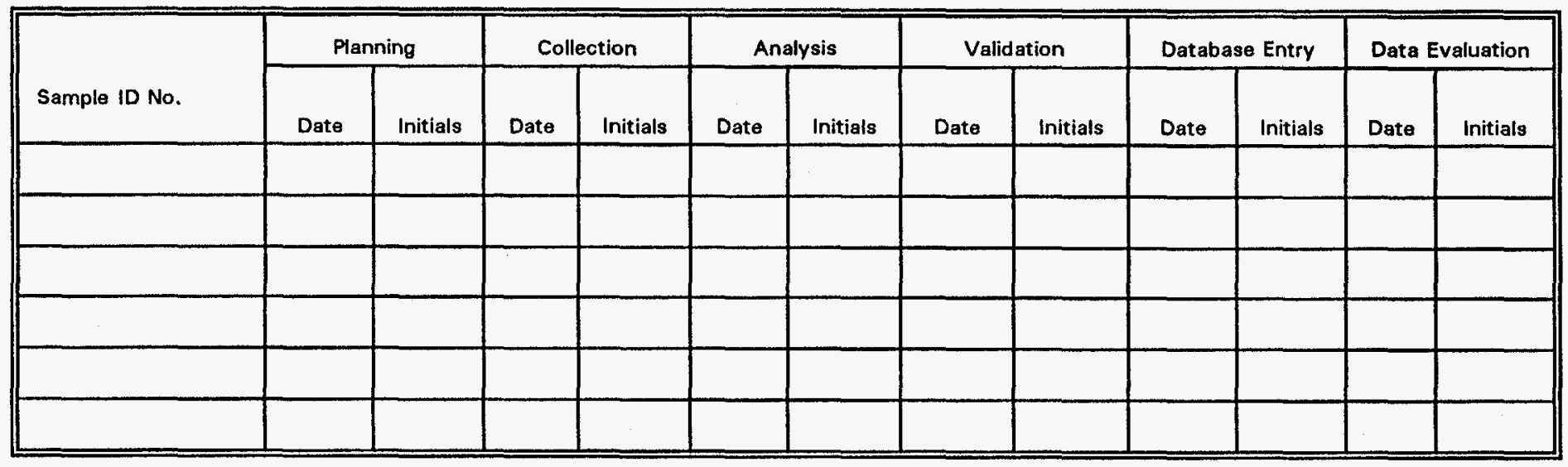

Comments (note any discrepancies):

FIGURE 6-7

Sample Tracking Log

EXAMPLE ONLY

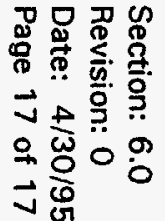




\subsection{HEADSPACE GAS SAMPLING}

This section describes minimum requirements for the collection of headspace gas samples using the headspace gas sampling methods described in the Methods Manual. This protocol is designed to ensure that representative headspace gas samples, including $O C$ samples, are consistently collected and transferred to the responsible laboratory in a manner that maintains their integrity. "Headspace gas" should be interpreted to mean hydrogen, methane, and the VOCs listed in Table 12-1 within a layer of confinement. These sampling requirements must be followed to collect representative samples from within TRU waste containers. Samples collected in accordance with this protocol must be handled as specified in Section 6.0 of this QAPP.

The TRU wastes to be sent to the WIPP facility are packaged in 208-liter (55-gallon) drums. Many contain 90 mil polyethylene liners as shown in Figure 7-1. Inside each liner is a 208-liter (55-gallon) poly bag that can contain waste items, residual materials, and/or packaging materials confined by several layers of plastic bags (Figure 7-1).

This protocol for sampling of the headspace gas within TRU waste drums is based on guidelines in EPA's Method TO-14 (EPA 1988a) and SW-846. As such, it is applicable to sampling the headspace gases in TRU waste drums containing waste in each of the matrix parameter categories described in the BIR. The method can be used for hydrogen, methane, and specific VOCs that are vapors at room temperature and pressure. It is based on the collection of headspace gas samples in SUMMA ${ }^{\circ}$ passivated canisters.

To accomplish headspace gas sampling, two SUMMA ${ }^{\circ}$ canister-based headspace sampling methods have been developed. The first of these uses a manifold, and is described in Section 7.2.1. The second, a direct canister method described in Section 7.2.2, employs a needle and filter attached directly to the SUMMA' sample canister. Participating sites have the option of using either the manifold or the direct canister methods, a combination of the two, or other equivalent methods for some or all layers of confinement and for collecting QC samples.

The following sections describe the equipment required to collect headspace gas samples from within drums of TRU waste. The manifold and direct canister methods both incorporate the use of SUMMA' canisters and are used when sampling each layer of confinement in the drum. Three different sampling heads are described allowing sampling through the drum lid carbon composite filter, through the drum lid itself, and through poly bags within the drum. 


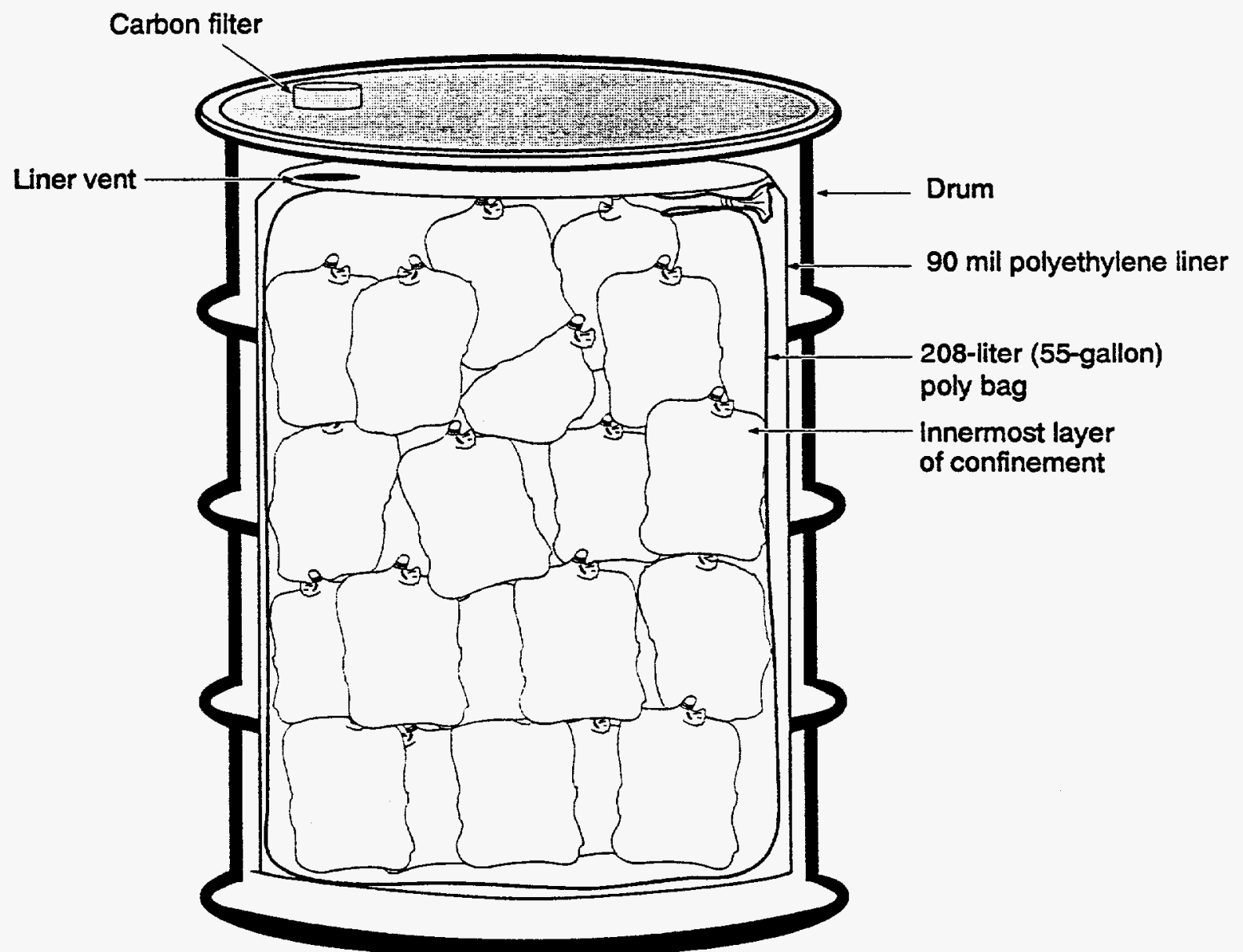

FIGURE 7-1

Schematic Diagram of Waste Drum with Minimum Layers of Confinement and Sampling Locations 


\subsection{Quality Assurance Objectives}

Headspace gas samples must be collected from three areas within drums of TRU waste (see Figure 7-2): 1) the drum headspace (i.e., the headspace directly under the drum lid), 2) the 208-liter (55-gallon) poly bag headspace, and 3) the headspace of the innermost layers of confinement. The precision and accuracy of the drum headspace gas sampling operations must be assessed by analyzing field OC headspace gas samples. These samples must include equipment blanks, field reference standards, field blanks, and field duplicates. Table 7-1 illustrates which classes of analytes are required for each type of sample collected. If the QAOs described below are not met, a nonconformance report must be prepared, submitted, and resolved (Section 2.1.2.1).

\section{Precision}

The precision of the headspace gas sampling and analysis operation must be assessed by simultaneous collection of field duplicates for VOCs, hydrogen, and methane determinations. Corrective actions must be taken if the RPD exceeds 25 percent.

\section{Accuracy}

A field reference standard must be collected using the headspace gas sampling equipment to assess the accuracy of the headspace gas sampling operation. Corrective action must be taken if the \%R of the field reference standard is less than 70 or greater than 130 .

\section{Completeness}

Sampling completeness shall be expressed as the number of valid samples collected as a percent of the total number of samples collected. Participating sampling facilities must achieve a minimum 90-percent completeness. The amount and type of data that may be lost during the headspace gas sampling operation cannot be predicted in advance. The importance of any lost or contaminated headspace gas samples must be evaluated by the site project $Q A$ officer and corrective action must be taken as appropriate.

\section{Comparability}

Consistent use and application of uniform procedures and equipment, as specified in the Methods Manual, should ensure that headspace gas sampling operations are comparable when sampling different layers of confinement and at the different sampling facilities. 

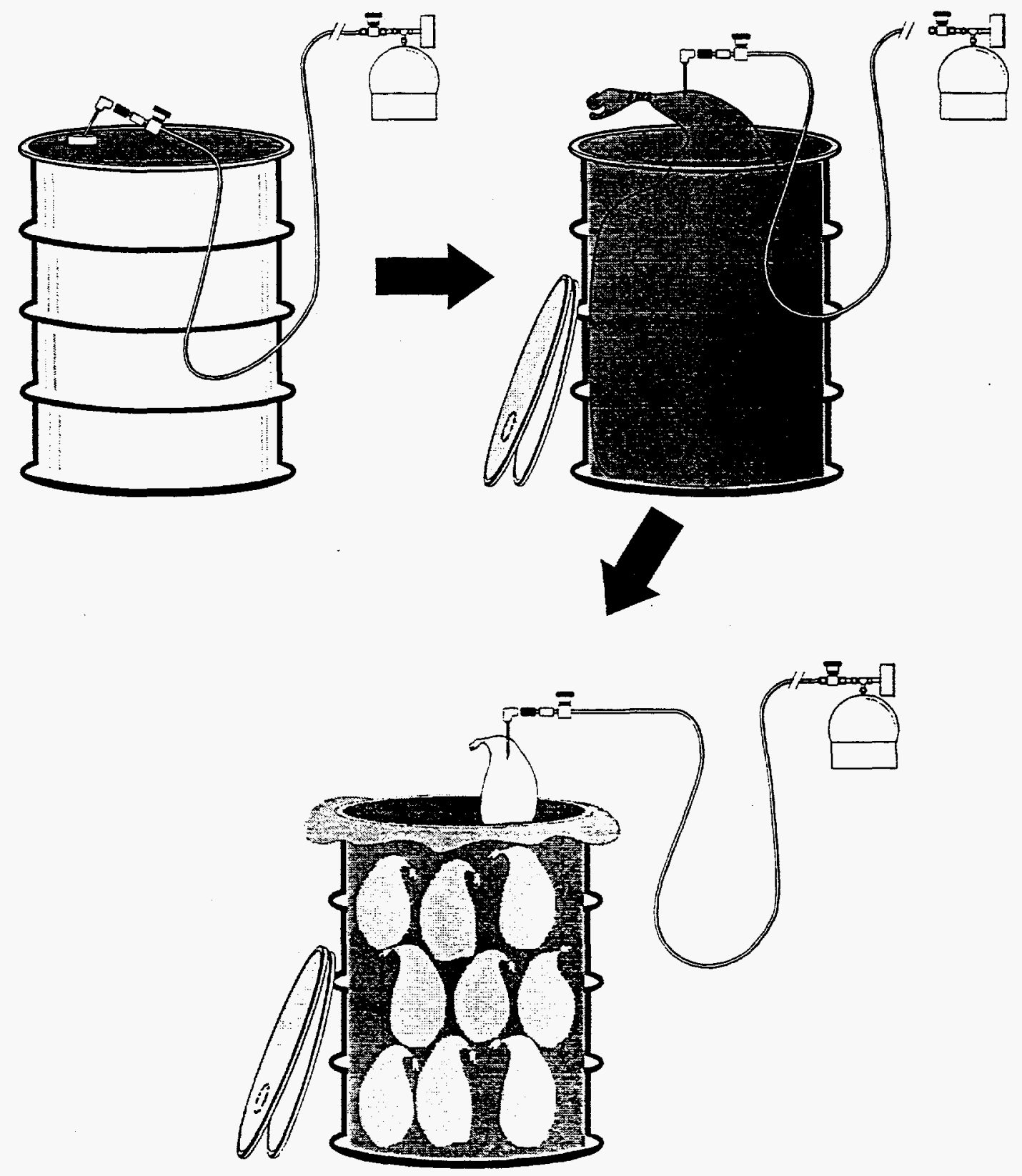

FIGURE 7-2

Overall Headspace Gas Sampling Scheme Illustrating Manifold Sampling 
TABLE 7-1

Analyses Required for Each Type of Headspace Sample Collected

\begin{tabular}{llll}
\hline Waste Container & Sample Type & $\mathrm{VOCs}^{\mathrm{a}}$ & $\mathrm{H}_{2}, \mathrm{CH}_{4}$ \\
\hline \multirow{3}{*}{ Drum } & Drum Lid & $\bullet$ & $\bullet$ \\
& $55-$ Gallon Poly Bag & $\bullet$ & $\bullet$ \\
& Innermost Layer of Confinement \\
& Field Duplicate \\
& Field Blank \\
& Equipment Blank \\
& Field Reference Standard & $\bullet$ & $\bullet$ \\
\hline
\end{tabular}

asee Table 12-1 


\section{Representativeness}

Specific headspace gas sampling steps to ensure samples are representative include

- Sample canister cleaning and leak check

- Sampling equipment cleaning or disposal after use

- Sampling equipment leak check

- Use of sample canisters with passivated internal surfaces

- Use of a low internal volume sampling equipment

- Collection of small sample volume: low sample volume to available headspace volume ratio

- Careful pressure regulation

- Performance audits

- Collection of equipment blanks, field reference standard, field blanks, and field duplicates

\subsection{Method Requirements}

Headspace gas samples for the determination of the analytes listed in Tables 11-1 and 12-1 must include those listed in Table 7-1. All sampling must be accomplished within a radiation containment area (e.g., glovebox, hot/warm cell). The configuration of the containment area and remote handling equipment at each sampling facility is expected to differ. A description of the containment area and remote handling equipment must be provided in the site QAPjP.

\subsubsection{Menifold}

This headspace gas sampling protocol employs a multiport manifold capable of collecting multiple simultaneous headspace samples for analysis and $\mathrm{QC}$ purposes. The sampling equipment must be leak checked and cleaned prior to first use and as needed thereafter. The manifold and sample canisters must be evacuated to $0.10 \mathrm{~mm} \mathrm{Hg}$ prior to sample collection. Cleaned and evacuated sample canisters must be attached to the evacuated manifold before the manifold inlet valve is opened. The manifold inlet valve must be attached to a changeable filter connected to different sampling head(s) depending on the layer of confinement to be sampled. The sampling head(s) must be capable of punching through the metal lid of the drum or penetrating a carbon composite filter, and puncturing poly bags.

The manifold must also be equipped with a purge assembly that allows equipment blanks, field reference standara, and field duplicates to be collected through the entire manifold, from the needle tip through all of the same manifold components that the drum headspace gas passes through. Field bianks shall be samples of room air collected in the sampling area in the immediate vicinity of the layer of confinement to be sampled. Field blanks are collected directly into the canister, without the use of the manifold.

The manifold, associated sampling heads, and the headspace gas sample volume requirements must be designed to ensure that a representative sample is collected. The manifold internal volume must 
be calculated and documented in the field logbook. The total volume of headspace gases collected during each sampling operation can be determined by adding the combined volume of the canisters attached to the manifold to the internal volume of the manifold. When an estimate of the available headspace gas volume can be made, less than 10 percent of that volume should be withdrawn.

As illustrated in Figure 7-3, the sampling manifold must consist of a sample side and a standard side. The dotted line indicates how the sample side shall be connected to the standard side for cleaning and collecting equipment blanks and field reference standards. The sample side must consist of the following major components:

- Applicable sampling head that forms a leak tight connection with the headspace sampling manifold.

- A flexible hose that allows movement of the sampling head from the purge assembly (standard side) to the waste container.

- A pressure sensor(s) that must be pneumatically connected to the manifold. This manifold pressure sensor(s) must be able to measure absolute pressure in the range from $0.05 \mathrm{~mm} \mathrm{Hg}$ to $1000 \mathrm{~mm} \mathrm{Hg}$. Resolution must be $\pm 0.005 \mathrm{~mm} \mathrm{Hg}$ at $0.05 \mathrm{~mm}$ of $\mathrm{Hg}$. The manifold pressure sensor(s) must have an operating range from approximately $15^{\circ} \mathrm{C}$ to $40^{\circ} \mathrm{C}$.

- Ports for attaching sample canisters. A sufficient number of ports must be available to allow simultaneous collection of headspace gas samples and duplicates for hydrogen, methane, and VOC analyses. Ports not occupied with sample canisters during cleaning or headspace gas sampling activities require a plug to prevent ambient air from entering the system. In place of using plugs, sites may choose to install valves that can be closed to prevent intrusion of ambient air into the manifold. Ports must have VCR fittings for connection to the sample canister(s) to prevent degradation of the fittings on the canisters and manifold.

- The sample canisters, as illustrated in Figure 7-4 must be leak-free welded stainless steel pressure vessels with a chromium-nickel oxide (Cr-NiO) SUMMA ${ }^{\infty}$ passivated interior surface, bellows valve, and a pressure/vacuum gauge. All sample canisters must have $V C R^{\oplus}$ fittings for connection to sampling and analytical equipment. The pressure/vacuum gauge must be mounted on each canister. It must be helium leak tested to $1.5 \times 10^{-7}$ standard $\mathrm{cc} / \mathrm{sec}$, have all stainless steel construction, and be capable of tolerating temperatures to $125^{\circ} \mathrm{C}$. The gauge range must be able to indicate from 30 psig pressure to a vacuum of 30 inches $\mathrm{Hg}$.

- A dry vacuum pump with the ability to reduce the pressure in the manifold to $0.05 \mathrm{~mm} \mathrm{Hg}$. A vacuum pump that requires oil may be used, but precautions must be taken to prevent diffusion of oil vapors back to the manifold. Precautions may include the use of a molecular sieve and a cryogenic trap in series between the headspace sampling ports and the pump.

- The distance between the tip of the needle and the valve that isolates the pump from the manifold must be minimized in order to minimize the dead volume in the manifold. The outer diameter of the system's tubing must be $1 / 8$-inch. 


\section{Sample Side}

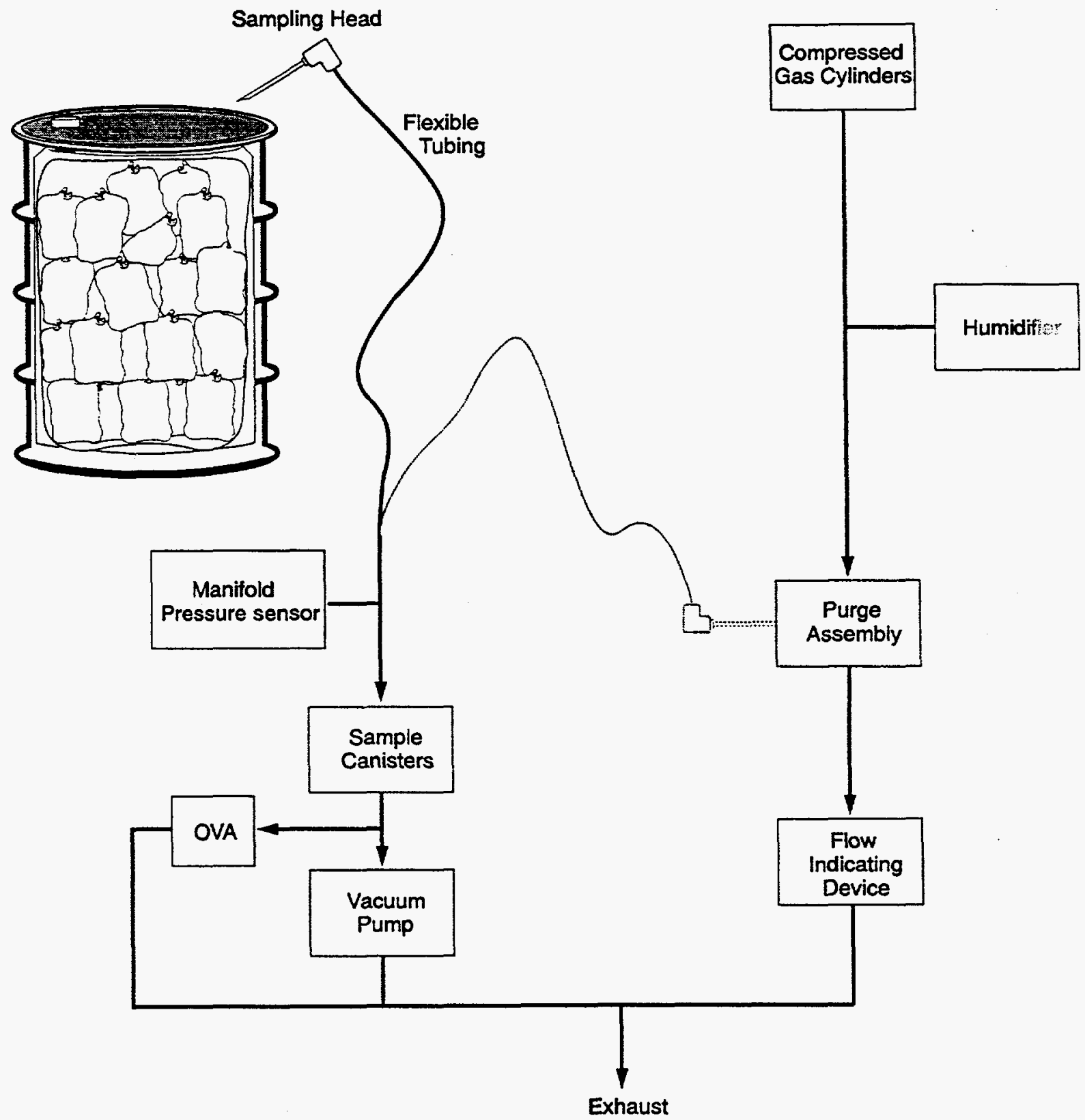

FIGURE 7-3

Headspace Sampling Manifold 
Revision: 0

Date: $4 / 30 / 95$

Page 9 of 23

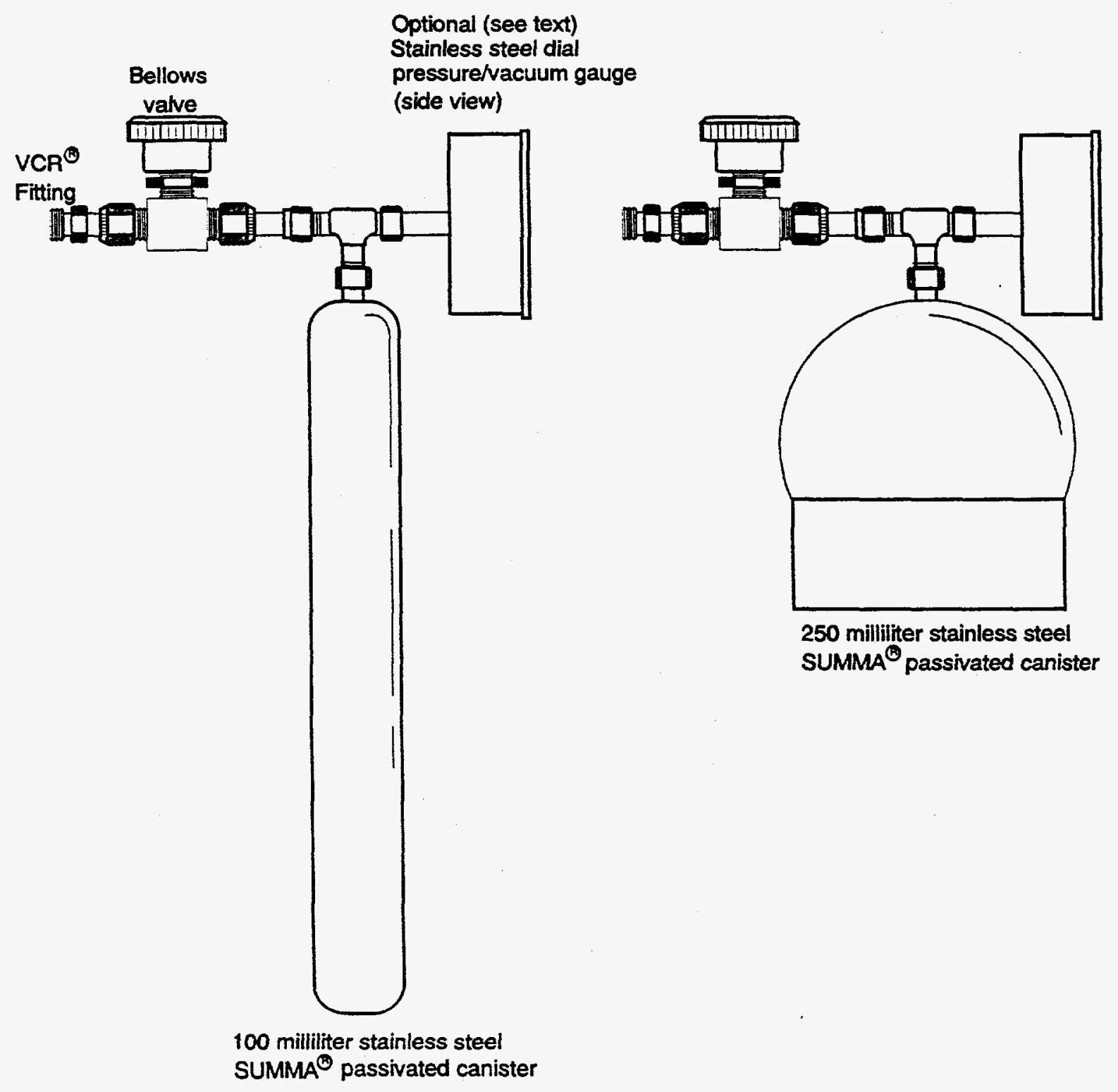

FIGURE 7-4

SUMMA ${ }^{\oplus}$ Canister Components Configuration

(Not to Scale) 
- An OVA capable of detecting all analytes listed in Table 12-1. The OVA must be capable of measuring total VOC concentrations as low as $0.1 \mathrm{ppm}$. Detection of 1,1,2-trichloro1,2,2-trifluoroethane may not be possible if a photoionization detector is used. The OVA measurement must be confirmed by the collection of equipment blanks at the frequency specified in Section 7.3 to check for manifold cleanliness.

The standard side must consist of the following major elements:

- A cylinder of compressed zero air, helium, or nitrogen to clean the manifold between samples and provide gas for the collection of equipment blanks. These high purity gases must be certified by the manufacturer to contain less than $1 \mathrm{ppm}$ total VOCs. The gases must be metered into the standard side of the manifold by two-stage stainless steel regulators. Alternatively, a zero air generator may be used provided a sample of the zero air is collected and demonstrated to contain less than $1 \mathrm{ppm}$ total VOCs. Zero air from a generator must be humidified.

- Cylinders of field reference standard gases. These cylinders provide gases for evaluating the accuracy of the headspace gas sampling process. Each cylinder of field reference gas must have a flow regulating device. The field reference standard gases must be certified by the manufacturer to contain known analytes at known concentrations.

- A humidifier filled with American Society for Testing and Materials (ASTM) Type II water, connected, and opened to the standard side of the manifold between the compressed gas cylinders and the purge assembly. Dry gases flowing to the purge assembly will pick up moisture from the humidifier. Moisture is added to the dry gases to condition the equipment blanks and field reference standards and to assist with system cleaning between headspace gas sample collection.

NOTE: Caution should be exercised to isolate the humidifier during the evacuation of the system to prevent flooding the manifold. In lieu of the humidifier, the compressed gas cylinders (e.g., zero air, field reference standard gas) may contain water vapor in the concentration range of 1,000 to $10,000 \mathrm{ppmv}$.

- A purge assembly which allows the sampling head (sample side) to be connected to the standard side of the manifold. The ability to make this connection is required to transfer gases from the compressed gas cylinders to the canisters. This connection is also required for system cleaning.

- A flow-indicating device connected downstream of the purge assembly to monitor the flow rate of gases through the purge assembly. The flow rate through the purge assembly must be monitored to assure that excess flow exists during cleaning activities and during equipment blank and field reference standard collection. Maintaining excess flow will prevent ambient air from contaminating the equipment blanks and field reference standards and allow samples of gas from the compressed gas cylinders to be collected near ambient pressure.

In addition to a manifold consisting of a sample side and a standard side, the area in which the manifold is operated must contain sensors for measuring ambient pressure and ambient temperature, as follows: 
- The ambient pressure sensor must have a sufficient measurement range for the ambient barometric pressures expected at the sampling location. It must be kept in the sampling area during sampling operations. Its resolution must be $1.0 \mathrm{~mm} \mathrm{Hg}$ or less, and calibration must be based on NIST, or equivalent, standards.

- The temperature sensor must have a sufficient measurement range for the ambient temperatures expected at the sampling location. The temperature sensor calibration must be traceable to NIST, or equivalent, standards.

\subsubsection{Direct Canister}

This headspace gas sampling protocol employs a canister sampling system to collect headspace gas samples for analysis and $Q C$ purposes without the use of the manifold described in Section 7.2.1. Rather than attaching the sampling heads discussed in Section 7.2.3 to a manifold, in this method the sampling heads are attached directly to an evacuated sample canister as shown in Figure 7-5.

Canisters must be evacuated to $0.10 \mathrm{~mm} \mathrm{Hg}$ prior to use and attached to a changeable filter connected to the appropriate sampling head, depending on the layer of confinement to be sampled. The sampling head(s) must be capable of punching through the metal lid of the drums and the rigid 90-mil liner, or penetrating a carbon composite filter to obtain the drum headspace samples, and puncturing poly bags. Field duplicates must be collected at the same time, in the same manner, and using the same type of sampling apparatus as used for headspace gas sample collection. Field blanks must be samples of room air collected in the immediate vicinity of the waste drum sampling area prior to removal of the drum lid. Equipment blanks and field reference standard must be collected using a purge assembly equivalent to the standard side of the manifold described in Section 7.2.1. These samples must be collected from the needle tip through the same components (e.g., needle, filter) that the headspace gas samples pass through.

The sample canisters, associated sampling heads, and the headspace sample volume requirements ensure that a representative sample is collected. When an estimate of the available headspace gas volume can be made, less than 10 percent of that volume should be withdrawn. A determination of the sampling head internal volume must be made and documented. The total volume of headspace gases collected during each headspace gas sampling operation can be determined by adding the volume of the sample canister(s) attached to the sampling head to the internal volume of the sampling head. Every effort must be made to minimize the internal volume of sampling heads.

Each sample canister used with the direct canister method must have a pressure/vacuum gauge able to indicate from 30 psig pressure to a vacuum of 30 inches $\mathrm{Hg}$. Canister gauges are intended to be gross leak-detection devices not vacuum certification devices. If a canister pressure/vacuum gauge 


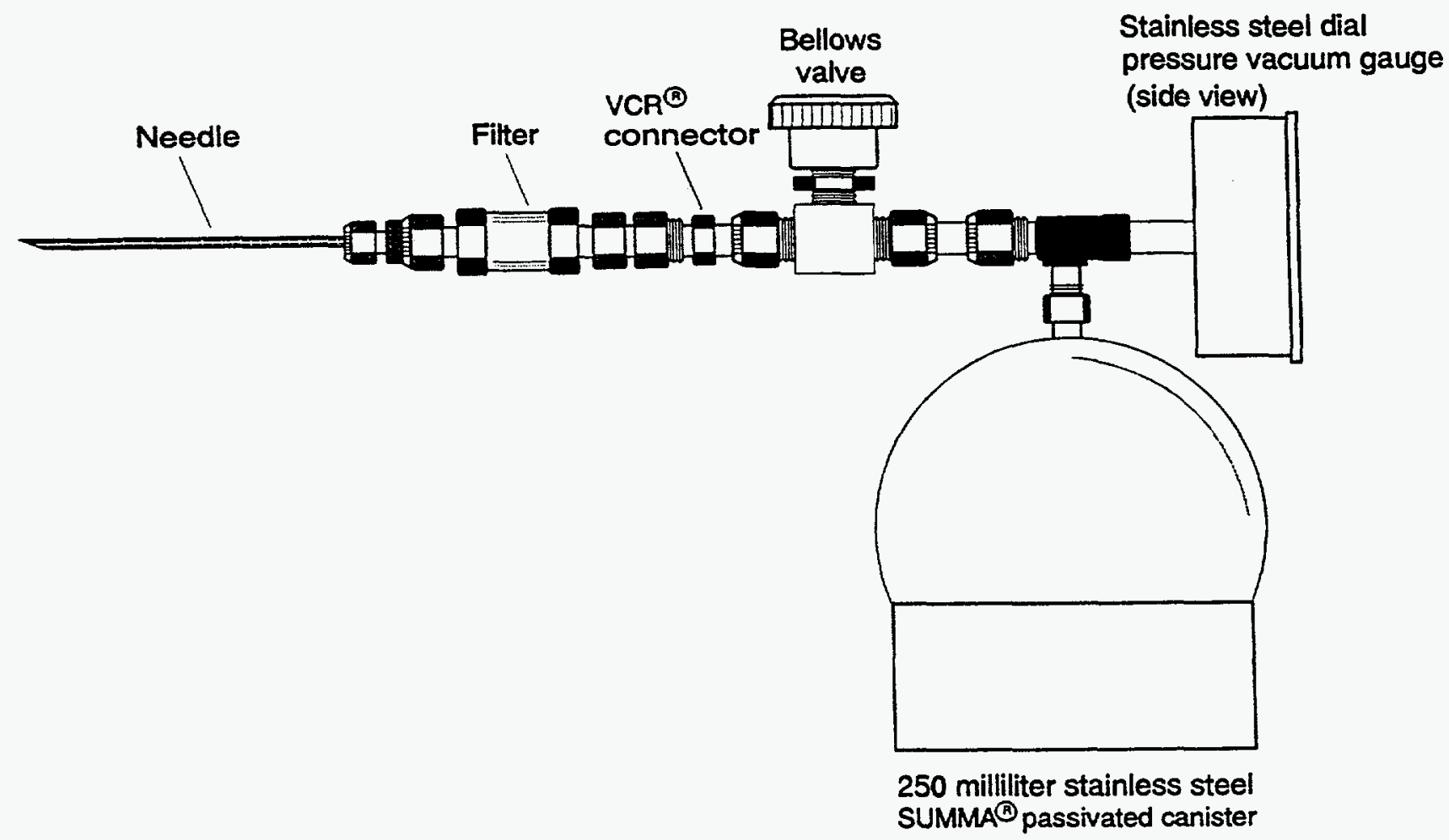

FIGURE 7-5

Schematic Diagram of Direct Canister with the Poly Bag Sampling Head 
indicates.an unexpected pressure change, refer to the Methods Manual to determine if the change is a result of ambient temperature and pressure differences or a canister leak. Prior to sampling, canisters must be evacuated to $0.10 \mathrm{~mm} \mathrm{Hg}$. This gauge must be helium leak tested to $1.5 \times 10^{-7}$ standard $\mathrm{cc} / \mathrm{sec}$, have all stainless steel construction, and be capable of tolerating temperatures to $125^{\circ} \mathrm{C}$.

The SUMMA ${ }^{\oplus}$ sample canisters must be used when sampling each layer of confinement in the drum. Three different sampling heads for attachment to the sample canister are described in Section 7.2.3. These heads must form a leak-tight connection with the canister and allow sampling through the drum lid carbon composite filter, through the drum lid itself and through the poly bags, both 208-liter (55-gallon) and innermost. Figure 7-5 illustrates the direct canister sampling equipment with the poly bag sampling head attached.

\subsubsection{Sampling Heads}

A sample of the headspace gas directly under the drum lid must be collected from within each drum. Two methods, sampling through the carbon filter and sampling through the drum lid, have been developed for collecting a representative sample.

\section{Sampling Through the Carbon Filter}

To sample the drum headspace gas through the drum's carbon composite filter, a side port needle (i.e., a hollow needle sealed at the tip with a small opening on its side close to the tip) must be pressed through the filter and into the headspace beneath the drum lid. This permits the gas to be drawn into the manifold or directly into canister(s). This procedure is described in detail in the Methods Manual and is specific to a type of carbon composite filter that permits insertion of the needle. To assure that the sample collected is representative, all of the general method requirements, sampling apparatus requirements, and $\mathrm{QC}$ requirements described in this section must be met in addition to the following requirements which are pertinent to drum headspace gas sampling through the carbon filter:

- The lid of the drum's 90 mil polyethylene liner must contain a hole for venting to the drum. If headspace gas samples are collected prior to venting the 90 mil liner, a nonconformance report must be prepared, submitted, and resolved (Section 2.1.2.1).

- For sample collection, the drum's carbon composite filter must be sealed as specified in Procedures 110.1 through 110.4 of the Methods Manual, or equivalent, to prevent outside air from entering the drum and diluting and/or contaminating the sample.

The sampling head for collecting drum headspace by penetrating the carbon composite filter must consist of a side port needle, a filter to prevent particles from contaminating the gas sample, and an adapter to connect the two. To prevent cross contamination, the sampling head must be cleaned or 
replaced after sample collection, after field reference standard collection, and after field blank collection. The following requirements must also be met:

- The housing of the carbon composite filter must allow insertion of the sampling needle through the filter element into the drum headspace.

- The side port needle must be used to reduce the potential for plugging.

- The purge assembly must be modified for compatibility with the side port needle.

\section{Sampling Through the Drum Lid}

Sampling through the drum lid, also described in the Methods Manual, must be performed when the drum's carbon composite filter does not permit insertion of the side port needle. To sample the drum headspace gas through the drum lid, the lid must be breached using a sparkless punch. The punch must form an airtight seal between the drum lid and the manifold or direct canister. To assure that the sample collected is representative, all of the general method requirements, sampling apparatus requirements, and $O C$ requirements must be met in addition to the following requirements:

- The seal between the drum lid and sampling head must be designed to minimize intrusion of ambient air.

- All components of the drum punch sampling system that come into contact with sample gases must be purged with humidified zero air, nitrogen, or helium prior to sample collection.

- Equipment blanks and field reference standards must be collected through all the components of the punch that contact the headspace gas sample.

- Pressure must be applied to the sparkless punch until the drum lid has been breached. Then the punch must be backed out to expose the headspace gas.

- Provisions must be made to relieve potential drum pressure increases during drum punch operations; pressure increases may occur during sealing of the drum punch to the drum lid.

- The lid of the drum's 90 mil polyethylene liner must contain a hole for venting to the drum. If headspace gas samples are collected prior to venting the 90 mil liner, a nonconformance report must be prepared, submitted, and resolved (Section 2.1.2.1).

- During sampling, the drum's carbon composite filter, if present, must be sealed to prevent outside air from entering the drum.

Sampling through the drum lid must be accomplished using the drum punch described in the Methods Manual, or equivalent. The same type of sampling head as used for the 208-liter (55-gallon) poly bag sampling must be pneumatically connected to the drum punch to provide a seal between the drum lid and the manifold or direct canister. The following requirements must also be met: 
- A flow indicating device to verify excess flow of $\mathrm{OC}$ gases must be pneumatically connected downstream of the drum punch and operated in the same manner as the flow indicating device described in Section 7.2.1.

- Equipment must be used adequately to secure the drum punch sampling system to the drum lid.

- Provisions must be made to prevent the punch from rotating as it is pressed through the drum lid.

\section{Sampling Through 208-liter (55-gallon) Bag}

In addition to collecting headspace gas samples directly under the drum lid, drums requiring visual examination must have their lids removed and the headspace gas within the innermost 208-liter (55-gallon) poly bag must be sampled. The sample must be collected from the 208-liter (55-gallon) poly bag regardless of the condition of the bag (e.g., breached or torn). The headspace gas must be drawn into the manifold or direct canister through a needle that punctures the bag to access the bag's headspace.

Holding the needle in the headspace, the operator must open the inlet valve of the manifold or direct canister to allow headspace gas to expand into the evacuated canister(s). Care should be taken to prevent placing the tip of the clean needle in an area where solid material or particulate matter might fill or clog the needle. Once the canister(s) has filled, the operator must close the inlet valve and prepare the canister(s) for shipment.

\section{Sampling Through Innermost Layer}

For drums requiring visual examination that have innermost layers of confinement (e.g., bags inside the drum's 208-liter (55-gallon) poly bag), all of the innermost layers of confinement (i.e., the poly bag layer closest to the waste) that meet the following minimum criteria must be sampled:

- The innermost layer of confinement must have a minimum of 1 liter of headspace gas from which a representative $100 \mathrm{~mL}$ sample must be withdrawn. A $250 \mathrm{~mL}$ sample may be collected if there is enough available headspace gas $(2.5$ liter, minimum). When field duplicates are collected, twice the available headspace gas must be present.

- Headspace gas contained within rigid innermost layers of confinement (e.g., glass, metal, and rigid plastic containers) will not be sampled, but the external poly bag closest to the rigid container must be sampled if a minimum of 1 liter of headspace is available in the poly bag.

The sampling operator must determine and document in writing, in accordance with site SOPs, which innermost layers of confinement contain sufficient headspace gas for sampling. This documentation must include the innermost layer of confinement identification number and estimated available 
headspace volume (less than 1 liter, greater than 1 liter, or greater than 2.5 liters). Site SOPs must address how information is to be documented when the estimated available headspace volume is less than 1 liter.

To accomplish innermost layer of confinement sampling, the operator must first determine whether to use a $100 \mathrm{~mL}$ or a $250 \mathrm{~mL}$ sample canister. If the innermost layer of confinement to be sampled contains at least 1 liter but not more than 2.5 liters of available headspace gas, then a $100 \mathrm{~mL}$ sample canister must be used. If the innermost layer of confinement to be sampled contains greater than 2.5 liters of available headspace, then a $250 \mathrm{~mL}$ sample canister may be used. In all cases, the maximum allowable sample volume should be collected. Once the appropriate sample canister size has been determined, the operator can sample in the same manner as for the 208-liter (55-gallon) poly bag.

\subsection{Quality Control}

Field OC samples must be collected on a per sampling batch basis. A sampling batch is a suite of samples collected consecutively using the same sampling equipment within a specific time period. A sampling batch can be up to 20 samples (excluding $Q C$ samples), all of which must be collected within 14 days of the first sample in the batch. Table 7-2 provides a summary of field QC sample collection requirements. Table 7-3 provides a summary of $\mathrm{OC}$ sample acceptance criteria.

The site project $Q A$ officer shall have the responsibility to monitor and document field $\mathrm{QC}$ sample results and fill out a nonconformance report if acceptance criteria are not met. The site project manager shall have the responsibility to ensure appropriate corrective action is taken if acceptance criteria are not met.

\section{Field Blanks}

Field blanks must be collected to evaluate background levels of Program-required analytes. Field blanks must be collected prior to sample collection, and at a frequency of one per sampling batch. The site project manager shall use the field blank data to assess impacts of ambient contamination, if any, on the sample results. If the concentration of any $V O C$ in a field blank exceeds three times the MDL for that $V O C$ in Table 12-1, a nonconformance must be initiated and resolved (Section 2.1.2.1).

\section{Equipment Blanks}

Equipment blanks must be collected to assess cleanliness prior to first use of all sampling equipment. After the initial cleanliness check, equipment blanks collected through the manifold must be collected at a frequency of one per sampling batch for VOC analysis. If the direct canister method is used, field blanks may be used in lieu of equipment blanks. The site project manager shall use the equipment 
TABLE 7-2

\section{Summary of Drum Field OC Headspace Sample Frequencies}

OC Samples

Q

Field blanks ${ }^{a}$

Equipment blanks ${ }^{b}$

Field reference standards ${ }^{c}$

Field duplicates
Manifold

Direct Canister

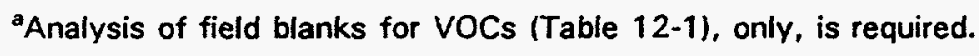

bOne equipment blank sample must be collected, analyzed for VOCs (Table 12-1), and demonstrated clean prior to first use of the headspace gas sampling equipment with each of the sampling heads, then at the specified frequency, for VOCs only thereafter. Daily, prior to work, the sampling manifold, if in use, must be verified clean using an OVA.

'One field reference standard must be collected, analyzed, and demonstrated to meet the QAOs specified in Section 7.1 prior to first use, then at the specified frequency thereafter.

${ }^{d}$ A sampling batch is a suite of samples collected consecutively using the same sampling equipment within a specific time period. A sampling batch can be up to 20 samples (excluding field $O C$ samples), all of which must be collected within 14 days of the first sample in the batch.

${ }^{\circ}$ One equipment blank and field reference standard must be collected after equipment purchase, cleaning, and assembly. 
TABLE 7-3

Summary of Sampling Quality Control Sample Acceptance Criteria

$\begin{array}{ccc} & \text { Acceptance } & \text { Corrective } \\ \text { OC Sample } & \text { Criteria } & \text { Action }\end{array}$

Field blanks

VOC amounts $<3 \times$ MDLs in Table 12-1

Equipment blanks

Hydrogen, Methane, and VOC amounts $<3 \times$ MDLs in

Table 11-1 and Table 12-1

Field reference

standards

Field duplicates
$70-130 \% R$

$\mathrm{RPD} \leq 25$
Nonconformance if any VOC amount $>3 \times$ MDLs in Table 12-1

Nonconformance if any analyte amount $>3 \times$ MDLs in

Table 11-1 and Table $: 2-1$

Nonconformance if \%R $<70$ or $>130$

Nonconformance if RPD > 25

MDL = Method detection limit

$\% R=$ Percent recovery

RPD $=$ Relative percent difference 
blank data to assess impacts of potentially contaminated sampling equipment on the sample results. Equipment blank results shall be acceptable if the concentration of hydrogen, methane, and each VOC analyte is less than three times the MDLs listed in Tables 11-1 and 12-1.

\section{Field Reference Standards}

Field reference standards shall be used to assess the accuracy with which the sampling equipment collects VOC, hydrogen, and methane samples into SUMMA' canisters prior to first use of the sampling equipment. Field reference standards must contain a minimum of six of the analytes listed in Table 12-1 at concentrations within a liner range of 0-100 ppmv and hydrogen and methane greater than or equal to the PROLs listed in Table 11-1. Field reference standards must have a known valid relationship to a nationally recognized standard (e.g., NIST). If commercial gases are used, a Certificate of Analysis from the manufacturer documenting traceability is required. Commercial stock gases must not be used beyond their manufacturer-specified shelf life. After the initial accuracy check, field reference standards collected through the manifold must be collected at a frequency of one per sampling batch and submitted blind to the analytical laboratory. For the direct canister method, field reference standard collection may be discontinued if the field reference standard results demonstrate the QAOs for accuracy specified in Section 7.1. Field reference standard results shall be acceptable if the accuracy is $70-130 \% R$.

\section{Field Duplicates}

Field duplicate samples must be collected simultaneously and in accordance with Table 7-2 and submitted blind to the analytical laboratory to assess the precision with which the sampling procedure can collect samples into SUMMA' canisters. Field duplicate results shall be acceptable if the RPD is less than or equal to 25 .

\subsection{Equipment Testing, Inspection, and Maintenance Requirements}

All sampling equipment components that come into contact with headspace sample gases must be constructed of relatively inert materials such as stainless steel or Teflon ${ }^{\oplus}$. A passivated interior surface on the stainless steel components is recommended.

To minimize the potential for cross contamination of samples the headspace sampling manifold and sample canisters must be properly cleaned and leak-checked prior to headspace gas sampling. Procedures for cleaning and preparing the manifold and sample canisters are provided in the Methods Manual. Cleaning requirements are presented below. 


\section{Headspace Gas Sample Canister Cleaning}

SUMMA ${ }^{\circ}$ canisters used in these methods must be subjected to a rigorous cleaning and certification procedure prior to use in the collection of any samples. Guidance for the development of this procedure has been derived from Method TO-14 (EPA 1988a) and can be found in the Methods Manual. Specific details must be provided in laboratory SOPs for the cleaning and certification of canisters.

Canisters must be cleaned and certified on an equipment cleaning batch basis. An equipment cleaning batch is the number of canisters cleaned together at one time using the same cleaning method. $A$ cleaning system, capable of processing multiple canisters at a time, composed of an oven (optional) and a cryogenically trapped vacuum manifold (Scientific Instrument Specialists or equivalent) must be used to clean SUMMA ${ }^{\circ}$ canisters. Prior to cleaning, a 24-hour leak test must be performed on all canisters. For a positive pressure check, a canister passes if the pressure does not change by more than \pm 2 psig in 24 hours. Any canister that fails must be checked for leaks, repaired, and reprocessed. One canister per equipment cleaning batch must be filled with humid zero air or humid high purity nitrogen and analyzed for VOCs. The equipment cleaning batch of canisters shall be considered clean if there are no VOCs above three times the MDLs listed in Table 12-1. After the canisters have been certified against leaks and background contamination, they must be evacuated to $0.10 \mathrm{~mm} \mathrm{Hg}$ or less for storage prior to shipment. The laboratory responsible for canister cleaning and certification shall maintain canister certification documentation and initiate the canister tags as described in Section 6.0 of this QAPP.

\section{Sampling Equipment Initial Cleaning and Leak-Check}

The surfaces of all headspace gas sampling equipment components that will come into contact with headspace gas must be thoroughly inspected and cleaned prior to assembly. The manifold and associated sampling heads must be purged with humidified zero air, nitrogen, or helium, and leakchecked after assembly. This cleaning must be repeated if the manifold and/or associated sampling heads are contaminated to the extent that the routine system cleaning is inadequate.

\section{Sampling Equipment Routine Cleaning and Leak-Check}

The manifold and associated sampling heads which are reused must be cleaned and checked for leaks in accordance with the cleaning and leak check procedures described in Procedures 110.1 and 110.2 of the Methods Manual, or equivalent. The procedures must be conducted after headspace gas and field duplicate collection; after field blank collection, if the field blank is collected through the manifold; and after the additional cleaning required for field reference standard collection has been completed. The protocol for routine manifold cleaning and leak-check requires that sample canisters be attached 
to the canister ports, or that the ports be capped or closed by valves, and requires that the sampling head be attached to the purge assembly. Humidified zero air, nitrogen, or helium, regulated through the purge assembly, must then be swept through the sample side of the sampling system.

VOCs must be removed from the internal surfaces of the headspace sampling manifold to levels that are less than three times the MDLs of the analytes listed in Table 12-1, as determined by analysis of an equipment blank or the OVA. This is achieved by sweeping the sample side of the sampling system. It is recommended that the headspace sampling manifold be heated and periodically evacuated and flushed with humidified zero air, nitrogen, or helium. When not in use, the manifold must be demonstrated clean before storage with a positive pressure of high purity gas (i.e., zero air, nitrogen, or helium) in both the standard and sample sides.

Sampling must be suspended and corrective actions must be taken when the analysis of an equipment blank indicates these limits have been exceeded. The site project manager must insure that corrective action has been taken prior to resumption of sampling.

\section{Manifold Cleaning After Field Reference Standard Collection}

The sampling system must be specially cleaned after a field reference standard has been collected because the field reference standard gases contaminate the standard side of the headspace sampling manifold when they are regulated through the purge assembly. This cleaning requires the installation of a gas-tight connector in place of the sampling head, between the flexible hose and the purge assembly. This configuration allows both the sample and standard side of the sampling system to be flushed (evacuated and pressurized) with humidified zero air, nitrogen, or helium which, combined with heating the pneumatic lines, should sweep and adequately clean the system's internal surfaces. After this protocol has been completed and prior to collecting another sample, the routine system cleaning and leak-check (see previous section) must also be performed.

\section{Sampling Head Cleaning}

To prevent cross contamination, the needle, adapters, and filter of the sampling heads must be cleaned in accordance with the cleaning procedures described in Procedures 110.1 and 110.2 of the Methods Manual, or equivalent. After sample collection, a sampling head must be disposed of or cleaned in accordance with the Methods Manual procedures, or equivalent, prior to reuse. As a further $\mathrm{OC}$ measure, the needle and filter, after cleaning, should be purged with zero air, nitrogen, or helium and capped for storage to prevent sample contamination by VOCs potentially present in ambient air. 


\subsection{Equipment Calibration and Frequency}

The manifold pressure sensor must be certified prior to initial use, then annually, using NIST, or equivalent, standards. If necessary, the pressure indicated by the pressure sensor(s) must be temperature compensated. The ambient air temperature sensor, if present, must be certified prior to initial use, then annually, to NIST traceable, or equivalent, temperature standards.

The OVA must be calibrated once per day, prior to first use, or as necessary according to the manufacturer's specifications. Calibration gases must be certified to contain known analytes at known concentrations. The balance of the OVA calibration gas must be consistent with the manifold purge gas when the OVA is used (i.e., zero air, nitrogen, or helium).

\subsection{Data Management}

Each sampling facility collecting headspace gas samples must record and report information pertinent to the collection of samples in accordance with Sections 3.0 and 6.0 of this QAPP, and in accordance with site QAPjP and SOP requirements. The site QAPjP must describe the procedures that will be used to coritrol this information and site-specific documentation must include example forms that will be used to document and report sampling activities. Each sampling facility must submit a sampling batch data report for each sampling batch to the site project office on approved standard forms. Sampling batch data reports must, at minimum, consist of the following:

- The sampling facility name, sampling batch number, sample numbers included in that sampling batch, and the signature releases of the sampling personnel as specified in Section 3.1.1

- Data review checklist verifying that the data generation level review, validation and verification, as described in Section 3.1.1, has taken place

- Information specified in Section 6.1

- Nonconformance reports, if applicable

In addition, sampling facilities located on sites shall record and maintain the following information items in their files, documented and retrievable sampling batch number. Contract sampling facilities shall forward these items along with sampling batch data reports to the site project office for storage in site project files:

- Copies of the sampling reports submitted to the site project office, filed in accordance with the sampling batch number

- Copies of the completed $\mathrm{COC}$ forms used to transfer the sampling batch to the analytical laboratories 
Section: 7.0

Revision: 0

Date: $4 / 30 / 95$

Page 23 of 23

- Cylinder gas certification information

- Instrument (e.g., OVA) calibration, maintenance, and repair records 


\subsection{SAMPLING OF HOMOGENOUS SOLIDS AND SOIL/GRAVEL}

This section describes the minimum requirements for collecting samples of TRU waste classified as homogenous solids and soil/gravel from 208-liter (55-gallon) drums, waste boxes, and smaller containers contained inside drums and waste boxes. Sampling procedures can be found in the Methods Manual, and the procedures for analyzing the samples can be found in Sections 13.0, 14.0, and 15.0 for VOCs, SVOCs, and metals, respectively.

This protocol is based on sampling methods similar to those approved by EPA for solid waste and soil sampling in SW-846, "Standard Practice for Thin-Walled Tube Sampling of Soil/Gravel" (ASTM 1983a), and "Standard Practice for Sampling Waste and Soil/Gravel for Volatile Organic Compounds" (ASTM 1991a). As such, it is applicable to the collection of samples from containers of TRU waste classified as homogenous solids and soil/gravel. It is designed to ensure that representative samples of these wastes, including $\mathrm{QC}$ samples, are consistently collected and transferred to the responsible laboratory in a manner that maintains their integrity to the fullest extent possible.

This protocol is designed for characterization of homogenous solids and soil/gravel on a waste stream basis. The TRU waste, classified as homogenous solids and soil/gravel, to be sent to the WIPP facility is packaged in waste containers of all sizes. The sampling strategy is such that the samples must be randomly obtained in both the horizontal and vertical planes of the waste. The waste is first cored at a location randomly selected in the waste's horizontal plane. Then, the core is removed from the waste, a location is randomly selected along the core's length, and samples in quantities required for the specific analyses (Table 6-2) are collected from that location. Thus, each location inside a waste drum has an equal chance of being sampled. For the waste packaged in smaller containers within drums or waste boxes, the smaller containers must be grouped according to waste stream and a representative sample must be collected from one randomly selected smaller container of each waste stream.

This sampling strategy is designed to provide the analytical laboratories the minimum amount of required sample, thus minimizing sample handling and the quantity of investigation-derived waste. The wastes must be analyzed for the target analytes listed in Tables 13-1 for VOCs, 14-1 for SVOCs, and 15-1 for metals.

\subsection{Quality Assurance Objectives}

To ensure sampling is conducted in a representative manner on a waste stream basis for waste containers containing homogenous solids and soil/gravel, samples must be collected randomly in both 
the horizontal and vertical planes of each container's waste. For waste containers that contain homogenous solids and soil/gravel in smaller containers (e.g., 1-gallon polyethylene bottles) within the waste container, one randomly chosen smaller container must be sampled.

\section{Precision}

Sampling precision must be determined by collecting and sampling field duplicates le.g., co-located cores as described in Section 8.3) once per sampling batch or once per week during sampling operations, whichever is more frequent. A sampling batch is a suite of homogenous solids and soil/gravel samples collected consecutively using the same sampling equipment within a specific time period. A sampling batch can be up to 20 samples (excluding field $\mathrm{OC}$ samples), all of which must be collected within 14 days of the first sample in the batch. The RPD between co-located samples must be calculated and reported by the site project QA officer.

\section{Accuracy}

Sampling accuracy shall not be measured. Because waste containers containing homogenous solids and soil/gravel with known quantities of analytes are not available, sampling accuracy can not be determined. However, sampling methods and requirements described are designed to minimize sample degradation and hence maximize sampling accuracy.

\section{Completeness}

Sampling completeness shall be expressed as the number of valid samples collected as a percent of the total number of samples collected. Participating sampling facilities must achieve a minimum 90-percent completeness.

\section{Comparability}

Consistent use and application of uniform procedures, sampling equipment, and measurement units must ensure that sampling operations are comparable. In addition, laboratories analyzing samples must participate in the PDP.

\section{Representativeness}

Specific steps to ensure the representativeness of samples include the following for both waste containers and smaller containers:

- Coring tools and sampling equipment must be clean prior to sampling

- The entire depth of the waste must be cored and the core collected must have a length greater than or equal to 50-percent of the depth of the waste. This is called the core recovery and is calculated as follows: 


$$
\text { Core recovery }=\frac{y}{x} * 100
$$

where $x$ is the depth of the waste in the container and $y$ is the length of the core collected from the waste

- Coring operations and tool selection should be designed to minimize alteration of the in-place waste characteristics. Minimal waste disturbance must be verified by visually examining the core and describing the observation (e.g., undisturbed, cracked, pulverized) in the field logbook.

If core recovery is less than 50-percent of the depth of the waste, a second coring location shall be randomly selected. The core from the second location shall be used for sample collection regardless of the core recovery.

\subsection{Method Requirements}

The methods used to collect samples of TRU waste classified as homogenous solids and soil/gravel from waste containers must be such that the samples are representative of the waste from which they were taken. Procedure 120.1 in the Methods Manual is an acceptable method for the collection of samples of homogenous solids and soil/gravel. To minimize the quantity of investigation-derived waste, laboratories conducting the analytical work may require no more sample than is required for the analysis, based on the analytical methods. Therefore, sampling must be conducted to collect samples in accordance with the specifications presented in Table 6-2. To obtain the sample quantities specified in Table 6-2, cores must be collected in accordance with the requirements in Section 8.2 .1 and sampled in accordance with the requirements in Sections 8.2.2.

\subsubsection{Core Collection}

Coring tools must be used to collect cores of homogenous solids and soil/gravel from waste containers, when possible, in a manner that minimizes disturbance to the core. A rotational coring tool, (i.e., a tool that is rotated longitudinally), similar to a drill bit, to cut, lift the waste cuttings, and collect a core from the bore hole, must be used to collect sample cores from containers of the waste. For homogenous solids and soil/gravel that are relatively soft, non-rotational coring tools may be used in lieu of a rotational coring tool.

To provide a basis for describing the requirements for core collection, diagrams of a rotational coring tool, (i.e., a light weight auger) and a non-rotational coring tool (i.e., a thin walled sampler) are 
provided in Figures 8-1 and 8-2, respectively. Each has been tested for its ability to collect a vertical core of simulated solidified waste contained in 208-liter (55-gallon) drums and 1-gallon poly bottles (EG\&G 1994b). The non-rotational coring tool has demonstrated core recoveries greater than 88 percent for soft simulated wastes. The rotational coring tool has demonstrated core recoveries greater than 75 percent for soft simulated wastes and greater than 94 percent for hard simulated wastes. Specific procedures for coring with these tools can be found in the Methods Manual.

The following requirements apply to the use of coring tools:

- Each coring tool must contain a removable tube (liner) that is constructed of fairly rigid material unlikely to affect the composition and/or concentrations of target analytes in the sample core (e.g., Teflon $\left.{ }^{\oplus}\right)$. Site QAPjPs must document that analytes of concern are not likely to be present in liner material. Liner outer diameter is recommended to be no more than 2 inches and no less than 1 inch. Liner wall thickness is recommended to be no greater than 1/16 inch. Before use, the liner must be cleaned in accordance the requirements in Section 8.3. The liner must fit flush with the inner wall of the coring tool and must be of sufficient length to hold a core that is representative of the waste along the entire depth of the waste. The liner material must have sufficient transparency to allow visual examination of the core after sampling. If sub-sampling is not conducted immediately after core collection and liner extrusion, then end caps constructed of material unlikely to affect the composition and/or concentrations of target analytes in the core (e.g., Teflon ${ }^{*}$ ) must be placed over the ends of the liner. End caps must fit tightly to the ends of the liner.

- A spring retainer, similar to that illustrated in Figures 8-1 and 8-2, and described in the Methods Manual, must be used with each coring tool when the physical properties of the waste are such that the waste may fall out of the coring tool's liner during sampling activities. The spring retainer must be constructed of relatively inert material (e.g., stainless steel, Teflon ${ }^{\circ}$ ) and its inner diameter must be not be less than the inner diameter of the liner. Before use, spring retainers must be cleaned in accordance with the requirements in Section $\mathbf{8 . 3}$.

- Coring tools must have an air lock mechanism that opens to allow air inside the liners to escape as the tool is pressed into the waste (e.g., ball check valve). This air lock mechanism must also close when the core is removed from the waste container.

- After disassembling the coring tool, a device (extruder) to forcefully extrude the liner from the coring tool must be used if the liner does not slide freely. All surfaces of the extruder that may come into contact with the core must be cleaned in accordance with the requirements in Section 8.3 prior to use.

- Coring tools must be of sufficient length to hold the liner and must be constructed to allow placement of the liner leading edge as close as possible to the coring tools leading edge. The Methods Manual provides general design specifications for coring tools.

- All surfaces of the coring tool that have the potential to contact the sample core must be cleaned in accordance with the requirements in Section 8.3 prior to use. 
Section: 8.0

Revision: 0

Date: 4/30/95

Page 5 of 12

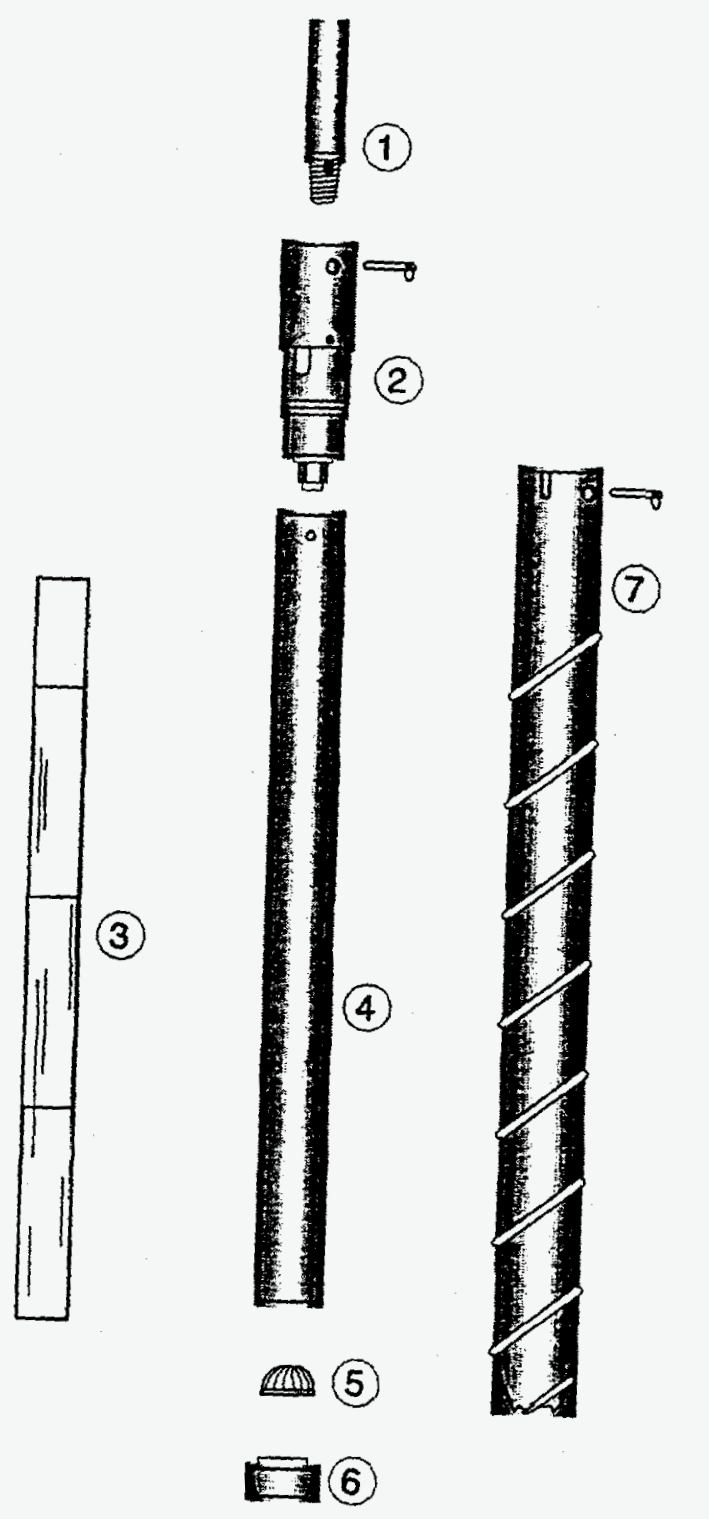
(1) Drill Rod
(2) Thrust Bearing Ball Check Valve
(3) Clear Teflor Liners
(4) Core Barrel
(5) Spring Retainer (optiona)
(6) Core barrel tip
(7) Auger and $P$ in

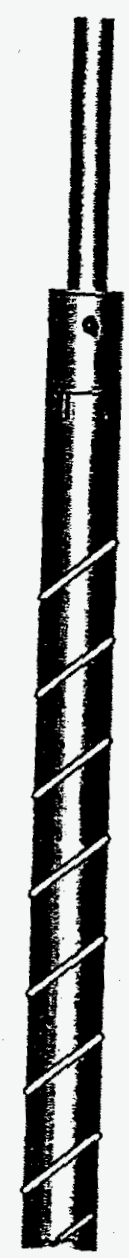

FIGURE 8-1

Rotational Coring Tool

(Light Weight Auger) 
Section: $\mathbf{8 . 0}$

Revision: 0

Date: 4/30/95

Page 6 of 12
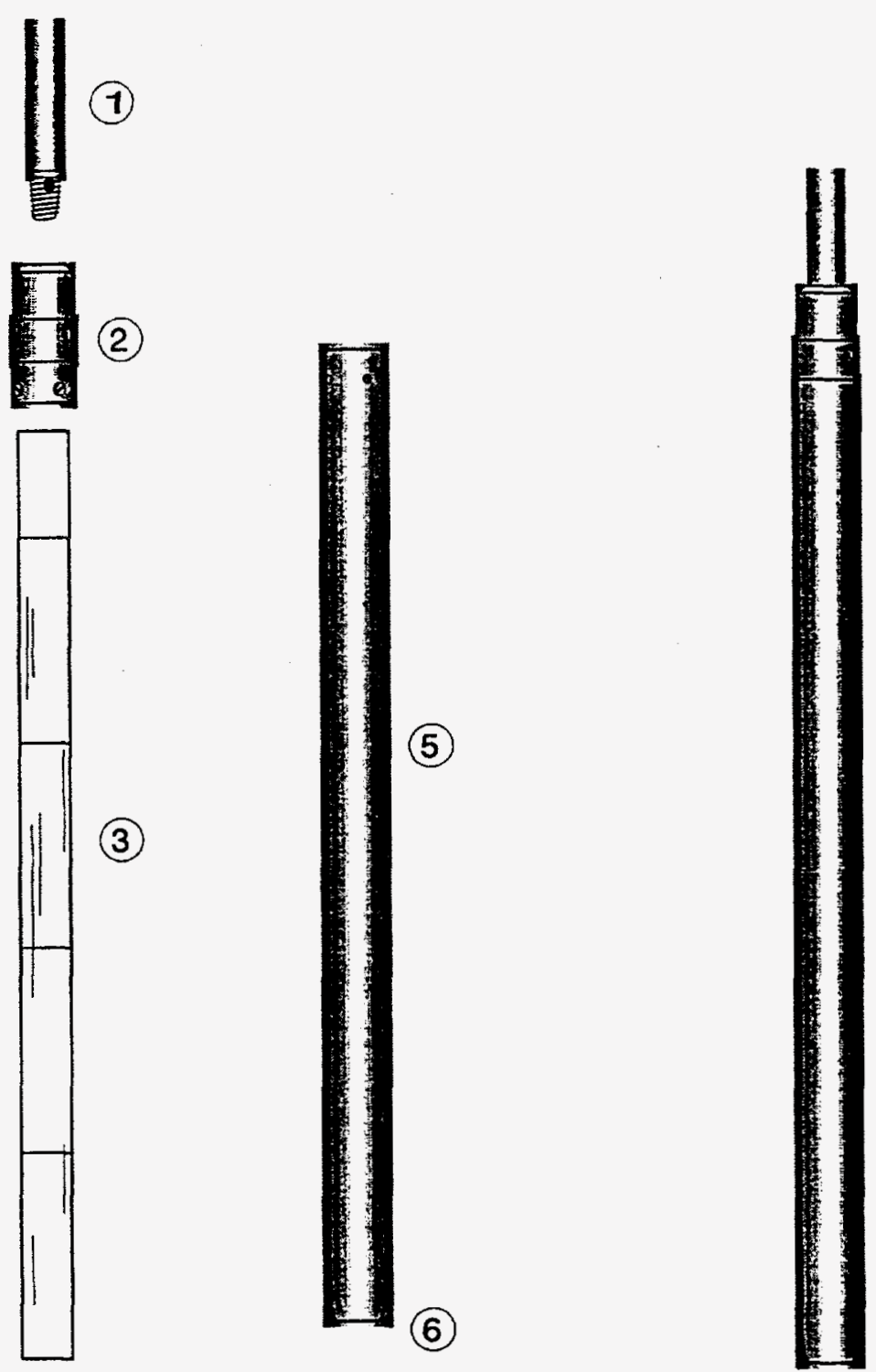

20

\section{(5)}

(3)

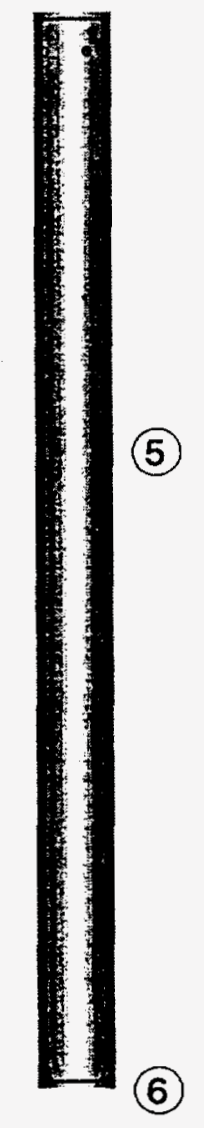
(1) Drill Rod
(4) Spring Retainer (optional)
(2) Bali check valve
(5) Tube
(3) Clear Teflor Piners
(6) Tapered $\pi p$

FIGURE 8-2

Non-Rotational Coring Tool

(Thin Walled Sampler) 
- The leading edge of the coring tools must be sharpened and tapered to a diameter equivalent to, or slightly smaller than, the inner diameter of the liner. Based on tests conducted with the coring tools described in the Methods Manual, a diameter slightly smaller (e.g., $1 / 10$ of an inch) has demonstrated a reduction in the drag of the homogenous solids and soil/gravel against the internal surfaces of the liner, thereby enhancing sample recovery.

- Rotational coring tools must have a mechanism to prevent the liner inside the coring tool from rotating with the coring tool during coring activities, thereby minimizing physical disturbance to the core. The Methods Manual and the coring tool illustrated in Figure 8-1 provide design information for a coring tool that meets this requirement.

- Rotational coring must be conducted in a manner that minimizes transfer of frictional heat to the core, thereby minimizing potential loss of VOCs. Information relevant to complying with this requirement (e.g., design of the rotational coring tool in Figure 8-1) is provided in the Methods Manual.

- Non-rotational coring tools must be designed such that the tool's kerf width is minimized. Kerf width is defined as one-half of the difference between the outer diameter of the tool and the inner diameter of the tool's inlet. The Methods Manual and the coring tool illustrated in Figure 8-2 provide design information for a coring tool that meets this requirement.

\subsubsection{Sample Collection}

To obtain representative samples in the quantities specified in Table 6-2, sampling of the core is required. Sampling must be conducted in accordance with the following requirements:

- Sampling must be conducted as soon as possible after core collection. If a substantial delay (i.e., more than 60 minutes) is expected between core collection and sampling, the core must remain in the liner and the liner must be capped at each end. If the liner is not extruded and capped, then two alternatives are permissible: 11 the liner must be left in the coring tool and the coring tool must be capped at each end, and 2) the coring tool must remain in the waste container with the air lock mechanism attached.

- Samples of homogenous solids and soil/gravel for VOC analyses must be collected prior to extruding the core from the liner. The sampling location must be randomly selected along the long axis of the liner and access to the waste must be gained by making a perpendicular cut through the liner and the core. A sampling device such as the metal coring cylinder described in ASTM Designation: 4547-91 (ASTM 1991a), or modified disposable syringe described in Procedure 120.1 of the Methods Manual, or equivalent, must be immediately used to collect the sample once the core has been exposed to air. Immediately after sample collection, the sample must be extruded into a $40 \mathrm{~mL}$ VOA vial, the top rim of the vial visually inspected and wiped clean of any waste residue, and the vial cap secured. A detailed procedure applicable to this sampling technique can be found in Procedure 120.1 of the Methods Manual. Additional guidance for this type of sampling can be found in Soil Sampling and Analysis for Volatile Organic Compounds (EPA 1991b).

- Samples of the homogenous solids and soil/gravel for SVOC, PCB, and metals analyses must be collected. These samples may be collected from the same location and in the same manner as the sample(s) collected for VOC analysis, or they may be collected by splitting or compositing a representative sub-section of the core. Guidance for splitting and 
compositing solid materials can be found in "Standard Practice for Reducing Field Samples of Aggregate to Testing Size" (ASTM 1987). All surfaces of the sampling tools that have the potential to come into contact with the sample must be constructed of materials unlikely to affect the composition or concentrations of target analytes in the waste (e.g., Teflon $\%$.

\subsection{Quality Control}

QC requirements for sampling of homogenous solids and soil/gravel include collection of co-located cores to determine precision; equipment blanks to verify cleanliness of the coring tools and sampling equipment; and analysis of reagent blanks to ensure reagents, such as deionized or high pressure liquid chromatography (HPLC) water, are of sufficient quality. Coring and sampling of homogenous solids and soil/gravel must comply, at minimum, with the following $Q C$ requirements.

\section{Co-Located Cores}

In accordance with the requirement to collect field duplicates found in SW-846, co-located cores must be collected to determine the combined precision of the coring and sampling procedures. Cores must be collected side-by-side as close as feasible to one another, handled in the same manner, visually inspected through the transparent liner, and sampled in the same manner at the same randomly selected sample location. If the visual examination detects inconsistencies in the waste at the sample location, another sampling location may be randomly selected, or the cores may be invalidated and colocated cores may again be collected. Co-located cores must be collected at a frequency of one per sampling batch or one per week during sampling operations, whichever is more frequent. A sampling batch is a suite of homogenous solids and soil/gravel samples collected consecutively using the same sampling equipment within a specific time period. A sampling batch can be up to 20 samples (excluding field $Q C$ samples), all of which must be collected within 14 days of the first sample in the batch. Samples collected from co-located cores must be submitted blind to the analytical laboratory.

\section{Equipment Blanks}

In accordance with SW-846, equipment blanks must be collected from fully assembled coring tools prior to first use at a frequency of one per equipment cleaning batch. An equipment cleaning batch is the number of sampling equipment items cleaned together at one time using the same cleaning method. The equipment blank must be collected from the fully assembled coring tool, in the area where the coring tools are cleaned, prior to covering with protective wrapping and storage. The equipment blank must be collected by pouring clean water (e.g., deionized water, HPLC water) down the inside of the liners of the assembled coring tool. The water must be collected in a clean sample container placed at the leading edge of the coring tool and analyzed for the analytes listed in Tables 13-1, 14-1, and 15-1. The results of the equipment blank will be considered acceptable if the 
analysis indicates no analyte at a concentration greater than three times the MDLs listed in Tables 13-1, 14-1, or 15-1. If analytes are detected at concentrations greater than three times the MDLs, then the associated equipment cleaning batch of coring tools must be cleaned again and another equipment blank collected.

Equipment blanks must be collected from liners that are cleaned separately from the coring tools. These equipment blanks must be collected at a frequency of one per equipment cleaning batch. The equipment blanks must be collected by randomly selecting a liner from the equipment cleaning batch, pouring clean water (e.g., deionized water, HPLC water) across its internal surface, collecting the water in a clean sample container, and analyzing the water for the analytes listed in Tables 13-1, 14-1, and 15-1. The results of the equipment blank analysis will be considered acceptable if the results indicate no analyte at a concentration greater than three times the MDLs listed in Tables 13-1, 14-1, or 15-1. If analytes are detected at concentrations greater than three times the MDLs, then the associated equipment cleaning batch of liners must be cleaned again and another equipment blank collected.

Sampling equipment (e.g., bowls, spoons, chisel, VOC sub-sampler) must also be cleaned. Equipment blanks must be collected for the sampling equipment at a frequency of one per equipment cleaning batch. After the sampling equipment has been cleaned, one item from the equipment cleaning batch is randomly selected, water (e.g., deionized water, HPLC water) is passed over its surface, collected in clean container, and analyzed for the analytes listed in Tables 13-1, 14-1, and 15-1. The results of the equipment blank will be considered acceptable if the results indicate no analyte present at a concentration greater than three times the MDLs listed in Tables 13-1, 14-1, or 15-1. If analytes are detected at concentrations greater than three times the MDLs, then the associated equipment cleaning batch of sampling equipment must be cleaned again and another equipment blank collected.

The results of equipment blanks must be traceable to the items in the equipment cleaning batch that the equipment blank represents. It is recommended that the equipment blank results for the coring tools, liners, and sampling equipment be reviewed prior to use. A sufficient quantity of these items should be maintained in storage to prevent disruption of sampling operations.

A site may choose to discard liners and sampling tools after one use. In this instance, cleaning and equipment blank collection is not required. 


\section{Coring Tool and Sampling Equipment Cleaning}

Coring tools and sampling equipment must be cleaned in accordance with the following requirements:

- All surfaces of coring tools and sampling equipment that will come into contact with the core and the samples must be clean prior to use. All items of sampling equipment must be cleaned in the same manner. Immediately following cleaning, coring tools and sampling equipment must be assembled and sealed inside clean protective wrapping.

- Each coring tool must have a unique identification number. Each number must be referenced to the waste container on which it was used. This information must be recorded in the field records. One coring tool from the equipment cleaning batch must be tested for cleanliness in accordance with the requirements specified above. The identification number of the coring tool from which the equipment blank was collected must be recorded in the field records. The results of the equipment blank analysis for the equipment cleaning batch in which each coring tool was cleaned must be submitted to the sampling facility with the identification numbers of all coring tools in the equipment cleaning batch.

- Sample containers must be cleaned in accordance with the Specifications and Guidance for Obtaining Contaminant-Free Sample Containers (EPA 1992b).

\subsection{Equipment Testing, Inspection, and Maintenance Requirements}

Prior to initiation of coring activities, coring tools must be tested in accordance with manufacturer specifications to ensure operation within the manufacturer's tolerance limits. Other specifications specific to the sampling operations (e.g., operation of containment structure and safety systems) should also be tested and verified as operating properly prior to initiating coring activities. Coring tools must be assembled, including liners, and tested. Air lock mechanisms and rotation mechanisms must be inspected for free movement of critical parts. Coring tools found to be malfunctioning must be repaired or replaced prior to use.

Coring tools and sample collection equipment must be maintained in accordance with manufacturer's specifications. Clean coring tools and sampling equipment must be sealed inside clean protective wrapping and maintained in a clean storage area prior to use. A sufficient supply of spare parts should be maintained to prevent delays in sampling activities due to equipment down time. Records of equipment maintenance and repair must be maintained in the field records in accordance with site SOPs.

Inspection of sampling equipment and work areas shall include the following:

- Sample collection equipment in the immediate area of sample collection must be inspected daily for cleanliness. Visible contamination on any equipment le.g., waste on floor of sampling area, hydraulic fluid from hoses) that has the potential to contaminate a waste core or waste sample must be thoroughly cleaned upon its discovery. 
- The waste coring and sampling work areas must be maintained in clean condition to minimize the potential for cross contamination between cores and samples.

- Expendable equipment (e.g., plastic sheeting, plastic gloves) must be visually inspected for cleanliness prior to use and properly discarded after each sample.

- Prior to removal of the protective wrapping from a coring tool designated for use, the condition of the protective wrapping must be visually assessed. Coring tools with torn protective wrapping should be returned for cleaning. Coring tools visibly contaminated after the protective wrapping has been removed must not be used and must be returned for cleaning or properly discarded.

- Sampling equipment must be visually inspected prior to use. All sampling equipment that comes into contact with waste samples must be stored in protective wrapping until use. Prior to removal of the protective wrapping from sampling equipment, the condition of the protective wrapping must be visually assessed. Sampling equipment with torn protective wrapping should be discarded or returned for cleaning. Sampling equipment visibly contaminated after the protective wrapping has been removed must not be used and must be returned for cleaning or properly discarded.

\subsection{Equipment Calibration and Frequency}

The scale used for weighing sub-samples must be calibrated as necessary to maintain its operation within manufacturer's specification, and after repairs and routine maintenance. Weights used for calibration must be traceable to a nationally recognized standard. Calibration records must be maintained in the field records.

\subsection{Data Management}

Each sampling facility must record information pertinent to sample collection in accordance with Sections 3.0 and 6.0 of this QAPP, and in accordance with site QAPjP and SOP requirements. The site QAPjP must describe the procedures that will be used to control this information and site-specific documentation must include example forms that will be used to document and report sampling activities. Each sampling facility must submit a sampling batch data report for each sampling batch to the site project office on approved standard forms. Sampling batch data reports must, at minimum, consist of the following:

- The sampling facility name, sampling batch number, sample numbers included in that sampling batch, and the signature releases of the sampling personnel as specified in Section 3.1 .1

- Data review checklist for each sampling batch verifying that the data generation level review, validation, and verification, as described in Section 3.1.1, has taken place

- Information specified in Section 6.1

- Nonconformance reports, if applicable 
In addition, sampling facilities located on sites shall record and maintain the following items in their files, documented and retrievable by sampling batch number. Contract sampling facilities shall forward these items along with sampling batch data reports to the site project office for storage in site project files.

- Copies of the sampling reports submitted to the site project office, filed in accordance with the sampling batch number

- Copies of the completed $\mathrm{COC}$ form(s) used to transfer the samples in that sampling batch to the analytical laboratories

- Coring information (e.g., coring duration, downward pressure applied, rotational speed, and torque applied, if applicable)

- Heat and dust generation observations

- Coring tool, liner, sampling equipment, and reagent certification information

- Instrument (e.g., scale) calibration, maintenance, and repair records 


\subsection{NONDESTRUCTIVE ASSAY}

Numerous RA techniques are available to determine the TRU content of bulk waste. RA methods may include both nondestructive and destructive techniques.

Nondestructive assay (NDA) techniques allow an item to be assayed without altering its physical or chemical form. NDA techniques can be classified as active or passive. Passive NDA is based on the observation of spontaneously emitted radiations created through radioactive decay of the isotopes of interest or their radioactive daughters. Most active NDA is based on the observation of gamma or neutron radiation that is emitted from a target isotope when that isotope undergoes a transformation resulting from an interaction with stimulating radiation provided by an appropriate, external source.

Destructive RA refers to the radiochemical analysis of a representative sample collected from the waste. The sample is physically and/or chemically processed for subsequent analysis by radioactivity counting or other instrumental techniques. Radiochemistry methods will be discussed in a future revision of the QAPP. Throughout this section, references to "RA measurement systems" shall include only NDA systems.

NDA methods can not directly identify and quantify all the individual radionuclides of interest. Therefore, some NDA techniques are commonly used in conjunction with isotope ratio calculations using data from other sources. Destructive RA techniques are used to directly quantify the radioisotopic content of identified, homogenous waste streams. Any NDA, destructive RA, or combination of these methods are acceptable as long as they address and achieve the OAOs of the Program. The selected methods may incorporate supporting data from acceptable knowledge, such as isotope ratios or scaling factors, when such data can be supported by auditable QA records.

It is not intended that the QAOs contained in this document be interpreted as being the only criteria for establishing acceptability of NDA measurement systems. The QAOs published in this document for NDA systems are used to establish minimum performance requirements for measurement systems used to generate waste characterization data for the Program. Parties responsible for determining the acceptability of NDA measurement systems for purposes other than TRU waste characterization for WIPP may establish requirements in addition to or in lieu of the OAOs for this Program. Such requirements do not affect the obligation to meet the QAOs of this Program for systems generating waste characterization data for WIPP. 
For the purposes of the Program, two parameters describing the waste must be known; the total alpha activity and the activity of the individual isotopes present. The total alpha activity is a controlling variable for the amount of radiolysis and associated radiolytic gas generation. The activities of individual isotopes are needed to determine fissile gram equivalent and to perform other required calculations. If a waste stream may be contaminated with radioactive materials of variable or unknown isotopic composition, a method independent of acceptable knowledge must be used to determine the isotope ratios. This does not preclude the use of acceptable knowledge for the determination of isotope ratios at some facilities, but does require that the bases for the isotope ratios which are used be documented and supportable. The measurement of total alpha activity and independent determination of isotopic ratios, obtained by nondestructive and/or destructive RA or acceptable knowledge, are considered adequate for use in the Program.

\subsection{Quality Assurance Objectives}

Each participating site must use one or more RA techniques. Each site shall demonstrate and technically justify that the RA techniques used are appropriate for the specific wastes to which they are applicable. The rationale for using a specific assay technique should include the physical form of the waste, the radionuclide content, and the waste generating process. In all cases, the total uncertainties in the assay must be calculated using the terms derived for compliance with the QAO for Total Uncertainty and reported with the data. The actual precision and accuracy values obtained for waste containers will be a function of the waste type, total TRU content, its distribution, and characteristics of the measurement instrumentation. The QAOs for precision, accuracy, minimum detectable concentration (MDC), completeness, and total uncertainty are summarized in Table 9-1. The QAO parameters are defined for the general case in Section 3.2. QAOs for NDA are specified over several different ranges of interest. These ranges are somewhat arbitrary but convenient divisions which are expected to have differing contributions to inventory or are related to significant cutoffs (e.g. for shippingl. Participating sites need only demonstrate for individual measurement systems that the QAOs can be achieved for the respective ranges over which that system will be used. Additional details on the individual QAO parameters are given below.

\section{Precision}

The precision of each measurement technique must be determined through replicate processing of a waste container containing a known quantity of the radioactive material of interest. The specific method for demonstrating compliance with the QAO for precision in RA is described in detail in Section 9.6 . 
TABLE 9-1

\section{Quality Assurance Objectives for Nondestructive Assay}

\begin{tabular}{|c|c|c|c|c|c|c|}
\hline $\begin{array}{c}\text { Range of } \\
\text { Waste Activity } \\
\text { in } \\
\alpha-\text { Curies }^{a}\end{array}$ & $\begin{array}{c}\text { Nominal } \\
\text { Compliance } \\
\text { Point } \\
\alpha \text {-Curies } \\
\text { (g WG Pu) }^{\mathrm{b}}\end{array}$ & $\begin{array}{c}\text { Precision }^{c} \\
\text { (\%RSD) }\end{array}$ & $\begin{array}{c}\text { Accuracy }{ }^{d} \\
(\% R)\end{array}$ & $\begin{array}{c}\text { Total } \\
\text { Uncertainty }\end{array}$ & $\begin{array}{c}\text { Completeness }^{f} \\
(\%)\end{array}$ & $\begin{array}{c}\mathrm{MDC} \\
(\mathrm{nCi} / \mathrm{g})^{\mathrm{g}}\end{array}$ \\
\hline 0 & 0 & & & & & 60 \\
\hline$>0$ to 0.04 & $\begin{array}{l}0.008 \\
(0.1)\end{array}$ & $\leq 20$ & $75-125$ & $\begin{array}{l}\text { Low } 40 \% \\
\text { High } 175 \%\end{array}$ & 100 & \\
\hline$>0.04$ to 0.4 & $\begin{array}{l}0.08 \\
(1.0)\end{array}$ & $\leq 15$ & $50-150$ & $\begin{array}{l}\text { Low } 30 \% \\
\text { High } 200 \%\end{array}$ & 100 & \\
\hline$>0.4$ to 4.0 & $\begin{array}{l}0.8 \\
(10)\end{array}$ & $\leq 10$ & $50-150$ & $\begin{array}{l}\text { Low } 30 \% \\
\text { High } 200 \%\end{array}$ & 100 & \\
\hline$>4.0$ & $\begin{array}{r}12.8 \\
(160)\end{array}$ & $\leq 5$ & $75-125$ & $\begin{array}{l}\text { Low } 50 \% \\
\text { High } 150 \%\end{array}$ & 100 & \\
\hline
\end{tabular}

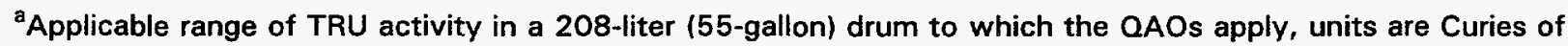
alpha-emitting TRU isotopes with half-lives greater than 20 years

${ }^{\mathrm{b}}$ The nominal activity (or weight of $\mathrm{Pu}$ ) in the 208-liter (55-gallon) drum used to demonstrate that QAOs can be achieved for the corresponding range in column 1, values in parentheses are the approximate equivalent weights of weapons grade plutonium (WG Pu), fifteen years after purification; for purposes of demonstrating QAOs,

"nominal" means within \pm 10 percent

${ }^{c} \pm$ one relative standard deviation based on fifteen replicate measurements of a non-interfering matrix

${ }^{\mathrm{d}}$ Ratio of measured to known values based on the average of fifteen replicate measurements of a non-interfering matrix, see Section 9.6 for additional details

e 95 -percent confidence bounds of all propagated uncertainties (Confidence bound divided by true value, expressed as a percent)

${ }^{f}$ Valid radioassay data is required for all waste containers, see Section 9.6 for additional details

${ }^{9}$ As defined in Sections 9.1 and 9.6 


\section{Accuracy}

Accuracy is determined through replicate processing of a waste container containing a known quantity of the radioactive material of interest. Accuracy is calculated from the ratio of the mean measured estimate to the known value for an accepted calibration or verification standard. Calibration standards are those used to determine the response characteristics of a measurement system. Verification standards are used to test the validity of a calibration independently of the original calibration standards. Whenever possible, both radioactive calibration and verification standards shall be obtained from sources which maintain measurement systems traceable to NIST. Evidence of such traceability and certificates for individual standards shall be obtained from the standards suppliers. The specific method for demonstrating compliance with the QAO for accuracy in RA is described in detail in Section 9.6. The bias of a RA technique or measurement system is defined as the systematic error component of the total uncertainty. The systematic error is constant for the test or test conditions. For the Program the determination of accuracy is also an estimate of the bias of a measurement system.

\section{Sensitivity Limits}

Discrimination between LLW and TRU wastes for the Program may only be made with systems for which adequate sensitivity limits have been documented. The ability to achieve the required detection limit in Table 9-1 must be demonstrated for each specific waste type/method combination planned for use in the Program.

For the Program, detection limits will be defined to be that level of radioactivity which, if present will yield a measured value less than the critical limit with 5 -percent probability. The critical limit is defined as that value which measurements of the background will exceed with 5-percent probability.

\section{Minimum Detectable Concentration}

The detection limit used in the Program is the MDC. This concept corresponds to a level of activity that is practically achievable with a given instrument, analytical method, and analyte/matrix combination. The MDC considers not only the instrument characteristics (background and efficiency), but all other factors and conditions which influence the measurement. It is an a priori (before the fact) estimate of the activity concentration that can be practically achieved under a set of typical measurement conditions. These would include the waste quantity, counting time, matrix specific corrections, decay corrections, and any other factors that comprise the activity concentration determination. It is useful for establishing that some minimum overall measurement conditions can be met. Any of several factors under operator control could be varied to obtain the required MDC. 
The MDC is an a priori estimate of the detection capabilities of a given measurement system and method. It is based on the premise that from a knowledge of the background count and other measurement system parameters, an a priori limit can be estimated for a particular measurement.

The MDC is defined on the basis of statistical hypothesis testing for the presence of activity. This approach is common to many authors and has been described extensively (Currie 1968; EPA 1980).

The derivation will not be repeated here, however, the MDC may be calculated from:

$$
M D C=K_{1} K_{2}\left(2.71+4.65 * s_{b}\right)
$$

where

$K$, is the proportionality constant relating the detector response (counts) to the activity, such as, $K=1 / e$ where $e$ is an overall detection efficiency, or $K=1 / I_{T} e_{T}$ where $I_{T}$ is the gamma ray-emission probability per decay and $e_{T}$ the detection efficiency for the gamma ray;

$K_{2}$ is the factor which relates the total activity determined by the measurement system to an activity concentration in waste under a given set of measurement conditions, for example, the weight of waste assayed and a self-absorption correction;

$s_{b}$ is the standard deviation of the background.

This equation incorporates the following assumptions:

- The preselected risk for concluding falsely that activity is present above the critical level $(a)$ and the predetermined degree of confidence for correctly detecting its presence above the critical level $(1-\beta)$ are 5 percent and 95 percent, respectively

- In the vicinity of the MDC, the gross measurement counts and background counts will be approximately equal

This equation represents the simplest case. Alternate equations have been described for multicomponent and spectrometry based systems (Pasternack and Harley 1971; Fisenne et al. 1973). Sites may propose calculational bases more appropriate to their measurement systems. Such alternate methods must be described in SOPs and incorporate the same risks of false detection and false nondetection as are described above. Calculations used to demonstrate attainment of the QAO for the MDC should use typical or average values for the parameters comprising $K_{2}$ in Equation 9-1. The specific method for demonstrating compliance with the QAO for MDC in RA is described in detail in Section 9.6. 


\section{Total Uncertainty}

Total uncertainty includes propagated uncertainty for all corrections and factors applied to the analysis of real wastes to compensate for inhomogeneities and matrix interferences. The ability to achieve the QAO for total uncertainty is not demonstrated solely from specific measurements. The ability to achieve this $Q A O$ will be determined from an evaluation by an expert review team of the propagation of all uncertainties as documented by the site. The QAOs for total uncertainty are expected to be achievable in the presence of backgrounds generated by alpha and gamma emitting sources and in the presence of interfering quantities of neutron and gamma absorbing and moderating material, as is the case for much of the waste encountered in the Program. The specific method for demonstrating compliance with the QAO for total uncertainty in RA is described in detail in Section 9.6.

\section{Completeness}

Acceptable RA data shall be obtained for 100 percent of the waste containers characterized for disposal. Acceptable radioassay data shall consist of data on the radioactivity content of the waste package obtained from measurement systems which have been demonstrated to have met all the relevant QAOs for radioassay. RA data shall be validated according to the requirement in Section 9.6 prior to shipment of the waste to WIPP.

\section{Comparability}

For purposes of the Program, when multiple systems are planned for use in determining the same or comparable parameters, the participating sites shall perform multiple, independent RAs of a sample of waste containers. Data from these multiple, independent radioassays shall be reported to CAO in the semi-annual QA reports in accordance with Section 2.2 of this QAPP as evidence of method comparability.

Regardless of the number and type of RA methods in use, each site shall participate in relevant, interlaboratory comparison programs. In this context, "relevant" means the measurement in any environmental or waste media of any parameter required in the waste characterization program using a measurement system or method planned for use in the waste characterization program. Data from such programs shall be reported to CAO for evaluation. Where existing programs are inadequate, modified or new programs will be developed to ensure that an appropriate program is available for each general class of RA.

\subsection{Methods Requirements}

Any RA method may be used as long as the documented performance characteristics of the method meet the program OAOs. Only systems being used for discriminating TRU from LLW must meet the 
QAO for MDC. When waste concentrations significantly exceed the LLW/TRU cutoff, operator controlled parameters (e.g., counting time) may be modified within preestablished limits as long as OAOs for precision continue to be met.

This section describes certain general provisions which will be applicable to all types of radioactivity measurements performed under the Program. Performance of software controlling the measurement process and analyzing data shall be demonstrated and documented in accordance with ASME NQA-1, Element 11, Supplement 11S-2 (ASME 1994). Performance may be demonstrated by the use of test problems and/or in the context of testing the performance of the measurement system with QC samples. Software testing must cover the full range of expected applications of the system.

\section{NDA Methods}

A variety of NDA technologies may be effective in meeting the requirements of the Program. Table 9-2 identifies a number of such instrument systems which are in use at various DOE and/or contractor testing facilities. The list is neither complete nor limiting and is meant to illustrate the breadth of choice available. QAOs for the project may be met with the listed systems or by modifications, functionally equivalent alternatives, multiple combinations, or hybrids of the systems. The following discussion is intended to provide clarification of the table entries.

Whenever applicable, the assay procedures cited in ASTM (1989a), ASTM (1989b), ASTM (1991b), ASTM (1992), and NRC standard practices and guidelines (NRC 1984) are recommended for use at all testing facilities. These procedures require the use of proper calibration standards, proper equipment and equipment setup, avoidance of practices (such as misalignment of the waste package) known to result in inaccurate assays, attention to proper record-keeping and equipment maintenance, and safe operation of the equipment.

NDA SOPs must instruct operators to perform all necessary background and performance checks prior to performing any assays of waste containers. These performance check data must be checked against predetermined acceptance criteria. If any criterion is not met, remedial action must be taken. Each site must include or reference in SOPs its method for determining and recording the acceptance criteria. The remedial action may include a repetition of the background and/or standards measurements. The disposition and use of any TRU waste assays performed during a period ending with a suspect performance check or during any resulting investigation or remedial action must be documented and justified. 
TABLE 9-2

NDA Methods for Potential Use for TRU Waste Assay

Types of Measurements

Methods

Gamma-Ray Measurements

Passive Neutron Measurements

Passive/Active Neutron Measurements

Thermal Neutron Capture
High Resolution Spectroscopy (Intrinsic Germanium) Transmission Corrected Gamma-Ray Measurements

- Segmented Gamma-Ray Scanner

- Computed Tomographic Gamma Ray Scanner

Shielded Neutron Assay Probe Totals Counter Passive Neutron Coincidence Counter

Advanced Matrix Corrected Passive Neutron Counter (Add-A-Source)

Am-Li Source Driven Coincidence Counter Californium Delayed-Neutron Counter (Shuffler) Neutron Generator Differential Die-Away Counter

Combined Thermal/Epithermal Neutron Counter

Californium Delayed-Neutron Counter

Neutron Generator Differential Die-Away Counter

Combined Thermal/Epithermal Neutron Counter 
SOPs for NDA systems must contain all necessary instructions for the operation of computerized data acquisition systems. Such software instructions shall include explanations of required input, options, and prohibitions for operators when exercising any interactive portions of the software.

Regardless of source, the procedures are subject to the following provisions:

- The procedures must be codified in the facility as SOPs which have been written, approved, and controlled under the provisions of the site QAPjP or a QA program with equivalent provisions for procedural control.

- The procedures must have been internally demonstrated in the facility and have documented performance characteristics which meet the QAOs of this program.

\subsection{Quality Controil}

RA is a quantitative measurement of key radioactivity parameters of the contents of a waste container. NDA systems must be checked through the use of calibration check and background waste containers as well as replicate determinations. As discussed in this section, routine performance checks shall be performed on all RA systems according to approved SOPs. All RA systems shall be operated in statistical control as determined by the control limits established by these site SOPs.

Each participating site must perform, and report in its semi-annual management reports to CAO, all required instrument performance parameters for each instrument used to perform measurements intended for use in the Program. MDCs for systems used to distinguish between LLW and TRU waste must meet the QAO specified in Section 9.1.

If any OC measurement fails to meet Program criteria, the analytical measurement may not be continued prior to taking appropriate corrective action. This section outlines the minimum QA/QC operations necessary to satisfy the analytical requirements of the Program.

\subsubsection{Measurement System Checks}

This section discusses additional OC testing for radioactivity measurement systems. It includes calibration and routine performance testing requirements used to ensure that measurement systems are in control and meet the performance specifications established for that measurement system to demonstrate compliance with the QAPP QAOs.

\section{Instrument Calibration}

Specific guidelines for instrument calibration are given in Section 9.5. Instruments must be calibrated at the frequencies specified in Section 9.5. 


\section{Instrument Performance Checks}

Although the efficiency factors vary for every sample geometry, radiation counting systems are in a sense "blind" to the conditions outside the detector which produce the radiation being measured. Because of this it is usually possible to verify the proper function of the instruments with rugged, longlived sources. Since the data obtained from these "check" sources is not directly used to calculate analytical data, they do not have to be NIST traceable, but only need to be adequately characterized for the proposed usage. The principal requirements for such sources are that they be long-lived, simple to reposition with respect to the detector(s), of sufficiently high activity to obtain adequate counting statistics in short count times, and relatively insensitive to handling.

Each of these conditions contributes to a situation where the sources can be easily and quickly counted. If long-lived and rugged, the sources' data should vary slowly with time in an easily predictable manner. For each instrument system used in radioactivity analyses, routine performance checks of efficiency, background, and energy resolution (for spectrometry systems) shall be performed. Data shall be logged, plotted on control charts and compared to preset control limits. These data shall be delivered with the analytical data, covering the time period over which the analyses were actually performed. Performance checks for non-spectrometric instruments shall include

- Efficiency checks

- Background checks

Performance checks for spectrometric instruments must also include

- Energy calibration checks

- Energy resolution checks

Except for system backgrounds, instrument performance checks shall be performed and documented at least twice each shift. These checks shall be performed prior to any actual waste measurements on each work shift and after completion of all waste measurements for the shift. When shift operations are contiguous or overlapping, the performance checks for the end of the shift completing work can be the same performance checks as those done at the beginning of the shift starting work. This procedure verifies acceptable performance of the measurement system.

The required frequencies for background measurements will be a function of the variability of the background signal and the analytical use of the background data. Backgrounds acquired over long count times, with low variability, and not used directly in the processing of analytical data need not be counted daily. Backgrounds used directly in the analytical data calculations must be counted on a frequency consistent with the potential variation of the background signal and the performance of R-4913 
the analytical measurements with which the backgrounds are associated. Site SOPs shall indicate the frequency of background measurements for each measurement system used in the Program.

\section{Replicate Counts}

Independent replicate measurements, at least duplicates, must be performed on 10 percent of the waste containers in accordance with the QAPjP and SOPs.

\subsubsection{Intercomparison Programs}

Most OC measurements take place in a closed system within a laboratory or measurement organization. Intercomparison programs provide a mechanism for comparing laboratory performance with that of other organizations performing measurements for the same analytes under comparable conditions. Participating RA testing facilities may possess near identical systems or may have significant differences, including operation under differing calibration regimes or utilization of systems with entirely different measurement principles.

Sites using NDA methods shall participate in any measurement comparison program(s) sponsored or endorsed by the NTP team leader. Such programs may be conducted as part of the PDP, through the NDA/NDE Interface Working Group (IWG), and/or through other third parties.

\subsubsection{NDA Operator Training}

Present-day NDA units are highly automated, computer-based systems. The instruments are computercontrolled using interactive software. Only trained personnel shall be aliowed to operate the assay equipment. Standardized training requirements for RA operators must be based upon existing industry standard training requirements of ASME NQA-1, Element 2, with the exception of Supplement 2S-2 (ASME 1994). Requalification of operators must be based upon evidence of continued satisfactory performance and must be done at least every two years. Unsatisfactory performance shall result in disqualification of the operator. Retraining and demonstration of satisfactory performance are required before an operator is again allowed to operate an RA system.

\subsection{Instrument Testing, Inspection, and Maintenance Requirements}

RA measurement systems must be calibrated and maintained in accordance with controls established and implemented in the site QAPjPs and SOPs, respectively. SOPs must cover the routine system calibration, performance checks, and operation of the system. For any types of RA systems which are addressed by ANSI, ASTM or other consensus standards, the site SOPs must be consistent with all relevant provisions of these standards. 


\subsection{Calibration Procedures and Frequencies}

All radiation measurement instruments must be calibrated for the specific analysis of interest. This involves the determination of the counting efficiency or some other form of response factor. Because counting efficiencies and response factors may vary with the isotope of interest, mode of decay, energy of decay, presentation geometry, and many other parameters, a unique calibration is required for each type of analysis system. Each counting system must be subjected to a complete calibration appropriate to its planned usage and based on applicable consensus standards such as those published by ASTM. Each calibration must be fuily supported with records which can be tracked to standards obtained from suppliers maintaining measurement systems traceable to NIST. Once established, the calibration is valid until a preset time limit has been exceeded or the instrument fails other performance checks. Complete verification of calibration of NDA for at least one counting geometry/sample matrix combination must be repeated at least annually.

Primary calibration standards shall be obtained from NIST, the New Brunswick Laboratory, or from suppliers maintaining measurement systems traceable to NIST whenever such standards are available. When standards are not available from such suppliers, the actual standards used shall be calibrated against primary standards obtained from NIST or from suppliers maintaining measurement systems traceable to NIST. The documentation of this cross-calibration shall be retained as a QA record. Working calibration standards shall be prepared using isotopes, geometries, and matrices having characteristics as close as possible to those expected for actual samples without compromising the quantitative integrity or homogeneity of the standard.

The range of applicability of system calibrations must be specified in site SOPs. If assay measurement values fall outside the applicable range, assay measurements must be repeated on alternate measurement systems covering the required range or other appropriate corrective actions must be taken and documented.

The commonly accepted techniques of transmission and live-time corrections to compensate for matrix variations present within a container are acceptable for the NDA techniques. Computer programs used to calculate activities of radioisotopes may use correction algorithms to compensate for some waste characteristics such as waste density, gamma absorption, neutron moderator, and neutron absorption indices. Calibration of RA measurement systems which utilize such correction factors shall include the determination of calibration factors and functional relationships to other waste parameters as part of the system calibration. Each site must determine and document the range of waste types to which it will apply any given calibration and set of correction factors. 
All computer programs and revisions thereof shall be documented, verified and validated as required by ASME NQA-1, Element 11 and Supplement 11S-2, "Supplementary Requirements for Computer Program Testing," (ASME 1994) before initial use for production of analytical data. Verification shall include both verification of the algorithm used and test runs of the program comparing the program output to true values. Test runs shall exercise all default and boundary values of parameters. Programs shall be documented in accordance with Standard for Software User Documentation (ANSI 1987). Documentation of computer programs shall include, at a minimum

- Program name

- Revision number

- Revision date

- Author(s)

- Program application

- Programming language (including version numbers of all compilers, linkers, etc.)

- Operating system

- Required hardware

- Descriptions of algorithms used

- User's manual

- Listing of Code

- Examples of input and output forms

- Results of test cases

- Copies of external data files

- Lists of default parameters

- Records of review and approval

Individual(s) responsible for the following functions must be identified:

- System operation and maintenance, including documentation and training

- Database integrity, including data entry, data updating and $\mathrm{OC}$

- Data and system security, backup and archiving

All RA equipment shall receive routine performance checks for such parameters as system counting efficiency and system background. Spectrometry based systems shall also receive routine performance checks for energy calibration and resolution. Routine performance checks shall be performed with check sources which are stable and constant or which change only by well-established and predictable quantities (e.g., radioisotope decay). Site SOPs for performance checks shall state the standards used, frequencies for each test, record keeping, control limits, and corrective actions to be taken when the control limit is exceeded. Control charts (e.g., based on acceptable ranges or variances) shall be used to track trends in the parameters measured in the performance checks. Performance checks shall be performed and documented at least twice each shift. These checks shall be performed prior to any actual waste measurements on each work shift and after completion of all waste measurements for the shift. When shift operations are contiguous or overlapping, the performance checks for the end 
of the shift completing work can be the same performance checks as those done at the beginning of the shift starting work.

\subsection{Data Management}

The results of RA for each waste container must be documented and available to the data user. Requirements for RA data reduction, validation, and reporting are presented below.

\section{Data Reduction}

The reduction of RA data may be accomplished using computer software that is specifically designed for the particular assay being performed. The software may vary from site to site. This software and/or other data reduction procedures must be specified in site QAPjPs and supporting SOPs.

Although generalized equations containing parameters commonly used to calculate the radioactivity in a given analysis can be written, not all parameters will be used in every technique. Additional or more complex calculations may be required for methods involving multiple measurements, the analysis of spectrometric data, or active interrogation techniques. The exact algorithms used by each site must be contained in the site-specific technical documentation.

\section{Data Validation}

All RA data must be reviewed and approved prior to being reported. The validation process is outlined in Section 3.0 and includes verification that the QAOs in Table 9-1 have been met. The demonstration that QAOs have been met for specific measurement systems need only be made for the ranges in Table 9-1 for which the measurement system will actually be used. These demonstrations will be made with all instrument control parameters set at specific values (e.g., a specific count time). The values for all parameters critical to the demonstration that QAOs have been met must be maintained the same for actual waste measurements as were used for the QAO demonstration. The following discussion provides details for demonstrating compliance with the QAOs for precision, accuracy, MDC, and total uncertainty.

Sites shall demonstrate compliance with the QAO for precision by replicate processing of a waste container (208-liter [55-gallon] drum) containing the quantities of TRU isotopes indicated in Table 9-1 for each range for which the measurement system is to be qualified. The activity shall be distributed in a well-characterized, non-interfering matrix and shall not be one of the standards used to calibrate the counting system. A total of fifteen replicate counts shall be obtained with removal of the waste container from the measurement system and reinsertion of the waste container into the measurement 
system between measurements. The precision shall be computed as the \%RSD of the distribution of these replicates as defined in Equations 3-2 and 3-3.

For systems using smaller volumes than the standard 208-liter (55-gallon) drum, the activity used shall be proportional to the concentration obtained by having the TRU activity distributed in a 208-liter (55-gallon) drum. Sites using destructive RA shall demonstrate compliance by carrying 15 replicates through the entire analytical process.

Sites shall demonstrate compliance with the QAO for accuracy by replicate processing of a waste container (208-liter [55-gallon] drum) containing the quantities of TRU isotopes indicated in Table 9-1 for each range for which the measurement system is to be qualified. This activity shall be in the form of a verification standard, that is, it shall be characterized as well as the calibration standards described in section 9.5 but it may not be one of the calibration standards nor shall it be derived from or calibrated against one of the calibration standards. The activity shall be distributed in a wellcharacterized, non-interfering matrix and shall not be one of the standards used to calibrate the counting system. A total of fifteen replicate counts shall be obtained with removal of the waste container from the measurement system and reinsertion of the waste container into the measurement system between measurements. The accuracy shall be computed as the $\% R$ of the known value as defined in Equation 3-5. When using Equation 3-5, $C_{m}$ is the average result of the fifteen replicate determinations and $C_{s m m}$ is the known value for the waste container used in the measurements.

For systems using smaller volumes than the standard 208-liter (55-gallon) drum, the activity used shall be proportional to the concentration obtained by having the TRU activity distributed in a 208-liter (55-gallon) drum. Sites using destructive RA shall demonstrate compliance by carrying 15 replicates through the entire analytical process.

Sites may demonstrate compliance with the $Q A O$ for MDC by replicate processing of an appropriately sized waste container containing only a well-characterized, non-interfering matrix with no added activity. A total of fifteen replicate counts shall be obtained with unloading and reloading between replicates. Sites may propose alternate methods for determining the variance of the background for specific measurement conditions. Any such alternate method must be fully justified and demonstrated to be more appropriate to the measurement system and specific conditions for which it is proposed. The MDC shall be computed using the variance of the background count and Equation 9-1 or the analogous computation using all parameters appropriate to the measurement method. 
The QAO for total uncertainty is intended to include estimates of the cumulative uncertainties from all correction factors and adjustments which are applied to the analytical data to compensate for inhomogeneous distribution, shielding, self-absorption, attenuation, and other matrix effects. Such methods may be unique to measurement systems, waste types, and sites. They may incorporate data from other measurements, be computed from information obtained from the measurement itself, or be average factors obtained from experiments. Uncertainties in any parameters influencing the computation of radioactivity content must be included in the calculation of total uncertainty. This specifically includes parameters such as the isotopic ratios when assumed to be constant or determined from data sources external to the actual measurement. Demonstration of compliance with the QAO for total uncertainty is not obtained solely from measurements on the non-interfering waste matrix although the results of such measurements may be used to estimate some of the contributing parameters.

To demonstrate compliance each site must document all such applied factors; their derivation, source or justification; the range of waste measurements to which they will be applied; and, the uncertainty associated with each factor. The uncertainties at the 95 -percent confidence level from all correcting factors shall be propagated along with estimates of the uncertainty due to any other source of precision error. It is this value which must meet the QAO for total uncertainty. This demonstration must be available for each different set of correction factors as applied to different waste types (ANSI/ASME 1985).

It is anticipated that compliance with this $Q A O$ will be evaluated in on-site reviews of the compliance packages by a team of knowledgeable experts in the field. The most probable source of members for the review teams is the existing NDA/NDE IWG and their associated staff. These individuals have the required theoretical and practical expertise as well as backgrounds in the TRU waste characterization area. Members of the IWG who are measurement staff at one site may serve as expert reviewers of measurement systems at other sites but not at their own site. The makeup, selection method, and role of the review team will be defined in a QA procedure by CAO. CAO will oversee the formation of this independent review team. This will provide the fairest possible evaluation of the site's compliance data.

\section{Data Reporting}

The results of RA must be documented and available to data users. RA testing facilities must retain all raw data in sufficient detail and with adequate support documentation to repeat all calculations as necessary. If activities of isotopes other than the nominal isotopes of interest are detected by an actual waste measurement, the activity of each of these isotopes must be reported as part of the waste assay for that container. 
RA testing data must be reported to the site project office on a testing batch basis. A testing batch is a suite of waste containers undergoing RA using the same testing equipment. A testing batch can be up to 20 waste containers without regard to waste matrix.

Each RA testing facility is required to submit testing batch data reports for each testing batch to the site project office on approved standard forms. Site-specific documentation must include example forms that will be used for reporting. RA testing batch data reports shall consist of the following:

- Cover page that includes testing facility name, testing batch number, drum numbers included in that testing batch, and signature releases of RA testing personnel as described in Section 3.1.1

- Table of contents

- Data review checklists for each testing batch verifying that the data generation level review as described in Section 3.1.1 has taken place. Checklists must contain tables showing the results of the testing batch $\mathrm{OC}$ samples

- Separate testing report sheet(s) for each sample in the testing batch that includes

- Title "Radioassay Data Sheet"

- Method used for NDA (i.e., procedure identification)

- TRUCON code, Item Description Code, matrix parameter category, as applicable

- Date of NDA examination

- Total Pu-239 fissile gram equivalents (g) and associated uncertainty

- Total alpha activity and associated uncertainty (Curies)

- TRU activity and associated uncertainty (nCi/g)

- Listing of individual radioisotopes present (Curies) and associated uncertainty (Curies)

- Thermal power and associated uncertainty (W)

- QC replicate (yes/no)

- Operator signature/date

- Reviewer signature/date

All associated uncertainties shall be reported at the 95-percent confidence level. A form containing all the information specified above must be completed and signed. Figure 1-5 indicates how the NDA data form should travel through the waste characterization process. In addition, RA testing facilities located on sites shall maintain the following items in their files, documented and retrievable by testing batch number. Contract RA testing facilities shall forward these items along with testing batch data reports to the site project office for storage in site project files.

- Original waste container COC forms

- All raw data, including instrument readouts, calculation records, and RA OC results

- All instrument calibration reports, as applicable 


\subsection{RADIOGRAPHY}

Radiography is a non-destructive qualitative and semi-quantitative technique that involves $X$-ray scanning of waste containers to identify and verify waste container contents. The results of radiography will be verified through visual examination of a statistically selected portion of retrievably stored waste containers in each waste stream, as described in Section 5.3.2.

\subsection{Quality Assurance Objectives}

The QAOs for radiography are detailed in this section. If the QAOs described below are not met, then corrective action, such as additional operator training must be taken. It should be noted that radiography does not have a specific MDL because it is primarily a qualitative determination. The objective of radiography for the Program is to verify the matrix parameter category as specified in the BIR and DOE (1995a) for each waste container, and estimate each waste material parameter weight (Table 10-1). All activities required to achieve these objectives must be described in site QAPjPs and SOPs.

Data to meet these objectives must be obtained from an audio/videotaped scan provided by trained radiography operators at the sites. Results must also be recorded on a radiography data form. The precision, accuracy, completeness, and comparability objectives for radiography data are presented below.

\section{Precision}

The qualitative determinations, such as verifying matrix parameter category, made during radiography do not lend themselves to statistical evaluation of precision. However, comparison of data derived from radiography and visual examination on the same waste containers at RFP and INEL indicates that radiography operators can provide estimated inventories and weights of waste items in a waste container (EG\&G 1993a). As a measure of precision, the site project QA officer shall calculate and report the RPD between the estimated waste material parameter weights as determined by radiography, and these same parameters as determined by visual examination.

\section{Accuracy}

The accuracy with which the matrix parameter category and waste material parameter weights can be determined must be documented through visual examination of a randomly selected statistical portion of waste containers (Section 5.0). The percentage of waste containers which requires a new matrix parameter category after visual examination must be calculated and reported by the site project $\mathrm{QA}$ officer as a measure of radiography accuracy. 
TABLE 10-1

Waste Material Parameters and Descriptions

Waste Material Parameter Description

Iron-based Metals/Alloys

Aluminum-based Metals/Alloys

Other Metals

Other Inorganic Materials

Cellulosics

Rubber

Plastics (waste materials)

Organic Matrix

Inorganic Matrix

Soils

Steel (packaging materials)

Plastics (packaging materials)
Iron and steel alloys in the waste; does not include the waste container materials

Aluminum or aluminum-based alloys in the waste materials

All other metals found in the waste materials

Nonmetallic inorganic waste including concrete, glass, firebrick, ceramics, sand, and inorganic sorbents

Materials generally derived from high polymer plant carbohydrates; (e.g., paper, cardboard, wood, cloth)

Natural or man-made elastic Latex materials; (e.g., surgeons' gloves, leaded rubber gloves)

Generally man-made materials, often derived from petroleum feedstock; (e.g., polyethylene, polyvinylchloride)

Cemented organic resins, solidified organic liquids, and sludges

Any homogeneous materials consisting of sludge, or aqueous-based liquids which are solidified with cement, calcium silicate, or other solidification agents; (e.g., waste water treatment sludge, cemented aqueous liquids, and inorganic particulates)

Generally consists of naturally occurring soils which have been contaminated with inorganic waste materials

208-liter (55-gallon) drums

90 mil polyethyline drum liner and plastic bags

Source: Waste Isolation Pilot Plant Transuranic Waste Baseline Inventory Report (DOE $1995 \mathrm{f}$ ). 


\section{Completeness}

An audio/videotape of the radiography examination and a radiography data form, validated according to the requirements in Section 3.0, must be obtained for 100 percent of the retrievably stored waste containers in the Program.

\section{Comparability}

The comparability of radiography data from different sites shall be enhanced by using standardized radiography procedures and operator qualifications in accordance with the requirements of this QAPP.

\subsection{Methods Requirements}

Radiography has been developed by DOE specifically to aid in the examination and identification of containerized waste. There is no equivalent or associated method found in EPA sampling and analysis guidance documents. All activities required to achieve the radiography objectives must be described in site QAPjPs and SOPs.

A radiography system normally consists of: an X-ray-producing device; an imaging system; an enclosure for radiation protection; a waste container handling system; an audio/video recording system; and an operator control and data acquisition station. Although these six components are required, it is expected there will be some variation within a given component between sites. The $\mathrm{X}$-ray-producing device must have controls which allow the operator to vary the voltage, thereby controlling image quality. It should be possible to vary the voltage, typically between $150-400 \mathrm{kV}$, to provide an optimum degree of penetration through the waste. For example, high-density material should be examined with the $X$-ray device set on the maximum voltage. This ensures maximum penetration through the waste container. Low-density material should be examined at lower voltage settings to improve contrast and image definition. The imaging system typically utilizes a fluorescent screen and a low light television camera.

To perform radiography, the waste container is scanned while the operator views the television screen. An audio/videotape is made of the waste container scan and is maintained as a permanent record. A radiography data form is also used to document the matrix parameter category and estimated waste material parameter weights of the waste. The estimated waste material parameter weights should be determined by compiling an inventory of waste items, residual materials, and packaging materials. The items on this inventory should be sorted by waste material parameter and combined with a standard weight look-up table to provide an estimate of waste material parameter weights. Additional detail concerning estimation of volume and weight of waste items is provided in the Methods Manual. 


\subsection{Quality Control}

The radiography system involves qualitative and semi-quantitative evaluations of visual displays. Operator training and experience are the most important considerations for assuring quality controls in regard to the operation of the radiography system and for interpretation and disposition of radiography results. Only trained personnel must be allowed to operate radiography equipment.

Standardized training requirements for radiography operators must be based upon existing industry standard training requirements and must comply with the training and qualification requirements of NQA-1, Element 2, except for Supplement 2S-2 (ASME 1994). Supplement 2S-2 is associated with radiography used in verifying safety-related parameters, such as welding, where quantitative comparisons can be utilized. As such, it is not applicable to waste management operations and not considered necessary or appropriate for training radiography operators involved in Program activities.

Each site must develop a program that provides radiography operators with training based on matrix parameter categories. Radiography operators must be instructed in the specific waste generating practices, typical packaging configuration, and associated waste material parameters expected to be found in each matrix parameter category at that site. Requalification of operators must be based upon evidence of continued satisfactory performance (primarily audio/videotape reviews) and must be done at least every two years. Unsatisfactory performance must result in disqualification. Retraining and demonstration of satisfactory performance are required before an operator is again allowed to operate the radiography system.

A training drum with various container sizes must be periodically scanned by each operator. The videotape must then be reviewed by a supervisor to ensure that operators' interpretations remain consistent and accurate. Imaging system characteristics of the monitoring system must be verified on a routine basis.

Independent replicate scans and replicate observations of the video output of the radiography process must be performed under uniform conditions and procedures. Independent replicate scans must be performed on one waste container per testing batch. Independent observations of one scan (not the replicate scan) must be made once per testing batch. A testing batch is a suite of waste containers undergoing radiography using the same testing equipment. A testing batch can be up to 20 waste containers without regard to waste matrix.

Oversight functions include periodic audio/video tape reviews of accepted waste containers and must be performed by qualified radiography personnel other than the operator who dispositioned the waste 
container. The results of this verification must be available to the radiography operator. The site project $\mathrm{QA}$ officer shall be responsible for monitoring the quality of the radiography data and calling for corrective action, when necessary.

As an additional $\mathrm{OC}$ check, the radiography results must be verified directly by visual examination of the waste container contents. Visual examination must be performed on a statistically determined portion of waste containers to verify the results of radiography. This verification must include the matrix parameter category and waste material parameter weights. The verification must be performed through an independent comparison of radiography and visual examination results. The results of the visual examination must be transmitted to the radiography facility. The selection of waste containers for visual examination must be conducted in accordance with the procedure specified in Section 5.0.

The visual examination must consist of a semi-quantitative and/or qualitative evaluation of the waste container contents, and must be recorded on audio/videotape. The visual examination program has been developed by DOE to provide an acceptable level of confidence in radiography. There is no equivalent method found in EPA sampling and analysis guidance documents. A detailed procedure that meets the requirements of this method can be found in the Methods Manual.

A training program using simulated and/or real waste must be developed based on waste form and waste management operations. This training program must be used to assess operator performance before actual waste characterization by visual examination. QAPJPs and supporting SOPs shall specify the training requirements and all other activities required to achieve the visual examination objectives.

In association with the Program, each visual examination facility must designate a visual examination expert. The visual examination expert must be familiar with the waste generating processes that have taken place at that site and also be familiar with all of the types of waste being characterized at that site as part of the Program. The visual examination expert shall be responsible for the overall direction and implementation of the visual examination aspects of the Program at that facility. Site QAPjPs must specify the selection, qualification, and training requirements of the visual examination expert.

Figure 10-1 illustrates the overall programmatic approach to the visual examination of waste. The visual examination expert must decide the extent of waste segregation that will be required to achieve Program objectives. If the waste is homogeneous, the expert may decide that a limited visual examination involving a confirmation of the radiography data is appropriate. If the waste is heterogeneous, the expert may decide a full visual examination by opening bags and segregating waste is warranted. Various degrees of segregation are possible based on the expert's judgment and R-4913 


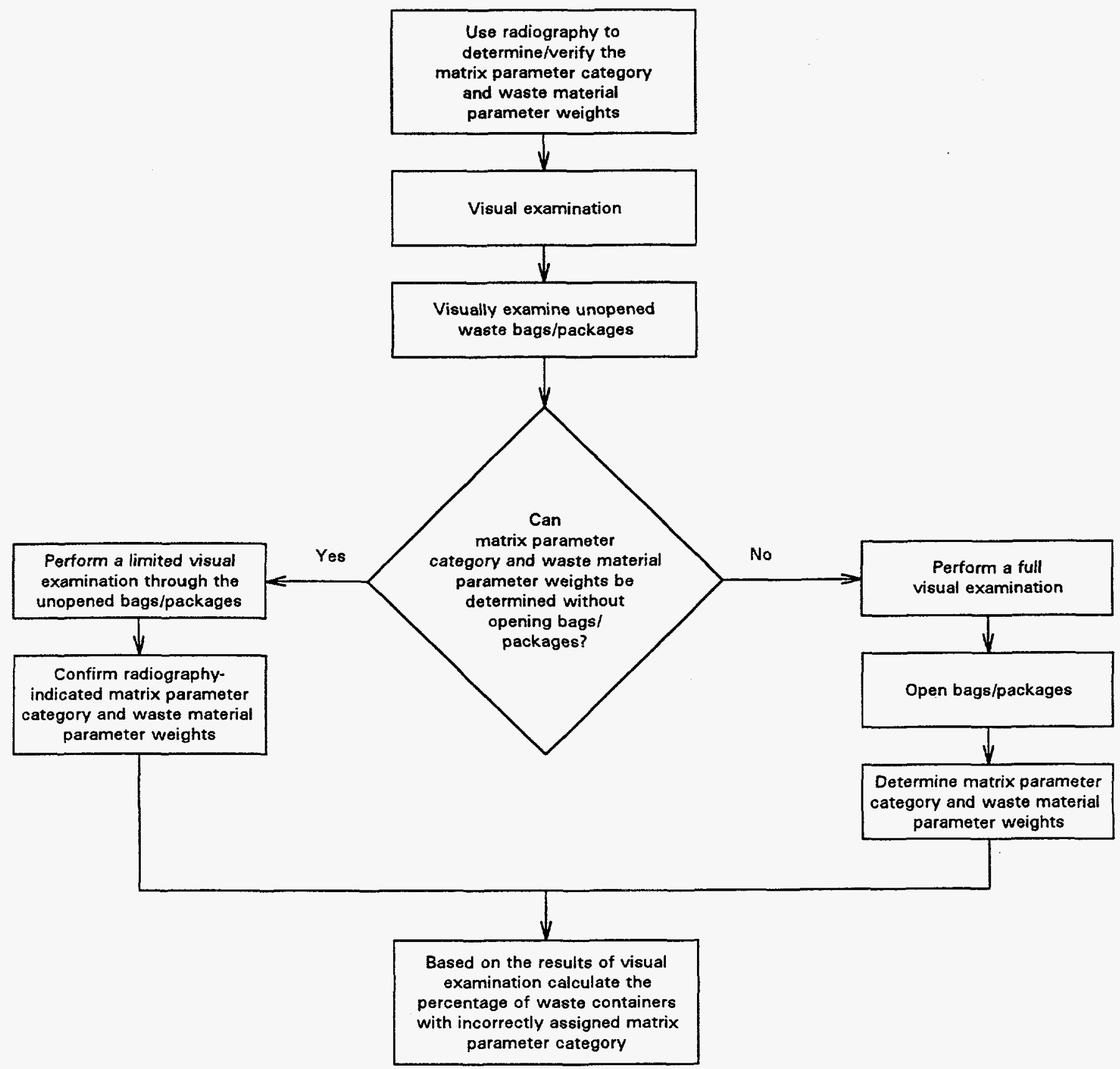

FIGURE 10-1

Overall Programmatic Approach to Visual Examination 
availability of acceptable knowledge data. Site QAPjPs must specify decision-making criteria for the visual examination expert. In all cases, SOPs must be developed to support the visual examination process, and the basis for the expert's decisions must be documented.

A description of the waste container contents must be recorded on a data form as described in Section 10.6. The description can be brief, but it must clearly identify the appropriate matrix parameter categories listed in the BIR and DOE (1995a) and provide enough information to estimate weights of waste material parameters, Table 10-1. In cases where bags are not opened, a brief written description of the contents of the bags must contain an estimate of the amount of each constituent in the bags. The written records of visual examination must be supplemented with the audio/video recording.

\subsection{Instrument Testing, Inspection, and Maintenance Requirements}

All equipment used during radiography must be tested and maintained in accordance with manufacturer instructions. Site QAPjP and SOPs must document the specific manufacturer's requirements for testing and inspection.

\subsection{Instrument Calibration and Frequency}

Radiography equipment must be calibrated and maintained in accordance with controls established and implemented in site QAPJPs and SOPs, respectively. These procedures must address performance criteria. When radiography equipment is in use, operational checks must be conducted at the beginning of each work shift. These checks must also include observation of a test pattern to ensure that the radiography system has adequate video quality.

\subsection{Data Management}

Each radiography facility is required to submit testing batch data reports for each testing batch to the site project office on approved standard forms. Site-specific documentation must include example forms that will be used for data reporting. Radiography testing batch data reports shall consist of the following:

- Cover page that includes radiography facility name, testing batch number, waste container numbers included in that testing batch, and signature releases of radiography facility personnel as described in Section 3.1.1

- Table of contents 
- Data review checklists for each testing batch verifying that the data generation level review, validation, and verification (Section 3.1.1) has taken place; checklists must contain tables showing the results of testing batch-related OC samples (i.e., replicate scans, independent observations)

- Separate testing report sheet(s) for each waste container in the testing batch that includes

- Title "Radiography Data Sheet"

- Date of radiography examination

- Waste container number

- TRUCON code, Item Description Code, and matrix parameter category, as applicable

- Visual examination performed (yes/no)

- Any changes made to matrix parameter category

- Estimate of each applicable waste material parameter weight

- Presence/absence of waste container liner (yes/no)

- Estimated inventory of waste container contents, e.g., number/count of a particular waste item, as applicable

- Description of contents packaging materials, including the number of layers of packaging

- $\quad$ OC replicate scan (yes/no); if yes, brief description of comparison results

- Audio/videotape identification number

- Operator signature/date

- Reviewer signature/date

- Nonconformance reports, if applicable

- For waste containers undergoing visual examination, the following additional data must be reported:

- Matrix parameter category determined by visual examination

- Waste material parameter weights determined by visual examination

In addition, radiography facilities located on sites shall maintain the following items in their files, documented and retrievable by testing batch number. Contract radiography facilities shall forward these items along with testing batch data reports to the site project office for storage in site project files. 
Revision: 0

Date: $4 / 30 / 95$

Page 9 of 9

- Audio/videotapes

- Original waste container COC forms

- All raw data, including instrument readouts, calculation records, and radiography $Q C$ results

- All instrument calibration reports, as applicable 


\subsection{HYDROGEN AND METHANE ANALYSIS}

This section identifies the required $Q A$ elements for the analysis of hydrogen and methane in gas samples. Gas samples are collected in SUMMA passivated canisters from the headspace of waste containers and inner layers of confinement. The collection of gas samples is detailed in Section 7.0 of this QAPP.

\subsection{Quality Assurance Objectives}

The development of DQOs specifically for this program has resulted in the QAOs listed in Table 11-1. The specified QAOs represent the required quality of data necessary to draw valid conclusions regarding the Program objectives. Program-required limits, such as the PRQL, are specified to ensure that the analytical data collected satisfy the requirements of all data users. Key data quality indicators for laboratory measurements are defined below and the methods to qualitatively and quantitatively assess these indicators are discussed in Section 3.0 of this QAPP.

\section{Precision}

Precision shall be assessed by analyzing laboratory duplicates and replicate analyses of laboratory control samples and PDP blind audit samples. Results from measurements on these samples will be compared to the criteria listed in Table 11-1. These QC measurements will be used to demonstrate acceptable method performance and to trigger corrective action when control limits are exceeded.

\section{Accuracy}

Accuracy as $\% R$ shail be assessed for the laboratory operations by analyzing PDP blind audit samples and laboratory control samples. Results from these measurements must be compared to the criteria listed in Table 11-1. These $O C$ measurements will be used to demonstrate acceptable method performance and to trigger corrective action when control limits are exceeded.

\section{Method Detection Limit}

MDLs shall be expressed in volume percent and must be less than or equal to those listed in Table 11-1. MDLs shall be determined based on the method described in Section 3.2. The detailed procedures for MDL determination shall be included in site SOPs.

\section{Program Required Quantitation Limit}

Laboratories must demonstrate the capability to quantitate analytes at or below the PROLs given in Table 11-1. Laboratories shall set the concentration of at least one calibration standard below the PRQL. The detailed procedures for PROL demonstration shall be included in laboratory SOPs. 
TABLE 11-1

Hydrogen and Methane Analysis Quality Assurance Objectives

\begin{tabular}{|c|c|c|c|c|c|c|}
\hline Analyte & CAS Number & $\begin{array}{c}\text { Precision" } \\
\text { (\%RSD or RPD) }\end{array}$ & $\begin{array}{c}\text { Accuracy } \\
\text { (\%R) }\end{array}$ & $\begin{array}{l}\text { MDL } \\
\text { (vol\%) }\end{array}$ & $\begin{array}{l}\text { PROL } \\
\text { (vol\%) }\end{array}$ & $\begin{array}{c}\text { Completeness } \\
\text { (percent) }\end{array}$ \\
\hline Hydrogen & $1333-74-0$ & $\leq 25$ & $70-130$ & 0.05 & 0.1 & 90 \\
\hline Methane & $74-82-8$ & $\leq 25$ & $70-130$ & 0.05 & 0.1 & 90 \\
\hline $\begin{array}{l}\text { \%RSD }= \\
\text { RPD }= \\
\% R= \\
\text { MDL }= \\
\text { PROL }=\end{array}$ & $\begin{array}{l}=\text { Percent relative stan } \\
=\text { Relative percent diff } \\
=\text { Percent recovery } \\
=\text { Method detection lin } \\
=\text { Program required qu }\end{array}$ & $\begin{array}{l}\text { dard deviation } \\
\text { rence } \\
\text { it } \\
\text { antitation limit }\end{array}$ & & & & \\
\hline
\end{tabular}




\section{Completeness}

Laboratory completeness shall be expressed as the number of samples analyzed with valid results as a percent of the total number of samples submitted for analysis. Participating laboratories must meet the completeness specified in Table 11-1.

\section{Comparability}

Data generated through analysis of samples from different sites shall be comparable. Comparability will be achieved by using standardized methods, traceable standards, and participation by all sites in the PDP.

\section{Representativeness}

Representativeness for headspace hydrogen and methane analysis shall be achieved by collecting sufficient numbers of samples using clean sampling equipment that does not introduce sample bias. Samples must be collected as described in Section 7.0 of this QAPP.

\subsection{Methods Requirements}

Laboratories must use either gas mass spectroscopy (MS) or gas chromatography (GC) for the analysis of hydrogen and methane. Alternate analytical methods, which meet all of the QAOs in Section 11.1, may be submitted to CAO for approval. The Methods Manual contains two procedures, "Determination of Hydrogen and Methane by Mass Spectrometry" and "Determination of Hydrogen and Methane by Gas Chromatography," that meet all of the QAOs listed in Table 11-1. The procedures are based on ASTM Method D-2650-83 (ASTM 1983b) and ASTM Method 1946-82 (ASTM 1982), respectively. Laboratory SOPs must specify the detailed requirements for implementation of the selected procedure(s).

Reduction in sample aliquot size and final volume from those suggested in these methods is allowable as long as the QAOs in Section 11.1 are achievable. Equivalency of modified methods shall be demonstrated by meeting the QAOs in Section 11.1 .

\section{Criteria for Standards}

Primary hydrogen and methane standards must be purchased from the best available source IScott Specialty Gases or equivalent). All commercial standards must be certified by the manufacturer. Laboratory SOPs must specify detailed requirements for the preparation of all standards. 


\section{Criteria for Qualitative and Quantitative Analysis}

Hydrogen and methane must be quantitated within the calibration range of the analytical instrument being used. Multiple dilutions may be required when the sample concentration exceeds the calibration range of the analytical instrument or the calibration curve.

For MS, the positive ions of different masses, which are formed by electron bombardment, shall be used for qualitative and quantitative analysis. The abundance of each mass present must be determined from the signal at the corresponding mass-to-charge ratio $(\mathrm{m} / \mathrm{z})$. Hydrogen and methane concentrations shall be reported as volume percent and calculated from the partial pressures of hydrogen and methane in a sample.

For GC, hydrogen and methane shall be identified by retention time (RT). The RT for each analyte must be within the RT window for the most recent calibration verification standard. RT windows are determined by injecting a minimum of three standards containing hydrogen and methane over a 72 hour period. RT windows shall be calculated as the mean plus or minus three times the standard deviation of the individual RTs for each standard analyzed in the 72 hour period. Quantitation shall be based on the area response of each analyte and reported as volume percent.

\subsection{Quality Control}

To assure that data of known and documented quality are generated, each participating laboratory shall implement a documented analytical laboratory QA program. Laboratory QA programs shall specify qualitative and quantitative acceptance criteria for the $\mathrm{QC}$ checks of this Program and corrective action measures to be taken when these criteria are not satisfied.

It shall be the responsibility of the laboratory $\mathrm{OA}$ officer to monitor and document procedure performance, including the analysis of $\mathrm{QC}$ samples. The laboratory $\mathrm{QA}$ officer and technical supervisor shall have the responsibility to implement corrective actions when acceptable procedure performance is not met.

Laboratories shall operate a formal $Q C$ program and maintain records to document the quality of the data generated. All $Q C$ elements established in the analytical methods must be implemented with laboratory SOPs including, but not limited to, method performance samples, laboratory duplicates, laboratory blanks, laboratory control samples, and blind audit samples. Specific OC samples and frequencies are based on an analytical batch and are summarized in Table 11-2. An analytical batch is defined as a suite of samples of a similar matrix that is processed as a unit using the same analytical 
TABLE 11-2

\section{Summary of Laboratory Quality Control Samples and Frequencies for Hydrogen and Methane Analysis}

\begin{tabular}{|c|c|c|c|}
\hline OC Sample & Minimum Frequency & $\begin{array}{l}\text { Acceptance } \\
\text { Criteria }\end{array}$ & $\begin{array}{l}\text { Corrective } \\
\text { Action }\end{array}$ \\
\hline $\begin{array}{l}\text { Method performance } \\
\text { samples }\end{array}$ & $\begin{array}{l}\text { Seven (7) samples initially } \\
\text { and four (4) semiannually }\end{array}$ & Meet Table 11-1 OAOs & $\begin{array}{l}\text { Repeat until } \\
\text { acceptable }\end{array}$ \\
\hline Laboratory duplicates & $\begin{array}{l}\text { One (1) per analytical } \\
\text { batch }\end{array}$ & $R P D \leq 25^{b}$ & $\begin{array}{l}\text { Nonconformance if } \\
R P D>25\end{array}$ \\
\hline Laboratory blanks & $\begin{array}{l}\text { One (1) per analytical } \\
\text { batch }\end{array}$ & $\begin{array}{l}\text { Analyte concentrations } \\
<3 \times \mathrm{MDL}\end{array}$ & $\begin{array}{l}\text { Nonconformance if } \\
\text { analyte concentrations } \\
>3 \times \mathrm{MDL}\end{array}$ \\
\hline $\begin{array}{l}\text { Laboratory control } \\
\text { samples }\end{array}$ & $\begin{array}{l}\text { One (1) per analytical } \\
\text { batch }\end{array}$ & $70-130 \% R$ & $\begin{array}{l}\text { Nonconformance if } \\
\% R<70 \text { or }>130\end{array}$ \\
\hline Blind audit samples & $\begin{array}{l}\text { Samples and frequency } \\
\text { controlled by the Gas PDP } \\
\text { Plan }\end{array}$ & $\begin{array}{l}\text { Specified in the } \\
\text { Gas PDP Plan }\end{array}$ & $\begin{array}{l}\text { Specified in the } \\
\text { Gas PDP Plan }\end{array}$ \\
\hline
\end{tabular}

${ }^{a}$ Corrective Action when $\mathrm{OC}$ samples do not meet the acceptance criteria; Nonconformance procedures are outlined in Section 2.1.2.1.

bApplies only to concentrations greater than the PROL listed in Table 11-1.

MDL = Method detection limit

PDP = Performance Demonstration Program

$\mathrm{QAO}$ = Quality assurance objective

$\% \mathrm{R} \quad=$ Percent recovery

RPD = Relative percent difference 
method, within a specific time period. An analytical batch can be up to 20 samples, lexcluding laboratory OC samples), all of which must be received by the laboratory within 14 days of the VTSR of the first sample in the batch.

Method performance samples shall be used to demonstrate acceptable laboratory performance prior to the analysis of any samples. Method performance samples may be purchased commercially or prepared by the laboratory and must contain hydrogen and methane at concentrations appropriate to verify that all of the QAOs in Table 11-1 are met. Initially, seven method performance samples shall be analyzed to demonstrate acceptable precision and accuracy and shall also be used to determine MDLs for hydrogen and methane according to the method described in Section 3.2. Acceptable procedure performance shall be demonstrated semiannually by analyzing four method performance samples.

The laboratory shall analyze field samples in duplicate at a minimum frequency of one per analytical batch. Laboratory duplicate results shall be considered acceptable for hydrogen and methane if they meet the QAO for precision specified in Table 11-1.

Laboratory blanks shall be SUMMA ${ }^{\circ}$ canisters filled with high-purity nitrogen 199.999 -percent pure) in the laboratory using the sample preparation manifold. The same procedure used to prepare field samples for analysis shall be used to prepare the laboratory blanks. Laboratory SOPs shall provide the details of blank preparation and analysis. Laboratory blanks must be analyzed daily and will be acceptable if analyte concentrations are less than three times the MDL.

Commercially purchased gas standards shall be used to prepare laboratory control samples. The gas standards used to prepare the laboratory control samples must be independent of those used for instrument calibration. Laboratory control samples must contain hydrogen and methane at concentrations in the calibration range of the analytical instrument and must be analyzed at a frequency of one per analytical batch. Laboratory control sample results shall be acceptable if the criterion for accuracy in Table 11-1 is satisfied.

Blind audit samples provided by the PDP shall be used to determine acceptable laboratory performance. Laboratory performance will be evaluated biannually.

\subsection{Instrument Testing, Inspection, and Maintenance Requirements}

Each laboratory must ensure that its analytical instruments are tested, inspected, and maintained such that the QAOs in Table $11-1$ are met. Analytical instruments must also meet all Methods Manual 
requirements for data systems, detectors, and sample inlet systems. Laboratories shall detail the testing, inspection, and maintenance requirements in site SOPs.

\subsection{Instrument Calibration and Frequency}

Mass spectrometers and gas chromatographs must be calibrated. All laboratories shall prepare and follow detailed SOPS covering all aspects of calibration and maintain instrument run logs that permit the reconstruction of the calibration sequence and frequency. MS and GC calibration requirements are summarized in Table 11-3.

An initial MS calibration shall be performed prior to the analysis of any samples to establish a mass pattern and sensitivity for hydrogen and methane. After the mass calibration has been performed, the base peak for hydrogen and methane must read 2 and 16, respectively. The sensitivity calibration shall be acceptable if two consecutive sensitivity measurements have a \%D of less than or equal to 15 for each analyte. Additional calibrations must be performed as specified by the manufacturer or when the RPD between the initial and continuing calibration results is greater than 10 or when the sum of the partial pressures for all components in the continuing sensitivity calibration gas exceeds plus or minus 3 percent of the total pressure of the introduced sample.

Continuing MS calibration shall be performed at the beginning and end of each analytical batch run. If the RPD of the base peaks between the continuing calibration and the most recent valid initial calibration is less than or equal to 10 , then the mass spectrometer shall be considered calibrated. The laboratory control sample may be used for continuing calibration. If the laboratory control sample is not used for continuing calibration, then the laboratory control sample must be run as a sample during the analytical sequence. The continuing calibration gas must be from a separate source than that used for the initial instrument calibration. The standard used for continuing calibration must contain both hydrogen and methane at concentrations within the calibration range of the analytical instrument.

Sensitivity calibration shall be verified by showing that the sum of the partial pressure of the components (hydrogen, methane, and makeup gases) in the standard gas cylinder equals the total pressure of the introduced sample plus or minus 3 percent. If the partial pressure sum differs from the total sample pressure, the problem must be assessed and corrective action taken and documented. Differences may be due to sensitivity errors or components that are unaccounted for in the standard. All laboratories shall prepare and follow detailed SOPs covering all aspects of MS calibration and maintain instrument run logs that permit the reconstruction of the calibration sequence and frequency. 
TABLE 11-3

Summary of MS and GC Calibration Requirements for Hydrogen and Methane Analysis

MS

Initial mass calibration

Initial sensitivity

calibration

Continuing mass

calibration

Continuing sensitivity

calibration

GC 3-pt initial calibration

(3 standards)

Continuing calibration
Frequency of Procedure

Initially and as needed

Initially and as needed

Beginning and end of each analytical batch

Beginning and end of each analytical batch

Initially and as needed

Every 12 hours
Acceptance Criteria

Base peak of 2 and 16 for hydrogen and methane, respectively

$\% \mathrm{D} \leq 15$ for each analyte from two consecutive sensitivity measurements

RPD $\leq 10$ for each analyte

Sum of partial pressure for all components in the standard gas cylinder equals total pressure of introduced sample $\pm 3 \%$

\%RSD of response factor for each analyte $\leq 35$

-or-

Linear regression plot vields straight line and \%R for each analyte is 70-130

$\% D \leq 30$ for each analyte

\footnotetext{
$\% \mathrm{D}=$ Percent difference

$\% \mathrm{R} \quad=$ Percent recovery

RPD $=$ Relative percent difference

$\%$ RSD $=$ Percent relative standard deviation
} 
For GC, an initial multipoint calibration curve for hydrogen and methane shall be obtained. The multipoint calibration must consist of a minimum of three standards with the low standard at a concentration less than the PROL (Table 11-1), and the high standard at a concentration such that it brackets the expected sample concentrations, yet remains within the linear range of the instrument. The initial calibration is considered valid and the average response factor can be used if the \%RSD for each analyte is less than or equal to 35 . Alternately a linear regression equation can be generated plotting area response versus concentration. If the resulting plot yields a straight line and the calculated value for each standard analyte is $70-130 \% R$, then the initial calibration is considered valid. A new multipoint calibration may also be required if there is a change in the instrument that may affect the analytical results or if indicated as a $\mathrm{OC}$ action.

A continuing calibration check standard must be analyzed at the beginning of each 12-hour shift. The response factor (or concentration) of the continuing calibration check standard shall be compared to the corresponding average response factor (or concentration) from the most recent valid initial calibration. If the $\% D$ between the average response factor (or concentration) and that of the continuing calibration check is less than or equal to 30 , the GC system shall be considered calibrated. If the continuing calibration does not meet the acceptance criteria, either another continuing calibration must be run, or a new calibration curve generated. Sample analysis cannot continue until the requirements are met.

The laboratory control sample may be used for the continuing calibration check. If the laboratory control sample is not used for continuing calibration, then the laboratory control sample must be run as a sample during the analytical sequence. The calibration check standard, or laboratory control sample, must be from a separate source than that used for the initial instrument calibration. The standard used for continuing calibration must contain both hydrogen and methane at concentrations within the calibration range of the analytical instrument.

\subsection{Data Management}

Data management includes requirements for data reduction, validation, and reporting. All of the data management requirements defined in Section 3.1.1 of this QAPP, as well as those described below, apply to data from hydrogen and methane analyses. Data management procedures demonstrating compliance with these requirements must be detailed in QAPjPs and SOPs and, as appropriate, include specific equations, sample calculations, and example forms for data reduction, validation, and reporting. 


\section{Data Reduction}

Hydrogen and methane concentrations must not be blank-corrected. Results from laboratory blanks shall be reported separately from field samples as specified in the data reporting section below. Hydrogen and methane concentrations determined by MS shall be quantified using the values of peak height (in $\mathrm{mV}$ ) and sensitivity (in $\mathrm{mV} / \mathrm{Torr}$ ). Concentrations shall be reported in units of volume percent. Hydrogen and methane concentrations determined by GC shall be quantified using average response factors or linear regression equations obtained from certified calibration standards. Procedures for data reduction can be found in the Methods Manual. SOPs must detail procedures for reducing raw data to reportable results.

\section{Data Validation}

All hydrogen and methane analysis data must be reviewed and approved prior to being reported. The validation process is outlined in Section 3.1.1 and includes verification that the QAOs in Table 11-1 have been met.

\section{Data Reporting}

Each laboratory analyzing samples is required to submit analytical batch data reports to the site project office for each analytical batch. Analytical batch data reports must be submitted on approved standard forms. Site-specific documentation must include example forms that will be used for reporting. Analytical batch data reports shall consist of the following:

- Cover page that includes the laboratory name, analytical batch number, sample numbers included in that analytical batch, a cross reference to field sample numbers, and the signature releases of laboratory personnel as specified in Section 3.1.1.

- Table of Contents.

- Summary COC Form that shows the date and time of sample transfer, and name of individuals handling the samples from the time of sampling through receipt at the laboratory.

- Original or a copy of the field sample canister tags.

- Data review checklists for each analytical batch verifying that the data generation level review, validation and verification, as described in Section 3.1.1, has taken place. Checklists must contain tables showing the results of the analytical batch QC samples (e.g., laboratory duplicates, laboratory control samples).

- A separate analytical report sheet for each sample in the analytical batch that includes the laboratory name, program name, the title "Hydrogen and Methane Analysis Data Sheet," analytical batch number, sampling batch number, laboratory sample number, field sample number, date sampled, date and time analyzed, method number, listing of program analytes, and analytical results in volume percent. Data qualifying flags shall be used as follows: 
- B-Analyte detected in blank

- E-Analyte exceeds the calibration curve

- J-Analyte less than PROL, but greater than or equal to MDL

- U-Analyte was undetected (Report MDL)

- D-Analyte was quantitated from a secondary dilution, or reduced volume sample aliquot

- Nonconformance reports, if applicable.

In addition, laboratories located on sites shall maintain the following items in their files, documented and retrievable by analytical batch number. Contract laboratories shall forward these items along with analytical results to the site project office for storage in site project files.

- Original COC forms.

- All raw data, including original instrument readouts and/or bench reports, calculation records, and laboratory OC sample results. Laboratory duplicate results are recorded along with the original sample results, and the RPD between the two results are calculated. Laboratory control sample results are entered with the accepted value and the \%R.

- All instrument calibration reports that include the accepted and measured values of calibration verification for all analytes. These reports must also contain the laboratory name, analytical batch number(s), initial and continuing calibration verification source, method identification, and calibration date and time.

- QC result summary, which includes true and found values for all QC samples plus associated result calculations. At a minimum, the $\mathrm{QC}$ data shall include blanks, laboratory control samples, duplicates, initial calibration data, initial and continuing calibration verifications, and all other method-specific $Q C$ listed in Table 11-3. The OC summary report must also contain the laboratory name, the analytical batch number (if applicable). and method names.

- Original field sample canister tags, if not submitted with the analytical batch data report. 


\subsection{GAS VOLATILE ORGANIC COMPOUND ANALYSIS}

This section identifies the required $Q A$ elements for the analysis of VOCs in gas samples. Gas samples are collected in SUMMA $^{\circ}$ passivated canisters from waste container headspace and inner layers of confinement. The collection of gas samples is detailed in Section 7.0 of this QAPP.

\subsection{Quality Assurance Objectives}

The development of DOOs specifically for this Program has resulted in the QAOs listed in Table 12-1. The specified $Q A O$ s represent the required quality of data necessary to draw valid conclusions regarding the Program objectives. Program-required limits, such as the PROL associated with VOC analysis, are specified to ensure that the analytical data collected satisfy the requirements of all data users. Key data quality indicators for laboratory measurements are defined below and the methods to quantitatively and qualitatively assess these indicators are discussed in Section 3.0 of this QAPP.

\section{Precision}

Precision shall be assessed by analyzing laboratory duplicates and replicate analyses of laboratory control samples and PDP blind audit samples. Results from measurements on these samples must be compared to the criteria listed in Table 12-1. These $Q C$ measurements will be used to demonstrate acceptable method performance and to trigger corrective action when control limits are exceeded.

\section{Accuracy}

Accuracy as \%R shall be assessed for the laboratory operations by analyzing PDP blind audit samples and laboratory control samples. Results from these measurements must be compared to the criteria listed in Table 12-1. These OC measurements will be used to demonstrate acceptable method performance and to trigger corrective action when control limits are exceeded.

\section{Method Detection Limit}

MDLs shall be expressed in nanograms for VOCs, and must be less than or equal to those listed in Table 12-1. MDLs shall be determined based on the method described in Section 3.2. The detailed procedures for MDL determination shall be included in site SOPs.

\section{Program Required Quantitation Limit}

Laboratories must demonstrate the capability to quantitate analytes at or below the PROLs given in Table 12-1. Laboratories shall set the concentration of at least one calibration standard below the PROL. The detailed procedures for PRQL demonstration shall be included in laboratory SOPs. 
TABLE 12-1

\section{Gas Volatile Organic Compounds Target Analyte List and Quality Assurance Objectives}

\begin{tabular}{|c|c|c|c|c|c|c|}
\hline Compound & $\begin{array}{l}\text { CAS } \\
\text { Number }\end{array}$ & $\begin{array}{c}\text { Precision } \\
\text { (\%RSD or RPD) }\end{array}$ & $\begin{array}{c}\text { Accuracy" } \\
\text { (\%R) }\end{array}$ & $\begin{array}{c}\mathrm{MDL}^{b} \\
\text { (ng) }\end{array}$ & $\begin{array}{l}\text { PRQL } \\
\text { (ppmv) }\end{array}$ & $\begin{array}{c}\text { Completeness } \\
\text { (percent) }\end{array}$ \\
\hline Benzene & $71-43-2$ & $\leq 25$ & $70-130$ & 10 & 10 & 90 \\
\hline Bromoform & $75-25-2$ & $\leq 25$ & $70-130$ & 10 & 10 & 90 \\
\hline Carbon tetrachloride & $56-23-5$ & $\leq 25$ & $70-130$ & 10 & 10 & 90 \\
\hline Chlorobenzene & $108-90-7$ & $\leq 25$ & $70-130$ & 10 & 10 & 90 \\
\hline Chloroform & $67-66-3$ & $\leq 25$ & $70-130$ & 10 & 10 & 90 \\
\hline Cyclohexane & $110-87-7$ & $\leq 25$ & $70-130$ & 10 & 10 & 90 \\
\hline 1,1-Dichloroethane & $75-34-3$ & $\leq 25$ & $70-130$ & 10 & 10 & 90 \\
\hline 1,2-Dichloroethane & $107-06-2$ & $\leq 25$ & $70-130$ & 10 & 10 & 90 \\
\hline 1,1-Dichloroethylene & $75-35-4$ & $\leq 25$ & $70-130$ & 10 & 10 & 90 \\
\hline cis-1,2-Dichloroethylene & $156-59-2$ & $\leq 25$ & $70-130$ & 10 & 10 & 90 \\
\hline Ethyl benzene & $100-41-4$ & $\leq 25$ & $70-130$ & 10 & 10 & 90 \\
\hline Ethyl ether & $60-29-7$ & $\leq 25$ & $70-130$ & 10 & 10 & 90 \\
\hline Formaldehyde ${ }^{c}$ & $50-00-0$ & $\leq 25$ & $70-130$ & 10 & 10 & 90 \\
\hline Hydrazine & $302-01-2$ & $\leq 25$ & $70-130$ & 10 & 10 & 90 \\
\hline Methylene chloride & $75-09-2$ & $\leq 25$ & $70-130$ & 10 & 10 & 90 \\
\hline $1,1,2,2$-Tetrachloroethane & $79-34-5$ & $\leq 25$ & $70-130$ & 10 & 10 & 90 \\
\hline Tetrachloroethylene & $127-18-4$ & $\leq 25$ & $70-130$ & 10 & 10 & 90 \\
\hline Toluene & $108-88-3$ & $\leq 25$ & $70-130$ & 10 & 10 & 90 \\
\hline $1,1,1$-Trichloroethane & $71-55-6$ & $\leq 25$ & $70-130$ & 10 & 10 & 90 \\
\hline Trichloroethylene & $79-01-6$ & $\leq 25$ & $70-130$ & 10 & 10 & 90 \\
\hline $\begin{array}{l}\text { 1,1,2-Trichloro-1,2,2- } \\
\text { trifluoroethane }\end{array}$ & $76-13-1$ & $\leq 25$ & $70-130$ & 10 & 10 & 90 \\
\hline 1,2,4-Trimethylbenzene & $95-63-6$ & $\leq 25$ & $70-130$ & 10 & 10 & 90 \\
\hline 1,3,5-Trimethylbenzene & $108-67-8$ & $\leq 25$ & $70-130$ & 10 & 10 & 90 \\
\hline $\mathrm{m}$-Xylene ${ }^{\circ}$ & $108-38-3$ & $\leq 25$ & $70-130$ & 10 & 10 & 90 \\
\hline $0-$ Xylene & $95-47-6$ & $\leq 25$ & $70-130$ & 10 & 10 & 90 \\
\hline p-Xylene ${ }^{\circ}$ & $106-42-3$ & $\leq 25$ & $70-130$ & 10 & 10 & 90 \\
\hline Acetone & $67-64-1$ & $\leq 25$ & $70-130$ & 150 & 100 & 90 \\
\hline Butano & $71-36-3$ & $\leq 25$ & $70-130$ & 150 & 100 & 90 \\
\hline Methanoi & $67-56-1$ & $\leq 25$ & $70-130$ & 150 & 100 & 90 \\
\hline Methyl ethyi ketone & $78-93-3$ & $\leq 25$ & $70-130$ & 150 & 100 & 90 \\
\hline Methyl isobutyl ketone & $108-10-1$ & $\leq 25$ & $70-130$ & 150 & 100 & 90 \\
\hline
\end{tabular}

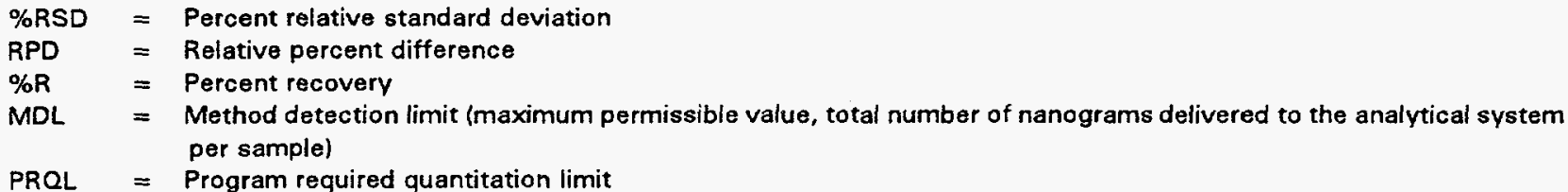

- Criteria apply to PRQL concentrations.

bValues based on delivering $10 \mathrm{~mL}$ to the analytical system.

'Required only for homogenous solids and soil/gravel from Los Alamos National Laboratory

${ }^{d}$ Required only for homogenous solids and soil/gravel from Oak Ridge National Laboratory and Savannah river Site

-These xylene isomers cannot be resolved by the analytical methods employed in this program. 


\section{Completeness}

Laboratory completeness shall be expressed as the number of samples analyzed with valid results as a percent of the total number of samples submitted for analysis. Participating laboratories must meet the completeness specified in Table 12-1.

\section{Comparability}

For VOC analysis, data generated through analysis of samples from different sites shall be comparable. Comparability will be achieved by using standardized methods, traceable standards, and participation by all sites in the PDP.

\section{Representativeness}

Representativeness for VOC analysis shall be achieved by collecting sufficient numbers of samples using clean sampling equipment that does not introduce sample bias. Samples must be collected as described in Section 7.0 of this QAPP.

\subsection{Methods Requirements}

Laboratories must use Gas Chromatography/Mass Spectrometry (GC/MS) methods for all of the analytes except alcohols and ketones, listed in Table 12-1. Alcohols and ketones listed in Table 12-1 may be analyzed by GC/MS or Gas Chromatography/Flame Ionization Detector (GC/FID). The GC/FID method must be used for the analysis of methanol, butanol, acetone, methyl ethyl ketone, and methyl isobutyl ketone when analysis of these compounds by GC/MS fails to meet the criteria specified in Table 12-1. Alternate anaiytical methods, which meet all of the QAOs in Section 12.1, may be submitted to CAO for approval. The analytes are segregated into flammable and nonflammable groups in Table 12-2.

Two GC/MS procedures and one GC/FID procedure, which have been demonstrated to meet Program requirements, are provided in the Methods Manual. The GC/MS procedures are based on SW-846 Methods 8240 and 8260 and EPA Method TO-14 (EPA 1988a). Laboratories shall implement the analytical procedures with SOPs.

Reduction in sample aliquot size and final volume from those suggested in these methods is allowable, as long as the QAOs in Section 12.1 are achievable. Equivalency of modified methods shall be demonstrated by meeting the QAOs defined in Section 12.1 . 
TABLE 12-2

Flammable and Nonflammable Volatile Organic Compounds

\title{
Acetone \\ Benzene \\ Butanol \\ Chlorobenzene \\ Cyclohexane \\ 1,1-Dichloroethane \\ 1,2-Dichloroethane \\ 1.1-Dichloroethylene \\ cis-1,2-Dichloroethylene \\ Ethyl benzene \\ Ethyl ether \\ Methanol \\ Methyl ethyl ketone \\ Methyl isobutyl ketone \\ Toluene \\ 1,2,4-Trimethylbenzene \\ 1,3,5-Trimethylbenzene \\ Xylenes
}

\author{
Bromoform \\ Carbon tetrachloride \\ Chloroform \\ Formaldehyde \\ Hydrazine \\ Methylene chloride \\ $1,1,2,2$-Tetrachloroethane \\ Tetrachloroethylene \\ 1,1,1-Trichloroethane \\ Trichloroethylene \\ 1,1,2-Trichloro-1,2,2-trifluoroethane
}




\section{Criteria for Standards}

Primary gas standards and primary liquid standards must be purchased from the best available source (Scott Specialty Gases or equivalent for gases; Supelco or equivalent for liquids) for the target analytes specified in Table 12-1. Commercially purchased primary gas standards and primary liquid standards must be certified by the manufacturer. Alternatively, primary gas standards and primary liquid standards may be prepared for the target analytes specified. Laboratory SOPs must specify detailed requirements for the preparation of all primary, secondary, and calibration standards. Samples and calibration standards must be analyzed at the same temperature $\left( \pm 2^{\circ} \mathrm{C}\right)$.

\section{Criteria for Qualitative and Quantitative Analysis}

To be qualitatively identified by GC/MS using internal standard quantitation, an analyte must elute within \pm 0.06 RRT units of the RRT of the continuing calibration check standard, and have a mass spectrum that corresponds to the standard mass spectrum. If external standard quantitation is used, an analyte must elute within a specified $R T$ window. RT windows for each analyte shall be determined by three different injections of standards containing all analytes over a 72 hour period. RT windows shall be calculated as the mean plus-or-minus three times the standard deviation of the individual RTs for each analyte. RT or RRT windows must be determined for all analytes prior to the analysis of any samples and whenever a new GC column is installed.

Criteria for GC/MS quantitative analysis depend on whether external or internal standard quantitation is used. If internal or external standard quantitation is used, the \%RSD criteria for all analytes must be met, otherwise, a second- or third-order regression calibration curve must be generated. \%RSD is calculated as the standard deviation of average response factors for an analyte divided by the mean of the five initial response factors for that analyte. If internal standard quantitation is used, the internal standard area counts for the sample analyses must be within 50-percent to 200-percent of the average internal standard area counts from the most recent continuing calibration. The integrated abundance from the Electron Ion Current Profile (EICP) of the primary characteristic ion is used to calculate concentrations. All analytes must be quantitated within the calibration range of the analytical instrument. Multiple dilutions may be required when sample concentrations exceed the calibration range of the instrument or calibration curve. The method used for quantitation shall be reported with the results.

For GC/FID qualitative analysis, RT windows shall be established for all analytes. Positive analyte identification shall be achieved by RT confirmation on both columns (see Methods Manual). The sample component peak must fall within the RT window for a given analyte for positive identification. RT windows are determined by injecting a minimum of three standards over a period of 72 hours. RT 
windows shall be calculated as the mean plus-or-minus three times the standard deviation of the individual RT for each calibration standard analyzed in the 72-hour period. RT windows must be determined for all analytes on each GC column prior to the analysis of any samples and whenever a new GC column is installed.

Quantitation of a given analyte using GC/FID shall be performed on one of the two columns. The column used for quantitation must be interferant free in the RT window corresponding to the analyte. Average response factors or linear regression equations shall be generated for each specified target analyte. All analytes must be quantitated within the calibration range of the analytical instrument. Multiple dilutions may be required when sample concentrations exceed the calibration range of the instrument or calibration curve. The method used for quantitation must be reported with the results.

\subsection{Quality Control}

To assure that data of known and documented quality are generated, each participating laboratory shall implement a documented analytical laboratory QA program. Laboratory QA programs shall specify qualitative and quantitative acceptance criteria for the $\mathrm{QC}$ checks of this Program and corrective action measures to be taken when these criteria are not satisfied.

It shall be the responsibility of the laboratory $\mathrm{QA}$ officer to monitor and document procedures performance, including the analysis of QC samples. The laboratory QA officer and technical supervisor shall have the responsibility to implement corrective actions when acceptable procedure performance is not met.

Laboratories shall operate a formal $Q C$ program and maintain records to document the quality of the data generated. All $Q C$ elements established in the analytical methods must be implemented with laboratory SOPs including, but not limited to, method performance samples, laboratory duplicates, laboratory blanks, laboratory control samples, and blind audit samples. Specific $\mathrm{QC}$ samples and frequencies are based on an analytical batch and are summarized in Table 12-3. An analytical batch is defined as a suite of samples of a similar matrix that is processed as a unit using the same analytical method, within a specific time period. An analytical batch can be up to 20 samples, lexcluding laboratory OC samples), all of which must be received by the laboratory within 14 days of the VTSR of the first sample in the batch.

Method performance samples shall be used to demonstrate acceptable laboratory performance prior to the analysis of any samples. Method performance samples can be obtained commercially (Scott Specialty Gases or equivalent) or prepared by the laboratory and must contain all of the analytes listed $R-4913$ 
TABLE 12-3

\section{Summary of Laboratory Quality Control Samples and Frequencies for Gas Volatile Organic Compounds Analysis}

\begin{tabular}{|c|c|c|c|}
\hline OC Sample & Minimum Frequency & $\begin{array}{l}\text { Acceptance } \\
\text { Criteria }\end{array}$ & $\begin{array}{l}\text { Corrective } \\
\text { Action }\end{array}$ \\
\hline $\begin{array}{l}\text { Method performance } \\
\text { samples }\end{array}$ & $\begin{array}{l}\text { Seven (7) samples initially } \\
\text { and four (4) semiannually }\end{array}$ & Meet Table 12-1 QAOs & $\begin{array}{l}\text { Repeat until } \\
\text { acceptable }\end{array}$ \\
\hline Laboratory duplicates & $\begin{array}{l}\text { One (1) per analytical } \\
\text { batch }\end{array}$ & $\mathrm{RPD} \leq 25^{\mathrm{b}}$ & $\begin{array}{l}\text { Nonconformance if } \\
\text { RPD }>25\end{array}$ \\
\hline Laboratory blanks & $\begin{array}{l}\text { Daily prior to sample } \\
\text { analysis }\end{array}$ & $\begin{array}{l}\text { Analyte amounts } \\
<3 \times \text { MDLs }\end{array}$ & $\begin{array}{l}\text { Nonconformance if } \\
\text { analyte amounts }>3 \\
\times \text { MDLs }\end{array}$ \\
\hline $\begin{array}{l}\text { Laboratory control } \\
\text { samples }\end{array}$ & $\begin{array}{l}\text { One (1) per analytical } \\
\text { batch }\end{array}$ & $70-130 \% R$ & $\begin{array}{l}\text { Nonconformance if } \\
\% R<70 \text { or }>130\end{array}$ \\
\hline Blind audit samples & $\begin{array}{l}\text { Samples and frequency } \\
\text { controlled by the Gas PDP } \\
\text { Plan }\end{array}$ & $\begin{array}{l}\text { Specified in the Gas } \\
\text { PDP Plan }\end{array}$ & $\begin{array}{l}\text { Specified in the Gas } \\
\text { PDP Plan }\end{array}$ \\
\hline
\end{tabular}

${ }^{a}$ Corrective Action when $\mathrm{OC}$ samples do not meet the acceptance criteria; Nonconformance procedures are outlined in Section 2.1.2.1.

${ }^{\text {b} A p p l i e s ~ o n l y ~ t o ~ c o n c e n t r a t i o n s ~ g r e a t e r ~ t h a n ~ t h e ~ P R Q L s ~ l i s t e d ~ i n ~ T a b l e ~ 12-1 . ~}$
$\mathrm{MDL}=$ Method detection limit
PDP = Performance Demonstration Program
$\mathrm{QAO}=$ Quality assurance objective
$\% \mathrm{R}=$ Percent recovery
$\mathrm{RPD} \quad=$ Relative percent difference 
in Table 12-1 at concentrations appropriate to verify that all QAOs are met. Initially, seven method performance samples shall be analyzed to demonstrate acceptable precision and accuracy and shall also be used to determine and document MDLs for all analytes according to the method described in Section 3.2. Acceptable procedure performance shall be demonstrated semiannually by analyzing four method performance samples.

Individual field samples shall serve as laboratory duplicates. The laboratory must analyze individual field samples in duplicate at a minimum frequency of one per analytical batch. Field canisters analyzed in duplicate shall be used to assess laboratory precision. Laboratory duplicate results shall be acceptable if the QAO for precision (Table 12-1) is satisfied.

Laboratory blanks shall be prepared by filling SUMMA' canisters with humid high-purity zero air or nitrogen (99.999-percent pure) in the laboratory. The same procedure used to prepare the field samples for analysis shall be used for the laboratory blanks. Laboratory SOPs shall give the details of blank preparation and analysis. Laboratory blanks must be analyzed daily before analysis of any samples. Laboratory blank results shall be acceptable if analyte amounts are less than three times the applicable MDL.

Laboratory control samples will be used to demonstrate ongoing laboratory performance and shall be prepared from gas or liquid standards independent of those used for instrument calibration. Laboratory control sample preparation details shall be given in laboratory SOPs. Laboratory control samples must contain a minimum of six of the analytes listed in Table 12-1 at concentrations within the calibration range of the analytical instrument. Laboratory control samples must be analyzed at a frequency of one per analytical batch and the results shall be acceptable if the \%R for all analytes is $70-130$.

Blind audit samples provided by the PDP shall be used to determine acceptable laboratory performance. Laboratory performance will be evaluated biannually.

\subsection{Instrument Testing, Inspection, and Maintenance Requirements}

Instrument testing, inspection, and maintenance requirements apply to the GC/MS instruments as well as the GC/FID instruments. Each is discussed separately below.

\section{GC/MS Instrument Requirements}

Laboratories shall use equipment and materials (gas chromatographs, mass spectrometers, data systems, traps, vacuum pumps) that meet all of the Methods Manual requirements. All gas chromatographs shall be equipped with capillary columns selected from among those recommended $R+4913$ 
in the Methods Manual and must have subambient temperature capabilities. GC/MS systems shall be operated in the full scan mode to allow the detection and quantitation of all analytes listed in Table 12-1 and the identification of nontarget compounds.

Prior to the analysis of any standards or samples, instrument performance criteria shall be met. GC/MS systems may be tuned using perfluorotributylamine (PFTBA) and must meet the 4-bromofluorobenzene (BFB) criteria specified in the Methods Manual. The BFB criteria shall be checked by analyzing $50 \mathrm{ng}$ of BFB at the beginning of each 12 hours of operation.

\section{GC/FID Instrument Requirements}

Laboratories must use equipment and materials that meet all of the Methods Manual requirements. Sample introduction shall be by thermostated gas injection valves with sample loops that permit the injection of gas standards directly on column. Each gas chromatograph must be equipped with two, dissimilar, wide-bore capillary columns.

\subsection{Instrument Calibration and Frequency}

All laboratories shall prepare and follow detailed SOPs covering all aspects of calibration and maintain instrument run logs that permit the reconstruction of the calibration sequence and frequency. Instrument calibrations and frequencies for GC/MS are as follows. An initial, multipoint calibration using internal or external standards shall be performed after instrument performance criteria have been satisfied. The multipoint calibration must consist of a minimum of five analytical standards that define the calibration range of the instrument for the analytes listed in Table 12-1. One of the standards must be at a concentration less than the PROLs specified in Table 12-1.

The initial GC/MS calibration curve shall be verified using a midpoint calibration standard. The continuing calibration standard shall be analyzed at the beginning of every 12 hours of operation. Prior to the analysis of this midpoint continuing calibration standard, the specified instrument performance criteria, using $50 \mathrm{ng}$ of $\mathrm{BFB}$, must be satisfied. The \%D criterion for all analytes must be met (Table 12-4). The $\% D$ is determined using continuing calibration response factors and average response factors or relative response factors from the most recent calibration. If internal standard quantitation is used, the midpoint standard must meet all of the daily calibration criteria for internal standard responses and RRTs. If the continuing calibration standard does not satisfy the criteria for linearity and consistency, a new five-point calibration curve must be generated. Sample analysis cannot proceed until the GC/MS system has satisfied the appropriate daily calibration criteria. 
TABLE 12-4

Summary of GC/MS and GC Calibration Requirements for Gas Volatile Organic Compounds Analysis

\begin{tabular}{|c|c|c|c|}
\hline Technique & Procedure & Frequency of Procedure & Acceptance Criteria \\
\hline \multirow[t]{3}{*}{ GC/MS } & BFB Tune & Every 12 hours & $\begin{array}{l}\text { Abundance criteria for all key ions are } \\
\text { met (see Methods Manual Procedure } \\
430.1 \text { or } 430.2 \text { ) }\end{array}$ \\
\hline & $\begin{array}{l}\text { 5-pt initial calibration } \\
\text { (5 standards) }\end{array}$ & Initially, and as needed & $\begin{array}{l}\text { \%RSD of response factor for each } \\
\text { analyte }<35\end{array}$ \\
\hline & Continuing calibration & Every 12 hours & $\begin{array}{l}\% D \text { for all compounds } \leq 30 \text { of initial } \\
\text { calibration }\end{array}$ \\
\hline \multirow[t]{3}{*}{ GC/FID } & $\begin{array}{l}\text { 3-pt initial calibration } \\
\text { (3 standards) }\end{array}$ & Initially, and as needed & $\begin{array}{l}\text { \%RSD of response factor for each } \\
\text { analyte }<30\end{array}$ \\
\hline & & & $\begin{array}{l}\text {-or- } \\
\text { linear regression plot yields straight } \\
\text { line and \%R is } 70-130 \text { for each } \\
\text { standard analyte }\end{array}$ \\
\hline & Continuing calibration & Every 12 hours & $\begin{array}{l}\% D \text { for all compounds } \leq 30 \text { of initial } \\
\text { calibration; RTs } \pm 3 \text { standard } \\
\text { deviations of initial calibration }\end{array}$ \\
\hline
\end{tabular}

$\mathrm{BFB} \quad=$ 4-Bromofluorbenzene

$\% \mathrm{D}=$ Percent difference

$\%$ RSD = Percent relative standard deviation

RT = Retention time 
An initial, multipoint external standard calibration curve shall be generated for GC/FID. The multipoint calibration must consist of a minimum of three analytical standards that define the calibration range of the instrument for acetone, butanol, methyl ethyl ketone, methanol, and methyl isobutyl ketone. One of the standards must be at a concentration less than the PROLs specified in Table 12-1. The calibration is considered valid if the \%RSD for response factors for all compounds is less than 30 . Alternately, a linear regression equation can be generated plotting area response versus concentration. If the resulting plot yields a straight line and the caiculated value for each standard analyte is $70-130$ $\% R$, then the initial calibration is considered valid.

The initial GC/FID calibration curve shall be verified using a midpoint calibration standard (continuing calibration standard). The continuing calibration standard shall be analyzed at the beginning of each 12 hours of operation. Response factors (or concentrations) for the continuing calibration standard shall be compared to the corresponding average response factor (or concentration) from the most recent valid three-point calibration. If the \%D between the average response factor (or concentration) and the continuing midpoint response factor (or concentration) is less than or equal to 30 , then the GC/FID system shall be considered calibrated. For those analytes where a second- or third-order regression curve is used, the instrument response from the continuing calibration standard for the analyte must fall within 30 percent of the value determined using the initial calibration curve. The RT of each analyte must fall within the RT window. If the continuing calibration standard does not meet these requirements, a new three-point initial calibration curve must be generated. Sample analysis cannot proceed until the GC/FID system has satisfied the calibration and RT requirements.

Laboratories shall maintain detailed instrument run logs covering all aspects of GC/MS and GC/FID calibrations to enable a reconstruction of calibration sequences and frequencies. GC/MS and GC/FID calibration requirements are summarized in Table 12-4.

\subsection{Data Management}

Data management includes requirements for data reduction, validation, and reporting. All of the data management requirements defined in Section 3.1.1 of this QAPP, as well as the specific procedures described below, apply to VOC analysis data. Data management procedures demonstrating compliance with these requirements must be detailed in QAPjPs and SOPS and, as appropriate, include specific equations, sample calculations, and example forms for data reduction, validation, and reporting.

\section{Data Reduction}

All organic analyte concentrations shall be quantified using average relative response factors for internal standard quantitation, average response factors for external standard quantitation, or a linear 
regression equation. Target analyte concentrations shall not be blank-corrected. Results from blanks run in association with samples shall be reported separately, flagging any target compounds detected, as described in the data reporting requirements below. Nontarget compounds shall be reported as tentatively identified compounds (TICs) and are reported with a higher uncertainty than the reported target analyte concentrations. For samples containing TICs with total ion current peaks greater than 10 percent of the nearest (RT) internal standard, appropriate search routines of the latest NIST or equivalent mass spectral library must be performed on the 20 greatest in area count. For samples analyzed using external standard quantitation, mass spectral library searches must be performed on up to 20 TICs (those with the greatest area counts) which have total ion current peak areas greater than 10 percent of the largest target analyte identified, or ten times greater than the standard deviation of the background. Positively identified TICs listed in 40 CFR Part 264, Appendix IX shall be added to the target analyte list by the site project officer if they are detected in 25 percent of all samples from a given matrix parameter category. Compounds identified by library searching shall be reported as TICs. Concentrations for TICs shall be calculated assuming a relative response factor equal to one (1) using the nearest internal standard; if external standard quantitation is used the response factor from a chemically similar compound shall be used.

All results shall be reported in parts per million on a volume/volume basis (ppmv) and shall be limited to two significant figures. Detailed procedures for data reduction can be found in the Methods Manual. SOPs must detail procedures for reducing raw data to reportable results.

\section{Data Validation}

All gas VOC analysis data must be reviewed and approved prior to being reported. The validation process is outlined in Section 3.1.1 and includes verification that the QAOs in Table 12-1 have been met.

\section{Data Reporting}

Each laboratory analyzing samples is required to submit analytical batch data reports for each analytical batch to the site project office on approved standard forms. Site-specific documentation must include example forms that will be used for reporting. Analytical batch data reports shall consist of the following:

- Cover page that includes the laboratory name, analytical batch number, sample numbers included in that analytical batch, a cross reference to field sample numbers, and the signature releases of laboratory personnel as specified in Section 3.1.1.

- Table of Contents. 
- Summary COC Form that shows the date and time of sample transfer, and name of individuals handling the samples from the time of sampling through receipt at the laboratory.

- Original or a copy of the field sample canister tags.

- Data review checklists for each analytical batch verifying that the data generation level review, validation and verification, as described in Section 3.1.1, has taken place. Checklists must contain tables showing the results of the analytical batch OC samples (e.g., laboratory duplicates, laboratory control samples).

- A separate analytical report sheet for each sample in the analytical batch that includes the laboratory name, program name, the title "Gas VOC Analysis Data Sheet," analytical batch number, sampling batch number, laboratory sample number, field sample number, date sampled, date and time analyzed, method number, listing of program analytes, and analytical results in ppmv. Data qualifying flags shall be used as follows:

- B-Analyte detected in blank

- E-Analyte exceeds the calibration curve

- J-Analyte less than PROL, but greater than or equal to MDL

- U-Analyte was undetected (Report MDL)

- D-Analyte was quantitated from a secondary dilution, or reduced volume sample aliquot.

- Nonconformance reports, if applicable.

In addition, laboratories located on sites shall maintain the following items in their files, documented and retrievable by analytical batch number. Contract laboratories shall forward these items along with analytical results to the site project office for storage in site project files.

- Original COC forms.

- All raw data, including original instrument readouts and/or bench reports, calculation records, and laboratory $\mathrm{QC}$ sample results. Laboratory duplicate results are recorded along with the original sample results, and the RPD between the two results are calculated. Laboratory control samples results are entered along with the accepted value and the \%R.

- All instrument calibration reports that include the accepted and measured values of calibration verification for all analytes. These reports must also contain the laboratory name, analytical batch number(s), initial and continuing calibration verification source, method identification, and calibration date and time.

- $Q C$ result summary, that includes true and found values for all $\mathrm{QC}$ samples plus associated result calculations. At a minimum, the $Q C$ data shall include blanks, laboratory control samples, duplicates, initial calibration data, initial and continuing calibration verifications, and all other method-specific $O C$ listed in Table 12-3. The OC summary report must also contain the laboratory name, the analytical batch number (if applicable), and method names.

- Original field sample canister tags, if not submitted with the analytical batch data report. 


\subsection{TOTAL VOLATILE ORGANIC COMPOUND ANALYSIS}

This section identifies the required $Q A$ elements for the analysis of total VOCs in samples of homogenous solids and soil/gravel. Samples must be collected from waste containers as detailed in Section 8.0 of this QAPP.

\subsection{Quality Assurance Objectives}

The development of DQOs specifically for this Program has resulted in the QAOs listed in Table 13-1. The specified QAOs represent the required quality of data necessary to draw valid conclusions regarding Program objectives. Program-required limits, such as the PROL associated with VOC analysis, are specified to ensure that the analytical data collected satisfy the requirements of all data users. Key data quality indicators for laboratory measurements are defined below and the methods to quantitatively and qualitatively assess these indicators are discussed in Section 3.2 of this QAPP.

\section{Precision}

Precision shall be assessed by analyzing laboratory duplicates, replicate analyses of laboratory control samples, matrix spike duplicates, and PDP blind audit samples. Results from measurements on these samples must be compared to the criteria listed in Table 13-1. These $O C$ measurements will be used to demonstrate acceptable method performance and to trigger corrective action when control limits are exceeded.

\section{Accuracy}

Accuracy as $\% R$ shall be assessed for the laboratory operations by analyzing laboratory control samples, matrix spikes, surrogate compounds, and PDP blind audit samples. Results from these measurements must be compared to the criteria listed in Table 13-2. These $O C$ measurements will be used to demonstrate acceptable method performance and to trigger corrective action when control limits are exceeded.

\section{Method Detection Limit}

MDLs shall be expressed in $\mathrm{mg} / \mathrm{kg}$ for VOCs, and must be less than or equal to those listed in Table 13-1. MDLs shall be determined based on the method described in Section 3.2. The detailed procedures for MDL determination shall be included in site SOPs. 
TABLE 13-1

\section{Total Volatile Organic Compounds Target Analyte List and Quality Assurance Objectives}

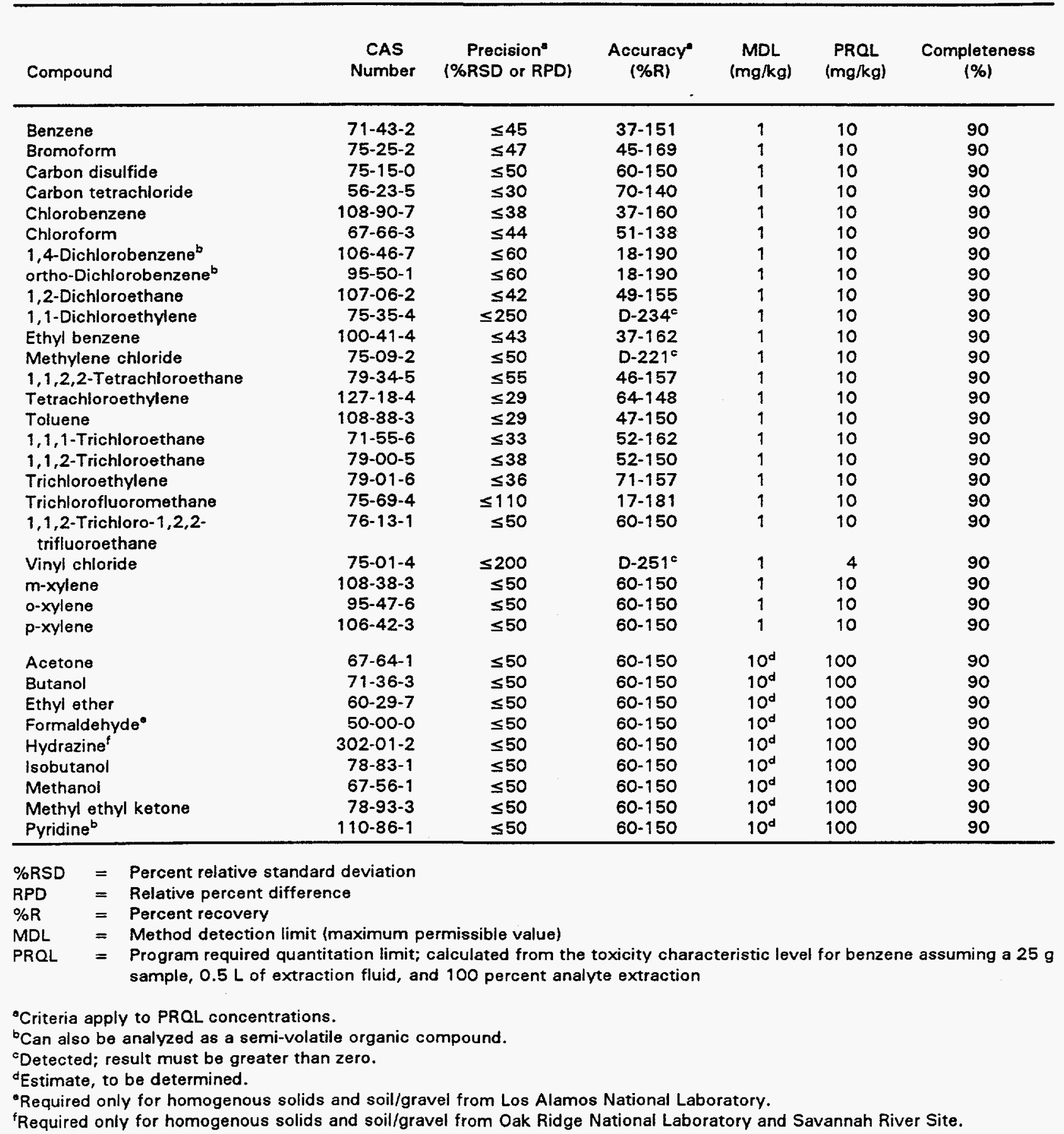




\section{Program Required Quantitation Limit}

Laboratories must demonstrate the capability to quantitate analytes in samples at or below the PRQLs given in Table 13-1. Laboratories shall set the concentration of at least one calibration standard below the PROL. The detailed procedures for PROL demonstration shall be included in laboratory SOPs.

\section{Completeness}

Laboratory completeness shall be expressed as the number of samples analyzed with valid results as a percent of the total number of samples submitted for analysis. Participating laboratories must meet the completeness specified in Table 13-1.

\section{Comparability}

For VOC analysis, data generated through analysis of samples from different sites shall be comparable. Comparability will be achieved by using standardized methods, traceable standards, and participation by all sites in the PDP.

\section{Representativeness}

Representativeness for VOC analysis shall be achieved by collecting unbiased samples. Samples must be collected as described in Section 8.0 of this QAPP.

\subsection{Methods Requirements}

Laboratories must use GC/MS methods for the determination of all of the analytes listed in Table 13-1. GC/FID must be used for the determination of nonhalogenated VOCs that perform poorly by purge and trap methods.

Two GC/MS methods, SW-846 Methods 8240B and 8260A, meet Program requirements and are provided in the Methods Manual. One GC/FID method, which meets Program requirements for nonhalogenated VOC analysis, is provided in the Methods Manual. Alternate methods, which meet all of the QAOs in Section 13.1, may be submitted to CAO for approval. Laboratory SOPs must specify the detailed requirements for implementation of the selected analytical method(s).

If needed, each site must decide, based on the nature of their waste stream, what preparation methods are appropriate for their waste types. Use of preparation methods in the Methods Manual, SW-846, or other nationally recognized standard methods (e.g., ASTM) is acceptable. Reduction in sample aliquot size and final volume from those suggested in these methods is allowable, as long as the QAOs in Section 13.1 are achievable. Equivalency of modified methods shall be demonstrated by meeting QAOs defined in Section 13.1. 


\section{Criteria for Standards}

Primary standards must be purchased from the best available source (Supelco or equivalent) for the target analytes specified in Table 13-1. Commercially purchased primary standards must be certified by the manufacturer. The determination of methanol requires that standards be prepared in a solvent other than methanol (e.g., propanol). Secondary analytical standards, surrogate standards, internal standards, calibration standards, and matrix spiking standards must be prepared as directed in the appropriate GC/MS or GC/FID method. Laboratory SOPs must specify detailed requirements for the preparation of all standards.

\section{Criteria for Quantitative and Qualitative Analysis}

To be qualitatively identified by GC/MS, a sample analyte must elute within a RRT window of plus or minus 0.06 RRT units and have a mass spectrum that corresponds to the analyte mass spectrum. RRT windows must be calculated from the individual RTs for each analyte from a calibration run within the same 12 hours as the sample.

Qualitative identification by GC/FID requires that a sample component elute within the RT window set by the most recent continuing calibration for each analytical column. RT windows for each analyte on each analytical column shall be determined by three different injections of standards containing all analytes over a 72 hour period. RT windows shall be calculated as the mean plus-or-minus three times the standard deviation of the individual RTs for each analyte.

Internal standard quantitation, as described in SW-846 Methods 8240B and 8260A, shall be used for GC/MS analysis. The criteria for system performance check compounds (SPCCs) and calibration check compounds (CCCs) must be met and response factors and the \%RSD for response factors must be calculated for all analytes. The GC/MS shall be considered in-control if all daily calibration criteria for BFB, SPCCs, CCCs, internal standard responses, and RTs are met. Quantitation of an analyte is based on the integrated abundance from the EICP of the primary ion.

External standard quantitation shall be used for GC/FID analysis. Analyte quantitation shall be based on the peak area response, or peak height response, from one of the two analytical columns. The column used for quantitation must be interferant free in the analyte's RT window. Quantitation shall be by calibration curve (three-point) or by response factor. The GC/FID shall be considered in-control if, after analyzing a mid-range continuing calibration standard, the response factor (or calculated concentration) for any analyte is less than $15 \% \mathrm{D}$ from the initial calibration average response factor (or true concentration) and all criteria for RT windows are met. 
All analytes must be quantitated within the calibration range of the analytical instrument. Multiple dilutions may be required when sample concentrations exceed the calibration range of the instrument.

\subsection{Quality Control}

To assure that data of known and documented quality are generated, each participating laboratory shall implement a documented analytical laboratory OA program. Laboratory QA programs shall specify qualitative and quantitative acceptance criteria for the $\mathrm{QC}$ checks of this Program and corrective action measures to be taken when these criteria are not satisfied.

It shall be the responsibility of the laboratory OA officer to monitor and document procedure performance, including the analysis of $Q C$ samples. The laboratory $Q A$ officer and technical supervisor shall have the responsibility to implement corrective actions when acceptable procedure performance is not met.

Laboratories shall operate a formal $Q C$ program and maintain records to document the quality of the data generated. All QC practices established in the analytical methods must be implemented with laboratory SOPs including, but not limited to, the analysis of method performance samples, laboratory duplicates, laboratory blanks, matrix spikes, matrix spike duplicates, laboratory control samples, surrogate compounds, and blind audit samples. Specific $\mathrm{OC}$ samples and frequencies are based on an analytical batch and are summarized in Table 13-2. An analytical batch is defined as a suite of samples of a similar matrix processed as a unit, using the same analytical method, within a specific time period. An analytical batch can be up to 20 samples, (excluding laboratory $Q C$ samples) all of which must be received by the laboratory within 14 days of the VTSR of the first sample of the batch.

Method performance samples shall be used to demonstrate acceptable laboratory performance prior to the analysis of any samples. Method performance samples must contain all of the analytes listed in Table 13-1 at concentrations appropriate to verify that all QAOs are met. Initially, seven method performance samples shall be analyzed to demonstrate acceptable precision and accuracy and shall also be used to determine MDLs for all analytes according to the method described in Section 3.2. Acceptable procedure performance shall be demonstrated semiannually by analyzing four method performance samples.

Laboratory blanks, laboratory duplicates, matrix spikes, and matrix spike duplicates must be prepared as indicated in the appropriate SW-846 or Methods Manual method and analyzed at a frequency of one per analytical batch. Surrogate compounds are added to each field sample and laboratory QC sample. 
TABLE 13-2

\section{Summary of Laboratory Quality Control Samples and Frequencies for Total Volatile Organic Compound Analysis}

\begin{tabular}{|c|c|c|c|}
\hline OC Sample & Minimum Frequency & $\begin{array}{l}\text { Acceptance } \\
\text { Criteria }\end{array}$ & $\begin{array}{l}\text { Corrective } \\
\text { Action }\end{array}$ \\
\hline $\begin{array}{l}\text { Method performance } \\
\text { samples }\end{array}$ & $\begin{array}{l}\text { Seven (7) samples initially } \\
\text { and four (4) semiannually }\end{array}$ & Meet Table 13-1 OAOs & Repeat until acceptable \\
\hline Laboratory duplicates $^{b}$ & $\begin{array}{l}\text { One (1) per analytical } \\
\text { batch }\end{array}$ & Meet Table 13-1 RPDs & $\begin{array}{l}\text { Nonconformance if RPDs } \\
>\text { Table } 13-1 \text { values }\end{array}$ \\
\hline Laboratory blanks & $\begin{array}{l}\text { One (1) per analytical } \\
\text { batch }\end{array}$ & $\begin{array}{l}\text { Analyte concentrations } \\
<3 \times \text { MDLs }\end{array}$ & $\begin{array}{l}\text { Nonconformance if } \\
\text { analyte concentrations } \\
>3 \times \text { MDLs }\end{array}$ \\
\hline Matrix spikes & $\begin{array}{l}\text { One (1) per analytical } \\
\text { batch }\end{array}$ & Meet Table 13-1 \%Rs & $\begin{array}{l}\text { Nonconformance if } \% \text { Rs } \\
\text { are outside the range } \\
\text { specified in Table } 13-1\end{array}$ \\
\hline Matrix spike duplicates & $\begin{array}{l}\text { One (1) per analytical } \\
\text { batch }\end{array}$ & $\begin{array}{l}\text { Meet Table 13-1 RPDs } \\
\text { and \%Rs }\end{array}$ & $\begin{array}{l}\text { Nonconformance if RPDs } \\
\text { and } \% \text { Rs }>\text { Table 13-1 } \\
\text { values }\end{array}$ \\
\hline $\begin{array}{l}\text { Laboratory control } \\
\text { samples }\end{array}$ & $\begin{array}{l}\text { One (1) per analytical } \\
\text { batch }\end{array}$ & $80-120 \% R$ & $\begin{array}{l}\text { Nonconformance if } \% R \\
<80 \text { or }>120\end{array}$ \\
\hline Surrogate compounds & Each analytical sample & $\begin{array}{l}\text { Average } \% R \text { from } \\
\text { minimum of } 30 \text { samples } \\
\text { for a given matrix } \pm 3 \\
\text { standard deviations }\end{array}$ & $\begin{array}{l}\text { Nonconformance if } \% \mathrm{R} \\
<\text { (average } \% \mathrm{R}-3 \\
\text { standard deviation) or } \\
>\text { (average } \% \mathrm{R}+3 \\
\text { standard deviation) }\end{array}$ \\
\hline Blind audit samples & $\begin{array}{l}\text { Samples and frequency } \\
\text { controlled by the Solid } \\
\text { PDP Plan }\end{array}$ & $\begin{array}{l}\text { Specified in the Solid } \\
\text { PDP Plan }\end{array}$ & $\begin{array}{l}\text { Specified in the Solid } \\
\text { PDP Plan }\end{array}$ \\
\hline
\end{tabular}

aCorrective Action when QC samples do not meet the acceptance criteria; Nonconformance procedures are outlined in Section 2.1.2.1.

${ }^{b}$ May be satisfied using matrix spike duplicate; acceptance criteria applies only to concentrations greater than the PRQLs listed in Table 13-1.

MDL = Method detection limit

$\mathrm{OAO}=$ Quality assurance objective

PDP = Performance Demonstration Program

$\% \mathrm{R}=$ Percent recovery

RPD $=$ Relative percent difference 
The choice of surrogate compounds is site specific. Matrix spike duplicates may be used in place of laboratory duplicates. Laboratory SOPs shall give the details of laboratory blank, laboratory duplicate, matrix spike, and matrix spike duplicate preparation and analyses. Laboratory duplicate results shall be acceptable if the Table 13-1 criteria for precision are met. Laboratory blank results shall be acceptable if analyte concentrations are less than three times the MDL for each analyte. Matrix spikes and matrix spike duplicates must contain at least five of the VOCs listed in Table 13-1 at concentrations at the PROLs listed in Table 13-1. Matrix spike results shall be acceptable if the Table 13-1 criteria for accuracy are met. Matrix spike duplicate results shall be acceptable if the Table 13-1 criteria for precision and accuracy are met.

Laboratory control samples must be used to demonstrate ongoing laboratory performance. Laboratory control samples shall contain at least ten of the analytes listed in Table 13-1 and shall be prepared, in water, at a concentration of $20 \mu \mathrm{g} / \mathrm{L}$ from standards independent of those used for instrument calibration. Laboratory control samples must undergo all sample preparation procedures performed on field samples. Laboratory control samples must be analyzed at a frequency of one per analytical batch and the results shall be acceptable if the \%R for all analytes is 80-120.

Blind audit samples provided by the PDP shall be used to determine acceptable laboratory performance. Laboratory performance will be evaluated biannually.

\subsection{Instrument Testing, Inspection, and Maintenance Requirements}

Laboratories shall use equipment and materials (purge-and-trap systems, gas chromatographs, mass spectrometers, flame ionization detectors, data systems, traps, vacuum pumps) that meet all of the SW-846 method requirements. All gas chromatographs shall be equipped with chromatographic columns selected from among those recommended by the methods and must have subambient temperature capabilities.

GC/MS systems shall be operated in the full scan mode to allow the detection and quantitation of all analytes listed in Table 13-1 and the identification of nontarget compounds. Nontarget compounds shall be reported as TICs and are reported with a higher uncertainty than the reported target analyte concentrations.

Prior to the analysis of any standards or samples, instrument performance criteria shall be met. GC/MS systems must be tuned using PFTBA and must meet the BFB criteria specified in the SW-846 methods. The BFB criteria shall be checked by analysis of $50 \mathrm{ng}$ of BFB at the beginning of each 12 hours of operation. 
For GC/FID analysis, laboratories shall use equipment and materials lgas chromatographs, data systems, detectors) that meet all of the method requirements. All gas chromatographs shall be equipped with two chromatographic columns selected from among those recommended by the method and have sub-ambient capabilities. Splitless glass injection liners must be periodically cleaned with nitric acid to dissolve salts deposited from the injection of aqueous samples.

\subsection{Instrument Calibration and Frequency}

Instrument calibration requirements are unique to each method. For GC/MS analysis, an initial, multipoint calibration using internal standards shall be performed after all instrument performance criteria have been satisfied. The multipoint calibration must consist of a minimum of five analytical standards that define the calibration range of the instrument for the analytes listed in Table 13-1. The initial calibration is considered valid if the response factor \%RSDs for CCCs are less than or equal to 30 , and the average response factors for each SPCC is greater than or equal to 0.30010 .250 for bromoform). Average relative response factors for each analyte can be used if the \%RSD is less than or equal to 15 . If the \%RS is greater than 15 , then a linear regression equation is used.

The initial GC/MS calibration curve shall be verified using a midpoint calibration standard (continuing calibration standard). The continuing calibration standard shall be analyzed at the beginning of every 12 hours of operation. Prior to the analysis of this midpoint standard, the specified instrument performance criteria using $50 \mathrm{ng}$ of BFB must be satisfied (Table 13-3). The midpoint standard must meet all of the daily calibration criteria for surrogate compound recovery, SPCCs, CCCs, internal standard area count criteria, and RTs as specified in the SW-846 methods. In addition, the response factor $\% \mathrm{D}$ for $\mathrm{CCC}$ s must be less than 20 . If the continuing calibration standard does not satisfy the criteria for linearity and consistency, a new five-point initial calibration curve must be generated. Sample analysis cannot proceed until the GC/MS system has satisfied the appropriate daily calibration criteria. SPCCs and CCCs should include only those common to Table 13-1 and SW-846 Methods $8240 \mathrm{~B}$ and $8260 \mathrm{~A}$.

For GC/FID analysis, an initial calibration must be performed. The calibration shall consist of a minimum of three analytical standards, injected in triplicate, that define the calibration range of the instrument for the appropriate nonhalogenated VOC analytes listed in Table 13-1. The initial calibration is considered valid if, for calibration curves, a computed correlation coefficient is greater than or equal to 0.93 , or, for response factors, the \%RSD of all analytes is less than 35 .

The GC/FID calibration curve shall be verified using a midpoint calibration standard (continuing calibration standard). The continuing calibration standard shall be analyzed at the beginning of every 
TABLE 13-3

\section{Summary of Calibration Requirements for Total Volatile Organic Compounds Analysis}

Technique Procedure Frequency of Procedure Acceptance Criteria

\begin{tabular}{|c|c|c|c|}
\hline \multirow[t]{3}{*}{ GC/MS } & BFB Tune & Every 12 hours & $\begin{array}{l}\text { Abundance criteria for all key ions are } \\
\text { met (see SW- } 846 \text { Method } 8240 \text { B or } \\
8260 \text { A) }\end{array}$ \\
\hline & $\begin{array}{l}\text { 5-pt initial calibration } \\
\text { (5 standards) }\end{array}$ & Initially, and as needed & $\begin{array}{l}\text { Response factor \%RSD for CCCs } \leq \\
30 ; \text { response factor for SPCCs } \\
\geq 0.30^{\mathrm{a}} \text {; average relative response } \\
\text { factor is used if \%RSD } \leq 15 ; \text { linear } \\
\text { regression equation is generated if } \\
\% \mathrm{RSD}>15\end{array}$ \\
\hline & Continuing calibration & Every 12 hours & $\begin{array}{l}\text { Response factor or conc. \%D for CCCs } \\
\leq 20 ; \text { response factor for SPCCs } \geq \\
0.30^{\circ} ; \mathrm{RT} \text { for internal standards must } \\
\text { be } \pm 30 \text { seconds from last daily } \\
\text { calibration check; internal standard } \\
\text { area count must be }>50 \% \text { or }< \\
200 \% \text { of the area counts from the last } \\
\text { daily calibration check; surrogate } \\
\text { compound \%R must be met (see } \\
\text { SW-846 Method } 8240 \mathrm{~B} \text { or } 8260 \mathrm{~A} \text { ) }\end{array}$ \\
\hline \multirow[t]{2}{*}{ GC/FID } & $\begin{array}{l}\text { 3-pt initial calibration } \\
\text { ( } 3 \text { standards) }\end{array}$ & Initially, and as needed & $\begin{array}{l}\text { Correlation coefficient } \geq 0.93 \\
\text { (calibration curves) or } \% \mathrm{RSD} \text { for } \\
\text { response factors }<35 \text { for all analytes }\end{array}$ \\
\hline & Continuing calibration & Every 12 hours & $\begin{array}{l}\text { Response factor or measured } \\
\text { concentration \%D for all analytes } \\
\leq 15 \text { of initial calibration; RT } \pm 3 \\
\text { standard deviations from initial } \\
\text { calibration }\end{array}$ \\
\hline
\end{tabular}

\footnotetext{
aromoform $\geq 0.25$

BFB = 4-Bromofluorbenzene

$\mathrm{CCC}=$ Calibration check compounds

$\% D=$ Percent difference

$\%$ RSD $=$ Percent relative standard deviation

RT $\quad=$ Retention time

SPCC = System performance check compounds
} 
12 hours of operation. The midpoint standard must meet the daily calibration criteria for response factor (or measured concentration) \%D and RTs. If any analyte in the continuing calibration standard does not satisfy the criteria for linearity and consistency, a new calibration curve or response factor must be prepared for that analyte. Sample analysis cannot proceed until the GC/FID system has satisfied the appropriate daily calibration criteria.

Laboratories shall maintain detailed instrument run logs covering all aspects of GC/MS and GC/FID calibration to enable a reconstruction of the calibration sequence and frequency. GC/MS and GC/FID calibration requirements are summarized in Table 13-3.

\subsection{Data Management}

Data management includes requirements for data reduction, validation, and reporting. All of the data management requirements defined in Section 3.1.1 of this QAPP, as well as those described below, apply to data from total $V O C$ analyses. Data management procedures demonstrating compliance with these requirements must be detailed in QAPjPs and SOPs and, as appropriate, include specific equations, sample calculations, and example forms for data reduction, validation, and reporting.

\section{Data Reduction}

All analytes determined by GC/MS shall have concentrations quantified using average relative response factors (internal standard quantitation). Target analyte concentrations shall not be blank-corrected. Results from blanks run in association with samples shall be reported separately, flagging any target analytes detected as described in data reporting requirements below.

Nontarget compounds shall be reported as TICs and are reported with a higher uncertainty than the reported target analyte concentrations. For samples containing TICs with total ion current peaks greater than 10 percent of the nearest RT internal standard, appropriate search routines of the latest NIST or equivalent mass spectral library must be performed on the 20 greatest in area count. Positively identified TICs listed in 40 CFR Part 264. Appendix IX shall be added to the target analyte list by the site project manager if they are detected in 25 percent of all samples from a given matrix parameter category.

All analytes determined by GC/FID shall be quantified using a linear regression equation or response factors (external standard quantitation). Target analyte concentrations shall not be blank-corrected. Results from blanks run in association with samples shall be reported separately, flagging any target analytes detected as described in data reporting requirements below. 
All VOC results shall be reported in miligrams per kilogram $(\mathrm{mg} / \mathrm{kg})$ on a weight/wet-weight basis and shall be limited to two significant figures. Detailed procedures for data reduction can be found in SW-846 and the Methods Manual. SOPs must detail procedures for reducing raw data to reportable units.

\section{Data Validation}

All total VOC analysis data must be reviewed and approved prior to being reported. The validation process is outlined in Section 3.1.1 and includes verification that the QAOs in Table 13-1 have been met.

\section{Data Reporting}

Each laboratory analyzing samples is required to submit analytical batch data reports for each analytical batch to the site project office on approved standard forms. Site-specific documentation must include example forms that will be used for reporting. Analytical batch data reports shall consist of the following:

- Cover page that includes the laboratory name, analytical batch number, sample numbers included in that analytical batch, a cross reference to field sample numbers, and the signature releases of laboratory personnel as specified in Section 3.1.1

- Table of Contents

- Summary COC Form that shows the date and time of sample transfer, and name of individuals handling the samples from the time of sampling through receipt at the laboratory

- Data review checklists for each analytical batch verifying that the data generation level review, validation, and verification, as described in Section 3.1.1, has taken place; checklists must contain tables showing the results of the analytical batch QC samples (e.g., laboratory duplicates, laboratory control samples)

- A separate analytical report sheet for each sample in the analytical batch that includes the laboratory name, program name, the title "Total VOCs Analysis Data Sheet," analytical batch number, sampling batch number, laboratory sample number, field sample number, date sampled, date extracted (if applicable), date and time analyzed, method number, listing of program analytes, and analytical results in $\mathrm{mg} / \mathrm{kg}$. VOC analysis data qualifying flags shall be used as follows:

- B-Analyte detected in blank

- E-Analyte exceeds the calibration curve

- J-Analyte less than PRQL, but greater than or equal to MDL

- U-Analyte was undetected (Report MDL)

- D-Analyte was quantitated from a secondary dilution, or reduced volume sample aliquot

- Nonconformance reports, if applicable 
In addition, laboratories located on sites shall maintain the following items in their files, documented and retrievable by analytical batch number. Contract laboratories shall forward these items along with analytical results to the site project office for storage in site project files.

- Original COC forms.

- All raw data, including original instrument readouts and/or bench reports, calculation records, and laboratory $\mathrm{OC}$ sample results. Laboratory duplicate results are recorded along with the original sample results, and the RPD between the two results are calculated. Laboratory control samples results are entered along with the accepted value and the $\% R$.

- All instrument calibration reports that include the accepted and measured values of calibration verification for all analytes. These reports must also contain the laboratory name, analytical batch number(s), initial and continuing calibration verification source, method identification, and calibration date and time.

- $Q C$ result summary, which includes true and found values for all $Q C$ samples plus associated result calculations. At a minimum, the $Q C$ data shall include blanks, laboratory control samples, matrix spikes, matrix spike duplicates, initial calibration data, initial and continuing calibration verifications, and all other method-specific QC listed in Table 13-3. The $\mathrm{OC}$ summary report must also contain the laboratory name, the analytical batch number (if applicable), and method names. 


\subsection{TOTAL SEMI-VOLATILE ORGANIC COMPOUND ANALYSIS}

This section identifies the required OA elements for the analysis of total SVOCs in samples of homogenous solids and soil/gravel. Samples must be collected from waste containers as detailed in Section 8.0 of this QAPP.

\subsection{Quality Assurance Objectives}

The development of DOOs specifically for this Program has resulted in the QAOs listed in Table 14-1. The specified OAOs represent the required quality of data necessary to draw valid conclusions regarding Program objectives. Program-required limits, such as the PROLs, are specified to ensure that the analytical data collected satisfy the requirements of all data users. Key data quality indicators for laboratory measurements are defined below and the methods to quantitatively and qualitatively assess these indicators are discussed in Section 3.0 of this QAPP.

\section{Precision}

Precision shall be assessed by analyzing laboratory duplicates, replicate analyses of laboratory control samples, matrix spike duplicates, and PDP blind audit samples. Results from measurements on these samples must be compared to the criteria listed in Table 14-1. These $Q C$ measurements will be used to demonstrate acceptable method performance and to trigger corrective action when control limits are exceeded.

\section{Accuracy}

Accuracy as $\% R$ shall be assessed for the laboratory operations by analyzing laboratory control samples, matrix spikes, surrogate compounds, and PDP blind audit samples. Results from these measurements must be compared to the criteria listed in Table 14-1. These $Q C$ measurements will be used to demonstrate acceptable method performance and to trigger corrective action when control limits are exceeded.

\section{Method Detection Limit}

MDLs shall be expressed in $\mathrm{mg} / \mathrm{kg}$ for SVOCs, and must be less than or equal to those listed in Table 14-1. MDLs shall be determined based on the method described in Section 3.2. The detailed procedures for MDL determination shall be included in site SOPs. 
TABLE 14-1

\section{Semi-Volatile Organic Compound Target Analyte List and Quality Assurance Objectives}

\begin{tabular}{|c|c|c|c|c|c|c|}
\hline Compound & $\begin{array}{c}\text { CAS } \\
\text { Number }\end{array}$ & $\therefore$ & $\begin{array}{c}\text { Accuracy } \\
\text { (\%R) }\end{array}$ & $\begin{array}{c}\mathrm{MDL} \\
(\mathrm{mg} / \mathrm{kg})\end{array}$ & $\begin{array}{l}\text { PROL } \\
(\mathrm{mg} / \mathrm{kg})\end{array}$ & $\begin{array}{l}\text { Completeness } \\
\text { (percent) }\end{array}$ \\
\hline Cresols & $1319-77-3$ & $\leq 50$ & $60-150$ & 5 & 40 & 90 \\
\hline ortho-Dichlorobenzene ${ }^{b}$ & $95-50-1$ & $\leq 64$ & $32-129$ & 5 & 40 & 90 \\
\hline 2,4-Dinitrophenol & $51-28-5$ & $\leq 119$ & $D-172^{d}$ & 5 & 40 & 90 \\
\hline 2,4-Dinitrotoluene & $121-14-2$ & $\leq 46$ & $39-139$ & 0.3 & 2.6 & 90 \\
\hline Hexachlorobenzene & $118-74-1$ & $\leq 319$ & $D-152^{d}$ & 0.3 & 2.6 & 90 \\
\hline Hexachloroethane & $67-72-1$ & $\leq 44$ & $40-113$ & 5 & 40 & 90 \\
\hline Nitrobenzene & $98-95-3$ & $\leq 72$ & $35-180$ & 5 & 40 & 90 \\
\hline $\begin{array}{l}\text { Polychlorinated Biphenyls } \\
\text { (PCBs) }\end{array}$ & & & & 5 & 40 & 90 \\
\hline Aroclor $1016^{\circ}$ & $\therefore 4-11-2$ & $\leq 33$ & $50-114$ & 5 & 40 & 90 \\
\hline Aroclor $1221^{\circ}$ & $1:-9-2$ & $: 0$ & $: 5-178$ & 5 & 40 & 90 \\
\hline Aroclor $1232^{\circ}$ & $11+$ & & $1+\cdots$ & 5 & 40 & 90 \\
\hline Aroclor $1242^{\circ}$ & 534 & & $\because$ & 5 & 40 & 90 \\
\hline Aroclor $1248^{\circ}$ & $12672-\angle$ & & 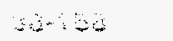 & 5 & 40 & 90 \\
\hline Arocior $1254^{c}$ & $11097-69-1$ & $\leq 2$ & $29-131$ & 5 & 40 & 90 \\
\hline Aroclor $1260^{\circ}$ & $11096-82-5$ & $\leq 56$ & $8-127$ & 5 & 40 & 90 \\
\hline Pentachlorophenol & $87-86-5$ & $\leq 128$ & $14-176$ & 5 & 40 & 90 \\
\hline Pyridine ${ }^{b}$ & $110-86-1$ & $\leq 50$ & $60-150$ & 5 & 40 & 90 \\
\hline
\end{tabular}

\begin{tabular}{|c|c|c|}
\hline$\%$ RSD & $=$ & Percent relative standard deviation \\
\hline RPD & $=\cdot$ & Belative percent difference \\
\hline$\% R$ & $=$ & "ercent recovery \\
\hline MDL. & $=$ & Method detection limit (maximum permissible value) \\
\hline PRQL & $=$ & $\begin{array}{l}\text { Program required quantitation limit; calculated from the toxicity characteristic level for nitrobenzene assuming a } \\
100 \mathrm{~g} \text { sample, } 2 \mathrm{~L} \text { of extraction fluid, an }-109.5 \text { analyte extraction }\end{array}$ \\
\hline
\end{tabular}

${ }^{8}$ Criteria apply to PRQL concentrations

${ }^{b} \mathrm{Can}$ also be analyzed as a vol-:

'PCBs; required only for matr:

iorganic sludges)

'Detected; result must be grea. 


\section{Program Required Quantitation Limit}

Laboratories must demonstrate the capability to quantitate analytes in samples at or below the PROLs given in Table 14-1. Laboratories shall set the concentration of at least one calibration standard below the PROL. The detailed procedures for PRQL demonstration shall be included in laboratory SOPs.

\section{Completeness}

Laboratory completeness shall be expressed as the number of samples analyzed with valid results as a percent of the total number of samples submitted for analysis. Participating laboratories must meet the completeness specified in Table 14-1.

\section{Comparability}

For SVOC analysis, data generated through analysis of samples from different sites shall be comparable. Comparability will be achieved by using standardized methods, traceable standards, and participation by all sites in the PDP.

\section{Representativeness}

Representativeness for SVOC analysis shall be achieved by collecting unbiased samples. Samples must be collected as described in Section 8.0 of this QAPP.

\subsection{Methods Requirements}

Laboratories must use GC/MS methods for the analysis of all analytes listed in Table 14-1. Alternatively, a Gas Chromatography/Electron Capture Detection (GC/ECD) method is available for the analysis of PCBs. Two EPA methods for GC/MS, SW-846 Methods $8250 A$ and $8270 B$, meet Program requirements and are provided in the Methods Manual. One EPA method for GC/ECD, SW-846 Method 8081 , meets Program requirements. A procedure based on SW-846 Method 8081, but optimized for use in the Program, is provided in the Methods Manual. Alternate methods, which meet all of the QAOs in Section 14.1, may be submitted to CAO for approval. Laboratories shall implement the appropriate analytical method(s) with SOPs.

Each site must decide, based on the nature of their waste stream, what preparation methods are appropriate for their waste types. Use of preparation methods in the Methods Manual, SW-846, or other nationally recognized standard methods (e.g., ASTM) is acceptable. Reduction in sample aliquot size and final volume from those suggested in these methods is allowable, as long as the OAOs in Section 14.1 are achievable. Equivalency of modified methods shall be demonstrated by meeting the OAOs defined in Section 14.1 . 


\section{Criteria for Standards}

Primary standards must be purchased from the best available source (Supelco or equivalent) for the target analytes specified in Table 14-1. C . . srcially purchased primary standards must be certified by the manufacturer. Secondary anai ?ndards, surrogate standards, internal standards, calibration standards, matrix spiking standa: standards must be prepared as directed in the appropriate GC/MS or GC/ECD method. Labora: nust specify detailed requirements for the preparation of all standards.

\section{Criteria for Quantitative and Qualitative Analysis}

To be qualitatively identified using GC/MS, a sample analyte must elute within a RRT window of plus or minus 0.06 RRT units and have a mass spectrum that corresponds to the standard mass spectrum. RRT windows must be calculated from the individual RTs for each analyte from a calibration run within the same 12 hours as the sample.

Qualitative identification of $\mathrm{PCBS}$ by $\mathrm{GC} / \mathrm{EC}$. at a sample component elute within the RT window set determined by the : .r standards. Initially, laboratories must run at least three standards for Aroclors 1016, 1221, 1232, 1242, 1248, 1254, and 1260. RT windows shall be defined as plus-or-minus three times the standard deviation of the absolute RT for each of the characteristic peaks of each Aroclor. The analyst shou a RT windows, but also should rely heavily on pattern recognition. RT windows must be determined over a 72 hour period when a new initial calibration curve is generated or a new GC column is installed.

Internal standard quantitation shall be used for GC/MS quantitative analysis. The criteria for SPCCs and CCCs must be met and response factors and \%RSD for response factors must be calculated for all analytes. The GC/MS shall be considered in-control if all daily calibration criteria for decafluorotriphenylphosphine (DFTPP), $s=-\ldots$. terma! standard responses, and RTs are met. Quantitation of an analyte is basec 9 integrated abundance from the EICP of the primary ion.

External standard quantitation shall be used for GC/ECD quantitative analysis. Because PCBs produce multi-peak chromatograms, analyte quantitation shall be based on the total area or height response measured from a common baseline under three to five major peaks for each Aroclor. Once qualitative analysis has been confirmed, laboratories shall produce a calibration curve for the appropriate Aroclor or Aroclor mixture. 
All analytes must be quantitated within the calibration range of the analytical instrument. Multiple dilutions may be required when sample concentrations exceed the calibration range of the analytical instrument.

\subsection{Quality Control}

To assure that data of known and documented quality are generated, each participating laboratory shall implement a documented analytical laboratory QA program. Laboratory QA programs shall specify qualitative and quantitative acceptance criteria for the $\mathrm{QC}$ checks of this program and corrective action measures to be taken when these criteria are not satisfied.

It shall be the responsibility of the laboratory $\mathrm{QA}$ officer to monitor and document procedure performance, including the analysis of QC samples. The laboratory $Q A$ officer and technical supervisor shall have the responsibility to implement corrective actions when acceptable procedure performance is not met.

Laboratories shall operate a formal $\mathrm{QC}$ program and maintain records to document the quality of the data generated. All $O C$ practices established in the analytical methods must be implemented with laboratory SOPs including, but not limited to, the analysis of method performance samples, laboratory duplicates, laboratory blanks, matrix spikes, matrix spike duplicates, laboratory control samples, and blind audit samples. Specific QC samples and frequencies are based on an analycal batch and are summarized in Table 14-2. An analytical batch is defined as a suite of samples of a similar matrix that is processed as a unit using the same analytical method, within a specific time period. An analytical batch can be up to 20 samples, (excluding laboratory OC samples), all of which must be received by the laboratory within 14 days of the VTSR of the first sample in the batch.

Method performance samples shall be used to demonstrate acceptable laboratory performance prior to the analysis of any samples. Method performance samples must contain all of the analytes listed in Table 14-1 at concentrations appropriate to verify that all QAOs are met. Initially, seven method performance samples shall be analyzed to demonstrate acceptable precision and accuracy and shall also be used to determine MDLs for all analytes according to the methods described in Section 3.2. Acceptable procedure performance shall be demonstrated semiannually by analyzing four method performance samples.

Laboratory duplicates, blanks, matrix spikes, and matrix spike duplicates must be prepared as indicated in the method and analyzed at a frequency of one per analytical batch. Surrogate compounds are added to each field sample and laboratory $O C$ sample. The choice of surrogate compounds is site $8-4913$ 
TABLE 14-2

\section{Summary of Laborate - for Total Semi-}

\section{$\checkmark$ Control Samples and Frequencies} anic Compounds Analysis

\begin{tabular}{|c|c|c|c|}
\hline OC Sample & Minimum Frequency & C.: & $\begin{array}{l}\text { Corrective } \\
\text { Action }^{\mathrm{a}}\end{array}$ \\
\hline $\begin{array}{l}\text { Method performance } \\
\text { samples }\end{array}$ & $\begin{array}{l}\text { Seven (7) samples } \\
\text { initially and four (4) } \\
\text { semiannually }\end{array}$ & Meet Table 14-1 QAOs & Repeat until acceptable \\
\hline Laboratory duplicates ${ }^{b}$ & $\begin{array}{l}\text { One (1) per analytical } \\
\text { batch }\end{array}$ & Meet Table 14-1 RPDs & $\begin{array}{l}\text { Nonconformance if RPDs } \\
>\text { Table } 14-1 \text { values }\end{array}$ \\
\hline Laboratory blanks & One " $"$ ner analytical & $\begin{array}{l}\text { Analyte concentrations } \\
<3 \times \mathrm{MDLs}\end{array}$ & $\begin{array}{l}\text { Nonconformance if } \\
\text { analyte concentrations > } \\
3 \times \text { MDLs }\end{array}$ \\
\hline Matrix spikes & $\begin{array}{l}\text { One }(1) p \\
\text { batch }\end{array}$ & $\cdots 1 \%$ Rs & $\begin{array}{l}\text { Nonconformance if \%Rs } \\
\text { are outside the range } \\
\text { specified in Table 14-1 }\end{array}$ \\
\hline $\begin{array}{l}\text { Matrix spike } \\
\text { duplicates }\end{array}$ & $\begin{array}{l}\text { One (1) per analytical } \\
\text { batch }\end{array}$ & $\begin{array}{l}\text { Meet Table 14-1 RPDs } \\
\text { and \%Rs }\end{array}$ & $\begin{array}{l}\text { Nonconformance if RPDs } \\
\text { and \%Rs > Table } 14-1 \\
\text { values }\end{array}$ \\
\hline $\begin{array}{l}\text { Laboratory control } \\
\text { samples }\end{array}$ & $\begin{array}{l}\text { One (1) per analytical } \\
\text { batch }\end{array}$ & $80-120 \% R s$ & $\begin{array}{l}\text { Nonconformance if \%R } \\
<80 \text { or }>120\end{array}$ \\
\hline Surrogate compounds & Each analytical sample & $\begin{array}{l}\text { Average } \% R \text { from minimum } \\
\text { of } 30 \text { samples from a given } \\
\text { matrix } \pm 3 \text { standard } \\
\text { deviations }\end{array}$ & $\begin{array}{l}\text { Nonconformance if } \% \mathrm{R} \\
<\text { (average } \% \mathrm{R}-3 \\
\text { standard deviations) or } \\
>\text { (average } \% \mathrm{R}+3 \\
\text { standard deviations) }\end{array}$ \\
\hline Blind audit samples & $\begin{array}{l}\text { Samples and frequency } \\
\text { controlled by the Solid } \\
\text { PDP Plan }\end{array}$ & $\begin{array}{l}\text { Specified in the Solid PDP } \\
\text { Plan }\end{array}$ & $\begin{array}{l}\text { Specified in the Solid } \\
\text { PDP Plan }\end{array}$ \\
\hline
\end{tabular}

${ }^{\circ}$ Corrective Action when $\mathrm{QC}$ samples do not $\mathrm{m}$. outlined in Section 2.1.2.1.

eptance criteria; Nonconformance procedures are

${ }^{b}$ May be satisfied by using matrix spike dup...s..., scceptance criteria applies only to concentrations greater than the PRQLs listed in Table 14-1.
$\mathrm{MDL}=$ Method detection limit
$\mathrm{QAO}=$ Quality assurance objective
PDP $\quad=$ Performance Demonstration Program
$\% R=$ Percent recovery
RPD $=$ Relative percent difference 
specific. Matrix spike duplicates may be used in place of laboratory duplicates. Laboratory SOPs shall give the details of duplicate, blank, matrix spike, and matrix spike duplicate preparation and analyses. Laboratory duplicate results shall be acceptable if the Table 14-1 criteria for precision are met. Laboratory blank results shall be acceptable if concentrations are less than $3 \times$ MDL for each analyte. Matrix spikes and matrix spike duplicates shall contain at least three of the SVOC analytes listed in Table 14-1. If PCB analysis is being performed, the matrix spike and matrix spike duplicate shall contain at least one of the aroclors listed in Table 14-1. SVOC and PCB spikes shall be at concentrations at the PROLs listed in Table 14-1. Matrix spike results shall be acceptable if the Table 14-1 criteria for accuracy are met. Matrix spike duplicate results shall be acceptable if the Table 14-1 criteria for precision and accuracy are met.

Laboratory control samples will be used to demonstrate ongoing laboratory performance. Laboratory control samples shall contain 1,4-dichlorobenzene, 2,4-dinitrotoluene, hexachloroethane, and nitrobenzene and shall be prepared, in water, at a concentration of $100 \mu \mathrm{g} / \mathrm{L}$ per laboratory control analyte from standards independent of those used for instrument calibration. Laboratory control samples must undergo all sample preparation procedures performed on field samples. Laboratory control samples must be analyzed at a frequency of one per analytical batch and the results shall be acceptable if the Table 14-1 criteria for accuracy are met. For PCBs, the laboratory control sample should contain only the most representative mixture at a concentration of $50 \mathrm{mg} / \mathrm{L}$.

Blind audit samples provided by the PDP shall be used to determine acceptable laboratory performance. Laboratory performance will be evaluated biannually.

\subsection{Instrument Testing, Inspection, and Maintenance Requirements}

Laboratories shall use equipment and materials (gas chromatographs, mass spectrometers, electron capture detectors, data systems, traps, vacuum pumps) that meet all of the SW-846 method requirements. All gas chromatographs shall be equipped with chromatographic columns selected from among those recommended by the SW-846 methods.

GC/MS systems shall be operated in the full scan mode to allow the detection and quantitation of all analytes listed in Table 14-1 and the identification of nontarget compounds. Nontarget compounds shall be reported as TICs and are reported with a higher uncertainty than the reported target analyte concentrations.

Prior to the analysis of any standards or samples, instrument performance criteria shall be met. GC/MS systems must be tuned using PFTBA and must meet the DFTPP criteria specified in the SW-846 
methods. The DFTPP criteria shall be checked by analysis of $50 \mathrm{ng}$ of DFTPP at the beginning of each 12 hours of operation. GC/ECD systems shall be primed daily with a solution containing an Aroclor at a concentration approximately 20 times the midpoint standard. The high concentration Aroclor ensures deactivation of the gas chromatograph column.

\subsection{Instrument Calibration and Frequency}

For GC/MS analysis, an initial, multipoint calibration using internal standards shall be performed after all instrument performance criteria have been satisfied. The multipoint calibration must consist of a minimum of five analytical standards that define the calibration range of the instrument for all of the analytes listed in Table 14-1. The initial calibration is considered valid if the response factor \%RSDs for CCCs is less than or equal to 30 , and average response factors for each SPCC is greater than or equal to 0.05 . Average relative response factors for a specific analyte can be used if the \%RSD is less than or equal to 15 . If \%RSD is greater than 15 , then a linear regression equation is used.

The initial GC/MS calibration curve shall be verified using a midpoint calibration standard (continuing calibration standard). The continuing calibration standard shall be analyzed at the beginning of every 12 hours of operation. Prior to the analysis of this midpoint standard, the specified instrument performance criteria using $50 \mathrm{ng}$ of DFTPP must be satisfied. The midpoint standard must meet all of the daily calibration criteria for SPCCs, CCCs, surrogate compound recovery, internal standard area count, and RTs as specified in the SW-846 methods. In addition, the response factor \%Ds must less than or equal to 20 with response factors greater than or equal to 0.05 for all analytes. If the continuing calibration standard does not satisfy the criteria for linearity and consistency, a new fivepoint initial calibration curve must be generated. Sample analysis cannot proceed until the GC/MS system has satisfied the appropriate daily calibration criteria. SPCCs and CCCs should only include those that are common to Table $14-1$ and SW-846 Methods $8250 \mathrm{~A}$ or $8270 \mathrm{~B}$.

For GC/ECD analysis, an initial multipoint calibration shall be performed only after qualitative analysis has identified the appropriate Aroclor(s). The multipoint calibration must consist of a minimum of three analytical standards that define the calibration range of the instrument for each Aroclor identified by qualitative analysis. A calibration curve plotting peak height or area against concentration shall be prepared. Alternatively, if the response factor \%RSDs are less than or equal to 20 , the average response factor can be used. The GC/ECD calibration curve shall be verified using a midpoint calibration standard (continuing calibration standard) at the beginning of every 12 hours of operation. The continuing calibration shall be valid if the response factor \%D is less than or equal to 15 for all analytes, and the RT of each analyte is plus-or-minus 3 standard deviations from initial calibration. 
Laboratories shall maintain detailed instrument run logs covering all aspects of GC/MS and GC/ECD calibrations to enable reconstruction of calibration sequences and frequencies. GC/MS and GC/ECD calibration requirements are summarized in Table 14-3.

\subsection{Data Management}

Data management includes requirements for data reduction, validation, and reporting. All of the data management requirements defined in Section 3.1.1 of this QAPP, as well as those described below, apply to data from SVOC analyses. Data management procedures demonstrating compliance with these requirements must be detailed in QAPjPs and SOPs and, as appropriate, include specific equations, sample calculations, and example forms for data reduction, validation, and reporting.

\section{Data Reduction}

All organic analyte concentrations shall be quantified using average relative response factors for internal standard quantitation or by total peak area or height for external standard quantitation. Target analyte concentrations shall not be blank-corrected. Results from blanks run in association with samples shall be reported separately, flagging any target analytes detected (see below).

Nontarget compounds shall be reported as TICs and are reported with a higher uncertainty than the reported target analyte concentrations. For samples containing TICs with total ion current peaks greater than 10 percent of the nearest RT internal standard, appropriate search routines of the latest NIST or equivalent mass spectral library must be performed on the 20 greatest in area count. Positively identified TICs listed in 40 CFR Part 264, Appendix IX shall be added to the target analyte list by the site project manger if they are detected in 25 percent of all samples from a given matrix parameter category.

All SVOC and PCB results shall be reported in $\mathrm{mg} / \mathrm{kg}$ on a weight/wet-weight basis and shall be limited to two significant figures. Detailed procedures for data reduction can be found in SW-846. SOPs must detail procedures for reducing raw data to reportable units.

\section{Data Validation}

All SVOC analysis data must be reviewed prior to being reported. The validation process is outlined in Section 3.1.1 and includes verification that the QAOs presented in Table 14-1 have been met.

\section{Data Reporting}

Each laboratory analyzing samples is required to submit analytical batch data reports for each analytical batch to the site project office on approved standard forms. Site-specific documentation must include 
TABLE 14-3

Summary of Calibration Requirements

for Semi-Volatile Orystic Compounds Analysis

Technique Procedure Frequency of Procecure Acceptance Criteria

\section{GC/MS \\ DFTPP Tune \\ Every 12 hours}

5-pt initial calibration (5 standards)

Continuing calibration

Every 12 hours

GC/ECD

3-pt initial calibration

(3 standards)

Continuing calibration
Initially and as needed
Initially and as needed

Every 12 hours as needed
Abundance criteria for all key ions are met (see SW-846 Method 8250A or 8270B)

Response factor \%RSD for CCCs $\leq$ 30; response factor for SPCCs $\geq$ 0.05 ; average relative response factor used if \%RSD $\leq 15$; linear regression equation generated if $\%$ RSD $>15$

$\% D \leq 20$ for all analytes; response factor for SPCCs $\geq 0.05$; RT for internal standards must be \pm 30 seconds from last daily calibration check; internal standards area count must be $>50 \%$ or $<200 \%$ of the area count from daily calibration check; surrogate compound \%R must be met (see SW-846 Method 8250A or $8270 \mathrm{~B}$ )

Response factor \%RSD $\leq 20$

$\% D \leq 15$ for all analytes compared to initial calibration

\footnotetext{
CCC $=$ Calibration check compounds

$\% \mathrm{D}=$ Percent difference

DFTPP = Decafluorotriphenylphosphine

$\%$ RSD $=$ Percent relative standard deviation

RT $=$ Retention time

SPCC $=$ System performance check compounds
} 
example forms that will be used for reporting. Analytical batch data reports shall consist of the following:

- Cover page that includes the laboratory name, analytical batch number, sample numbers included in that analytical batch, a cross reference to field sample numbers, and the signature releases of laboratory personnel as specified in Section 3.1.1.

- Table of Contents.

- Summary COC Form that shows the date and time of sample transfer, and name of individuals handling the samples from the time of sampling through receipt at the laboratory.

- Data review checklists for each analytical batch verifying that the data generation level review, validation, and verification, as described in Section 3.1.1 has taken place. Checklists must contain tables showing the results of the analytical batch $\mathrm{OC}$ samples (e.g., laboratory duplicates, laboratory control samples).

- A separate analytical report sheet for each sample in the analytical batch that includes the laboratory name, program name, the title "Total SVOCs Analysis Data Sheet," analytical batch number, sampling batch number, laboratory sample number, field sample number, date sampled, date extracted, date and time analyzed, method number, listing of program analytes, and analytical results in $\mathrm{mg} / \mathrm{kg}$. SVOC analysis data qualifying flags shall be used as follows:

- B-Analyte detected in blank

- E-Analyte exceeds the calibration curve

- J-Analyte less than PRQL, but greater than or equal to MDL

- U-Analyte was undetected (Report MDL)

- D-Analyte was quantitated from a secondary dilution, or reduced volume sample aliquot

- Nonconformance reports, if applicable.

In addition, laboratories located on sites shall maintain the following items in their files, documented and retrievable by analytical batch number. Contract laboratories shall forward these items along with analytical results to the site project office for storage in site project files.

- Original COC forms.

- All raw data, including original instrument readouts and/or bench reports, calculation records, and laboratory $\mathrm{OC}$ sample results. Laboratory duplicate results are recorded along with the original sample results, and the RPD between the two results are calculated. Laboratory control sample results are entered along with the accepted value and the $\% R$.

- All instrument calibration reports that include the accepted and measured values of calibration verification for all analytes. These reports must also contain the laboratory name, analytical batch number(s), initial and continuing calibration verification source, method identification, and calibration date and time. 
- QC result summary, whic associated result calculatior: control samples, matrix spike: continuing calibration verificatir The OC summary report must number (if applicable), and methc. es true and found values for all $O C$ samples plus vinimum, the $Q C$ data shall include blanks, laboratory $\times$ spike duplicates, initial calibration data, initial and all other method-specific OC listed in Table 14-2. tain the laboratory name, the analytical batch 


\subsection{TOTAL METAL ANALYSIS}

This section identifies the required $Q A$ elements for the analysis of total metals in samples of homogenous solids and soil/gravel. Total metals are those solubilized by hot acid leaching le.g., SW-846 Method 3051). Samples must be collected from waste containers as detailed in Section 8.0 of this QAPP.

\subsection{Quality Assurance Objectives}

The development of DOOs for the Program has resulted in the QAOs listed in Table 15-1. The specified QAOs represent the required quality of data necessary to draw valid conclusions regarding Program objectives. Program-required limits, such as the PRQLs associated with metal analysis, are specified to ensure that the analytical data collected satisfy the requirements of all data users. Key data quality indicators for laboratory measurements are defined below and the methods to assess compliance with these indicators are presented in Section 3.2 of this QAPP.

\section{Precision}

Precision shall be assessed by analyzing laboratory matrix spike duplicates, replicate analyses of laboratory control samples, and PDP blind audit samples. Results from measurements on these samples must be compared to the criterion listed in Table 15-1. These $\mathrm{QC}$ measurements will be used to demonstrate acceptable method performance and to trigger corrective action when control limits are exceeded.

\section{Accuracy}

Accuracy shall be assessed through the analysis of laboratory matrix spikes, PDP blind audit samples, and laboratory control samples. Results from these measurements must be compared to the criterion listed in Table 15-1. These OC measurements will be used to demonstrate acceptable method performance and to trigger corrective action when control limits are exceeded.

\section{Program Required Detection Limits}

Program required detection limits (PRDLs), expressed in units of $\mu \mathrm{g} / \mathrm{L}$, are the maximum values for instrument detection limits (IDLs) permissible for Program support under this QAPP. IDLs must be less than or equal to the PRDL for the method used to quantitate a specific anaiyte. Any method listed in Table 15-2 may be used if the IDL meets this criteria. For high concentration samples, an exception to the above requirements may be made in cases where the sample concentration exceeds five times the IDL of the instrument being used. In this case, the analyte concentration may be reported even 
TABLE 15-1

Total Metals Target Analyte List and Quality Assurance Objectives

\begin{tabular}{lcccccc}
\hline Analyte & CAS Number & $\begin{array}{c}\text { Precision } \\
\text { (\%RSD or RPD) }\end{array}$ & $\begin{array}{c}\text { Accuracy } \\
(\% R)^{b}\end{array}$ & $\begin{array}{c}\text { PRDL } \\
(\mu g / \mathrm{L})\end{array}$ & $\begin{array}{c}\text { PROL } \\
(\mathrm{mg} / \mathrm{kg})\end{array}$ & $\begin{array}{c}\text { Completeness } \\
(\%)\end{array}$ \\
\hline Antimony & $7440-36-0$ & $\leq 30$ & $80-120$ & 100 & 100 & 90 \\
Arsenic & $7440-38-2$ & $\leq 30$ & $80-120$ & 100 & 100 & 90 \\
Barium & $7440-39-3$ & $\leq 30$ & $80-120$ & 2000 & 2000 & 90 \\
Beryllium & $7440-41-7$ & $\leq 30$ & $80-120$ & 100 & 100 & 90 \\
Cadmium & $7440-43-9$ & $\leq 30$ & $80-120$ & 20 & 20 & 90 \\
Chromium & $7440-47-3$ & $\leq 30$ & $80-120$ & 100 & 100 & 90 \\
Lead & $7439-92-1$ & $\leq 30$ & $80-120$ & 100 & 100 & 90 \\
Mercury & $7439-97-6$ & $\leq 30$ & $80-120$ & 4.0 & 4.0 & 90 \\
Nickel & $7440-02-0$ & $\leq 30$ & $80-120$ & 100 & 100 & 90 \\
Selenium & $7782-49-2$ & $\leq 30$ & $80-120$ & 20 & 20 & 90 \\
Silver & $7440-22-4$ & $\leq 30$ & $80-120$ & 100 & 100 & 90 \\
Thallium & $7440-28-0$ & $\leq 30$ & $80-120$ & 100 & 100 & 90 \\
Vanadium & $7440-62-2$ & $\leq 30$ & $80-120$ & 100 & 100 & 90 \\
Zinc & $7440-66-6$ & $\leq 30$ & $80-120$ & 100 & 100 & 90 \\
& & & & & & \\
\hline
\end{tabular}

$\%$ RSD $=$ Percent relative standard deviation

RPD = Relative percent difference

$\% \mathrm{R}=$ Percent recovery

PRDL = Program required detection limit (i.e., maximum permissible value for (DL)

PROL = Program required quantitation limit

a $\leq 30 \%$ control limits apply when sample and duplicate concentrations are $\geq 10 \times$ IDL for ICP-AES and AA techniques, and $\geq 100 \times$ IDL for ICP-MS techniques. If less than these limits, the absolute difference between the two values shall be less than or equal to the PRDL.

bApplies to laboratory control samples. If a solid laboratory control sample material which has established statistical control limits is used, then the established control limits for that material should be used for accuracy requirements.

'PRDL set such that it is a factor of 10 below the PROL for $100 \%$ solid samples, assuming a $100 \mathrm{X}$ dilution during digestion. 
though the IDL may exceed the PRDL. IDLs shall be determined semiannually (i.e., every 6 months). Detailed procedures for IDL determination shall be included in laboratory SOPs.

\section{Program Required Quantitation Limit}

Laboratories must demonstrate the capability of analyte quantitation at or below the PROLs, in units of $\mathrm{mg} / \mathrm{kg}$ dry weight, given in Table 15-1. The PRDLs are set an order of magnitude less than the PRQLs (assuming 100-percent solid sample diluted by a factor of 100 during preparation). Laboratories shall set the concentration of at least one $Q C$ or calibration standard at or below the solution concentration equivalent of the PROL. Detailed calibration procedures shall be included in site SOPs.

\section{Completeness}

Laboratory completeness shall be expressed as the number of samples analyzed with valid results as a percent of the total number of samples submitted for analysis. Participating laboratories must meet the completeness specified in Table 15-1.

\section{Comparability}

Data generated through analysis of samples from different sites shall be comparable. Comparability will be achieved by using standardized methods, traceable standards, and participation by all sites in the PDP.

\section{Representativeness}

Representativeness for metals analysis shall be achieved by the collection of unbiased samples. Samples must be collected as described in Section 8.0 of this QAPP.

\subsection{Methods Requirements}

Total metals analysis is a two-step process involving a sample preparation step followed by an analysis. Multiple preparation methods and analytical techniques may be required to complete the analysis of all metal target analytes.

Each site must decide, based on the nature of their waste stream, what preparation methods are appropriate for their waste types. Use of preparation methods from the Methods Manual, SW-846, or other nationally recognized standard methods (e.g., ASTM) is acceptable. The Methods Manual includes an acceptable sample preparation procedure based on microwave-assisted hot acid digestion.

Reduction in sample aliquot size and final volume from those suggested in these methods is allowable, as long as the OAOs outlined in Section 15.1 are achievable. Changes affecting the chemistry of the 
methods (e.g., different reagents) may require proof of equivalency. Equivalency shall be determined by demonstrating that the QAOs defined in Section 15.1 can be met using the modified method(s), and by performing the method precision and accuracy demonstration required in Section 15.3. All modifications to standard methods must be documented and justified by the laboratory and approved by CAO.

SW-846 provides guidance regarding appropriate sample preparation techniques for the determinative methods listed in Table 15-2. To convert analytical results into units of $\mathrm{mg} / \mathrm{kg}$ dry weight, the percent solid content may be determined for each field sample on a separate aliquot from that used for digestion and analysis. Procedures for sample preparation and percent solid determination shall be included in laboratory SOPs.

The analytical methods for metal analytes, which are summarized in Table 15-2, are found in SW-846. These techniques can be grouped into the following three categories:

1. Atomic Mass Spectrometry, which consists of Inductively Coupled Plasma-Mass Spectrometry (ICP-MS)

2. Atomic Emission Spectroscopy, which consists of Inductively Coupled Plasma Atomic Emission Spectroscopy (ICP-AES)

3. Atomic Absorption Spectroscopy, which includes Graphite Furnace Atomic Absorption Spectroscopy (GFAA), Flame Atomic Absorption Spectrocopy (FLAA), Cold Vapor Atomic Absorption Spectroscopy (CVAA), and Hydride Generation Atomic Absorption Spectroscopy (HAA)

Any of the analytical methods listed in Table 15-2 may be used for a specific metal analyte provided that the QAOs listed in Table 15-1 can be met. FLAA should be used only as backup to ICP-AES. Alternate methods that meet all of the QAOs in Section 15.1 may be used with approval from CAO. Laboratory SOPs shall specify the requirements for implementation of the selected analytical methods.

\section{Criteria for Standards}

Stock standards solutions for metals analysis must be purchased or prepared from ultra-high purity grade chemicals or metals (99.99 to 99.999-percent pure). Concentrations of all stock standard solutions must have a known valid relationship to a nationally recognized standard material (e.g., NIST). If commercial stock solutions are used, a Certificate of Analysis from the manufacturer documenting traceability is required. Commercial stock solutions must not be used beyond their manufacturerspecified shelf life. 
TABLE 15-2

Total Metal Analytical Methods

\begin{tabular}{|c|c|c|c|c|c|c|c|}
\hline \multirow[b]{2}{*}{ Analyte } & \multirow[b]{2}{*}{$\begin{array}{c}\text { CAS } \\
\text { Number }\end{array}$} & \multicolumn{6}{|c|}{ SW-846a Analytical Method } \\
\hline & & ICP-AES & ICP-MS & FLAA & GFAA & CVAA & HAA \\
\hline Antimony & $7440-36-0$ & $6010 A^{b}$ & $6020^{\circ}$ & 7040 & 7041 & - & $7062^{\circ}$ \\
\hline Arsenic & $7440-38-2$ & $6010 A^{b}$ & $6020^{\circ}$ & - & $7060 A^{c}$ & -- & $\begin{array}{r}7061 A^{b} \\
7062^{c}\end{array}$ \\
\hline Barium & $7440-39-3$ & $6010 A^{b}$ & $6020^{c}$ & $7080 A^{c}$ & $7081^{b}$ & -- & - \\
\hline Beryllium & $7440-41-7$ & $6010 A^{b}$ & $6020^{c}$ & 7090 & 7091 & -- & - \\
\hline Cadmium & $7440-43-9$ & $6010 A^{b}$ & $6020^{c}$ & 7130 & $7131 A^{c}$ & - & - \\
\hline Chromium & $7440-47-3$ & $6010 A^{b}$ & $6020^{c}$ & 7190 & 7191 & - & - \\
\hline Lead & $7439-92-1$ & $6010 A^{b}$ & $6020^{c}$ & 7420 & 7421 & - & - \\
\hline Mercury & $7439-97-6$ & - & - & - & - & $7471 A^{\circ}$ & - \\
\hline Nickel & $7440-02-0$ & $6010 A^{b}$ & $6020^{c}$ & 7520 & -- & - & - \\
\hline Selenium & $7782-49-2$ & $6010 A^{b}$ & - & -- & 7740 & - & $\begin{array}{c}7741 A^{c} \\
7742^{\circ}\end{array}$ \\
\hline Silver & $7440-22-4$ & $6010 A^{b}$ & $6020^{\circ}$ & $7760 A^{b}$ & $7761^{b}$ & - & - \\
\hline Thallium & $7440-28-0$ & $6010 A^{b}$ & $6020^{c}$ & 7840 & 7841 & - & - \\
\hline Vanadium & $7440-62-2$ & $6010 A^{b}$ & -. & 7910 & 7911 & -- & -- \\
\hline Zinc & $7440-66-6$ & $6010 A^{b}$ & $6020^{c}$ & 7950 & $7951^{b}$ & -- & -- \\
\hline
\end{tabular}

aTest Methods for Evaluating Solid Waste, Physical/Chemical Methods, Third Edition, Final Update I and Final Update II (SW-846) (EPA, 1995)

' Method contained in SW-846, Final Update I

'Method contained in SW-846, Final Update II 
Working calibration and OC standards shall be diluted from the stock standard solutions using volumetric glassware and calibrated pipettors. Working calibration standards (i.e., solutions analyzed by the instrument), blanks, and $Q C$ standards must be prepared using the same type of acids, at the same concentrations present in the prepared samples. Working calibration standards must be verified with each use by an initial calibration verification standard prepared fresh daily from an independent source.

Working calibration and QC standards for ICP-MS, ICP-AES and FLAA must be prepared at least weekly. If the standards contain analytes in concentrations less than $1 \mathrm{mg} / \mathrm{L}$, the standards should be prepared fresh daily prior to use. All working calibration and QC standards for GFAA, CVAA, and HAA must be prepared fresh on a daily basis. Working standards for CVAA shall be processed using the same preparation method as the samples. Standard solutions containing silver are light-sensitive and should be stored in the dark or in opaque containers. Laboratory SOPs must specify detailed requirements for the preparation of all standards.

\section{Criteria for Quantitative Analysis}

All analytical instruments used to quantitate metal analytes shall be configured and operated according to manufacturer's instructions and SW-846 method requirements. Instrument settings must be established and documented for each analyte on that instrument. All analytes must be quantitated within the calibration range of the analytical instrument. Multiple dilutions may be required for sample concentrations greater than the calibration range of the instrument. A minimum of two integrations shall be used to quantitate all analytes and the average reported.

Interferences shall be examined for all techniques, and if detected, corrective action taken to minimize their effects. SW-846 presents acceptable procedures for determining and overcoming matrix interference effects. Background correction shall be used for all techniques. Due to the expected nature of program samples, deuterium background correction shall not be used for GFAA or FLAA methods. The method of standard additions (MSA) shall be used when appropriate. The analytical methods referenced in Table 15-2 provide guidance concerning the use of MSA. Interference detection and correction shall be addressed in laboratory SOPs.

Use of proven matrix modifiers other than those specified in standard methods is acceptable, provided that the choice of modifier is documented in laboratory SOPs. Fluorescence detection for mercury analysis is acceptable. 
Laboratory water, reagents, and gases used during analysis shall be of sufficient purity to ensure that samples are not contaminated. These materials shall be acceptable for use if analysis of laboratory blanks prepared and analyzed with them show analyte levels no greater than three times the analyte IDLs.

\subsection{Quality Control}

The daily quality of analytical data generated in laboratories analyzing total metals shall be controlled by the implementation of a documented laboratory QA program. Laboratory QA programs must specify qualitative and quantitative acceptance criteria for $\mathrm{OC}$ checks and corrective action measures to be taken when these criteria are not met. Specific $Q C$ elements are listed in Table 15-3.

It shall be the responsibility of the laboratory $Q A$ officer to monitor and document procedure performance, including the analysis of $Q C$ samples. The laboratory $Q A$ officer and technical supervisor shall have responsibility to implement corrective actions when acceptable procedure performance is not met.

Method performance samples shall be used to demonstrate acceptable laboratory performance prior to the analysis of any samples. Method performance samples must contain all of the analytes listed in Table 15-1 at concentrations appropriate to verify that all QAOs are met. Initially, seven method performance samples shall be analyzed to demonstrate acceptable precision and accuracy and shall also be used to determine IDLs for all analytes. Demonstration of acceptable procedure performance shall be repeated semiannually by the analysis of four method performance samples. Method performance demonstration should be conducted over a period of several days to account for long-term variability.

For laboratory OC purposes, an analytical batch is defined as a suite of samples of a similar matrix, processed as a unit, using the same analytical method, within a specific time period. An analytical batch can be up to 20 samples (excluding laboratory $Q C$ samples), all of which must be received by the laboratory within 14 days of the VTSR of the first sample in the batch. Specific OC samples for each analytical batch shall include laboratory blanks, matrix spikes, matrix spike duplicates, and laboratory control samples.

Laboratory blanks shall undergo the same digestion and analytical procedures used to prepare waste samples. Matrix spikes and matrix duplicates must contain the metal(s) being analyzed at concentrations at the PROL listed in Table 15-1. Solid laboratory control samples le.g., characterized surrogate sludges) should be used whenever it is possible to match the matrix of the waste samples. 
TABLE 15-3

\section{Summary of Laboratory Quality Control Samples and Frequencies for Total Metals Analyses}

\begin{tabular}{|c|c|c|c|}
\hline OC Samples & Minimum Frequency & $\begin{array}{l}\text { Acceptance } \\
\text { Criteria }\end{array}$ & Corrective Actions ${ }^{a}$ \\
\hline $\begin{array}{l}\text { Method performance } \\
\text { samples }\end{array}$ & $\begin{array}{l}\text { Seven (7) samples initially, } \\
\text { and four (4) semiannually }\end{array}$ & Meet Table 15-1 QAOs & Repeat until acceptable \\
\hline Laboratory blanks & $\begin{array}{l}\text { One (1) per analytical } \\
\text { batch }\end{array}$ & $\begin{array}{l}\leq 3 \times 1 D L \\
1 \leq 5 \times 1 D L \text { for } \\
\text { ICP-MS }\left.\right|^{b}\end{array}$ & $\begin{array}{l}\text { Redigest and reanalyze } \\
\text { any samples with } \\
\text { analyte concentrations } \\
\text { which are } \\
\leq 10 \times \text { blank value and } \\
\geq 0.5 \times \text { PROL }\end{array}$ \\
\hline Matrix spikes & $\begin{array}{l}\text { One (1) per analytical } \\
\text { batch }\end{array}$ & $80-120 \% R$ & $\begin{array}{l}\text { Nonconformance if } \% R \\
<80 \text { or }>120\end{array}$ \\
\hline Matrix spike duplicates & $\begin{array}{l}\text { One (1) per analytical } \\
\text { batch }\end{array}$ & $\begin{array}{l}R P D \leq 30 \\
80-120 \% R\end{array}$ & $\begin{array}{l}\text { Nonconformance if } \\
\text { RPD }>30 \text { or if \%R }< \\
80 \text { or }>120\end{array}$ \\
\hline $\begin{array}{l}\text { Laboratory control } \\
\text { samples }\end{array}$ & $\begin{array}{l}\text { One (1) per analytical } \\
\text { batch }\end{array}$ & $80-120 \% R$ & $\begin{array}{l}\text { Redigest and reanalyze } \\
\text { for affected analytes }\end{array}$ \\
\hline Blind audit samples & $\begin{array}{l}\text { Samples and trequency } \\
\text { controlled by the Solid } \\
\text { PDP Plan }\end{array}$ & $\begin{array}{l}\text { Specified in the Solid } \\
\text { PDP Plan }\end{array}$ & $\begin{array}{l}\text { Specified in the Solid } \\
\text { PDP Plan }\end{array}$ \\
\hline
\end{tabular}

${ }^{a}$ Corrective Actions when $\mathrm{OC}$ samples do not meet acceptance criteria; Nonconformance procedures are outlined in Section 2.1.2.1.

${ }^{b}$ Applies only to concentrations greater than the PROLs listed in Table 15-1.

IDL = Instrument detection limit

PDP = Performance Demonstration Program

PRQL = Program required detection limit

$\% \mathrm{R}=$ Percent recovery

RPD $=$ Relative percent difference 
Otherwise, commercially purchased standards shall be used to prepare laboratory control samples. The laboratory control samples must contain the metal(s) being analyzed and be quantitated within the calibration range of the instrument. Laboratory SOPs shall address requirements for preparing matrix spikes, matrix spike duplicates, laboratory blanks, and laboratory control samples.

Blind audit samples provided by the PDP shall be used to determine acceptable laboratory performance. Laboratory performance will be evaluated biannually.

\subsection{Instrument Testing, Inspection, and Maintenance Requirements}

Laboratories shall use equipment and materials that meet all of the SW-846 method requirements. Analytical instruments shall be tested, inspected, and maintained to ensure all the Program QAOs listed in Table 15-1 can be met. Measurements at the specified PROLs must meet the precision requirements specified in Table 15-1. Site QAPjPs and SOPs shall detail specific actions and schedules for instrument testing, inspection and maintenance, based on manufacturer's recommendations and requirements included in the specific SW-846 method (if applicable).

\subsection{Instrument Calibration and Frequency}

All analytical instruments must be calibrated before use, and calibration must be checked at routine intervals during analysis. Minimum calibration requirements and analytical run $Q C$ are summarized in Table 15-4.

\subsection{Data Management}

Data management includes procedures for data reduction, validation, and reporting. All of the data management procedures defined in Section 3.1.1 of this QAPP, as well as those described below, apply to data from metal analyses. Data management procedures must be detailed in QAPjPs and SOPs and, as appropriate, include specific equations, sample calculations, and example forms for data reduction, validation, and reporting.

\section{Data Reduction}

All quantitative values shall be reported in $\mathrm{mg} / \mathrm{kg}$ on a wet weight basis and shall be limited to two significant figures. Detailed procedures for data reduction can be found in SW-846. SOPs must detail procedures for reducing raw data to reportable units.

If dilutions are performed, calculations must take the appropriate dilution factor into account. For ICPMS, signals at 206,207 , and $208 \mathrm{~m} / \mathrm{z}$ shall be summarized for lead to compensate for any differences 
TABLE 15-4

\begin{tabular}{|c|c|c|c|c|}
\hline Technique & Procedure & Frequency of Procedure & Acceptance Criteria & Corrective Action \\
\hline \multirow[t]{7}{*}{ ICP-MS } & Mass Tune & Daily & $\begin{array}{l}4 \text { Replicate } \% \text { RSD }<10 \text {; mass calibration } \\
\text { within } 0.1 \text { amu; resolution }<1.0 \text { amu full } \\
\text { width at } 10 \text { percent peak height }\end{array}$ & $\begin{array}{l}\text { Manufacturer } \\
\text { recommendations }\end{array}$ \\
\hline & $\begin{array}{l}1 \text {-pt. initial } \\
\text { calibration } \\
\text { (1 standard and a } \\
\text { blank) }\end{array}$ & Daily & $\begin{array}{l}90-110 \% \mathrm{R} \text { for initial calibration } \\
\text { verification solution } \\
95-105 \% \mathrm{R} \text { for highest calibration } \\
\text { standard }\end{array}$ & $\begin{array}{l}\text { Repeat tune and initial } \\
\text { calibration }\end{array}$ \\
\hline & $\begin{array}{l}\text { Continuing } \\
\text { calibration }\end{array}$ & $\begin{array}{l}\text { Every } 10 \text { samples plus beginning } \\
\text { and end of run }\end{array}$ & $\begin{array}{l}90-110 \% \mathrm{R} \text { for check standard; blank } \\
\text { must measure } \leq 5 \times I D L ; \text { internal standard } \\
\text { areas must be } \leq 20 \% \mathrm{D} \text { of calibration } \\
\text { blank internal standard areas }\end{array}$ & $\begin{array}{l}\text { Correct problem, recalibrate } \\
\text { and rerun last } 10 \text { samples }\end{array}$ \\
\hline & $\begin{array}{l}\text { Interference } \\
\text { correction } \\
\text { verification }\end{array}$ & $\begin{array}{l}\text { Beginning and end of run or } \\
\text { every } 12 \text { hours, whichever is } \\
\text { more frequent }\end{array}$ & $\begin{array}{l}\text { Solution containing interferants only must } \\
\text { measure } \leq 5 \times 1 D L \text { for interferants; solution } \\
\text { containing interferants plus analytes must } \\
\text { be within } 80-120 \% R \text { for all analytes }\end{array}$ & $\begin{array}{l}\text { Correct problem and } \\
\text { recalibrate }\end{array}$ \\
\hline & Serial dilution & $\begin{array}{l}\text { once per analytical batch or per } \\
\text { matrix within an analytical batch }\end{array}$ & $\begin{array}{l}5 x \text { dilution of sample which is }>100 \times 1 \mathrm{DL} \\
\text { must be } \leq 10 \% \mathrm{D} \text { of initial value }\end{array}$ & Define in Laboratory SOPs \\
\hline & $\begin{array}{l}\text { Post-digestion } \\
\text { spike }\end{array}$ & $\begin{array}{l}\text { once per analytical batch or per } \\
\text { matrix within an analytical batch } \\
\text { if serial dilution, matrix spike, or } \\
\text { matrix spike duplicate does not } \\
\text { meet acceptance criteria }\end{array}$ & $75-125 \% R$ & Define in Laboratory SOPs \\
\hline & $\begin{array}{l}\text { Internal standard } \\
\text { area verification }\end{array}$ & Every sample & $\begin{array}{l}\text { Area must be } \leq 30 \% \mathrm{D} \text { of calibration blank } \\
\text { internal standard areas }\end{array}$ & $\begin{array}{l}\text { Dilute sample } 5 x \text { and } \\
\text { reanalyze }\end{array}$ \\
\hline ICP-AES & $\begin{array}{l}1 \text {-pt. initial } \\
\text { calibration } \\
\text { (1 standard and a } \\
\text { blank) }\end{array}$ & Daily & $\begin{array}{l}90-110 \% \mathrm{R} \text { for initial calibration } \\
\text { verification solution } \\
95-105 \% \mathrm{R} \text { for highest calibration } \\
\text { standard }\end{array}$ & $\begin{array}{l}\text { Correct problem and repeat } \\
\text { initial calibration }\end{array}$ \\
\hline
\end{tabular}


TABLE 15-4

Summary of Calibration Requirements and Analysis QC for Total Metals Analysis (Continued)

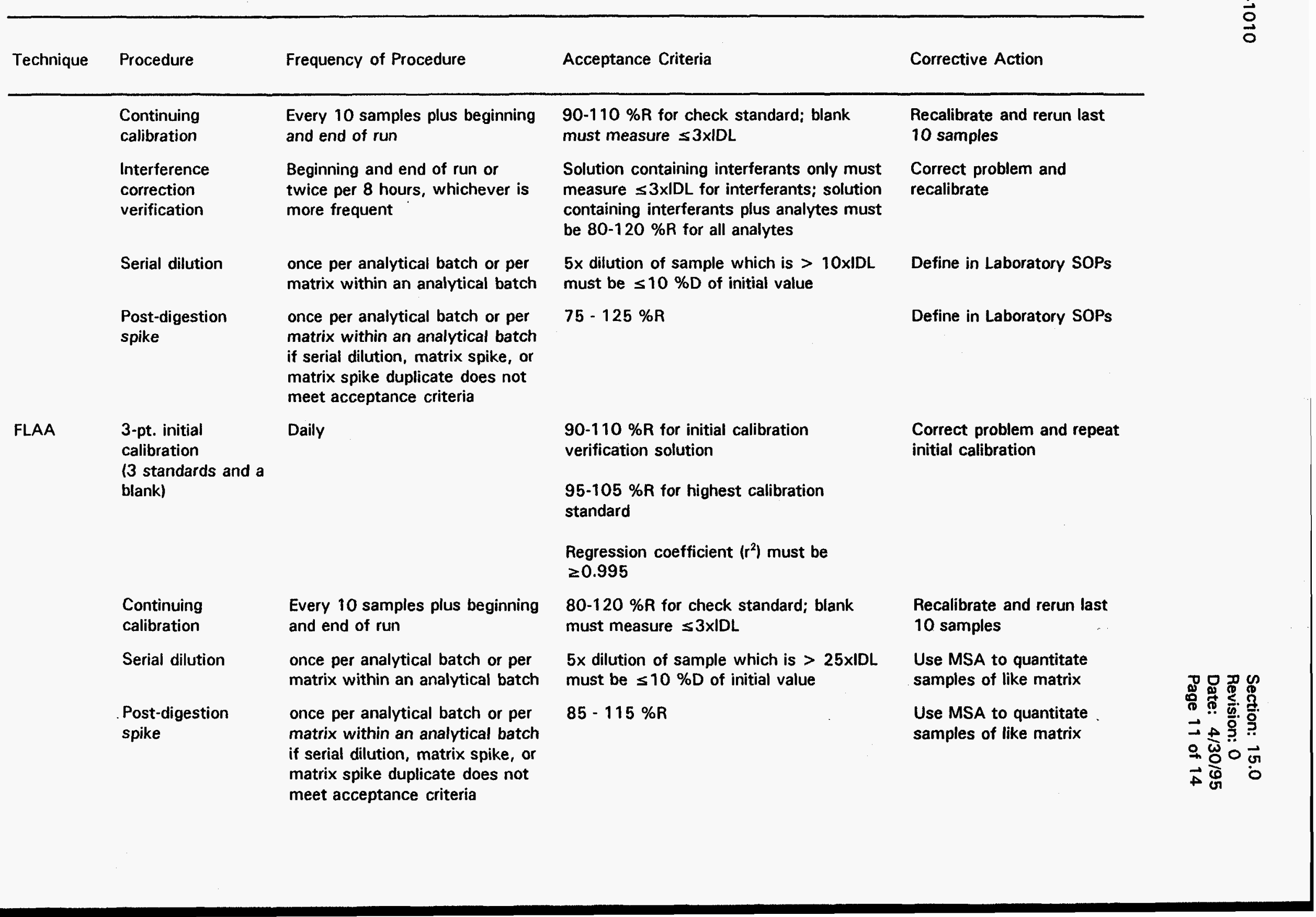


TABLE 15.4

Summary of Calibration Requirements and Analysis QC for Total Metals Analysis

(Continued)

\begin{tabular}{|c|c|c|c|c|c|}
\hline Technique & Procedure & Frequency of Procedure & Acceptance Criteria & Corrective Action & \\
\hline \multirow[t]{4}{*}{ GFAA } & $\begin{array}{l}\text { 3-pt. initial } \\
\text { calibration } \\
\text { ( } 3 \text { standards and a } \\
\text { blank) }\end{array}$ & Daily & $\begin{array}{l}90-110 \% \mathrm{R} \text { for initial calibration } \\
\text { verification solution } \\
95-105 \% \mathrm{R} \text { for highest calibration } \\
\text { standard } \\
\text { Regression coefficient }\left(r^{2}\right) \text { must be } \\
\geq 0.995\end{array}$ & $\begin{array}{l}\text { Correct problem and repeat } \\
\text { initial calibration }\end{array}$ & \\
\hline & $\begin{array}{l}\text { Continuing } \\
\text { calibration }\end{array}$ & $\begin{array}{l}\text { Every } 10 \text { sample injections plus } \\
\text { beginning and end of run }\end{array}$ & $\begin{array}{l}\text { 80-120 \%R for check standard } \\
\text { (mandatory): blank (optional) should } \\
\text { measure S3xIDL. }\end{array}$ & $\begin{array}{l}\text { Recalibrate and rerun last } \\
10 \text { samples }\end{array}$ & \\
\hline & Serial dilution & $\begin{array}{l}\text { once per analytical batch or per } \\
\text { matrix within an analytical batch }\end{array}$ & $\begin{array}{l}5 x \text { dilution of sample which is }>25 \times 1 D L \\
\text { must be } \leq 10 \% D \text { of initial value }\end{array}$ & $\begin{array}{l}\text { Use MSA to quantitate } \\
\text { samples of like matrix }\end{array}$ & \\
\hline & $\begin{array}{l}\text { Post-digestion } \\
\text { spike }\end{array}$ & $\begin{array}{l}\text { once per analytical batch or per } \\
\text { matrix within an analytical batch }\end{array}$ & $85-115 \% \mathrm{R}$ & $\begin{array}{l}\text { Use MSA to quantitate } \\
\text { sample of like matrix }\end{array}$ & \\
\hline \multirow[t]{4}{*}{$\begin{array}{l}\text { CVAA } \\
\text { HAA }\end{array}$} & $\begin{array}{l}\text { 5-pt. initial } \\
\text { calibration } \\
\text { ( } 5 \text { standards and a } \\
\text { blank) }\end{array}$ & Daily & $\begin{array}{l}90-110 \% \mathrm{R} \text { for initial calibration } \\
\text { verification solution } \\
95-105 \% \mathrm{R} \text { for highest calibration } \\
\text { standard } \\
\text { Regression coefficient }\left(r^{2}\right) \text { must be } \\
\geq 0.995\end{array}$ & $\begin{array}{l}\text { Correct problem and repeat } \\
\text { initial calibration }\end{array}$ & \\
\hline & $\begin{array}{l}\text { Continuing } \\
\text { calibration }\end{array}$ & $\begin{array}{l}\text { Every } 10 \text { samples plus beginning } \\
\text { and end of run }\end{array}$ & $\begin{array}{l}80-120 \% \mathrm{R} \text { for check standard } \\
\text { (mandatory); blank (optional) should } \\
\text { measure } \leq 3 \times \text { xIDL }\end{array}$ & $\begin{array}{l}\text { Recalibrate and rerun last } \\
10 \text { samples }\end{array}$ & 品品邑 \\
\hline & Serial dilution & $\begin{array}{l}\text { once per analytical batch or per } \\
\text { matrix within an analytical batch }\end{array}$ & $\begin{array}{l}5 x \text { dilution of sample which is }>25 \times I D L \\
\text { must be } \leq 10 \% \mathrm{D} \text { of initial value }\end{array}$ & $\begin{array}{l}\text { Use MSA to quantitate } \\
\text { samples of like matrix. }\end{array}$ & 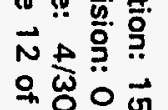 \\
\hline & $\begin{array}{l}\text { Post-digestion } \\
\text { spike }\end{array}$ & $\begin{array}{l}\text { once per analytical batch or per } \\
\text { matrix within an analytical batch }\end{array}$ & $85-115 \% R$ & $\begin{array}{l}\text { Use MSA to quantitate } \\
\text { samples of like matrix }\end{array}$ & $\vec{A}$ \\
\hline
\end{tabular}


in the abundances of these isotopes between samples and standards. All automated data reduction spreadsheets, algorithms, and programs shall be verified and the verification must be documented.

\section{Data Validation}

All total metal analyses data must be reviewed and approved before being reported. The validation process is outlined in Section 3.1.1 and includes verification that the QAOs presented in Table 15-1 have been met.

\section{Data Reporting}

Each laboratory analyzing samples is required to submit analytical batch data reports for each analytical batch to the site project office on approved standard forms. Site-specific documentation must include example forms that will be used for reporting. Analytical batch data reports shall consist of the following:

- Cover page which includes the laboratory name, analytical batch number, sample numbers included in that analytical batch, a cross reference to field sample numbers, and the signature releases of laboratory personnel as specified in Section 3.1.1.

- Table of Contents.

- Summary COC Form which shows the date and time of sample transfer, and name of individuals handling the samples from the time of sampling through receipt at the laboratory.

- Data review checklists for each analytical batch that verifies the data generation level review, validation, and verification, as described in Section 3.1.1, has taken place. Checklists must contain tables showing the results of the analytical batch $\mathrm{QC}$ samples (e.g., laboratory duplicates, laboratory control samples).

- A separate analytical report sheet for each sample in the analytical batch that includes the laboratory name, Program name, the title "Total Metal Analysis Data Sheet," analytical batch number, sampling batch number, laboratory sample number, field sample number, date sampled, date extracted, date and time analyzed, method number, target analytes, percent solids, and analytical results in $\mathrm{mg} / \mathrm{kg}$. Metals analysis data qualifying flags shall be used as follows:

- B-Analyte blank concentration (laboratory or calibration verification) greater than or equal to 20 percent of the sample concentration prior to dilution correction

- J-Analyte greater than or equal to IDL but less than $5 \times$ IDL before dilution correction

- U-Analyte was undetected (Report IDL corrected for dilution)

- Nonconformance reports, if applicable. 
In addition, laboratories located on sites shall maintain the following items in their files, documented and retrievable by analytical batch number. Contract laboratories shall forward these items along with analytical results to the site project office for storage in site project files.

- Original COC forms.

- All raw data, including original instrument readouts and/or bench reports, calculation records, and laboratory $\mathrm{OC}$ sample results. Laboratory duplicate results are recorded along with the original sample results, and the RPD between the two results are calculated. Laboratory control sample results are entered along with the accepted value and the \%R.

- All instrument calibration reports which include the accepted and measured values of calibration verification for all analytes. These reports must also contain the laboratory name, analytical batch number(s), initial and continuing calibration verification source, method identification, and calibration date and time.

- OC result summary, which includes true and found values for all QC samples plus associated result calculations. At a minimum, the $\mathrm{QC}$ data shall include blanks, laboratory control samples, matrix spikes, matrix spike duplicates, initial calibration data, initial and continuing calibration verifications, and all other method-specific QC listed in Table 15-4. The QC summary report also must contain the laboratory name, and the analytical batch number, and method names. 


\section{DEFINITIONS}

ABSOLUTE CANISTER PRESSURE - Pressure measured relative to absolute zero pressure. It is calculated by the sum of the pressure indicated on the canister pressure gauge and the ambient barometric pressure.

ACCURACY - The degree of agreement between a measured value and an accepted reference or the true value. Accuracy is determined as the percent recovery $(\% R)$ and may be expressed as relative percent accuracy (RPA).

ANALYSIS DATE/TIME - The date and military time (24-hour clock) of the introduction of the sample, standard, or blank into the analysis system.

ANALYTE - The element, ion, or compound an analysis seeks to determine; the element of interest.

ANALYTICAL BATCH - A suite of samples of a similar matrix (i.e., gas or solid) processed as a unit, using the same analytical method, within a specific time period. An analytical batch can be up to 20 samples (excluding laboratory $Q C$ samples), all of which must be received by the laboratory within 14 days of the validated time of sample receipt (VTSR) of the first sample of the batch.

ANALYTICAL METHOD - The sample preparation and instrumentation procedures or steps that must be performed to estimate the quantity of analyte in a sample.

ANALYTICAL SAMPLE - Any solution or media introduced into an instrument on which an analysis is performed excluding instrument calibration, initial calibration verification, initial calibration blank, continuing calibration verification and continuing calibration blank. Note the following are all defined as analytical samples: TRU waste samples, duplicate samples, laboratory control samples, and field and manifold blanks.

ASSESSMENT - The evaluation process used to measure the performance or effectiveness of a system and its elements. In this QAPP, assessment is an all-inclusive term used to denote any of the following: audit, performance evaluation, management systems review, peer review, inspection, or surveillance.

AUDIT - A planned and documented investigative evaluation of an item or process to determine the adequacy and effectiveness as well as compliance with established procedures, instructions, drawings, and/or other applicable documents.

BLIND AUDIT SAMPLE - A sample of known composition provided as a single-blind sample to the analytical laboratory. Used by DOE to evaluate analytical laboratory performance. Blind audit samples are distributed to participating laboratories as part of the Performance Demonstration Program.

CALIBRATION - The establishment of an analytical curve relating instrument response (signal) to analyte amount or concentration.

CALIBRATION BLANK - A sample volume containing undetectable quantities of analytes.

CHAIN-OF-CUSTODY (COC) - A set of procedures established to ensure that sample data integrity is maintained. 
COMPARABILITY - A qualitative parameter expressing the confidence with which one data set can be compared with another. Sample data should be comparable with other measurement data for similar samples and sample conditions.

COMPLETENESS - The percentage of measurements made which are judged to be valid measurements. The completeness goal is to generate a sufficient amount of valid data based on Program needs.

CONDITION ADVERSE TO QUALITY - An all-inclusive term used in reference to any of the following: failures, malfunctions, deficiencies, defective items, and nonconformances. A significant condition adverse to quality is one which, if uncorrected, could have a serious effect on safety or operability.

CONTINUING CALIBRATION STANDARDS - Analytical standards run periodically to verify the calibration of the analytical system.

CONTROL LIMITS - A range within which specified measurement results must fall to be compliant. Control limits may be mandatory, requiring corrective action if exceeded, or advisory, requiring that noncompliance data be flagged.

CORRECTIVE ACTION - Measures taken to rectify conditions adverse to quality and, where necessary, to preclude repetition.

CORRELATION COEFFICIENT - A number ( $r$ ) that indicates the degree of dependence between two variables (e.g., concentration and absorbance). The more dependent they are the closer the value to one. Determined by least squares analysis.

DATA QUALITY OBJECTIVES (DQO) - DQOs are qualitative and quantitative statements derived from the outputs of the first six steps of the DOO Process (see below). DOOs; 1) clarify the study objective, 2) define the most appropriate type of data to collect, 3) determine the most appropriate conditions from which to collect the data, and 4) specify tolerable limits on decision errors which will be used as the basis for establishing the quantity and quality of data needed to support compliance decisions. DQOs are used to develop a scientific and resource-effective data collection design.

DOO PROCESS - The DQO Process is a strategic planning approach based on the Scientific Method that is used to prepare for a data collection activity. It provides a systematic procedure for defining the criteria that a data collection design should satisfy, including when to collect samples, where to collect samples, the tolerable level of decision errors for the study, and how many samples to collect. By using the DQO Process, DOE will assure that the type, quantity, and quality of environmental data used in decision making will be appropriate for the intended application. In addition, DOE will guard against committing resources to data collection efforts that do not support a defensible decision. The DQO process consists of seven steps and is more fully described in EPA (1994b).

DATA REDUCTION - Operations necessary to correct data from the raw form to a final form as required by the customer.

DAY - Unless otherwise specified, day shall mean calendar day.

DOE FIELD OFFICE - The first line DOE field element that carries the organizational responsibility for 1) managing and executing assigned programs, 2) directing contractors who conduct the programs, and 3) assuring that environment, safety, and health are integral parts of each program.

EQUIPMENT BLANKS - Samples of high purity gas or water used to clean sampling equipment. They are collected after the equipment has been cleaned and prior to sampling. These blanks are useful in documenting adequate cleaning of sampling equipment. 
EQUIPMENT CLEANING BATCH - A number of sampling equipment items cleaned together at one time using the same cleaning method.

FIELD BLANKS - Field blanks are headspace gas background samples that are collected in the field in the immediate vicinity of the sample collection location. They accompany the sample containers through collection, shipment to the analytical laboratory, and storage prior to analysis, and are used to identify any contamination from field conditions.

FIELD DUPLICATES - Two separate, independent samples collected from the same source, as close as possible to the same place and time, stored in separate containers, and analyzed independently. Field duplicates are used to document the precision of the sampling and analysis process.

FIELD REFERENCE STANDARDS - Standard headspace gas samples containing known concentrations of target analytes. They are used to identify any bias in the sampling process.

FLAMMABLE VOC - A headspace gas VOC that has a National Fire Protection Association Flammability Hazard Degree of 3 or 4 and a flashpoint of less than $100^{\circ} \mathrm{F}$ or considered, by EPA, to be a significant fire hazard under WIPP repository conditions. Flammable headspace gas VOCs that are evaluated for the Program are listed in Table 1-3.

FREQUENCY (10 percent) - A frequency specification during an analytical sequence allowing for no more than 10 analytical samples between required quality control measurements, as specified by this QAPP.

GASES - Hydrogen, methane, and the VOCs listed in Table 12-1.

GAUGE PRESSURE - The pressure that is measured by the canister pressure gauge. Zero gauge pressure is equal to ambient barometric pressure.

GUIDANCE MATERIAL - Recommended practices to complete a given task and maintain reasonable assurance that the goals for that task will have been attained at completion. This type of material provides a means of accomplishing a task that has been found acceptable to the responsible agency. The word "should" is used to denote guidance material.

HEADSPACE - For any volume contained by a drum, 55-gallon poly bag, or innermost layer of confinement, the total contained volume minus the volume occupied by the waste material. "Headspace" is also used to refer to the gases contained in this volume.

HIGH PURITY GAS - Gas certified by the manufacturer to contain less than $1 \mathrm{ppm}$ total VOCs.

HOLDING TIME - The maximum permissible time allowed between time of sample collection and time of analysis.

INDEPENDENT ASSESSMENT - A quality assurance program assessment that is conducted by an independent group or organization, having authority and freedom from the line organization, to evaluate the scope, status, adequacy, programmatic compliance, and implementation effectiveness of the quality assurance program.

INDEPENDENT STANDARD - A laboratory-prepared standard solution that is composed of analytes from a different source than those used in the standards for the initial calibration.

INNERMOST LAYER OF CONFINEMENT - Within a waste container, a plastic bag that is closest to waste that may be a source of VOCs and/or hydrogen and methane. 
INSTRUMENT CALIBRATION - Analysis of analytical standards for a series of different specified concentrations; used to define the quantitative response, linearity, and dynamic range of the instrument to target analytes.

INSTRUMENT DETECTION LIMIT (IDL) - The minimum signal that an instrument can detect with 99-percent confidence that the analyte concentration is greater than zero.

INTERFERENTS - Substances that affect the analysis for the element or compound of interest.

ITEM DESCRIPTION CODE (IDC) - A site-specific, internal numerical code applied to individual waste forms to provide identification that is used for physical segregation and computerized record keeping and tracking.

LABORATORY BLANK - An analyte-free matrix to which all reagents are added in the same volumes or proportions as used in sample analysis. The laboratory blank is used to document contamination resulting from the laboratory sample preparation and analytical process.

LABORATORY CONTROL SAMPLE - A control sample of known composition. Laboratory control samples are analyzed using the same analytical methods employed for the Program samples received.

LABORATORY DUPLICATE - A second aliquot of a sample that is treated the same as the original sample to determine the precision of the method.

LINEAR RANGE, LINEAR DYNAMIC RANGE - The concentration range over which the analytical curve remains linear.

MANAGEMENT ASSESSMENT - A determination of managerial effectiveness in establishing and implementing QAPPs that conforms to DOE policy requirements. It is based on an analysis of functional appraisals, internal audits, and other information, and on the application of appropriate criteria. It is a review and evaluation of management performance covering all quality assurance and management responsibilities to assure proper quality assurance program balance.

MATRIX PARAMETER CATEGORY - A collection of descriptive titles, definitions, and associated numerical codes used to classify mixed waste at DOE facilities. Matrix parameter categories are defined in The DOE Waste Treatability Group Guidance (DOE 1995a).

METHOD BLANK - An analyte-free matrix to which all reagents are added in the same volumes or proportions as used in sample processing. The method blank must be carried through the complete sample preparation and analytical procedure. The method blank is used to document contamination resulting from the analytical process.

METHOD DETECTION LIMIT (MDL) - The minimum concentration of a substance that can be measured and reported for a given method with 99-percent confidence that the analyte concentration is greater than zero. MDL is determined from analysis of a sample in a given matrix type containing the analyte of interest.

MIXED WASTE - Waste that is regulated by both the Atomic Energy Act and the Resource Conservation and Recovery Act.

NARRATIVE - Portion of the data package that includes descriptive documentation of any problems encountered in processing the samples, corrective actions taken, and problem resolution. 
NEWLY GENERATED WASTE - Waste that is generated after the development and implementation of a TRU waste characterization program that meets the requirements outlined in this QAPP.

OPERATIONAL VARIANCE - Approved and controlled changes to Program-related plans or procedures. Operational variances affect operations but not the ability to achieve the performance standards or quality requirements specified in this QAPP or site QAPjPs. (see Section 2.1)

OUT OF CONTROL - One or more of several conditions relating to the plotting of control data and indicating unacceptable results.

PACKAGING MATERIAL - Flexible containment materials, e.g., plastic bags.

PERCENT DIFFERENCE (\%D) - The difference between the average initial calibration response factor and the continuing calibration response factors divided by the average initial calibration response.

PERFORMANCE ASSESSMENT (PA) - A determination of the long-term performance of the WIPP disposal system in accordance with the requirements of the EPA Standard, 40 CFR Part 191, Subpart B and $\mathrm{C}$.

PRECISION - A measure of mutual agreement among individual measurements of the same property made under prescribed similar conditions; often expressed as a standard deviation or relative percent difference (RPD).

PROCEDURE - A detailed, step-by-step description of the sequence of actions to be followed in order to perform a given task. If followed in sequence, a procedure provides enough information that a trained person could complete the covered task without additional information.

PROCESS BATCH - An amount of material subjected to a particular unit chemical process, unit physical mixing process or other short-term operation, resulting in a final product and/or waste stream that is substantially uniform.

PROGRAM REQUIRED DETECTION LIMIT (PRDL) - The maximum values for instrument detection limits permissible for the Program. PRDLs are presented in Table 15-1.

PROGRAM REQUIRED QUANTITATION LIMIT (PROL) - Minimum level of analyte quantitation acceptable under this QAPP. An analyte PROL should be a minimum of three times the MDL.

PROTOCOL - Material that constitutes the absolute minimum requirements for compliance with a given program. The words "shall" or "must" is used to denote these requirements. Verbatim compliance with protocols is mandatory.

PURGE AND TRAP - An analytical technique used to isolate volatile (purgeable) organics by stripping the compounds from water or soil with a stream of inert gas, trapping the compounds on a porous polymer trap, and thermally desorbing the trapped compounds onto the gas chromatographic column.

QUALITY ASSURANCE (QA) - All those planned and systematic actions necessary to provide adequate confidence that a facility, structure, system, or component will perform satisfactorily and safely in service. The goals of $\mathrm{OA}$ are to assure that research, development, demonstration, scientific investigations, and production activities are performed in a controlled manner; that components, systems, and processes are designed, developed, constructed, tested, operated, and maintained according to engineering standards, quality practices, and Technical Specifications/ Operational Safety Requirements; and that resulting technology data are valid, defensible, and retrievable. QA includes 
quality control, which comprises all those actions necessary to control and verify the features and characteristics of a material, process, product, or service to specified requirements.

QUALITY ASSURANCE OBJECTIVES (OAOs) - The characteristics of data that are associated with its ability to satisfy a given purpose or objective. The characteristics of major importance are accuracy, precision, completeness, representativeness, and comparability.

QUALITY CONTROL $(Q C)$ - The routine application of procedures for controlling the monitoring process. $Q C$ is the responsibility of all those performing the hands-on operations in the field and in the laboratory.

RADIOASSAY (RA) - Assay methods used to identify and quantify radionuclides in TRU waste.

RADIOGRAPHY - A nondestructive testing method that utilizes $X$-rays to inspect and determine the physical form of waste.

RECOVERY - The numerical ratio of the amount of analyte measured by the laboratory method divided by the known amount of analyte added to the matrix (i.e., spiked sample) to be analyzed. Usually expressed as a percent $(\% R)$.

REPRESENTATIVENESS - The degree to which sample data accurately and precisely represent a characteristic of a population, parameter variations at a sampling point, or an environmental condition. Representativeness is a qualitative parameter that concerns the proper design of the sampling program.

RESIDUAL MATERIAL - Anything not characterized as a waste item or packaging material.

RETRIEVABLY STORED WASTE - Waste that has been generated before the development and implementation of a TRU waste characterization program that meets the requirements outlined in this QAPP.

REVIEWIDATA REVIEW - The process used to ensure the proper collection and reduction of raw data has been accomplished. Data review requirements for the Program are described in Section 3.1.

RUN - A continuous analytical sequence consisting of prepared samples and all associated quality assurance measurements as required by this QAPP.

SAMPLE - A portion of material to be analyzed that is contained in single or multiple containers and identified by a unique sample number.

SAMPLE NUMBER - A unique identification number that is designated for each sample. The sample number appears on all sample reports which document information on that sample.

SAMPLING BATCH - A suite of samples of a similar matrix (i.e., gas or solid) collected consecutively using the same sampling equipment within a specific time period. A sampling batch can be up to 20 samples (excluding field OC samples), all of which must be collected within 14 days of the first sample in the batch.

STANDARD DEVIATION - The square root of the variance of a set of values.

SUMMA ${ }^{\circ}$ CANISTER - A stainless steel pressure vessel with SUMMA ${ }^{\infty}$ passivated interior surfaces for the collection and storage of gas samples. The SUMMA' ${ }^{\circ}$ passivation process involves the formation of chromium-nickel oxide on the interior surface of the canister. This type of canister is used for sample storage stability of many specific organic compounds. 
SUPERCOMPACTED WASTE - Supercompaction is a volume reduction process.

TARGET COMPOUNDS - Those gases, VOCs, semi-VOCs, and metals identified by the Program as analytes. Target compounds for the Program are listed in Table 1-3.

TENTATIVELY IDENTIFIED COMPOUNDS (TICS) - Non-target compounds identified using GC/MS. These reported concentrations will have a higher uncertainty associated with them than the reported target analyte concentrations.

TESTING BATCH - A suite of waste containers undergoing radioassay (Section 9.0) or radiography (Section 10.0 ) using the same testing equipment. A testing batch can be up to 20 waste containers without regard to waste matrix.

TRANSURANIC (TRU) WASTES - Laboratory and process wastes that contain alpha-emitting radionuclides of atomic number greater than 92 (e.g., the radioactive isotopes of plutonium), have halflives longer than 20 years, and are present in concentrations greater than 100 nanocuries per gram of waste.

VALIDATION - An activity that demonstrates or confirms that a process, item, data set, or service satisfies the requirements defined by the user. Data validation requirements for the Program include signature release and are described in Section 3.1.

VALIDATED TIME OF SAMPLE RECEIPT (VTSR) - The documented date and time on which a sample is received at the analytical facility, as recorded on the chain-of-custody.

VARIANCE - A measure of the dispersion of a series of results around their average. It is the sum of the squares of the individual deviations from the average of the results, divided by the number of results minus one.

VERIFICATION - The act of authenticating or formally asserting the truth that a process, item, data set, or service is, in fact, that which is claimed. Data verification is the process used to confirm that all review and validation procedures have been completed. Data verification requirements for the Program are described in Section 3.1.

VOLATILE ORGANIC COMPOUNDS (VOCs) - For the purposes of the Program, those gas VOCs listed in Table 12-1, the target VOCs listed in Table 13-1, and any additional compounds tentatively identified by the VOC analytical procedures used to satisfy Program requirements.

WASTE CONTAINER - A disposable containment vessel for waste materials including integral liner or shielding materials intended for emplacement at the WIPP (i.e., 55-gallon waste drums or waste boxes).

WASTE ITEMS - Easily identifiable discrete pieces/chunks of waste (e.g, raschig rings).

WASTE MATERIAL PARAMETER - Physical forms of waste that may impact long-term repository performance. Waste material parameters are listed and described in Table 10-1.

WASTE STREAM - Waste material generated from a single process or activity that is similar in material, physical form, isotopic make-up, and hazardous constituents.

WASTE STREAM LOT - A portion of a waste stream identified for the purpose of facilitating random sampling. 


\section{REFERENCES}

10 CFR Part 71. September 1994. "Packaging and Transportation of Radioactive Material." Code of Federal Regulations, Washington, D.C., Office of the Federal Register National Archives and Records Administration.

10 CFR Part 830. April, 1994. "Nuclear Safety Management." Code of Federal Regulations, Washington, D.C., Office of the Federal Register National Archives and Records Administration.

40 CFR Part 191. December 1993. "Environmental Radiation Protection Standards for the Management and Disposal of Spent Nuclear Fuel, High-Level and Transuranic Radioactive Wastes." Code of Federal Regulations, Washington, D.C., Office of the Federal Register National Archives and Records Administration.

40 CFR Part 261. October 1994. "Identification and Listing of Hazardous Waste." Code of Federal Regulations, Washington, D.C., Office of the Federal Register National Archives and Records Administration.

40 CFR Part 264. December 1994. "Standards for Owners and Operators of Hazardous Waste Treatment, Storage, and Disposal Facilities." Code of Federal Regulations, Washington, D.C., Office of the Federal Register National Archives and Records Administration.

40 CFR Part 268. January 1995. "Land Disposal Restrictions." Code of Federal Regulations, Washington, D.C., Office of the Federal Register National Archives and Records Administration.

40 CFR Part 270. December 1994. "EPA Administered Permit Programs: The Hazardous Waste Permit Program." Code of Federal Regulations, Washington, D.C., Office of the Federal Register National Archives and Records Administration.

55 FR 47700. November 14, 1990. "Conditional No-Migration Determination for the Department of Energy Waste Isolation Pilot Plant (WIPP)." Federal Register 55: p. 47700.

58 FR 8029. February 11, 1993. "Criteria for the Certification of Compliance with Environmental Radiation Protection Standards for the Management and Disposal of Spent Nuclear Fuel, High-Level and Transuranic Radioactive Wastes; Advanced Notice of Proposed Rulemaking." Federal Register 58: p. 8029.

ANSI. 1987. Standard for Software User Documentation. New York, New York, American National Standards Institute.

ANSI/ASME. 1985. Measurement Uncertainty, Part 1, Instruments and Apparatus. ANSI/ASME PTC 19.1-1985, New York, New York, The American Society of Mechanical Engineers.

ANSI/ASOC. 1993. Quality Systems Requirements for Environmental Programs. ANSI/ASOC E4-1993, American Society for Quality Control.

ASME. 1994. Quality Assurance Requirements for Nuclear Facility Applications. ASME NQA-1-1994 Edition, New York, New York, American Society of Mechanical Engineers.

ASTM. 1982. "Standard Method for Analysis of Reformed Gas by Gas Chromatography." ASTM 1946-82, Annual Book of ASTM Standard's, Philadelphia, Pennsylvania, American Society for Testing and Materials. 
ASTM. 1983a. "Standard Practice for Thin-Walled Tube Sampling of Soils." ASTM D1587-83, Annual Book of ASTM Standards, Philadelphia, Pennsylvania, American Society for Testing and Materials.

ASTM. 1983b. "Standard Test Method for Chemical Composition of Gases by Mass Spectrometry." ASTM D2650-83, Annual Book of ASTM Standards, Philadelphia, Pennsylvania, American Society for Testing and Materials.

ASTM. 1987. "Standard Practice for Reducing Field Samples of Aggregate to Testing Size." ASTM C702-87, Annual Book of ASTM Standards, Philadelphia, Pennsylvania, American Society for Testing and Materials.

ASTM. 1989a. "Standard Test Method for Determination of Plutonium Isotopic Composition by Gamma-Ray Spectrometry." ASTM C1030-89, Annual Book of ASTM Standards, Philadelphia, Pennsylvania, American Society for Testing and Materiais.

ASTM. 1989b. "Standard Test Method for Nondestructive Assay of Special Nuclear Material in Low Density Scrap and Waste by Segmented Passive Gamma-Ray Scanning." ASTM C1133-89, Annual Book of ASTM Standards, Philadelphia, Pennsylvania, American Society for Testing and Materials.

ASTM. 1991a. "Standard Practice for Sampling Waste and Soils for Volatile Organic Compounds." ASTM D4547-91, Annual Book of ASTM Standards, Philadelphia, Pennsylvania, American Society for Testing and Materials.

ASTM. 1991b. "Standard Test Method for Nondestructive Assay of Plutonium in Scrap and Waste by Passive Neutron Coincidence Counting." ASTM C1207-91, Annual Book of ASTM Standards, Philadelphia, Pennsylvania, American Society for Testing and Materials.

ASTM. 1992. "Standard Test Method for Nondestructive Analysis of Special Nuclear Materials in Homogeneous Solutions by Gamma-Ray Spectrometry." ASTM C1221-92, Annual Book of ASTM Standards, Philadelphia, Pennsylvania, American Society for Testing and Materials.

Cochran, William, C 1977. Sampling Techniques. New York, New York, John Wiley \& Sons: pp. 7778.

Currie, Lloyd A. 1968. "Limits for Qualitative Detection and Quantitative Determination." Analytical Chemistry, No. 40: pp. 586-93.

Department of Defense. 1989. Military Standard: Sampling Procedures and Tables for Inspection by Attributes, MIL-STD-105E, U.S. Department of Defense.

DOE. 1990. WIPP No-Migration Variance Petition. DOEMIPP 89-003, Revision 1, Carlsbad, New Mexico, Waste Isolation Pilot Plant, U.S. Department of Energy.

DOE. 1991. Waste Acceptance Criteria for the Waste Isolation Pilot Plant. WIPP-DOE-069, Revision 4, Carlsbad, New Mexico, Waste Isolation Pilot Plant, U.S. Department of Energy.

DOE. 1992. TRUPACT-// Content Codes (TRUCON). DOE/WIPP 89-004, Revision 6, Carlsbad, New Mexico, Waste Isolation Pilot Plant, U.S. Department of Energy. 
DOE. 1994a. Performance Demonstration Program Plan for Nondestructive Assay for the TRU Waste Characterization Program. CAO-94-1045, Current Revision, Carlsbad, New Mexico, Carlsbad Area Office, U.S. Department of Energy.

DOE. 1994b. Quality Assurance Program Description. CAO-94-1012, Current Revision, Carlsbad, New Mexico, Carlsbad Area Office, U.S. Department of Energy.

DOE. 1995a. DOE Waste Treatability Group Guidance. DOE/LLW-217, Revision O, Idaho Falls, Idaho, INEL-Lockheed Idaho Technologies Company, U.S. Department of Energy.

DOE. 1995b. Information Management Plan. Current Revision, Carlsbad, New Mexico, Carlsbad Area Office, U.S. Department of Energy.

DOE. 1995c. Performance Demonstration Program Plan for the Analysis of Simulated Headspace Gases for the TRU Waste Characterization Program. CAO-95-1076, Current Revision, Carlsbad, New Mexico, Carlsbad Area Office, U.S. Department of Energy.

DOE. 1995d. Performance Demonstration Program Plan for the Analysis of Solidified Wastes for the TRU Waste Characterization Program. CAO-95-1077, Current Revision, Carlsbad, New Mexico, Carlsbad Area Office, U.S. Department of Energy.

DOE. 1995e. Transuranic Waste Characterization Sampling and Analysis Methods Manual. DOE/WIPP-91-043, Current Revision, Carlsbad, New Mexico, Carlsbad Area Office, U.S. Department of Energy.

DOE. 1995f. Waste Isolation Pilot Plant Transuranic Waste Baseline Inventory Report. CA0-94-1005, Current Revision, Carlsbad, New Mexico, Carlsbad Area Office, U.S. Department of Energy.

DOE Order 1324.5B. 1995. Records Management Program. Washington, D.C., U.S. Department of Energy.

EG\&G. 1991. Recommended Methods for Statistical Analysis of Data Containing Less-ThanDetectable Measurements. EGG-SARE-9247, Idaho Falls, Idaho, C. L. Atwood, L. G. Blackwood, G. A. Harris, and C. A. Loehr, EG\&G-Idaho, Inc., Idaho National Engineering Laboratory.

EG\&G. 1993a. Preliminary Assessment of Real-Time Radiography and Visual Characterization for Selected Waste Containers. RFP-4604, Golden, Colorado, D. L. Zeigler and R. V. Harder, EG\&G Rocky Flats, Rocky Flats Plant.

EG\&G. 1993b. Program Plan for Certification of INEL Contact Handled Stored Transuranic Waste. WM-PD-88-011-6, Idaho Falls, Idaho, T. L. Clements, Jr., EG\&G Idaho, Inc., Idaho National Engineering Laboratory.

EG\&G. 1994a. Description of the SWEPP Certified Waste Sampling Program for FY-94. Engineering Design File, RWMC-363, Revision 6, Idaho Falls, Idaho, EG\&G - Idaho Inc., Idaho National Engineering Laboratory.

EG\&G. 1994b. Idaho National Engineering Laboratory Simulated Solidified Transuranic Waste Sampling Program. EGG-WM-11222, Idaho Falls, Idaho, M. J. Connolly, EG\&G - Idaho Inc., Idaho National Engineering Laboratory.

EPA. 1980. Upgrading Environmental Radiation Data. EPA 520/1-80-012, Washington D.C., Office of Radiation Programs, U.S. Environmental Protection Agency. 
EPA. 1988. "Compendium Method TO-14, The Determination of Volatile Organic Compounds (VOC) in Ambient Air Using SUMMA ${ }^{\circ}$ Passivated Canister Sampling and Gas Chromatographic Analyses." in Compendium of Methods for the Determination of Toxic Organic Compounds in Ambient Air. Research Triangle Park, North Carolina, Quality Assurance Division, Environmental Monitoring Systems Laboratory, U.S. Environmental Protection Agency.

EPA. 1991a. National Enforcement Investigations Center Policies and Procedures. EPA-330/9-78001-R, Denver, Colorado, National Enforcement Investigations Center, U.S. Environmental Protection Agency.

EPA. 1991b. Soil Sampling and Analysis for Volatile Organic Compounds. EPA/540/4-91/001, T. E. Lewis, A. B. Crockett, R. L. Siegrist, K. Zarrabi, Office of Research and Development, U.S. Environmental Protection Agency.

EPA. 1992. Specification and Guidance for Obtaining Contaminant-Free Sample Containers. Directive No. 9240.0-05A, Office of Solid Waste and Emergency Response, U.S. Environmental Protection Agency.

EPA. 1994a. EPA Requirements for Quality Assurance Project Plans for Environmental Data Operations. EPA QA/R-5, Washington D.C., Quality Assurance Management Staff, U.S. Environmental Protection Agency (Draft Interim Final).

EPA. 1994b. Guidance for the Data Quality Objectives Process. EPA-QA/G-4, Washington D.C., Quality Assurance Management Staff, U.S. Environmental Protection Agency.

EPA. 1994c. Waste Analysis at Facilities that Generate, T eat, Store, and Dispose of Hazardous Waste; A Guidance Manual. EPA-530-R-94-024, Vashington D.C., Office of Solid Waste and Emergency Response, U.S. Environmental Protection Agency.

EPA. 1995. Test Methods for Evaluating Solid Waste, Phys-al/Chemical Methods. SW-846, Third Edition, Final Update I and Final Update II, Washington, D.C., Office of Solid Waste and Emergency Response, U.S. Environmental Protection Agency.

Fisenne, I. M., et al. 1973. "Least Squares Analysis and Minimum Detection Levels Applied to MultiComponent Alpha Emitting Samples." Radiochem. Radioanal. Letters, 16, No. 1: pp. 5-16.

Gilliom, R. J. and D. R. Helsel. 1986. "Estimation of Distributional Parameters for Censored Trace Level Water Quality Data; 1. Estimation: Techniques." Water Resources Research, Vol. 22, p. 147.

Johnson and Kotz. 1969. Discrete Distributions. Boston, Massachusetts, Houghton Mifflin Co.

Kupper, L. L. and K. B. Hafner. 1989. "How Appropriate are Popular Sample Size Formulas?", The American Statistician, Vol. 43: pp.101-105.

Madansky, A. 1988. Prescriptions for Working Statisticians, New York, New York, Springer-Veriag.

NRC. 1984. Nondestructive Assay of Special Nuclear Material Contained in Scrap and Waste. Regulatory Guide 5.11, Washington, D.C., Office of Nuclear Regulatory Research, U.S. Nuclear Regulatory Commission.

Nuclear Packaging Inc. 1992. Safety Analysis Report for the TRUPACT-ll Shipping Package. Revision 12, Federal Way, Washington, Nuclear Packaging, Inc. 
Oliver, K. D., J. D. Pleil, and W. A. McClenny. 1986. Atmospheric Environment 1986, Vol. 20, No. 7: pp. 1403-1411.

Pasternack B. S. and N. H. Harley. 1971. "Detection Limits for Radionuclides in the Analysis of MultiComponent Gamma-Spectrometric Data." Nucl. Instr. and Meth, No. 91: pp. 533-40. 


\section{APPENDIX A \\ Determining the Number of Containers \\ to Visually Examine Using the Hypergeometric Distribution}

For the hypergeometric approach to determining the number of containers to be visually examined, the acceptable level of uncertainty in the estimate of the proportion miscertified (along with the information on the previous percentage miscertified) determines the number of containers that must be examined. The rationale and details of this methodology are discussed below.

In a population of size $N$, there are $M$ miscertified containers, so the true proportion of the miscertified containers in the population is $M / N=p_{\text {true }}$. Since $\rho_{\text {zrue }}$ (or $M$ ) is not known, we wish to estimate it by randomly sampling some of the containers. If in a sample of $n$ containers, $x$ are found to be miscertified, the sample estimate of the true population proportion $p_{\text {true }}$ is

$$
\hat{p}=\frac{x}{n}
$$

This value is only an estimate, and as such has some uncertainty associated with it. This uncertainty is quantified by calculating the upper one-sided $(1-a)$ percent confidence limit for $p$, call it $p_{\text {ucL }}$. This confidence limit gives the largest value the true proportion could take on and still have a "reasonable" chance (e.g., an $\alpha=.10$ probability) of producing $x$ miscertified containers in a sample of $n$ out of $N$. This upper confidence limit is calculated as

$$
p_{U C L}=M_{U C L} / N
$$

where $M_{U C L}$ is the largest value of $M$ such that the probability of observing $x$ or fewer miscertified containers in a sample of size $n$ is less than or equal to $a$. That is, it is the largest value of $M$ such that the following inequality is true:

$$
\sum_{k=0}^{x} \frac{\left(\begin{array}{c}
M \\
k
\end{array}\right)\left(\begin{array}{c}
N-M \\
n-k
\end{array}\right)}{\left(\begin{array}{l}
N \\
n
\end{array}\right)} \leq \alpha .
$$

where each term in parentheses has the usual combinatorial interpretation. For example:

$$
\left(\begin{array}{c}
M \\
k
\end{array}\right)=\frac{M !}{k !(M-k) !}
$$

Each term in the sum in Equation (A-3) is the hypergeometric probability of observing $k$ miscertified containers in a sample of size $n$ from a population of size $N$ in which there are $M$ miscertified containers 
land hence the population proportion of miscertified containers is $p=M / M$ ). The value $M_{U C L}$ is obtained by substituting different values for $M$ into Equation (A-3) until the largest value satisfying the inequality is found.

\section{Calculating Required Sample Size}

Note that in Equation (A-3), the upper confidence limit is dependent on $x$, the number of miscertifications observed in the sample, as well as on $n$, the sample size. So, to obtain the required sample size, the values of $x$ that are likely to be seen also need to be considered. Sample size is thus determined by setting a desired upper confidence limit value and then manipulating $x$ and $n$ in Equation (A-3). The detailed steps are given in the following algorithm, along with an example application to clarify the steps involved:

Algorithm Steps

1. Set parameters.

Estimate the approximate number of miscertified containers in the population of interest (generally based on results from previous sampling efforts), call it $M_{\text {est }}$.

Choose a value for $a$, where $(1-a) 100 \%$, is the desired confidence level for the confidence limit calculation.

Specify $p_{U C L}$, the desired upper bound for the confidence limit and calculate $M_{U C L}=N p_{U C L}$, the associated number of miscertified containers. Note that $p_{U C L}$ must be chosen such that $M_{U C L}$ is an integer.

Set a value for $\gamma$, the desired assurance level, so that the outcome of the sampling will produce the desired result (i.e., $100 \gamma \%$ of the possible sample values for $x$ will yield the desired confidence limit results).

2. Pick an initial guess or starting value for the sample size, call it $n_{t}$. Set a counter variable $i=1$.
Example

If previous experience shows the miscertification rate to be about 2 percent, and the population under consideration contains 140 containers, then $M_{\text {est }}=3$ is obtained by multiplying .02 by 140 and rounding up to the next largest integer.

If a 90-percent confidence level is desired, then $\alpha$ is $1-.90=.10$.

If the true value is thought to be about 2 percent, but 10 percent is an acceptable upper bound on the estimate, then $p_{U C L}=.10$ and $M_{U C L}=140(.10)=$ 14.

Select $\gamma=.80$. The calculated sample size will produce the desired confidence limit results in 80 percent of the possible sampling outcomes. (For the 20 percent of the outcomes not covered, the calculated upper confidence bound will be somewhat higher than the desired value of .10.)

Let $n$, be 33 . 


\section{Algorithm Steps}

3. Find the smallest value for $x$ such that:

$$
\sum_{k=0}^{x} \frac{\left(\begin{array}{c}
M_{e x} \\
k
\end{array}\right)\left(\begin{array}{c}
N-M_{e s x} \\
n_{i}-k
\end{array}\right)}{\left(\begin{array}{l}
N \\
n_{i}
\end{array}\right)} \geq \gamma
$$

Call this $x$ value $x_{\max }$, since it is the largest value of $x$ likely to be observed.

4. Find $a_{i}$, the probability of $x_{\max }$ or fewer miscertified if $M=M_{U C L}$ and $n=n_{i}$, i.e.,

$$
a_{i}=\sum_{k=0}^{x_{\max }} \frac{\left(\begin{array}{c}
M_{U C L} \\
k
\end{array}\right)\left(\begin{array}{c}
N-M_{U C L} \\
n_{i}-k
\end{array}\right)}{\left(\begin{array}{l}
N \\
n_{i}
\end{array}\right)}
$$

5. Compare results to $a$, and iterate if necessary as follows:

If $a_{i-1}<a$ and $a_{i}>a$, then stop. The required sample size is $n_{t-1}$.

If $a_{i-1}>a$ and $a_{i}<a$, then stop. The required sample size is $n_{i}$. If neither of the above is true then go on to Step 6.

\section{Example}

For $M_{\text {est }}=3, N=140, n_{i}=n_{1}=33$, calculating the individual probability terms in the sum for $k=0$, and 1 give:

$\operatorname{pr}(0$ miscertified $)=.443$

$\operatorname{pr}(1$ miscertified $)=.418$

The two terms sum to .861 , which is larger than $\gamma=.80$, so $x_{\max }=1$.

(example for $i=1$ )

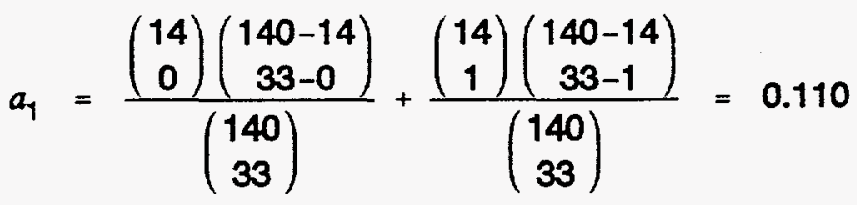

At the first iteration, there is no previous value of $a_{i t}$ so go on to Step 6. 
6. If $a_{i}>a$, then $n_{i+1}=n_{i}+1$

if $a_{i} \leq a$, then $n_{i+1}=n_{i}-1$

$.110>.10$ so $n_{2}=34$

Increment $i(i . e ., i=i+1)$ and repeat Steps 3, 4, and 5 .

$$
i=2
$$

Step 3: $x_{\max }=1$

Step 4: $a_{2}=.099$

Step 5: $a_{1}>.10$ and $a_{2}<.10$, so stop. The required sample size is $n=34$. 